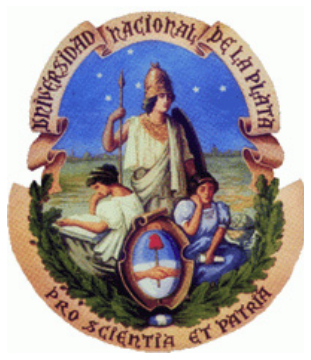

Universidad Nacional de La Plata Facultad de Ciencias Exactas

Departamento de Física-IFLP

Doctorado en Ciencias Exactas

Disipación de potencia por nanopartículas magnéticas expuestas a campos de radiofrecuencia para terapia oncológica por hipertermia

Ignacio J. Bruvera

Tesis de Doctorado

La Plata

30 de Marzo de 2015 



\author{
Universidad Nacional de La Plata \\ Facultad de Ciencias Exactas \\ Departamento de Física-IFLP
}

Ignacio J. Bruvera

\title{
Disipación de potencia por nanopartículas magnéticas expuestas a campos de radiofrecuencia para terapia oncológica por hipertermia
}

Trabajo presentado en la Carrera de Doctorado en Ciencias Exactas del Departamento de Física-IFLP de la Universidad Nacional de La Plata como requisito parcial para la obtención del grado de Doctor en Física.

Director: Pedro Mendoza Zélis

Universidad Nacional de La Plata

Co-director: Gerardo F. Goya Instituto de Nanociencia de Aragón

La Plata

30 de Marzo de 2015 

A los que no llegan sólo porque la vida no es justa. Que sean cada vez menos. 



\section{Agradecimentos}

Mucho tiempo 5 años. Además de que concentrar la gran mayoría del trabajo en los últimos meses hace que tenga que esperar hasta último momento para escribir esto, uno nunca sabe quién le puede salvar el cuello in extremis... y una excusa más, estoy escribiendo esto cuando ya no me da la cabeza para trabajar en la tesis, así que sepan disculpar la falta de elocuencia.

Antes del conveniente agradecimiento cronológico, un par de destacados.

Sin muchas dudas el centro del cartel le toca a Pedro. En el mundillo de la física hay variedad, como en todo amontonamiento humano. Y digo variedad de calidades tanto científicas como personales. El Prof. Dr. Mendoza destaca en ambas. Es ante todo un gran tipo, al que ni siquiera alguien especializado en la crítica cruda como un servidor puede endilgarle actitud reprochable alguna. Es noble, abnegado y más modesto de lo que sus capacidades requieren. Tanto así que cuando volví de España y retomé la tesis bajo su dirección, no tenía completa idea de lo brillante que era (y sigue siendo felizmente). Acá es donde aparece la otra parte, además de tener una agudeza e intuición extraordinarias, ama hacer ciencia. Le gusta tanto que da envidia. Le gusta tanto que me resulta imposible imaginarlo haciendo otra cosa. Pedro trabajó mucho en esta tesis, casi demasiado, al punto que me da hasta culpa. Trabajó un montón, y tengo la sensación de que más que por su compromiso como director (que cumplió con creces) lo hizo por su amor a la física, a su laburo, a ordenar un poco esta realidad que nos queda tan grande. No me imagino mejor director, lo único que puedo reprocharle es que confió más de lo conveniente en mi autodisciplina y responsabilidad, y lo digo porque es lo que parece, una vil estrategia para sacarme un poco de culpa por todo lo que esta tesis pudo haber sido y no fue. Soy su primer dirigido, duro comienzo. Si el karma existe, vendrán muchas más y mejores tesis y tesistas. Que se sepa que la mayor parte de las cosas buenas que aparecen en las páginas que siguen son mérito de Pedro Mendoza Zélis.

El siguiente es un clásico, al menos en este caso, más que merecido. Es una trivialidad que los padres son una condición necesaria para la existencia, el repollo y la cigüeña han perdido creyentes a pesar de la resistencia de la iglesia a la educación sexual. Pero el afán reproductivo sólo no es un gran mérito. Supongo que los motivos para crear una persona de la nada serán variables de padre a padre pero si me tengo que guiar por el experimento de más de 30 años que tenemos con el Jorge Alberto y la Eva Noemí, pareciera que su intención es la de hacer todo lo posible por que yo sea feliz (menos poner dos toallas en el baño). Si algo me espanta de la paternidad, es sentir que nunca sería capaz de la entrega absoluta que mis viejos me mostraron siempre. No me creo tan generoso. Los hijos somos culpa de los padres y no se si eso los deja muy bien parados, pero si algo puedo asegurar, es que si algún error cometieron, la falta de amor y dedicación no fue uno de ellos, dicho lo cual creo que quedan eximidos de toda culpa. Gracias a mis viejos.

Y ahora intentaré ir en orden de aparición para minimizar los olvidos. 
Todo esto empezó gracias a la generosidad de Quique, que aceptó tolerarme por tiempo indeterminado hasta que encontrara cómo viajar a Europa. Mis condolencias porque terminó siendo más tiempo del recomendado por 9 de cada 10 odontólogos, aunque con un recreo en el medio. Lo suficiente como para que se olvidara y me volviera a aceptar al regreso. Eventualmente se acordó y me derivó a Pedro que, si fuera por la eficiencia y la buena voluntad de ciertos colegas, hubiera quedado como director ad honorem. Fuera de las idas y venidas con la tesis, el papel de Quique como Papá pitufo del G3M es indiscutible. No le queda chica la barba. Juntar tal cantidad de buena ciencia y buena gente no es fortuito, es el grupo de Quique Sánchez.

Siguiendo el orden cronológico, es el turno de la persona que tuvo que terminar su grado en condiciones difíciles: encerrada por horas conmigo en el labo, al son de la bomba refrigeradora. En este racconto hay mucha gente que quiero y que por alguna extraña razón me soporta, pero son muy pocas las personas que además elegiría para el gabinete de crisis en caso de apocalipsis, una de ellas es la licenciada Cecilia Laborde. Además de ser la mejor compañera de laboratorio que he tenido, se convirtió en una amiga que ya sea por Skype, en un bar de Buenos Aires o en un tenedor libre pakistaní en Londres (sin carteles de advertencia en el ají picante) siempre presta el oído y el hombro. Gracias Ceci.

Cuando volví de España en modo okupa pude evitar la dura calle gracias a gente generosa con más capacidad cardíaca que inmobiliaria. Mis hermanos tienen el mérito extra de haberme hospedado por tiempo indefinido aún teniendo la experiencia previa de convivir conmigo. Después de más de dos años, todavía no terminé la mudanza. Joako y César tuvieron la inocencia que da la ignorancia junto con la hospitalidad que da el ser buenos tipos. Mi futón está a su disposición, ya lo saben.

Tanto antes, como durante y después del impás europeo hubo una persona con el extraño pasatiempo de adueñarse de mis problemas gratuitamente. Mariano es otro de esos tipos que exuda ciencia. Es incapaz de contener su espíritu inquisidor. Si a eso le sumamos un don natural para transmitir ideas, se convierte en un sostén casi adictivo para trabajar en esto. Además es mi amigo, y además es super católico. Esto no sólo me da crédito para hacer chistes sino que aporta una perspectiva totalmente distinta a la mía en varios temas. Él me dijo alguna vez que su religión lo hace mejor persona (aunque no creo que la necesite para eso), yo le digo que su amistad hace mi vida más rica.

Un consejo que siempre doy a la gente que se inicia en esto de la ciencia es que, más importante que el tema, es con quién y donde se trabaja. Como mencioné arriba, en ese sentido estoy cubierto. El G3M es un gran grupo humano, que además hace buena ciencia. Quiero destacar especialmente a Gustavo, otro que no dudo de calificar de gran persona y uno de los tipos que más me hace enojar en el mundo, algo en lo que, en nombre de la armonía universal, creo que soy recíproco. Lamentablemente, no puedo ser recíproco con la ayuda que me prestó durante toda la tesis, ahí seguro que saco la mejor parte.

Otra que me ha hecho enojar mucho (ni que sea muy difícil) es Elisa, pero ni los ataques de indignación que me suele causar se sostienen ante su arrolladora candidez. Elisa es ante todo 
una madre, una madrasa a la que le sobra cariño para repartir a todos los que la rodean, muchas veces en forma de almuerzos con alto contenido de amor materno.

Finalmente quiero mencionar a Diego, un típico colombiano: ritmo para la salsa, debilidad por el ron y una potencia de trabajo que hace quedar mal al resto de latinoamérica. A Diego lo estuve explotando mucho en estas últimas semanas en donde me ayudó a pesar de estar igual de presionado que yo (bastante más de hecho). Por eso, gracias totales.

Dije que lo importante es con quién y donde, pero el donde no es muy distinto del con quién. Los edificios son sólo las condiciones de contorno, los lugares son la gente, y mi lugar desde hace 13 años es el estado degenerado $<$ Dpto. de física/IFLP $>$. Además del G3M+, el grupo ampliado con los que he disfrutado las mejores comilonas del ambiente científico, hay mucha más gente que, sin compartir una relación académica directa, formó parte del día a día de todos estos años. Los voy a extrañar como se extraña el pago.

Un apartado especial para el personal de apoyo del IFLP y para los ingenieros del laboratorio de electrónica, esenciales para un generador de objetos rotos como yo. La medalla a la paciencia va para el ingeniero Gustavo Sieben que además de devanarse los sesos con nuestros problemas electrónicos, soldó mucho más veces de las que le correspondía las malditas bobinas que estelarizan el capítulo 3. Más menciones especiales: para el doctor en suspenso Alberto Lencina, uno de los mejores docentes que conozco y con el que he tenido el placer de dar clases. Espero que disfrutes tu retiro a la campiña, por acá se te va a echar de menos. Para Mauricio Matera, otro gran docente y colega que me ha compartido su sapiencia a menudo, y para Diego Richard y Andrés Biasetti, que en su papel de consejeros lograron que la burocracia y la mala leche de algunos no me impidieran doctorarme.

Otras que siempre hacen más que lo que les corresponde (al menos cuando hay ecuaciones diferenciales involucradas) son Mariel y Gabi. Desde aquel lejano 2008 (o 2007?) en el que me dieron clases, no han cejado en su empeño por hacerme hacer cuentas, tanto así que cada vez que tengo una que no me resuelve la computadora, subo a la cocinita, les robo un café, puteamos un rato, y si queda tiempo les pregunto cómo hacerla. El ristretto de festejo doctoral será con ustedes damas.

Por más que estos últimos años no lo haya tenido a mano, cada cosa que haga en ciencia y docencia va a tener la influencia del Toto, para bien o para mal :). Aclaro, no está muerto, sólo felizmente jubilado.

Sigo recorriendo los pasillos de física mentalmente y si me distraigo siempre termino en la misma puerta: oficina 23 1/2. Ya sea sin ganas de trabajar, para planear el almuerzo, robar galletitas o para intercambiar chusmeríos, fue el destino por defecto durante todo este tiempo. Claro está que lo interesante no es el número en la puerta sino el contenido, Mariela, Felipe y la susodicha Elisa fueron la barra de contención intramuros.

Y sí Jere, estabas incluido en esto antes de que me preguntaras.

El tipo que fue mi alumno y a esta altura ya me debe haber enseñado más física a mi que yo a él (yo sí que le presto atención). A base de comida no china de los chinos con Jere pasamos los almuerzos hablando de la vida y de la actualidad mundial. Una especie de "Almorzando con Mirtha" pero con cubiertos de plástico y sin miedo al zurdaje. Nos merecemos un atracón de 
despedida con toda la pompa que se puede tener sentado en las escalinatas con bandejitas de plástico. Se te va a extrañar pibe.

El último agradecimiento de física va para la dueña de la máquina de café del pasillo. Su involuntario aporte de cucharitas de plásticos fue esencial para la construcción del arreglo de bobinas que sostienen esta tesis. En cuanto pueda, le tramito un honoris causa.

Ahora le toca a mi equipo de respaldo, firme en su puesto desde que arranqué con el plano inclinado. David y Pablo me dan seguridad en la vida, difícil que ellos no tengan la posta cuando los necesito. Si se puede mandar en binario, David te lo soluciona y el ingenieri desarmista Mereles es el capo del SolidWorks que dibujó el posicionador del sistema de bobinas, posiblemente lo que mejor ha funcionado en toda la tesis. No se mueran nunca muchachos, y no cambien de número sin avisar.

Otra con la que he hablado mucho de la vida, de la ciencia y del mundo es la licenciada Cecilia Valenti, la persona que me enseñó que uno no es su trabajo y tantas otras cosas con su método registrado de desquiciarte primero y congeniar después. Principialmente por eso, también tiene una silla en el comité de crisis. Un mina cuya única constante es que siempre está cambiando. Espero que encuentres tu lugar en el mundo.

Entre esos aportes de última hora que mencioné arriba está la revisión de una de las secciones por parte de una de las pocas personas a la que le permito corregir mi redacción. Gracias Valen, por eso y por la frase prestada, prometo que será devuelta oportunamente. Tarea para el hogar: avisale al ruso que piratea papers que está incluído en estos agradecimientos.

Esto cierra (por ahora) con mi hermano por elección. ¿Qué te voy a decir Juanelo?, estamos condenados al éxito, gracias por estar, siempre.

Espero no dejar a nadie afuera. Esto últimos meses de trabajar en serio fueron duros y estoy llegando con la reserva. Poca gente va a leer lo que sigue así que me despido diciendo acá que el electromagnetismo no mata, matan los boludos útiles y los miserables que los manejan. Tratemos de que no proliferen.

La Plata, 4 de marzo de 2015

P.D. 1: Un punto más para el Dr. Mendoza. Terminó de armar el programa para procesar los datos de magnetización RF el día que murió Cerati, el script se llama "Zona de promesas"...

P.D. 2: Agradecimiento de último momento a todos los no incluidos arriba que en estos días me preguntan cómo va la cosa y me dan ánimos. Parece una tontería pero ayuda. En especial a Rocío Fleitas, que debe estar preocupada por eso que le tengo que devolver pero no sería decoroso mencionar en público (diría que es cosa de gatos pero sería aún peor;)). 


\section{Resumen}

De acuerdo a la OMS, los distintos tipos de cáncer constituyen una de las principales causas de muerte en el mundo habiendo sido responsable de 8,2 millones de los decesos en 2012[1]. Esto se manifiesta principalmente en los países de alto ingreso promedio en donde las enfermedades infecciosas están más controladas, la mortalidad infantil es baja y la esperanza de vida es mayor[2]. Así, la investigación en oncología resulta sumamente rentable por lo que existen varias terapias desarrollados para tratar la enfermedad y aumentar la esperanza y calidad de vida de los pacientes.

Algunos de los tipos más comunes de cáncer, como el de mama, el cervical y el colo-rectal poseen una alta tasa de remisión cuando son detectados y tratados en forma temprana. Los principales tratamientos se basan en cirugía, radioterapia y quimioterapia[3] por lo que estas técnicas han concentrado la mayor parte de la investigación y desarrollo. Aún así, los conocidos efectos colaterales de estos tratamientos no han podido eliminarse completamente. Por todo esto, la búsqueda de técnicas más eficientes y de acción más específica, con menores efectos no deseados, resulta importante a la hora de brindar una mejor calidad de vida a los pacientes.

Existen y se desarrollan continuamente varios tipos de terapias complementarias. En particular, las llamadas terapias por hipertermia aprovechan el hecho de que las células tumorales presentan una menor tolerancia térmica que las células sanas. Las células normales comienzan a degradarse por encima de los $46^{\circ} \mathrm{C}$ mientras que las tumorales lo hacen por encima de los $42^{\circ} \mathrm{C}$, de esta forma las últimas pueden ser selectivamente destruidas o sensibilizadas para aumentar la eficiencia de las terapias estándar[4],[5],[6].

Las Nanopartículas Magnéticas (NPM) poseen propiedades únicas que las convierten en un vehículo ideal para nuevas terapias basadas en disipación térmica localizada y selectiva. Las suspensiones de NPM (ferrofluidos, FF) pueden ser inyectadas directamente en la zona de interés o transportadas hasta los tejidos afectados desde su punto de ingreso al organismo. NPM con un momento magnético permanente alto pueden ser manipuladas mediante campos magnéticos externos moderados, tanto para concentrarlas en áreas específicas como para hacerlas disipar calor[7],[8],[9].

Las NPM hechas de óxidos de hierro son biocompatibles, y las compuestas por materiales de baja biocompatibilidad pueden ser recubiertas con materiales no tóxicos. La funcionalización de su superficie mediante el agregado de compuestos orgánicos e inorgánicos les confiere la capacidad de evadir al sistema inmunitario y de hacer blanco en tejidos específicos[10],[11]. Trabajos realizados en el Hospital Charité de Berlín, junto a investigadores de la FriedrichSchiller-Universität de Jena, demostraron que NPM inyectadas intersticialmente y calentadas mediante campos de radiofrecuencia, pueden destruir células cancerígenas en tumores cerebrales humanos, mejorando los resultados de subsecuentes tratamientos de radioterapia[15]. También, el grupo de trabajo de Andreas Jordan en Charité realiza ensayos en pacientes con cáncer de próstata [16]. Asimismo, ensayos clínicos de diversos tipos de cáncer (glioblastoma multiforme, cáncer de próstata, recurrencias locales o tumores residuales, cáncer de esófago, cáncer de páncreas, cáncer de mama), se encuentran en diferentes grados de avance: pre-clínica, 
fase I (estudio de factibilidad) o fase II (estudio de eficacia)[17].

Para relacionar el desempeño de la terapia térmica con parámetros físicos y químicos relevantes de las NPM tales como distribución de tamaños, forma, composición, fase magnética, características de la interfaz y distribución de momentos magnéticos, es necesaria tanto una detallada caracterización experimental como un cuidadoso estudio teórico de la interacción de las NPM con los campos RF para cada caso específico. Un paso en esta dirección es la determinación del factor de frecuencia de la potencia específica absorbida del campo y liberada al medio en forma de calor por la muestra (SAR, por Specific Absorption Rate o SLP por Specific Loss Power) el que puede obtenerse de la componente fuera de fase de la susceptibilidad AC, como función de la temperatura, amplitud de campo y frecuencia.

Los resultados presentados en esta tesis apuntan al desarrollo tanto de NPM optimizadas para la hipertermia magnética, como de nuevas técnicas de caracterización y modelos que permitan comprender mejor los mecanismos de interacción de estos objetos con los campos RF utilizados en la hipertermia. Se trabajó con dos conjuntos de muestras de NPM de distintas características y orígenes sometiéndolas a todas las técnicas de caracterización disponibles para luego comparar los resultados obtenidos con las predicciones de los modelos desarrollados.

En el primer capítulo se introducen los conceptos básicos sobre NPM, sus propiedades características y aplicaciones generales. La última parte de la introducción se dedica a la hipertermia magnética. Se desarrollan las generalidades de la terapia y los últimos avances en el área.

El segundo capítulo está dedicado a los modelos teóricos desarrollados para describir la interacción entre las NPM y los campos RF. Se detallan primero los parámetros que caracterizan a una muestra de NPM. Luego se describen los 2 mecanismos de disipación de potencia contemplados y se expone el modelo de Stoner-Wolhfarth para la inversión de un sistema de NPM fijas sin efectos térmicos, sometidas a un campo magnético externo. Todo esto como base para el posterior desarrollo de un modelo para la inversión de momentos en NPM fijas con agitación térmica, primero para un sistema con sus anisotropías orientadas paralelas al campo y luego para un sistema con anisotropías orientadas en una dirección arbitraria. Este último modelo se extiende luego a un sistema con una distribución uniforme de orientaciones. Se obtiene la dependencia de la magnetización primero con el tiempo y luego con el campo y con la temperatura para sistemas monotamaño y con distribución de volúmenes. Junto a cada uno de los modelos desarrollados, se presentan las curvas obtenidas por resolución numérica de las ecuaciones generadas reproduciendo diferentes condiciones experimentales habitualmente usadas en la caracterización de NPM.

El tercer capítulo comienza describiendo brevemente las técnicas experimentales convencionales utilizadas para luego extenderse en la descripción de las desarrolladas específicamente para este trabajo. Dentro de estas últimas se presenta la caracterización realizada del equipo generador RF, incluyendo la ampliación del rango de frecuencias accesibles mendiante el mismo, y la construcción de un sistema inductivo que permite relevar ciclos de magnetización RF a fin de caracterizar las NPM en las mismas condiciones de campo y frecuencia presentes en la 
aplicación. Se describe además el tratamiento de datos realizado para obtener estos ciclos.

En el cuarto capítulo, se describen los procesos de síntesis y las características de todas las muestras estudiadas para terminar exponiendo y discutiendo los resultados de la caracterización. Además se comparan los resultados experimentales con las simulaciones numéricas obtenidas a partir de los parámetros propios de cada muestra. La primera sección corresponde al estudio realizado sobre 3 series de NPM de magnetita dopada con zinc a fin de aumentar su magnetización de saturación. Estas muestras fueron caracterizadas exhaustivamente con todas las técnicas disponibles para correlacionar sus propiedades estructurales con su disipación de potencia bajo campos RF. Se verifica además la incorporación de zinc en la estructura de la magnetita y se describe el efecto de esta incorporación en la respuesta magnética. La segunda sección está dedicada al estudio de NPM de magnetita cubiertas con una monocapa adsorvida de ácido oléico. Utilizando el sistema de medición de ciclos de histéresis a RF descrito en el capítulo anterior, se elabora un mapa de disipación de potencia en función de la amplitud y la frecuencia del campo magnético para la muestra en suspensión y para un ferrogel fabricado a partir de las mismas NPM. Esto permite estudiar la diferencia en la disipación de potencia entre partículas en suspensión y partículas fijas. Además se comparan los resultados de potencia disipada obtenidos con el sistema inductivo con los obtenidos con el sistema calorimétrico convencional.

Finalmente, en el quinto capítulo se presentan las conclusiones generales de todo el trabajo surgidas de la comparación de los resultados experimentales y las predicciones teóricas. 



\section{Índice general}

1. Introducción $\quad 1$

1.1. Materiales magnéticos 3

1.1.1. Dominios magnéticos 4

$\begin{array}{ll}\text { 1.1.2. Nanopartículas magnéticas } & 7\end{array}$

1.2. Aplicaciones de NPM en biomedicina 9

1.3. Hipertermia magnética. 11

1.3.1. Conceptos básicos de hipertermia mediante NPM 11

Relajación magnética $\quad 13$

$\begin{array}{ll}\text { 1.3.2. Síntesis de NPM } & 14\end{array}$

1.3.2.1. Síntesis de núcleos magnéticos $\quad 14$

1.3.2.2. Recubrimiento de los núcleos magnéticos 16

$\begin{array}{ll}\text { 1.3.3. Estructura y morfología de NPM } & 17\end{array}$

1.3.3.1. Efectos de la distribución de tamaño 18

1.3.3.2. Efectos de la interacción entre NPM 18

2. Modelado de la respuesta de NPM a campos magnéticos 21

2.1. Mecanismo de magnetización en nanopartículas 23

Efectos térmicos: Superparamagnetismo 23

La constante de anisotropía $\quad 24$

2.2. Mecanismo de absorción de energía de NPM en campos RF 25

Dependencia de la absorción con los parámetros del material 26

$\begin{array}{ll}\text { Mecanismos de relajación } & 27\end{array}$

Relajación de Brown $\quad 27$

Relajación de Neel 28

2.3. Inversión de momentos sin efectos térmicos 29

2.4. Relajación de NPM con agitación térmica $\quad 32$

2.4.1. Anisotropías paralelas al campo 32

2.4.1.1. Magnetización en función del campo 34

2.4.1.2. Dependencia del campo coercitivo con la temperatura 38

2.4.1.3. Magnetización en función de la temperatura 41

Enfriamiento con y sin campo: ZFC-FC de un sistema ordenado 41

Dependencia de la temperatura de bloqueo con las condiciones de medida 45

2.4.2. Anisotropías con orientación aleatoria 45

2.4.2.1. Magnetización en función del campo 48

2.4.2.2. Magnetización en función de la temperatura $\quad 50$

3. Técnicas experimentales $\quad 53$

3.1. Técnicas convencionales $\quad 55$

3.2. Caracterización de NPM para hipertermia 56 
3.2.1. Determinación de concentración de Fe en FF

3.2.2. Determinación de SAR mediante medidas calorimétricas

3.2.2.1. Caracterización de la relación Campo-Frecuencia del generador $\mathrm{RF}$

3.2.2.2. Caracterización de la geometría del campo de la bobina utilizada

3.2.3. Desarrollo de sistema inductivo de relevamiento del ciclo de magnetización a RF y determinación del SAR

4. Caracterización de NPM

4.1. Muestra I

4.1.1. Síntesis

Síntesis serie 1 (S1)

Síntesis serie $2(\mathrm{~S} 2)$

Síntesis serie 3 (S3)

4.1.2. Análisis de composición y estructura: DRX, TEM y SEM 71

4.1.3. Caracterización XAS

4.1.4. Resultados Mössbauer $\quad 82$

4.1.5. Análisis magnético $\quad 87$

4.1.6. Disipación de potencia $\quad 89$

4.1.7. Conclusiones 92

4.2. Muestra II 95

4.2.1. Síntesis 95

4.2.2. Caracterización estructural: TEM 95

4.2.3. Caracterización magnética 95

4.2.3.1. Magnetización en función de la temperatura a campo constante: ZFC-FC 95

4.2.3.2. Magnetización en función del campo a temperatura constante: ciclos M vs. H. 102

4.2.4. Medición de ciclos RF 103

4.2.4.1. NPM en suspensión: Ferrofluido 103

4.2.4.2. NPM fijadas: Ferrogel 105

Comparación entre FG, FF y simulaciones $\quad 105$

4.2.5. Comparación de resultados electromagnéticos y calorimétricos 109

$\begin{array}{ll}\text { 4.2.6. Conclusiones } & 111\end{array}$

$\begin{array}{ll}\text { 5. Discusión y conclusiones generales } & 115\end{array}$ 


\section{Introducción}

Capítulo 1 
«-But, after all, what use is it?

-Why, sir, there is every probability that you will soon be able to tax it!»

-Pero, después de todo, ¿cual es su utilidad?

-Bueno señor, pronto usted podrá cobrar impuestos sobre esto!

Conversación entre el ministro de hacienda de Reino Unido y

Michael Faraday (físico británico) al presentar este sus descubrimientos sobre electromagnetismo.

R. A. Gregory, Discovery, Or The Spirit and Service of Science (1916), 3. 
A partir de la segunda mitad del siglo pasado se tomó conocimiento de que el comportamiento a pequeña escala de los materiales magnéticos difiere fuertemente del comportamiento de los sistemas masivos. En particular, las propiedades de suspensiones de pequeñas partículas de materiales magnéticos llamadas ferrofluidos (FF) insinuaban aplicaciones tecnológicas prometedoras siendo los únicos materiales fluidos con fuerte respuesta a los campos magnéticos[19]. Entre otras características, la capacidad de estos materiales para absorber energía de un campo electromagnético y disiparla al medio mediante calor los convirtió en potenciales agentes hipertérmicos para terapias médicas.

La hipertermia i.e. el calentamiento de los tejidos por encima de la temperatura fisiológica, se utiliza como terapia oncológica desde la antigüedad y fue retomada por la ciencia moderna a partir de la observación del médico alemán W. Busch en 1866 de la desaparición de un sarcoma en un paciente que había sufrido fiebre alta y prolongada debido a una infección[20]. Sin embargo, el desarrollo efectivo de esta aplicación tuvo que esperar hasta la década de 1980 cuando el avance en las técnicas de síntesis y caracterización permitió la fabricación de FF estables y con propiedades controladas. El descubrimiento de que las partículas magnéticas monodominio presentan una elevada capacidad disipativa, mucho más grande que la de las partículas multidominio, llevó al renacimiento de la hipertermia magnética como tratamiento oncológico y al consecuente crecimiento constante de la investigación en el tema[8].

\subsection{Materiales magnéticos ${ }^{1}$}

Cuando un material se expone a un campo magnético de intensidad $\mathbf{H}$, sus momentos atómicos contribuyen a la respuesta efectiva, la inducción magnética $\mathbf{B}$, como

$$
B=\mu_{0}[H+M]
$$

con $\mu_{0}=4 \pi \times 10^{-7} \mathrm{H} / \mathrm{m}$ (Henry sobre metro) la permeabilidad del vacío y $M=m / V$ la cantidad de momentos magnéticos $m$ por unidad de volumen $V$. En el SI, tanto $M$ como $H$ se expresan en $\mathrm{A} / \mathrm{m}$ y $B$ en $\mathrm{T}$ (teslas).

Describiendo la respuesta magnética de un material por su aproximación a primer orden en $H$ como

$$
M=\frac{\partial M}{\partial H} H=\chi H
$$

con la derivada primera $\chi$ llamada susceptibilidad magnética, se puede determinar una clasificación según la naturaleza de esta última.

Los materiales con suceptibilidad pequeña y negativa $\left(-10^{-6} ;-10^{-3}\right)$ se llaman diamagnetos. Este tipo de respuesta proviene del efecto del campo magnético sobre los orbitales electrónicos y está presente en todos los elementos, pero por ser la más débil de las interacciones, sólo se manifiesta macroscópicamente en los materiales constituidos por átomos sin momento magnético neto i.e. materiales con todas sus capas electrónicas cerradas[23].

\footnotetext{
${ }^{1}$ Un desarrollo más amplio de lo aquí expuesto se puede encontrar en [21].
} 
Los materiales constituidos por átomos o moléculas con momento atómico neto, que interactúan débilmente entre sí, se llama paramagnetos. Presentan una susceptibilidad pequeña y positiva $\left(10^{-6} ; 10^{-1}\right)$ por lo que su magnetización es débil y proporcional al campo. Esta linealidad se mantiene en un rango amplio dado que la débil respuesta coloca la saturación en campos sumamente altos. En la mayoría de los casos, la susceptibilidad es inversamente proporcional a la temperatura[20].

Finalmente existen materiales formados por átomos o moléculas con momento magnético neto que interactúan fuertemente entre sí. Estos materiales presentan orden magnético espontáneo aún en ausencia de campo. Dependiendo de la naturaleza de la interacción y del orden resultante se clasifican en:

- Antiferromagnetos: La interacción entre momentos favorece una alineación antiparalela. Se forman dos subredes iguales intercaladas y orientadas en sentidos opuestos. Debido a esto, su magnetización macroscópica es en principio nula manifestándose sólo para grandes campos aplicados lo que resulta en una susceptibilidad de magnitud similar a la paramagnética.

- Ferrimagnetos: Pueden ser descritos como antiferromagnetos en donde las redes que se orientan antiparalelamente están formadas por momentos de diferente magnitud. Como consecuencia manifiestan una magnetización neta en la dirección de la red de mayor momento y una susceptibilidad alta, dependiente de $\mathrm{H}$ que puede llegar a $10^{1}$.

- Ferromagnetos: La interacción entre momentos, llamada interacción de intercambio, tiende a alinearlos paralelamente por lo que responden al campo externo con susceptibilidades altas, dependientes de $H$ como en el caso de los ferrimagnetos. Su alta susceptibilidad permite alinear todos los momentos del material con campos accesibles en laboratorio. La magnetización llega a su valor máximo para una dada temperatura cuando se obtiene la máxima proyección de los momentos individuales en la dirección del campo.

Los ciclos $M$ vs. $H$ de los materiales ferro y ferrimagnéticos presentan una característica forma sigmoidal (fig. 1.1) definida por: la magnetización de saturación $M_{s}$, que depende de la temperatura; la curva virgen, que se recorre sólo una vez desde el estado original de magnetización nula hasta $M_{s}$; el valor de campo coercitivo $H_{c}$ al que la magnetización se hace nula y la magnetización remanente $M_{R}$ a campo nulo.

Tanto los antiferro, como los ferri y ferromagnetos cambian su comportamiento magnético por encima de la temperatura en la que la energía térmica supera a la energía de interacción entre momentos. Este valor se llama temperatura de Curie $\left(T_{c}\right)$ para los ferro y ferrimagnetos y temperatura de Neel para los antiferromagnetos. Los ferromagnetos en particular, se comportan como paramagnetos por encima de $T_{c}$.

\subsubsection{Dominios magnéticos}

En los ferromagnetos, la energía asociada a la interacción de intercambio se minimiza cuando todos los momentos se orientan paralelos. Pero un material volumétrico magnetizado a sa- 


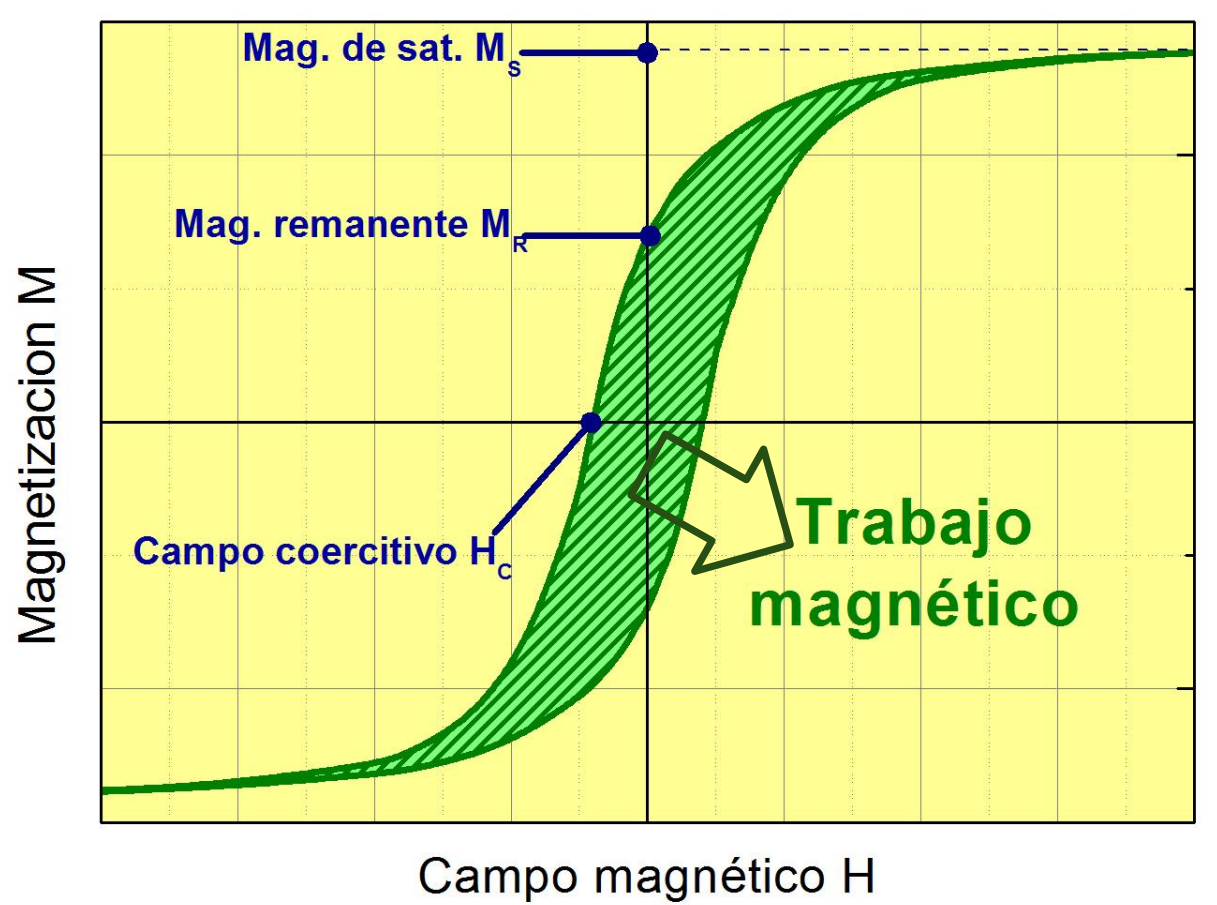

Figura 1.1: Ciclo de magnetización $M$ en función del campo $H$ para un material ferromagnético típico. Se denotan los parámetros característicos. El área del ciclo es igual al trabajo magnético realizado sobre el sistema.

turación genera un campo dependiente de la geometría que en el interior del material tiene el sentido opuesto a la magnetización misma, por lo que se llama campo desmagnetizante (fig 1.2).

La energía magnetostática asociada a este campo se minimiza si el objeto se reorganiza en regiones adyacentes con magnetizaciones opuestas (fig 1.3).

Las regiones de momentos paralelos en las que se organiza el material para minimizar la energía magnetostática se llaman dominios magnéticos y son la causa de que los materiales ferromagnéticos se presenten usualmente sin una magnetización neta en ausencia de campo. La separación en dominios encuentra su límite debido a que otras energías entran en juego. En el modelo más simple, la interfaz entre dominios es de espesor nulo, pero esto implicaría la existencia de muchos pares de momentos vecinos orientados antiparalelamente lo que aumentaría la energía de intercambio. Así, debido a la interacción de intercambio, el sistema tiende a organizarse de manera que las transiciones entre dominios sean espacialmente extendidas, con los momentos de la interfaz cambiando gradualmente de orientación a lo largo de la pared (fig 1.4).

Por otro lado, la estructura cristalina de los materiales define orientaciones preferenciales para los momentos atómicos de manera que existe una energía de anisotropía cristalina que se minimiza cuando los momentos magnéticos apuntan en las llamadas direcciones "fáciles". Así, una configuración con paredes de dominio extendidas, con una rotación gradual de momentos, posee una energía de anisotropía mayor que una configuración en la que los momentos sólo apuntan en las direcciones de los ejes fáciles. De esta manera, el espesor de las paredes de 


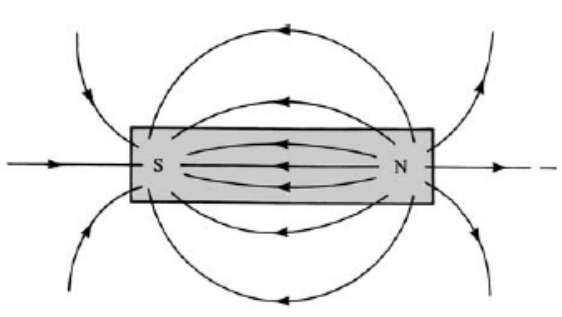

(a)
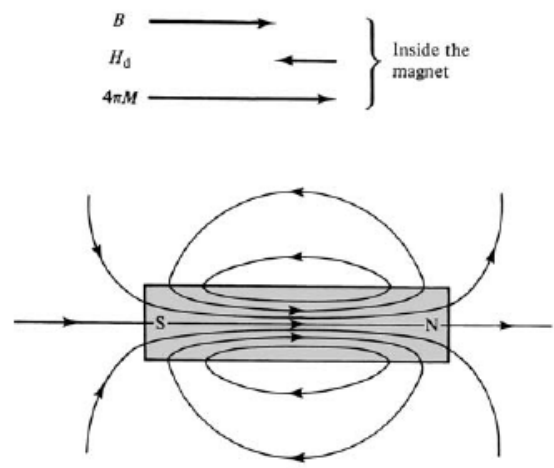

(b)

Figura 1.2: Esquema de la dirección y sentido de los campos dentro de un imán (Inside the magnet). Se observa como aparece un campo desmagnetizante $H_{d}$ en sentido opuesto a $M$. En a) se muestra la dirección de $H$ y en $b$ ) la dirección de $B$ calculado según la expresión 1.1[21]

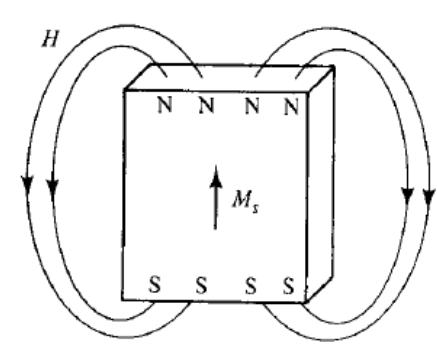

(a)

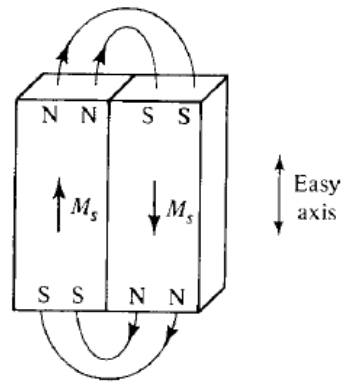

(b)

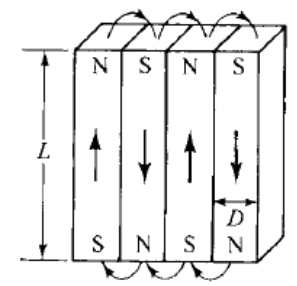

(c)

Figura 1.3: Esquema de la división de un material en dominios. Se observa como el campo externo $H$ disminuye desde el valor máximo de objeto monodominio a) a medida que se aumenta la cantidad de divisiones. Easy axis=Eje fácil[21]. 


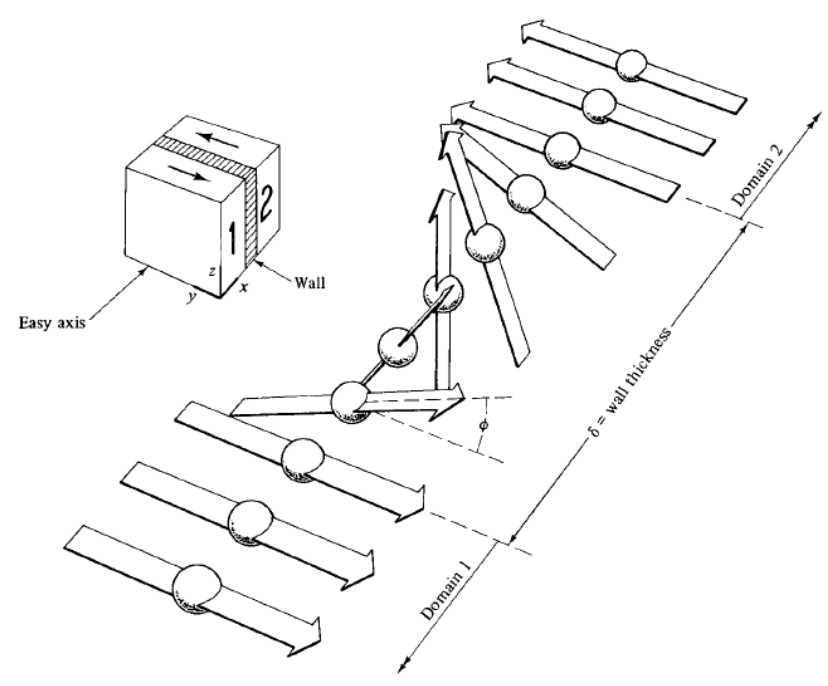

Figura 1.4: Esquema de la estructura de una pared entre dominios antiparalelos. Se observa la rotación gradual de los momentos a lo ancho de la pared. Easy axis= Eje fácil. Wall= Pared. Domain=Dominio. Wall thickness=espesor de pared.[21].

dominio queda definido por la competencia entre todas estas interacciones.

\subsubsection{Nanopartículas magnéticas}

La energía magnetostática de un cuerpo de longitud característica $D$ varía con su volumen $D^{3}$, mientras que la energía asociada a la formación de paredes de dominio varía con el área de estas a su vez proporcional a la sección transversal del cuerpo $D^{2}$. De esto se desprende que existe un tamaño crítico por debajo del cual deja de ser favorable la formación de paredes de dominio. Este tamaño crítico depende principalmente de la relación $\frac{E_{w}}{M_{s}}$ entre la energía de las paredes de dominio $E_{w}$ y la magnetización de saturación $M_{s}$ del material en cuestión. Así, partículas de materiales ferro y ferrimagnéticos menores a algunas decenas de nanómetros presentan un ordenamiento monodominio. En una primera aproximación, esto se puede considerar equivalente a que las partículas por debajo del tamaño crítico se encuentran permanentemente saturadas en el sentido de que todos sus momentos se encuentran apuntando en la misma dirección. Así, un campo $H$ aplicado a una partícula multidominio debe aportar la energía magnetostática necesaria para lograr $M_{s}$ mientras que en una partícula monodominio esto ya no es necesario.

Teniendo en cuenta esto, se puede asociar tamaños característicos de partícula a su respuesta magnética típica (fig 1.5). Comenzando por los tamaños mayores, se pueden distinguir los siguientes comportamientos:

- Multidominio: La magnetización cambia por movimiento de paredes de dominio. Al exponer el material a un campo $H$, los dominios con mayor proyección en la dirección del campo crecen a costa de los demás. Se ha observado experimentalmente que, en este rango de tamaños, para muchos materiales el campo coercitivo crece al achicarse la partícula como: 


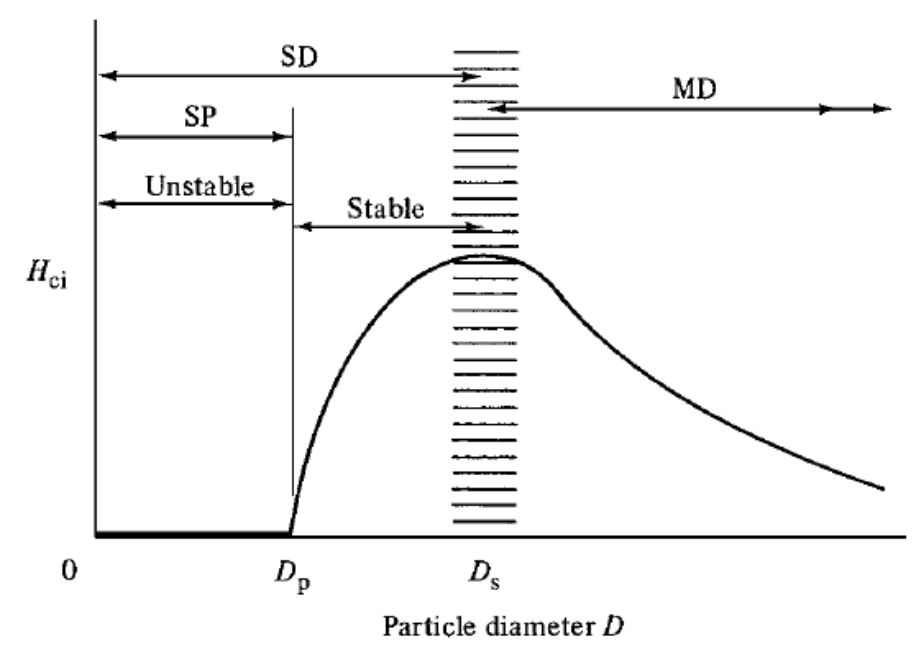

Figura 1.5: Variación esquemática de la coercitividad intrínseca de un material ferromagnético con el tamaño D. $S P=$ superparamagnético. $S D=$ monodominio. $M D=$ multidominio. Unstable=Inestable. Stable= Estable. Particle diameter= Diámetro de partícula.[21].

$$
H_{c}=a+\frac{b}{D}
$$

con $a$ y $b$ constantes. No hay fundamento teórico para esta expresión.

- Monodominio: Por debajo de un tamaño crítico $D_{s}$, la partícula se vuelve monodomio y la coercitividad alcanza su valor máximo debido a que, ya sin paredes de dominio, el campo debe superar a la anisotropía para rotar la magnetización. Para tamaños aún menores la agitación térmica se vuelve comparable a la energía de anisotropía que varía monótonamente con el volumen y la coercitividad empieza a disminuir según:

$$
H_{c}=f+g D^{-3 / 2}
$$

con $f$ y $g$ constantes. Esta dependencia está bien comprendida y se explicará más adelante.

- Superparamagnetismo: Para una dada combinación de tamaño de partícula monodominio, tiempo de medida y temperatura, la coercitividad se vuelve cero. Durante el tiempo de observación, la agitación térmica invierte la magnetización de manera que en promedio se mide un valor nulo en ausencia de campo. Este estado se llama superparamagnético (SPM) y se manifiesta en un ciclo de magnetización sigmoidal pero sin área. 


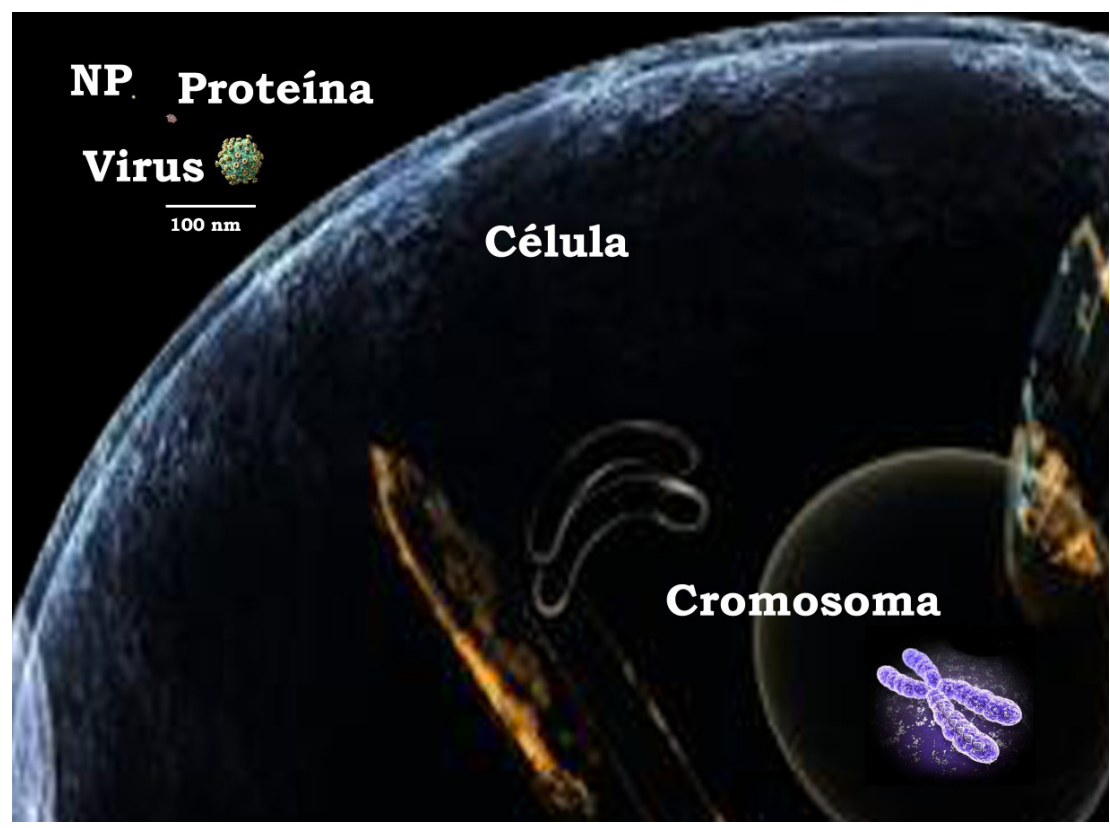

Figura 1.6: Representación a escala de tamaños representativos de los objetos biológicos que interactúan con las nanopartículas: Célula $(\sim 2000 \mathrm{~nm})$, cromosoma $(\sim 200 \mathrm{~nm})$, virus $(\sim 100 \mathrm{~nm})$, proteína $(\sim 10 \mathrm{~nm})$, nanopartícula $(\sim 1 \mathrm{~nm})$. Todos estos elementos se presentan en realidad en un amplio rango de tamaños en los sistemas a estudiar.

\subsection{Aplicaciones de NPM en biomedicina ${ }^{2}$}

Por las propiedades antes mencionadas, y otras que se desarrollan más adelante, las nanopartículas magnéticas (NPM) ofrecen una amplia gama de aplicaciones en biomedicina. El desarrollo actual de las técnicas de síntesis y caracterización permite contar con NPM de tamaño y forma controlados. Esto las convierte en agentes ideales para interactuar de forma precisa con los entes biológicos de menor tamaño como células, bacterias, virus, proteínas y genes (figs. 1.6 y 1.7). Además, pueden ser 'funcionalizadas' i.e. recubiertas con o adosadas a compuestos con actividad biológica con el fin de interactuar selectivamente con el tejido objetivo de una terapia o diagnóstico.

Por otro lado, al ser expuestas a un campo magnético alterno, las NPM pueden transferir energía del campo al medio mediante calor. Esto se puede utilizar tanto para calentar el tejido circundante como para activar materiales termosensibles injertados en el organismo[24] (fig 1.8). Otra aplicación de la respuesta de las NPM a los campos externos es su utilización como agentes de contraste para resonancia magnética nuclear.

El calentamiento de tejido con fines terapéuticos, conocido como hipertermia concentra desde hace dos décadas gran parte de las investigaciones en NPM y es la principal motivación de este trabajo.

\footnotetext{
${ }^{2}$ Un desarrollo más amplio de lo aquí expuesto se puede encontrar en [22].
} 


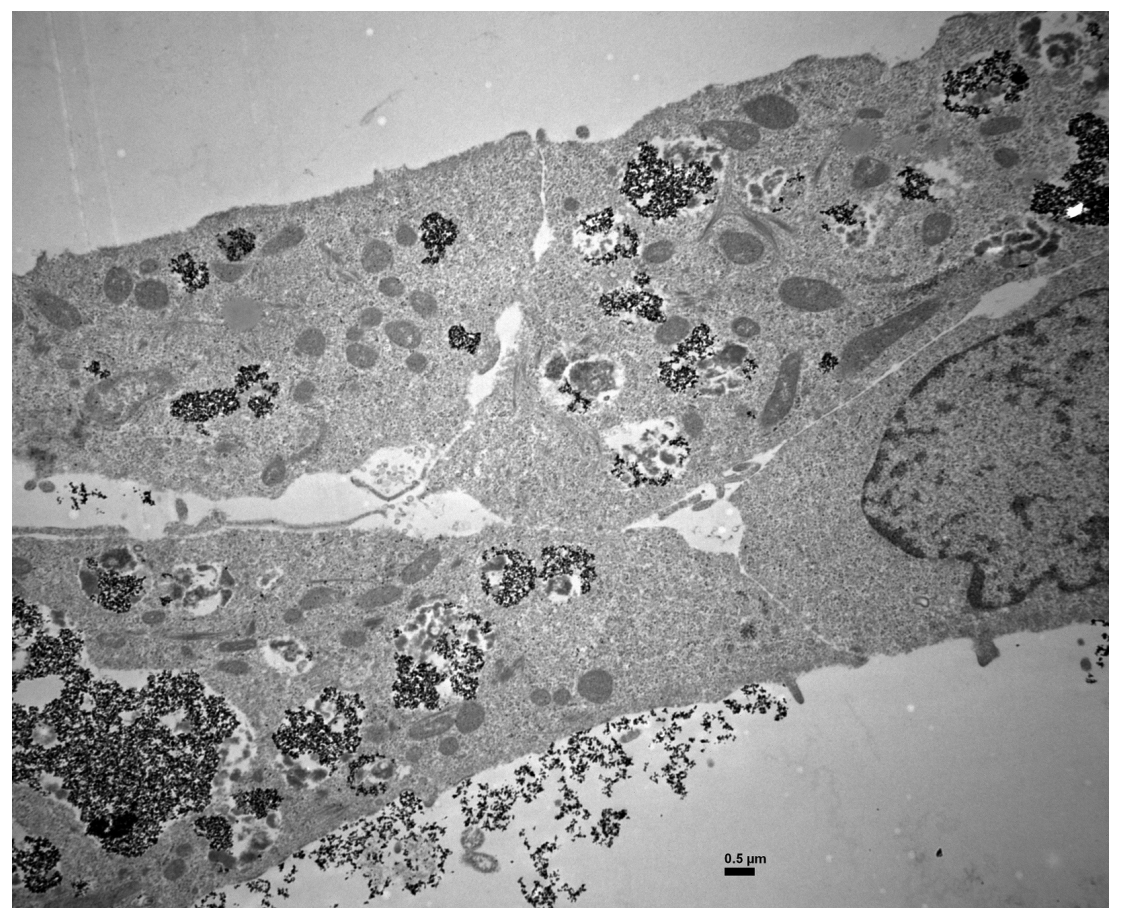

Figura 1.7: Imagen TEM de un cultivo celular (adenocarcinoma pulmonar humano) expuesto a NPM de magnetita tomada en el marco de la tesis doctoral de la lic. Elisa DeSousa del Grupo de magnetismo y materiales magnéticos del IFLP. Se observa cómo las células incorporan gran cantidad de partículas en endosomas[126].

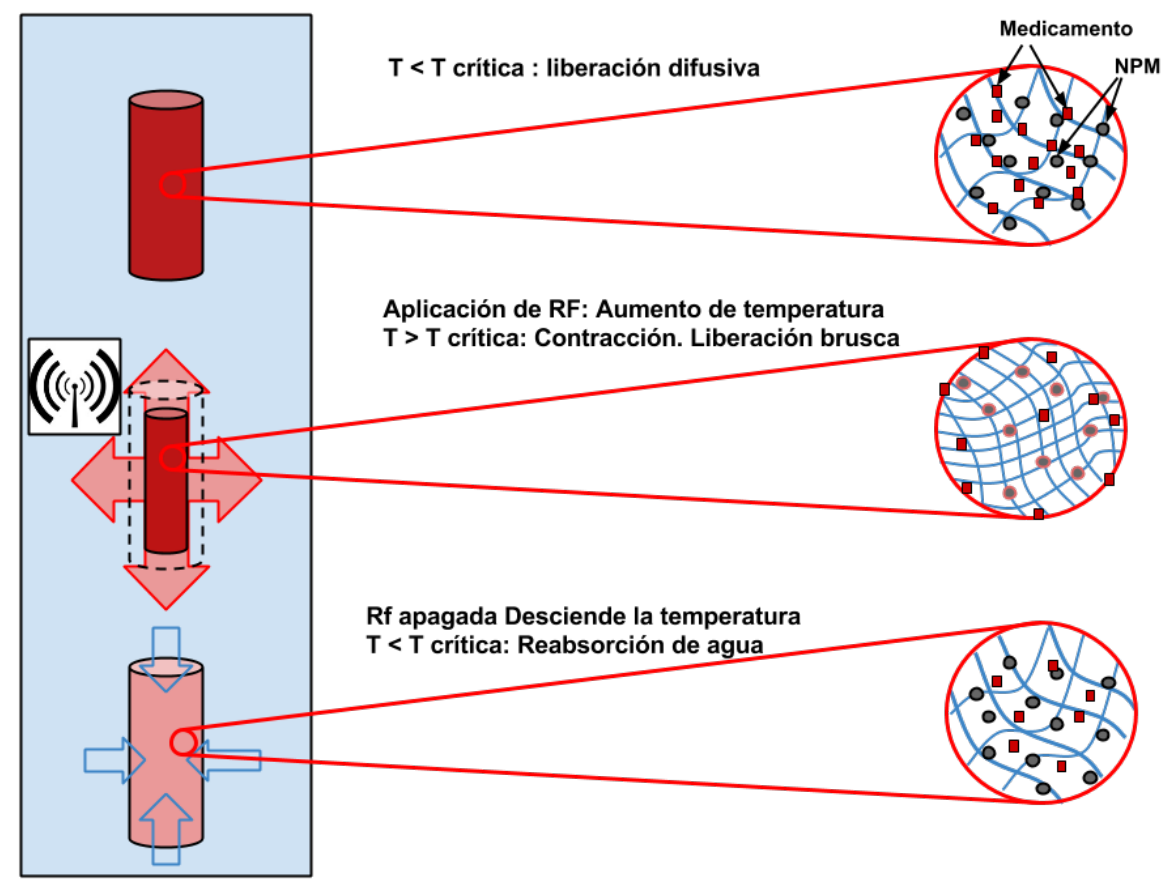

Figura 1.8: Ejemplo de aplicación biomédica de NPM. Incorporadas a un hidrogel termosensible cargado con un medicamento, provocan la contracción del gel al calentarse por la aplicación de un campo de radiofreucuencia, liberando la droga.[24] 


\subsection{Hipertermia magnética.}

Como expresan Dutz y Hergt en su más reciente y muy completa revisión del tema [54], en la actualidad, la destrucción selectiva de tejido tumoral mediante el aumento local de temperatura constituye una terapia oncológica aprobada y establecida [116].

Existen varias vías, basadas en diferentes mecanismos físicos, para llevar el tejido biológico a temperatura hipertérmica $\left(42^{\circ} \mathrm{C}<\mathrm{T}<46^{\circ} \mathrm{C}\right)$ : irradiación de microondas a partir de antenas [117], calentamiento óhmico mediante electrodos [118], irradiación láser mediante fibra óptica [119] y calentamiento por baño térmico de cuerpo entero, entre otras [120]. Sin embargo, todos estos procedimientos carecen de la capacidad de controlar con precisión la distribución de temperatura en el tejido objetivo.

La hipertermia mediante nanopartículas magnéticas (MPH por elegir una de sus tantas siglas en inglés) por otro lado, hace posible un verdadero calentamiento local al introducir la fuente térmica (las NPM) en el tejido tumoral y transferirles energía mediante un campo de radiofrecuencia externo. En las últimas décadas, la viabilidad de la técnica se ha demostrado mediante varios ensayos clínicos[121, 122, 123, 124, 125], en particular para el tratamiento de cáncer de próstata y gliomas ${ }^{3}$.

Si bien los resultados preliminares resultan prometedores, aún existen aspectos importantes a mejorar para que la MPH pueda convertirse en una terapia estándar. Los dos principales objetivos en esta etapa de la investigación son: desarrollar métodos confiables y seguros para hacer llegar las NPM al interior de cada tipo de tumor para lo que, además de la inyección intratumoral, se están investigando métodos alternativos como el marcado con anticuerpos; y aumentar la capacidad de las partículas para disipar potencia, de manera de alcanzar temperaturas hipertérmicas utilizando la menor cantidad posible de material .

La hipertermia provoca daños reversibles en el tejido tumoral, pero como terapia complementaria aumenta la eficiencia de la radioterapia y la quimioterapia[8]. Alternativamente, vale mencionar que existe y se utiliza la técnica de termoablación. En esta, se generan temperaturas de hasta $56{ }^{\circ} \mathrm{C}$ mediante el mismo mecanismo de la MPH con el fin de destruir el tejido tumoral vía necrosis ${ }^{4}$.

\subsubsection{Conceptos básicos de hipertermia mediante NPM}

La MPH consiste en la destrucción de tejido tumoral mediante calor, por sí sola o en combinación con las terapias oncológicas convencionales [57]. La fuente térmica consiste en NPM ubicadas en el tejido a tratar y expuestas a un campo RF generado por bobinas externas al cuerpo del paciente.

En principio, los campos RF producen corrientes de Foucault en cualquier medio conductor, pero no es este el mecanismo aplicable en MPH. Los óxidos de hierro, que resultan los materiales más adecuados para las NPM, son pobres conductores eléctricos. Además, el voltaje

\footnotetext{
${ }^{3}$ Los gliomas son un tipo de neoplasia (crecimiento anormal de tejido) que se produce en el cerebro o en la médula espinal [55].

${ }^{4}$ A diferencia de la muerte celular programada, llamada apoptosis, en la que la célula realiza una serie de procesos previos que minimizan el efecto sobre el resto del organismo, en la necrosis, un agente externo provoca la ruptura no regulada de la membrana celular, liberando al entorno el contenido de la célula. Esto activa la respuesta del sistema inmunológico con la subsecuente inflamación de la zona afectada [56].
} 
inducido en las NPM es sumamente bajo debido a su pequeño tamaño por lo que tampoco resulta aprovechable en nanopartículas metálicas que de por sí, presentan otros problemas para su utilización. Así, el término "calentamiento inductivo" aplicado a la MPH en parte de la literatura debería ser evitado.

Por otro lado, las dimensiones y la constitución del cuerpo humano sí permiten la generación de importantes corrientes de Foucault al ser expuesto el paciente a campos electromagnéticos alternos. Lejos de una ventaja, esto constituye una limitación a tener en cuenta para la aplicación de la MPH a fin de evitar calentamiento excesivo fuera de la zona de interés. Así, el calentamiento de tejido mediante NPM aprovecha un proceso totalmente distinto, puramente magnético, basado en la disipación de energía por histéresis que se desarrolla con detalle en la sección 2.2.

La histéresis es la principal fuente de disipación térmica en los materiales magnéticos. El origen de este fenómeno es el acoplamiento entre los espines atómicos y la red cristalina que provoca un retraso en la respuesta del material a los campos magnéticos externos. La resultante transformación de energía electromagnética en calor es indeseable en la mayoría de las aplicaciones convencionales por lo que se suele referir a ella en términos de "pérdidas magnéticas". La energía disipada durante un ciclo de magnetización está dada por el área del mismo dado que este área es igual al trabajo magnético realizado por el campo sobre el sistema. Así, la potencia disipada se puede expresar en términos de este área multiplicada por la frecuencia del campo aplicado. Consecuentemente, un aumento de la frecuencia conlleva en general un aumento de la potencia disipada. Pero más allá de esta relación lineal, la frecuencia también determina la forma del ciclo por lo cual, la eficiencia de un sistema MPH depende fuertemente de la amplitud y frecuencia del campo aplicado.

Además de las pérdidas por histéresis, en suspensiones fluidas de materiales magnéticos se presenta un mecanismo de disipación adicional. Ante la posibilidad de rotar espacialmente para seguir al campo, las NPM pueden disipar energía mediante la interacción viscosa con la matriz fluida. Considerar o no este mecanismo dependerá entonces del entorno en el que se encuentren las NPM durante su caracterización y su utilización final.

Adicionalmente, es necesario considerar la complejidad técnica implicada en la generación de campos magnéticos alternos de alta potencia. Esta complejidad crece sensiblemente con la extensión espacial del campo requerido llegando a ser un importante desafío para volúmenes grandes como el del cuerpo humano.

Respecto a las NPM para hipertermia, obviamente la característica más importantes es su absorción específica de potencia. Esta cantidad expresa la potencia absorbida por unidad de masa por parte de las NPM expuestas a un campo RF de determinada amplitud y frecuencia. Se presentan varias siglas para referirla en la literatura siendo las más utilizadas SLP (Specific Loss Power) y SAR (Specific Absorption Rate). En el marco de una teoría de respuesta lineal, considerando campos de baja amplitud, es posible definir una cantidad característica del material dividiendo el SLP por el producto $H^{2} f$ para obtener la disipación intrínseca de potencia ILP (Intrinsic Loss Power) [58]. Esta cantidad puede ser utilizada para comparar el rendimiento de materiales medidos en diferentes condiciones en la región de campos poco intensos [59]. El caso ideal de disipación de potencia se da para un sistema de NPM elipsoidales, uniaxiales, 
magnetizadas homogéneamente y orientadas permanentemente con sus ejes fáciles paralelos al campo. Este modelo fue resuelto teóricamente sin considerar agitación térmica por Stoner y Wolhfarth en un trabajo fundacional[60] y se desarrolla en la sección 2.3.

Surge de estas consideraciones que, de todos los parámetros que caracterizan a las NPM, el más importante es la coercitividad $H_{c}$. La dependencia de $H_{c}$ con el tamaño de los materiales magnéticos ha suscitado una gran atención debido a su aplicación en medios de grabación magnética [65] con un gran aporte de Heider et al respecto a NPM [66]. De estos trabajos se desprende que la coercitividad depende de la estructura del material y que, en particular, varía en función del grado de cristalinidad. Las NPM se obtienen mayoritariamente mediante procesos de síntesis química que resultan generalmente en una estructura cristalina poco perturbada, pero usualmente es necesario considerar una capa exterior de material amorfo a fin de compatibilizar los tamaños magnéticos determinados mediante distintas técnicas [67].

\section{Relajación magnética}

La histéresis magnética es un proceso fuera del equilibrio. Así, al retirar el campo aplicado, la magnetización macroscópica tenderá a desaparecer con un tiempo de relajación característico $\tau$. En los minerales magnéticos este tiempo es del orden de los millones de años, lo que se utiliza para obtener información sobre la variación de los polos magnéticos del planeta [68]. Pero en las NPM este valor puede ser tan bajo como decenas de nanosegundo [59] debido a la relación entre la energía de anisotropía $K V_{M}$ y la energía térmica $k T$, en donde $K$ es la "constante de anisotropía" que corresponda y tiene unidades de densidad volumétrica de energía.

Es este mismo tiempo $\tau$ el que se asigna al retraso de la respuesta magnética ante un campo variable en el tiempo que da origen a la disipación de potencia.

El mecanismo de inversión de la magnetización superando la barrera impuesta por la anisotropía tiene una fuerte dependencia con el tamaño, se conoce comúnmente como Relajación de Néel y su tiempo asociado se calcula como

$$
\tau_{N}=\tau_{0} e^{K V_{M} / k T}
$$

con $\tau_{0}=10^{-9}$ s y $V_{M}$ el volumen magnéticamente activo de la NPM. Es el único proceso presente en el caso de NPM fijadas, sin posibilidad de rotar, como se supone que ocurre cuando son internalizadas por las células tumorales durante la MPH [69].

Como se mencionó antes, en el caso de NPM suspendidas en una matriz fluida, otro mecanismo de relajación se hace posible. Las suspensiones diluidas de NPM conocidas como ferrofluidos (FF) poseen varias aplicaciones técnicas [70]. Típicamente se trata de suspensiones en medios orgánicos dada la dificultad de estabilizar las NPM en medio acuoso, aspecto que se menciona más adelante.

La rotación de la NPM debido al torque surgido de la interacción entre su macromomento y el campo se enfrenta a la interacción viscosa con el medio. En este caso, conocido como relajación de Brown [71], la disipación ocurre por fricción y su tiempo característico depende del volumen hidrodinámico $V_{H}$ de la NPM y de la viscosidad del medio $\eta$ como

$$
\tau_{B}=\frac{3 \eta V_{H}}{k T}
$$


Vale remarcar la diferencia entre el volumen magnético $V_{M}$ y el volumen hidrodinámico $V_{H}$. Estas cantidades suelen diferir, no sólo por la existencia de capas desordenadas en el material, sino también por el efecto de capas de fluido diferenciado adheridas a la partícula y por los eventuales recubrimientos utilizados a fin de estabilizar el FF y de funcionalizar las NPM. Cada partícula utilizará para relajar el mecanismo energéticamente más conveniente (el tiempo más corto) según sus características y condiciones.

Como se mencionó, en el momento de la aplicación MPH, las NPM se encuentran inmovilizadas, por lo que el mecanismo de Brown no es viable. Pero los FF son la forma de conservar las muestras de NPM de manera que estas no se aglomeren, permitiendo su almacenamiento, transporte y caracterización. Además, las suspensiones biocompatibles son necesarias para la administración tanto mediante inyección directa como mediante flujo sanguíneo guiada por anticuerpos.

\subsubsection{Síntesis de NPM}

Como se mencionó en la sección anterior, las propiedades magnéticas de las NPM dependen de sus propiedades estructurales y morfológicas. Se han reportado importantes diferencias en ambas características entre muestras de NPM de tamaño comparable preparadas por diferentes rutas.

Los métodos más usuales son químicos por vía húmeda, pero existen muchos otros tales como evaporación láser, molido de partículas macroscópicas y biomineralización en bacterias.

Se expone a continuación una breve descripción de los principales métodos de preparación de NPM de óxidos de hierro.

\subsubsection{Síntesis de núcleos magnéticos}

- Síntesis húmeda: Esta ruta de síntesis es un método relativamente simple y bien establecido para la preparación de grandes cantidades de NPM. Generalmente, la matriz de crecimiento es un líquido orgánico, pero muchos trabajos científicos abordan la precipitación en medio acuoso. Típicamente se obtienen óxidos de hierro magnéticos (magnetita o maghemita) mediante coprecipitación de soluciones acuosas de sales de $F e^{+2}$ y $F e^{+3}$ por el agregado de una base. El tamaño medio se puede controlar con la relación $F e^{+2} / F e^{+3}$, la temperatura, el $\mathrm{pH}$ y el tipo de base. Los trabajos fundamentales sobre este tipo de síntesis fueron realizados por Khallafalla y Reimers [72] y Massart [73].

Las NPM resultantes suelen ser de entre $5 \mathrm{~nm}$ y $15 \mathrm{~nm}$ con distribuciones de tamaños relativamente anchas.

- Síntesis con polioles: Esta síntesis, basada en la hidrólisis oxidativa alcalina de $F e^{+2}$ y $\mathrm{Fe}^{+3}$ en una mezcla de polioles (e.g. polietilen/dietilenglicol o N-metildietanolamina).

Las NPM obtenidas por este método muestras un comportamiento magnético interesante a pesar de su distribución de tamaño. Mediante una correcta elección de temperatura, velocidad de reacción y tipo de solvente, es posible obtener estructuras de NPM multinúcleo tipo flor [74] que presentan valores de SAR de hasta 2000 W/g [75].

- Descomposición térmica: Esta prometedora vía de síntesis, se basa en la descomposición térmica de compuestos organometálicos (precursores) en solventes orgánicos en 
ebullición. Su principal ventaja es la estrecha distribución de tamaños que se obtiene. Típicamente se utilizan carbonilos de hierro o acetilacetonatos de hierro como precursores y ácido oléico o ácidos grasos como surfactantes. El tamaño y la morfología de las NPM es controlado mediante la relación entre precursores, surfactantes y solventes.

Entre los trabajos más importantes sobre este método se puede mencionar a Hyeon [76] y Park [77] que fue capaz de obtener partículas con muy baja dispersión en torno de los $13 \mathrm{~nm}$. Varios grupos modificaron el método de Hyeon y Park obteniendo NPM de entre $5 \mathrm{~nm}$ y $18 \mathrm{~nm}$ con buena disipación de potencia [80, 79, 78].

- Reacción hidrotermal: Las reacciones hidrotermales se realizan en autoclave, en medio acuoso a temperaturas en torno a los $200^{\circ} \mathrm{C}$ y presiones por encima de $2000 \mathrm{psi}$. Se basan en la capacidad del agua para hidrolizar y deshidratar sales metálicas a alta temperatura y en la baja solubilidad en agua de las partículas obtenidas [81]. El tamaño y la morfología de las NPM es controlado principalmente por las concentraciones de los reactivos, la temperatura y el tiempo de autoclavado [82]. Los tamaños típicos obtenidos están en el rango $[10 ; 50] \mathrm{nm}$.

- Microemulsiones: En la síntesis por microemulsión se utiliza un método de dos fases para obtener partículas prácticamente monotamaño. Para esto, se dispersan nanogotas de agua $([10 ; 50] \mathrm{nm})$ en una fase oleosa y se estabilizan mediante moléculas surfactantes en la interfaz agua/aceite [83, 84]. Estas gotas hacen las veces de nanoreactores, limitando la difusión y por ende, la nucleación, crecimiento y aglomeración de las partículas [85]. Estas partículas presentan una gran afinidad por el material biológico [86] y un SAR adecuado para hipertermia[87] volviéndolas especialmente interesantes para aplicaciones médicas.

- Evaporación láser: Este método es adecuado para obtener grandes cantidades de partículas. Los materiales de partida son polvos gruesos de hematita [88], micropolvos metálicos o bloques de hierro macizos [89]. Estos materiales son evaporados mediante un láser en una cámara de evaporación. Debido al relativamente grande gradiente de temperatura fuera de la zona de evaporación, se produce una condensación sumamente rápida de la fase gaseosa en forma de partículas. El material condensado es removido hacia un filtro mediante flujo de aire. El resultado es un polvo dino de magnetita/maghemita con baja tendencia a la aglomeración y una distribución de tamaños relativamente angosta. El tamaño medio ([20;50] nm) y la fase magnética son controlados por la intensidad del láser y la composición de la atmósfera de la cámara de evaporación [90].

- Biomineralización: Las bacterias magnetotácticas son organismos acuáticos capaces de sintetizar magnetosomas (estructuras celulares que contienen NPM alineadas) y utilizarlos a modo de brújula con el fin de orientarse en busca del mejor hábitat [91]. En condiciones de laboratorio reproduciendo su ambiente anaeróbico, es posible obtener NPM uniformes de entre $20 \mathrm{~nm}$ y $45 \mathrm{~nm}$ [92, 93]. Las partículas pueden ser luego extraídas mediante disrupción celular.

Si bien los magnetosomas presentan valores de SAR muy altos de hasta $1000 \mathrm{~W} / \mathrm{g}$ [95], su uso en aplicaciones médicas se ve imposibilitado porque su recubrimiento contiene 
proteínas bacterianas. La investigación actual en el tema se centra en el estudio y optimización del proceso de biomineralización con el fin de trasladar estos conocimientos a la síntesis por vía húmeda [94].

- Sol-Gel: Este método permite sintetizar una variedad de partículas de óxidos metálicos y resulta sumamente fácil de realizar [96]. El proceso se basa en la hidroxilación y condensación de precursores en solución de iones metálicos (sol). Luego de la generación del 'sol' mediante solventes, se obtiene una estructura tridimensional del óxido metálico (gel). La desventaja del método es justamente la obtención de estructuras tridimensionales en lugar de partículas individuales.

\subsubsection{Recubrimiento de los núcleos magnéticos}

La mayoría de las NPM para aplicaciones biomédicas consisten en un núcleo magnético recubierto por alguna otro sustancia. Estos recubrimientos cumplen varias funciones:

- Estabilización: Una vez finalizada la síntesis, es necesario prevenir la aglomeración a la que tienden la mayoría de las NPM debido a las fuerzas de corto alcance como Van der Waals y la atracción dipolar magnética $[35,36]$. En particular, la interacción dipolar entre NPM se vuelve despreciable más allá de los 3 diámetros de separación [99]. Debido a esto, las NPM suelen ser recubiertas con materiales orgánicos electricamente neutros como el dextrano o el quitosano (estabilización estérica)[59], moléculas orgánicas cargadas como el ácido cítrico (estabilización electrostática)[98], o materiales inorgánicos inertes como el óxido de silicio [97].

- Biocompatibilidad: En principio, los óxidos de hierro presentan una alta biocompatibilidad [100] siendo los únicos materiales aprobados por la OMS para uso médico, pero ciertas vías de síntesis pueden resultar en modificaciones superficiales que provocan un comportamiento tóxico de las NPM. Además, existen propuestas de utilización para MPH, de NPM de materiales magnéticos químicamente no biocompatibles como las manganitas de lantano dopadas con estroncio[103]. Estos compuestos presentan temperaturas de orden magnético cercanas a las utilizadas en MPH por lo que ofrecen la posibilidad de generar un calentamiento autoregulado.

Por otro lado, la incorporación de las NPM por parte de las células objetivo está condicionada por las propiedades superficiales de las primeras. Por ejemplo, la carga superficial de las NPM afecta la tendencia de las mismas a adherirse a las diferentes estructuras celulares [101].

Así, se vuelve necesario en muchos casos dotar a las NPM de un recubrimiento que asegure su biocompatibilidad. Estos recubrimientos pueden consistir tanto en materiales inertes como óxido de silicio como en partículas biológicas como proteínas [102].

- Funcionalización: El recubrimiento también puede estar constituido por o servir de punto de anclaje para moléculas que doten a las NPM de funciones adicionales al calentamiento.

Adosar una molécula fluorescente a las NPM permite el seguimiento de su incorporación por parte de las células y de su distribución dentro de las mismas mediante detección 
óptica[105]. Si el fluoróforo es sensible a condiciones tales como temperatura o $\mathrm{pH}$, su utilización como sensor intracelular es directa[104].

Es posible también cargar al recubrimiento con fármacos que pueden ser así concentrados preferentemente en la zona de interés por guiado magnético[106].

Por último, la funcionalización de la superficie de las NPM con anticuerpos monoclonales, fragmentos de anticuerpos u otras moléculas bioespecíficas permite dirigirlas hacia la zona de interés. De esta manera se ha logrado concentrar NPM en tumores, aunque aún en cantidades insuficientes para lograr efectos hipertérmicos[107].

\subsubsection{Estructura y morfología de NPM}

Como se mencionó en la sección anterior, las diferentes rutas de síntesis resultan en NPM con una amplia variedad de distribuciones de tamaño y morfologías, lo que se termina traduciendo en grandes diferencias en su respuesta a los campos magnéticos.

A fin de poder acercarse lo más posible a la compresión de los mecanismos de disipación, resulta sumamente importante contar con una caracterización estructural detallada y confiable. Debido a las dimensiones de las NPM y a la necesidad de mantenerlas y caracterizarlas en suspensión, esta tarea requiere de la utilización de varias técnicas independientes que deben ser contrastadas entre sí.

La microscopía por transmisión de electrones (TEM por sus siglas en inglés) y la microscopía por barrido de electrones (SEM) resultan casi indispensables actualmente en la caracterización de NPM en particular y de nanoestructuras en general. Proveen información visual directa de la morfología, estructura y distribución de tamaños de las partículas. Pero la interpretación apresurada de estas imágenes puede llevar a error.

Lo primero que hay que tener en cuenta en el caso de NPM para MPH es que tanto TEM como SEM se realizan en alto vacío, por lo que el estado en el que se observan las partículas dista mucho del estado nativo en suspensión. En general, la preparación de la muestra consiste en el depósito de una gota de FF muy diluido sobre la rejilla de microscopía y su posterior secado natural o inducido. Es común, sobre todo con materiales magnéticos, que durante el proceso de secado las partículas tiendan a aglomerarse y autorganizarse formando estructuras sobre la rejilla. Así, por estas técnicas, no es posible saber al observar un agregado si este estaba presente en la suspensión o se formó durante el secado.

Otro punto a tener en cuenta es que se están observando objetos tridimensionales en una imagen bidimensional. En particular en TEM, se observa la proyección sobre el plano imagen de la "sombra" generada por los objetos que se interponen en el plano focal de un haz de electrones 5 . Así, es usual observar objetos superpuestos que asemejan un objeto único.

Finalmente, tal vez la limitación más importante de la microscopía de electrones es su validez estadística. A diferencia de otras técnicas que generan información a partir de todo el volumen de muestra, en TEM y SEM se observa en cada imagen solo una región de una rejilla en la

\footnotetext{
${ }^{5}$ Esto es así en la configuración convencional. También es posible obtener la transformada de Fourier de la imagen en el espacio de las coordenadas llevando el plano focal a la posición del sensor. De esta manera se obtiene una imagen en el espacio de las frecuencias espaciales a modo de difractograma, lo que resulta muy valioso a la hora de estudiar la estructura cristalina de los materiales.
} 
que se depositó una gota de material diluido. En el caso de querer determinar la distribución de tamaños, el aumento necesario limita la cantidad de partículas por imagen a algunos cientos en el mejor de los casos. Por esto resulta indispensable trabajar en base a una gran cantidad de imágenes para asegurar la representatividad de los datos.

Para compensar las limitaciones de la microscopía con electrones es usual recurrir a la difracción de rayos X (DRX) que, además de la información composicional, permite obtener el tamaño cristalino promedio de los objetos dispersores a partir del ensanchamiento de los picos mediante la fórmula de Scherrer. La información obtenida por DRX es estadísticamente sólida dado que proviene de todo el volumen irradiado.

Otras técnicas disponibles para la determinación de tamaños son la microscopía de fuerza atómica/magnética, la dispersión de luz dinámica (tamaño hidrodinámico), la dispersión de neutrones y la dispersión de rayos $\mathrm{X}$ a ángulo bajo. Esta última cuenta con la ventaja de poder aplicarse directamente a las partículas en suspensión, brindando información valiosa sobre la posible existencia de agregados.

Finalmente, también es posible obtener valores de momento magnético medio a partir de medidas magnéticas para luego relacionar esta información con el tamaño de partícula.

\subsubsection{Efectos de la distribución de tamaño}

Quedó claramente establecida en las secciones anteriores la relevancia del tamaño de partícula en el comportamiento magnético de las muestras. El tamaño determina el tiempo de relajación de los dos mecanismos considerados. En particular, el tiempo de Nèel presenta una dependencia exponencial con el volumen. Dado que el tiempo de relajación determina la frecuencia de resonancia a partir de la cual se obtiene la máxima eficiencia de calentamiento (respecto a la invertida), siempre es deseable que la dispersión de tamaños sea pequeña. Además, un tamaño bien definido simplifica mucho la caracterización y el modelado. Pero las muestras de dispersión despreciable son difíciles de obtener. Típicamente, existe una relación de compromiso entre la eficiencia de la síntesis y la dispersión de tamaños, ya sea por la complejidad del proceso o por la selección de tamaños posterior.

Así, a fin de describir el comportamiento de los sistemas reales, generalmente es necesario considerar una distribución de tamaños que puede ser conocida a partir de los métodos descritos en la sección anterior. Típicamente la distribución queda definida por dos parámetros(el valor medio $\bar{D}$ y la desviación estándar $\sigma$ o funciones simples de los mismos) dado que suelen ser bien descritas por una función log normal o, en el caso de $\bar{D}>>\sigma$, por una gaussiana.

Varios estudios numéricos concluyen que el efecto de la distribución de tamaños es en general negativo para la disipación de potencia [108, 109], si bien consideran distribuciones aún más angostas que las usualmente obtenidas experimentalmente.

\subsubsection{Efectos de la interacción entre NPM}

Inicialmente se considera a los FF como suspensiones diluidas de NPM al punto de que la interacción entre las mismas es despreciable. Pero usualmente es necesario recurrir a muestras de mayor concentración para realizar algunas caracterizaciones. Además, aún en FF diluidos, cierto grado de aglomeración espontánea es inevitable y, debido a la intensidad de las fuerzas 
de corto alcance, una vez formados, estos agregados son prácticamente imposibles de disgregar sin comprometer la integridad de la muestra. Por otro lado, como surge de las imágenes TEM de NPM incorporadas por células (fig. 1.7), en la aplicación terapéutica, la distancia entre partículas es casi nula.

Estudios vía simulaciones Monte Carlo describen la formación de cadenas dipolares y otras configuraciones de NPM tendientes a cancelar el flujo magnético en ferrofluidos concentrados [110]. La formación de dímeros, trímeros y agregados mayores debido a la interacción dipolar fue computada por el mismo método por Castro et al [111].

Cuanto mayor es el tamaño de las NPM, su momento fluctúa con menor frecuencia y la probabilidad de interactuar dipolarmente con otra partícula crece. En otras palabras, si la partícula es pequeña, la dirección de su momento fluctúa tan rápido que la interacción dipolar efectiva con las demás NPM es nula.

El efecto de la concentración en el comportamiento magnético de los FF también fue confirmado experimentalmente en varios trabajos [112,113,114], la mayoría de los cuales reportan una disminución de la disipación de potencia para muestras muy concentradas. Una posible explicación para este efecto es la modificación del perfil de energía del sistema debido a la interacción dipolar [115]. 



\section{Modelado y simulación de la respuesta de las NPM a campos magnéticos}

Capítulo 2 
«(...)we have to remember that what we observe is not nature in itself but nature exposed to our method of questioning.»

(...)debemos recordar que lo que observamos no es la naturaleza en sí misma, sino la naturaleza expuesta a nuestro método de interrogarla.

Werner Heisenberg

Físico alemán

"Physics and philosophy: The revolution in modern science." (1958). 


\subsection{Mecanismo de magnetización en nanopartículas}

Como se mencionó en la introducción, debido al balance entre la energía de anisotropía y la energía magnetostática, existe un tamaño crítico para los materiales magnéticos por debajo del cual se obtienen partículas monodominio. Si bien depende del material en cuestión, en general se consideran partículas monodominio por debajo de los $100 \mathrm{~nm}$, ancho típico de una pared de dominio.

A menos que se aclare lo contrario, en adelante todos los sistemas a los que se hará mención se considerarán constituidos por NPM monodominio. Además, consideraremos partículas uniaxiales, i.e., tales que la combinación de las energías de anisotropía de forma y cristalina se minimiza cuando la magnetización se orienta en una única dirección particular que llamaremos "eje fácil" siendo el "eje difícil" (máximo de energía de anisotropía) cualquier dirección perpendicular al eje fácil. Con estas consideraciones, en la mayoría de los casos la orientación de la magnetización de la NPM es equivalente a la orientación de su momento magnético; entendido este como el macromomento de módulo constante $M_{s} V_{m}$ siendo $M_{s}$ la magnetización de saturación y $V_{m}$ el volumen magnéticamente activo de la NPM.

En la aproximación más simple, sin considerar el efecto de la agitación térmica en torno de la dirección de fácil magnetización, en ausencia de campo la magnetización de una NPM se orienta en la dirección del eje fácil, siendo energéticamente equivalentes ambos sentidos.

Si se aplica un campo magnético externo en la dirección del eje fácil, se rompe la simetría entre los dos sentidos favoreciendo la orientación paralela al campo. Pero dado que las dos orientaciones fáciles ( 0 y $\pi$ respecto al campo) están separadas por el máximo a $\frac{\pi}{2}$ correspondiente al eje difícil, en ausencia de agitación térmica la magnetización original no se invierte a menos que el campo externo sea lo suficientemente grande como para eliminar uno de los mínimos i.e. a menos que la energía Zeeman sea mayor que la barrera de potencial. Esto se traduce en un ciclo de histéresis rectangular con una brusca inversión de magnetización cuando $H=H_{c}$ (fig 2.4).

Si el campo externo se aplica perpendicular al eje fácil, al aumentar su intensidad, la proyección de la magnetización crece de forma lineal hasta $M_{s}$. Al retirar el campo, el mínimo de energía vuelve a la dirección del eje fácil y la magnetización regresa a esa orientación resultando todo esto en un ciclo sin área (fig. 2.4). [135]

\section{Efectos térmicos: Superparamagnetismo}

La energía de anisotropía que constituye la barrera de potencial entre las dos orientaciones de magnetización fácil está dada por el producto $K V$ entre el volumen $V$ de la NPM y las constante de anisotropía $K$. Así, en el régimen monodominio esta energía disminuye con el tamaño. Cuando la energía térmica $k T=1 / \beta$ es comparable con la barrera, la probabilidad de detectar la inversión espontánea de la magnetización aún sin campo aplicado deja de ser despreciable. La frecuencia temporal de esta inversión dependerá de la relación $\beta K V$. Si el tiempo entre inversiones es menor que el tiempo característico de la técnica de medida utilizada, se medirán siempre estados de equilibrio y la magnetización observada será nula en ausencia de campo. Este fenómeno es llamado superparamagnetismo (SPM) debido a la similitud cualitativa entre 
este comportamiento y la respuesta de un material paramagnético de momentos localizados en donde el ciclos $\mathrm{M}$ vs. $\mathrm{H}$ carece de área. La principal diferencia se encuentra en el orden de magnitud de la respuesta dado que una NPM de $5 \mathrm{~nm}$ presenta un momento del orden de 10000 $\mu_{B}$ mientras que el momento de un átomo del orden de $1 \mu_{B}$ [136]. En ambos casos el campo externo tiende a alinear los momentos en contra de la agitación térmica.

En el límite de anisotropía despreciable frente a la energía térmica, el comportamiento de un sistema de NPM esta bien descrito por la teoría del paramagnetismo en donde la magnetización $\boldsymbol{M}$ de un sistema de $N$ momentos $\boldsymbol{m}$ tiene la forma de la función de Langevin $L[x]$ :

$$
\mathbf{M}=N \mathbf{m}\left(\operatorname{cotgh}\left[\frac{\mathbf{m} H}{k T}\right]-\frac{k T}{\mathbf{m} H}\right)=N \mathbf{m}\left(\operatorname{cotgh}[x]-\frac{1}{x}\right)=N \mathbf{m} L[x]
$$

$\operatorname{con} x=\mathbf{m} H / k T$.

En el caso superparamagnético, la magnitud de $\boldsymbol{m}$ permite observar la curva completa de magnetización hasta la saturación, aún para campos moderados.

Si la anisotropía es finita y las NPM están alineadas con su eje fácil paralelo al campo, la magnetización queda descrita por la función de Brillouin con $\mathrm{J}=1 / 2$ :

$$
\mathbf{M}=N \mathbf{m} \tanh [x]
$$

Vale remarcar el hecho de que el estado SPM sólo se define en función de la temperatura y del tiempo característico de la técnica de medida o de la interacción considerada i.e. no es una propiedad intrínseca de las NPM. Así, si bien abundan ejemplos en la bibliografía [54, 137, 138], es incorrecto referirse a NPM superparamagnéticas de manera absoluta (es común por ejemplo el uso del término SPION: Superparamagnetic Iron Oxide Nanoparticle $[139,140,141])$. Para tamaños suficientemente pequeños, a temperaturas suficientemente altas, los tiempos de inversión magnética de las NPM pueden resultar mucho menores que los tiempos característicos de la mayoría de las técnicas magnetométricas que son del orden del segundo. Existen sin embargo técnicas como la magnetometría RF desarrollada en este trabajo en donde los tiempos de detección son del orden de $10^{-5} \mathrm{~s}$ pudiendo observarse ciclos histeréticos en muestras SPM para la magnetometría DC a temperatura ambiente. Aún con las técnicas magnetométricas relativamente 'lentas', la observación del estado SPM está totalmente condicionada por las temperatura. Como se desarrolla en la sección 2.4.1.2 en base a un trabajo de García Otero et al [143], el campo coercitivo, que determina el ancho del ciclo, depende en el caso más simple de la raíz cuadrada de la temperatura llegando a ser nulo para temperaturas suficientemente altas por lo que es posible observar ciclos tanto histeréticos como SPM para la misma muestra, midiendo en diferentes condiciones.

\section{La constante de anisotropía}

Vale detenerse brevemente a discutir sobre la constante de anisotropía $K$ introducida previamente. Tanto en este trabajo como en la gran mayoría de la bibliografía citada, se refiere profusamente a la constante $K$ como la densidad volumétrica de energía de anisotropía que presentan las NPM. La anisotropía magnética se entiende como la tendencia de los objetos extendidos a magnetizarse en una o varias direcciones preferenciales. Esto se traduce en un término de energía que se minimiza cuando la magnetización es paralela a estas direcciones 
"fáciles". Existen múltiples fuentes de anisotropía magnética siendo las más importantes en el marco de este trabajo la anisotropía cristalina y la de forma. Dependiendo de la estructura cristalina del material, la anisotropía cristalina se define con una constante por dirección pudiendo ser estas iguales entre sí, o presentar 3 valores distintos. La anisotropía de forma está dada por la geometría del objeto y en el caso de NPM también se consideran los efectos de superficie.

Se observa que las NPM monodominio presentan generalmente anisotropía uniaxial definida por un único valor de $K$ efectivo que se supone resultado de la combinación de todas las fuentes de anisotropía. Como se verá más adelante, este valor es totalmente determinante para la respuesta magnética de los materiales vía la dependencia exponencial que lo liga al tiempo de relajación. Un valor de $K$ grande se traduce en NPM magneticamente "duras" que requieren de un campo intenso para invertir su magnetización. Así, la determinación de la constante de anisotropía es uno de los objetivos de muchos de los experimentos. Pero distintos experimentos realizados sobre la misma muestra suelen arrojar valores de $K$ incompatibles. Debido a esto es necesario remarcar la calidad de cantidad efectiva que tendrá $K$ en todas las consideraciones subsecuentes. Es por simplicidad que se considera una única cantidad fija independiente de las condiciones de medida ignorando así la comprobada dependencia de $\mathrm{K}$ con la temperatura $[144,145,146]$ y, como será evidente en este trabajo, con la amplitud y frecuencia del campo aplicado.

\subsection{Mecanismo de absorción de energía de NPM en campos RF}

El tema central de esta tesis es la absorción y disipación de potencia por parte de NPM sometidas a campos de radiofrecuencia. La energía disipada por las NPM al medio es la energía que estas absorben del campo RF. Así, esta transferencia se puede estudiar de forma equivalente a partir de la variación de energía interna del sistema adiabático conformado por las NPM y el medio en el que están soportadas debido al trabajo magnético realizado por el campo, o a partir del calor disipado al medio por las NPM, despreciando la variación de energía interna de las mismas. Se utiliza el primer enfoque siguiendo la deducción de Rosensweig en [109].

La primera ley de la termodinámica para un sistema de densidad constante y volumen unidad se escribe como

$$
\Delta U=\delta Q+\delta W
$$

donde $U$ es la energía interna, $Q$ el calor entrante y $W$ el trabajo realizado sobre el sistema. Para un proceso adiabático en donde el diferencial de trabajo magnético está dado por $\delta W=$ H. $d \mathbf{B}$ la variación de energía interna es

$$
\Delta U=\mathbf{H} \cdot d \mathbf{B}
$$

donde $\mathbf{H}(\mathrm{A} / \mathrm{m})$ es la intensidad de campo magnético y $\mathbf{B}=\mu_{0}(\mathbf{H}+\mathbf{M})(\mathrm{T})$ es la inducción magnética, $\mathbf{M}$ la magnetización y $\mu_{0}=4 \pi \times 10^{-7} \mathrm{H} / \mathrm{m}$ es la permeabilidad del vacío.

Para el caso en el que los campos son colineales, reemplazando en 2.1 e integrando por partes obtenemos

$$
\Delta U=-\mu_{0} \oint M d H
$$


Así, la energía absorbida del campo en un período es el área del ciclo $M$ vs. $H$. Cuando la magnetización se retrasa respecto al campo, la integral es positiva indicando la conversión de trabajo magnético en energía interna.

Considerando una susceptibilidad compleja $\chi=\chi^{\prime}+i \chi^{\prime \prime}$ y un campo aplicado temporalmente sinusoidal $H(t)=H_{0} \cos [\omega t]=R e\left[H_{0} e^{i \omega t}\right]$ la magnetización queda expresada como

$$
M(t)=R e\left[\chi H_{0} e^{i \omega t}\right]=H_{0}\left(\chi^{\prime} \cos [\omega t]+\chi^{\prime \prime} \operatorname{sen}[\omega t]\right)
$$

en donde se observa como $\chi^{\prime}$ es la componente en fase de la susceptibilidad y $\chi^{\prime \prime}$ la componente fuera de fase.

Reemplazando la expresión para $H$ y la ecuación 2.3 en 2.2 se obtiene

$$
\Delta U=2 \mu_{0} H_{0}^{2} \chi^{\prime \prime} \int_{0}^{T} \operatorname{sen}^{2}[\omega t] d t
$$

en donde se observa como sólo sobrevive la componente fuera de fase de la susceptibilidad. Integrando y multiplicando por la frecuencia del campo $f=2 \pi \omega$ se obtiene la potencia específica absorbida por unidad de volumen

$$
p=f \Delta U=\mu_{0} \pi H_{0}^{2} f \chi^{\prime \prime}
$$

Lo siguiente es relacionar $\chi^{\prime \prime}$ con los parámetros del material.

\section{Dependencia de la absorción con los parámetros del material}

La ecuación de relajación de Shliomis [51] se reduce para al caso de un fluido estático en un campo oscilatorio a

$$
\frac{d M[t]}{d t}=\frac{1}{\tau}\left(M_{0}[t]-M[t]\right)
$$

donde $\tau$ es el tiempo de relajación, $M_{0}[t]=\chi_{0} H_{0} \cos [\omega t]=R e\left[\chi_{0} H_{0} e^{i \omega t}\right]$ es la magnetización de equilibrio al campo sinusoidal aplicado y $\chi_{0}$ es la susceptibilidad de equilibrio.

Reemplazando las expresiones complejas de $M_{0}$ y $M$ en 2.6

$$
\chi=\frac{\chi_{0}}{1+i \omega \tau}
$$

que expresa la dependencia de la susceptibilidad compleja con la frecuencia y de la que se desprenden las componentes real e imaginaria de la susceptibilidad

$$
\begin{aligned}
\chi^{\prime} & =\frac{\chi_{0}}{1+(\omega \tau)^{2}} \\
\chi^{\prime \prime} & =\frac{\chi_{0} \omega \tau}{1+(\omega \tau)^{2}}
\end{aligned}
$$


Reemplazando 2.9 en 2.5 obtenemos la expresión de la potencia específica absorbida en función de los parámetros del material

$$
p=\pi \mu_{0} H_{0}^{2} f \chi_{0} \frac{\omega \tau}{1+(\omega \tau)^{2}}
$$

donde llamaremos "factor de frecuencia" al factor resonante $\frac{\omega \tau}{1+(\omega \tau)^{2}}$.

La susceptibilidad de equilibrio $\chi_{0}$ depende del campo. Aproximándola, a falta de una mejor opción, por la susceptibilidad superparamagnética obtenida de la función de Langevin $L[x]=\operatorname{cotgh}[x]-\frac{1}{x} \operatorname{con} x=\frac{\mu_{0} M_{s} V H}{k T n}$ siendo $n$ la concentración masa en volumen de NPM,

$$
\chi_{0}=\chi_{i} \frac{3}{x} L[x]
$$

$$
\operatorname{con} \chi_{i}=\left.\frac{\partial M}{\partial H}\right|_{i}=\frac{M_{s} x}{3 H} .
$$

En en límite de $x$ pequeño $L[x] \longrightarrow x / 3$ por lo que finalmente la potencia específica queda expresada como

$$
p=\frac{\pi \mu_{0}^{2} M_{s}^{2} V H_{0}^{2} f}{3 k T n} \frac{\omega \tau}{1+(\omega \tau)^{2}} .
$$

Así, a fin de aumentar la potencia absorbida se debe encontrar la combinación óptima de parámetros de la muestra $\left(M_{s}, V, \tau\right)$ y parámetros del campo $\left(H_{0}, f\right)$.

\section{Mecanismos de relajación}

El mecanismo utilizado por las NPM para transferir al medio la energía absorbida del campo es totalmente determinante en el proceso de disipación de potencia dado que de él depende el tiempo de relajación $\tau$ que controla el factor de frecuencia.

Los dos mecanismos de transferencia contemplados son los mismos que se consideran para la relajación magnética de un sistema con agitación térmica cuando se lo expone a un campo externo constante que luego se retira. Los tiempos característicos de cada mecanismo provienen de hecho de la evolución temporal de la magnetización en este tipo de procesos de relajación. Con el surgimiento de las aplicaciones AC de los materiales magnéticos, se extendió este formalismo para describir la respuesta de los materiales magnéticos a los campos alternos.

\section{Relajación de Brown}

Sea un sistema de NPM de volumen hidrodinámico $V_{H}$ y momento $\mathbf{m}$ suspendidas en un fluido de viscosidad $\eta$ a temperatura $T$, con su magnetización anclada al eje fácil e inicialmente orientadas por un campo constante. Al retirarse este, la interacción con el medio viscoso agitado térmicamente comienza a apartar a las NPM de su orientación inicial. La magnetización global del sistema en la dirección del campo inicial disminuye entonces con el tiempo de relajación de Brown [71] 


$$
\tau_{B}=\frac{3 \eta V_{H}}{k T}
$$

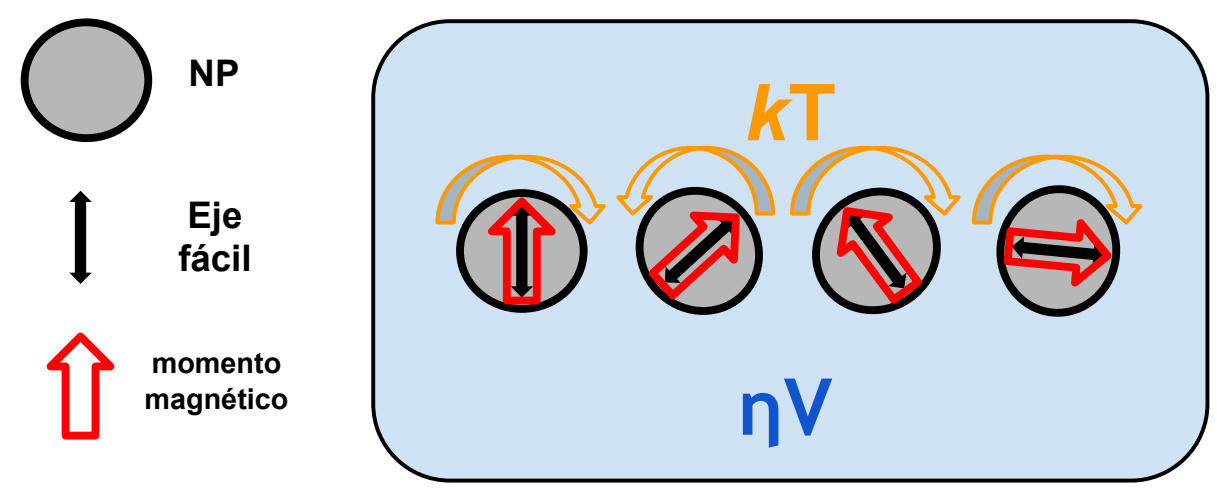

Figura 2.1: Esquema del mecanismo de relajación de Brown. El momento magnético está permanentemente alineado con el eje fácil. La interacción con la matriz viscosa agitada térmicamente modifica la orientación de las NPM.

En el caso de un sistema de NPM expuesto a un campo alterno $\mathbf{H}$, las NPM será objeto de un torque $\mathbf{m} \times \mathbf{H}$ que tiende a orientarlas en la dirección del campo. La interacción con el fluido viscoso provoca un retraso en la respuesta a este torque, caracterizado por el tiempo de relajación de Brown. En caso de predominar este mecanismo, la energía obtenida por la NPM de la interacción con el campo se disipa al medio mediante la interacción con el fluido viscoso.

\section{Relajación de Neel}

Sea un sistema de NPM de volumen magnético $V_{M}$, con constante de anisotropía uniaxial $K$, a temperatura $T$, imposibilitadas de rotar y con sus vectores de magnetización inicialmente orientados por un campo constante. Al retirarse este, si la energía térmica $k T$ es suficiente para superar la barrera de anisotropía $K V_{M}$, la magnetización de las NPM comenzará a fluctuar entre los dos sentidos de la dirección fácil. A medida que las poblaciones orientadas en uno y otro sentido se equilibren, la magnetización total del sistema disminuirá con el tiempo de relajación de Nèel

$$
\tau_{N}=\tau_{0} e^{\frac{K V_{M}}{k T}}
$$

$\operatorname{con} \tau_{0} \in\left[10^{-10} ; 10^{-9}\right] \mathrm{s}[131]$.

Si este sistema se expone a un campo alterno, el perfil de energía se modifica y la frecuencia de las inversiones se altera. El retraso en la respuesta de las inversiones al campo debido a la presencia de la barrera está caracterizado por el tiempo de Nèel.

En el caso de campo aplicado constante, cuando la energía térmica $k T$ sea suficiente para superar la barrera durante el tiempo de medida, se habla de NPM "desbloqueadas". Si esto sucede 


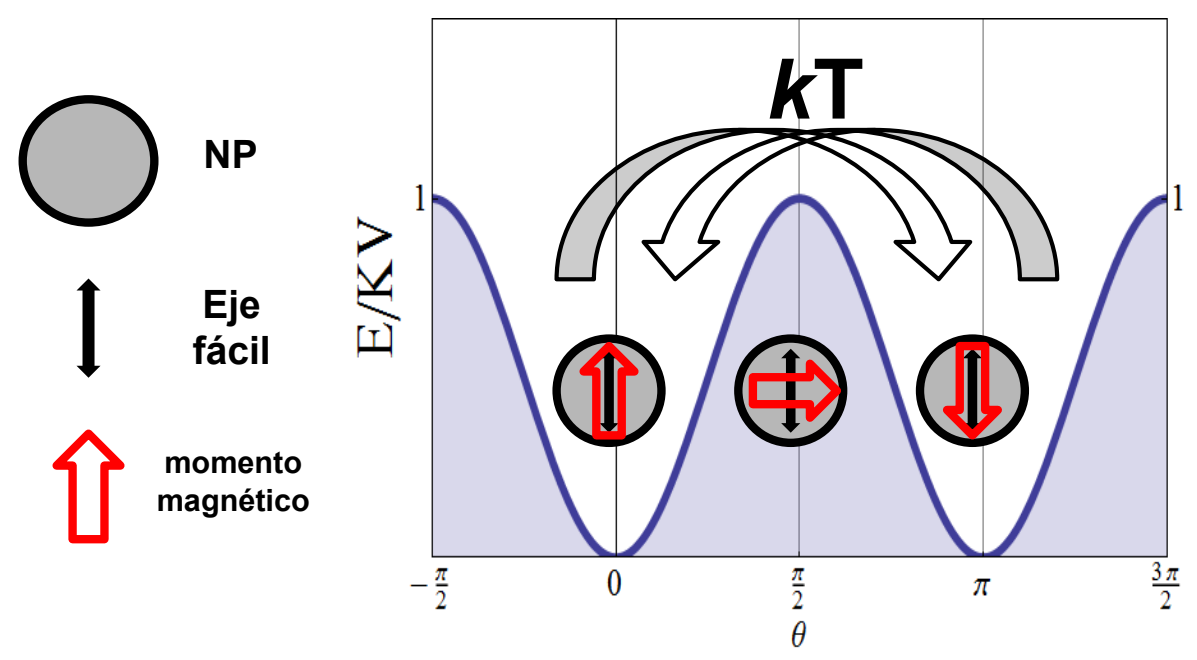

Figura 2.2: Esquema del mecanismo de relajación de Nèel. Si la energía térmica $k T$ es suficiente para superar la barrera de anisotropía $K V$, la magnetización de las NPM fluctúa entre los dos sentidos de la dirección fácil.

a campo nulo, el sistema se mide en régimen SPM.

En el caso de una NPM con posibilidad de rotar y energía de anisotropía finita, los mecanismos de Nèel y Brown compiten predominando siempre el más rápido, de manera que el tiempo de relajación efectivo $\tau$ se obtiene como

$$
\frac{1}{\tau}=\frac{1}{\tau_{B}}+\frac{1}{\tau_{N}}
$$

\subsection{Modelo de Stoner-Wohlfarth: Inversión de momentos a temperatura cero}

El modelo de Stoner-Wohlfarth (SW) fue presentado en un trabajo de 1948 [60] en donde los autores resuelven la respuesta magnética de un sistema de NPM monodominio, de volumen magnético $V$, con anisotropía uniaxial de constante $K$, magnetización $M$ constante, espacialmente fijas y bajo un campo $\mathbf{H}$ de dirección constante (fig. 2.3). La magnetización está contenida en el plano definido por el campo y el eje de anisotropía y no se consideran efectos térmicos. Se contemplan dos términos de energía: la energía de anisotropía $E_{K}$ que depende del ángulo $\delta$ entre el eje fácil y la magnetización $\mathbf{M}$ como

$$
E_{K}=K V \operatorname{sen}^{2}[\delta]
$$

,y la energía Zeeman $E_{h}$ que depende del ángulo $\theta$ entre $\mathbf{M}$ y $\mathbf{H}$ como

$$
E_{h}=-\mu_{0} M_{s} V H \cos [\theta]
$$




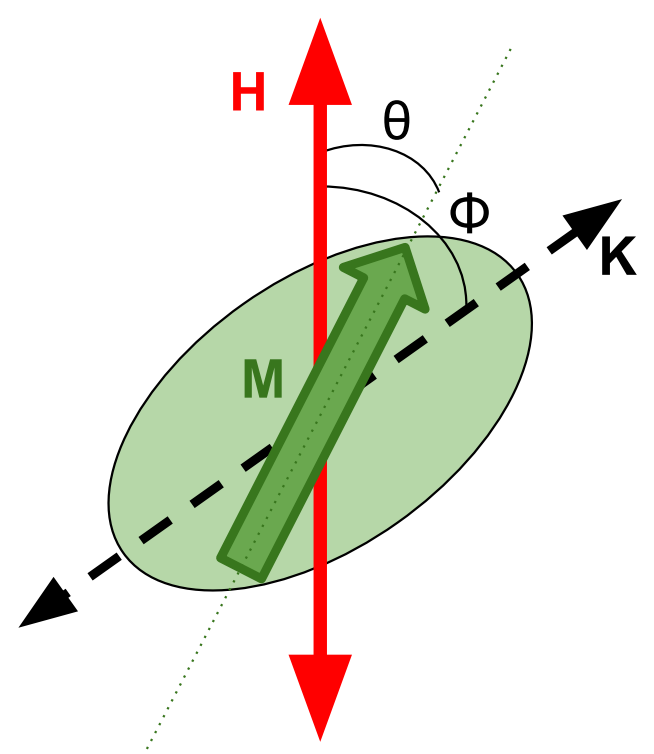

Figura 2.3: Modelo de Stoner-Wohlfarth. NPM monodominio, uniaxial con campo aplicado. Se consideran, la energía Zeeman $E_{h}$ que depende del ángulo $\theta$ entre la magnetización $M$ y el campo y la energía de anisotropía $E_{K}$ que depende del ángulo $\delta=\theta-\phi$ entre la magnetización $M$ y el eje fácil $K$ con $\phi$ el ángulo entre $K$ y el campo $H$.

en donde $M_{S}$ es la magnetización de saturación de las NPM por lo que el producto con el volumen es igual al momento $\mu_{N P M}$ de cada partícula: $M_{S} V=\mu_{N P M}$.

Utilizando por conveniencia el ángulo $\phi$ entre el eje fácil y $\mathbf{H}$ que cumple $\delta=\theta-\phi$, se puede escribir la energía de una NPM como

$$
E=K V\left(\operatorname{sen}^{2}[\theta-\phi]-2 h \cos [\theta]\right)
$$

en donde $h=\frac{H}{H_{K}}$ con el campo de anisotropía $H_{K}=\frac{2 K}{\mu_{0} M_{s}}$.

En el trabajo se describen los ciclos de magnetización para diferentes orientaciones $\phi$ de las NPM respecto al campo y finalmente para un sistema de NPM con orientaciones aleatorias, encontrando numéricamente la posición de los mínimos de energía. En ausencia de agitación térmica, la posición de los mínimos define unívocamente el valor de la magnetización.

En la figura 2.4 se muestran los resultados de estos cálculos para diferentes valores de $\phi$. Para $\phi=0$ se observa un ciclo cuadrado que constituye el de máximo área para el sistema. En este caso, con las NPM orientadas paralelas al campo $h$, al variar este, los mínimos de energía no cambian de posición. El pozo en la dirección del campo aumenta su profundidad mientras que el otro pozo la disminuye. Partiendo de un estado saturado i.e. con todas las NPM magnetizadas en la dirección del campo, al invertirse este, la magnetización no sufrirá cambios hasta que el mínimo en $\theta=0$ desaparezca cuando $h=-1$ (recordar que no se consideran efectos térmicos). En ese punto, la magnetización se invierte completa e instantaneamente. En el otro extremo, cuando $\phi=\pi / 2$, la posición de los mínimos va cambiando junto con el campo. Partiendo de un estado saturado, las NPM modifican la orientación de su magnetización de forma continua. 
Cuando el campo tiene valor nulo, los mínimos se encuentran en la dirección del eje fácil y la magnetización presenta una proyección nula en la dirección del campo. Esto resulta en un ciclo sin área con una magnetización que varía de forma lineal hasta alcanzar la saturación para $h= \pm 1$.

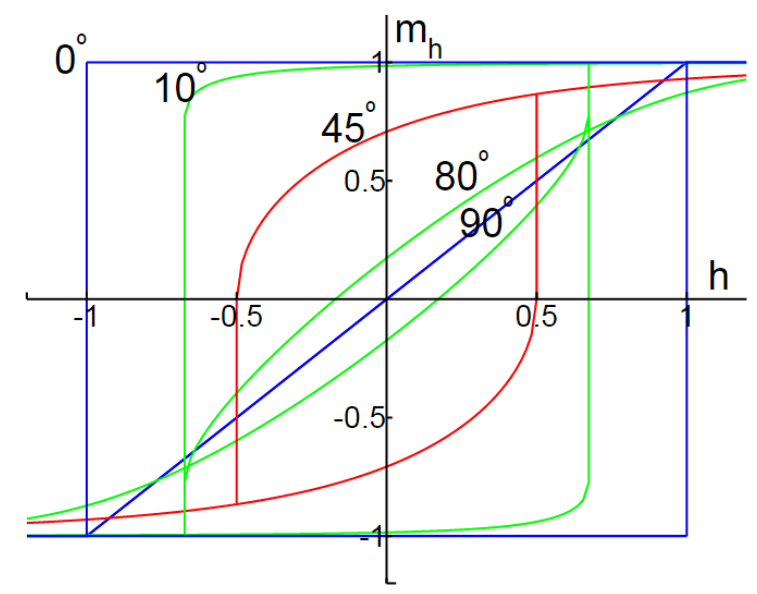

Figura 2.4: Ciclos de magnetización de un sistema $S W$ para diferentes valores de $\phi$. Se observa como se pasa del ciclos de área máxima para $\phi=0$ a un ciclo de área nula para $\phi=\pi / 2$. Se indica en grados de arco $\left(^{\circ}\right)$ el valor de $\phi$ para cada ciclo.

Para el caso de un sistema con NPM orientadas al azar, el área del ciclo pasa a depender exclusivamente del tamaño y la constante de anisotropía de las NPM. En la figura 2.5 se muestra el ciclo incluyendo la curva virgen.

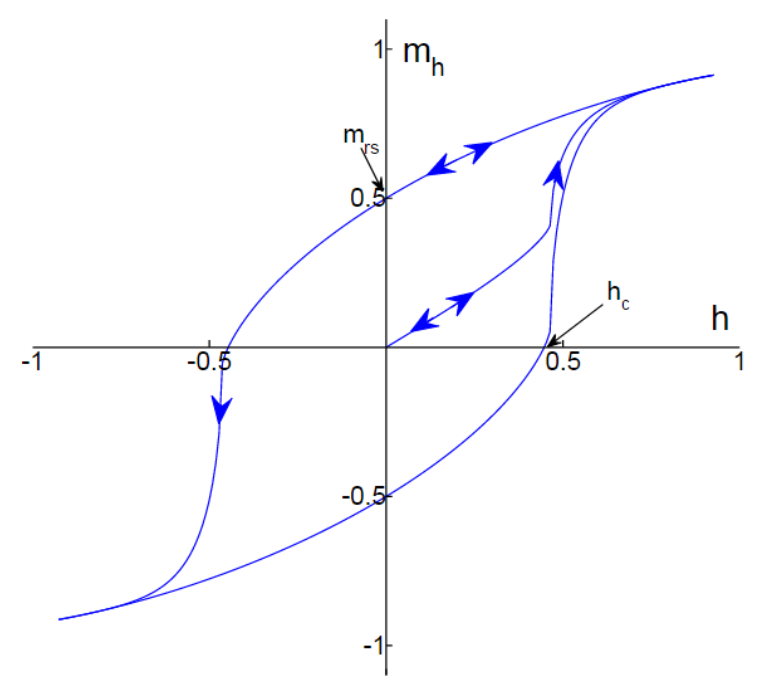

Figura 2.5: Ciclo de magnetización de un sistema SW para NPM orientadas al azar. 


\subsection{Relajación de NPM con agitación térmica}

El modelo de SW no contempla efectos térmicos, la magnetización sólo depende del campo aplicado y de la orientación de las NPM respecto a este. Al incluir la temperatura, se vuelven posibles las transiciones entre estados estables y los efectos de tamaño se hacen más notorios [129]. Como parte de este trabajo se extendió el modelo SW incluyendo el efecto de las fluctuaciones térmicas a fin de simular los ciclos de magnetización de muestras reales. Se modelaron tanto los sistemas ordenados para diferentes valores de $\phi$ como un sistema desordenado con distribución isótropa de orientaciones a fin de encontrar ecuaciones que describan la dependencia de la magnetización con el campo, de manera similar a la presentada por Lu, Usov y Carrey ([61, 62, 63]), y la dependencia de la magnetización con la temperatura de manera similar a la presentada por Usov [64]. Como primera aproximación, se consideran transiciones entre mínimos despreciando la precesión de la magnetización de las NPM en torno de los mismos, por lo que la barrera de energía para la inversión es única para todas las NPM que se encuentran en el mismo mínimo.

A partir de las ecuaciones obtenidas, se calcularon ciclos M vs. H y curvas M vs. T para NPM monotamaño y con distribución de volúmenes, tanto para sistemas ordenados como orientados al asar y con diferentes condiciones de medida. Se estudió el efecto tanto de las características del sistema como de las condiciones de medida sobre las curvas resultantes.

\subsubsection{Anisotropías paralelas al campo}

Se resuelve primero el caso más simple: un conjunto de NPM indénticas, no interactuantes, orientadas con sus ejes de anisotropía paralelos al campo aplicado i.e. $\phi=0$ en la ecuación 2.18, lo que resulta en un perfil de energía según la ecuación

$$
E=K V\left(\operatorname{sen}^{2}[\theta]-2 h \cos [\theta]\right) .
$$

Se obtiene así un potencial en $\theta$ para cada valor de $h$ (fig.2.6).

Derivando 2.19 se obtiene la posición y nivel de energía de los mínimos

$$
\begin{gathered}
E[0]=-2 K V h \\
E[\pi]=2 K V h
\end{gathered}
$$

y del máximo en el rango $[0 ; \pi]$

$$
\left.E[\arccos [-h]]=K V\left(1+h^{2}\right)\right]
$$

Ahora, para un valor dado de $h$, la frecuencia de inversión $p_{i \rightarrow j}$ desde el mínimo $i$ hasta el mínimo $j$ de una NPM se puede expresar como la inversa del tiempo de relajación de Nèel $2.2[130,131]$

$$
p_{i \rightarrow j}=p_{0}^{i j} e^{-\beta \Delta_{i j}}
$$

con $p_{0}^{i j}$ la "frecuencia de intentos"modulada por la probabilidad de éxito tipo Boltzman con $\beta=1 / k T$ y $\Delta_{i j}$ la altura de la barrera entre $i$ y $j$. En este caso, la posición angular de los 


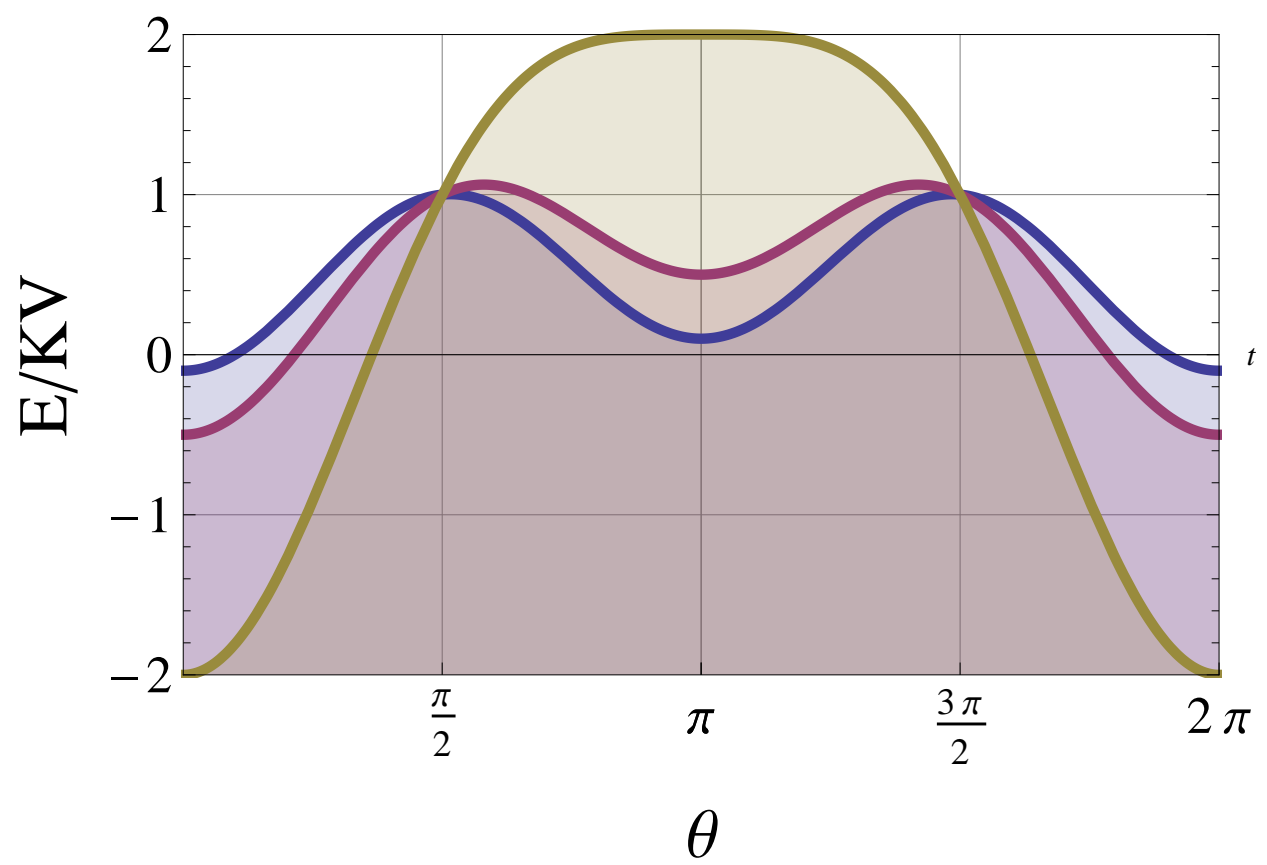

Figura 2.6: Perfiles de energía en función de $\theta$ para distintos valores de $2 h$ : 0,1 (azul), 0,5(morado) y 2(pardo). Se observa como al aumentar el campo se favorece la orientación en la dirección del mismo $(\theta=0)$. Valores negativos de $H$ favorecen el mínimo a $\theta=\pi$.

mínimos es fija y la altura de la barrera en uno y otro sentido de inversión dependerá del campo aplicado como

$$
\begin{aligned}
& \Delta_{0 \rightarrow \pi}=E[\arccos [-h]]-E[\pi]=K V(1+h)^{2} \\
& \Delta_{\pi \rightarrow 0}=E[\arccos [-h]]-E[0]=K V(1-h)^{2}
\end{aligned}
$$

Llamaremos $u$ al mínimo en $\theta=0$ y $d$ al mínimo en $\theta=\pi$.

Estrictamente hablando, $p_{0}^{u d}$ y $p_{0}^{d u}$ son constantes solo si la magnetización solo puede orientarse en la dirección del eje fácil y ningún otra orientación está permitida. Esto es equivalente a considerar mínimos de ancho nulo. En caso contrario, $p_{0}^{u d}$ y $p_{0}^{d u}$ serán funciones de la temperatura y del campo aplicado. Sin embargo, si los mínimos son angostos y la anisotropía es alta, se puede esperar que la dependencia con $T$ y $H$ de estas constantes sea despreciable comparada con la dependencia exponencial que acompañan. Además, se puede demostrar que considerar ambas constantes iguales entre sí es una buena aproximación por lo que usaremos $p_{0}^{u d}=p_{0}^{d u}=p_{0}=\frac{1}{\tau_{0}}[132]$.

El módulo $M$ de la magnetización se puede escribir en función de la magnetización de saturación total del sistema $M_{s}$ y del número de partículas en cada pozo por unidad de volumen $N_{u}$ y $N_{d}$ tales que $N_{u}+N_{d}=N$ con $N$ el número total de partículas. 


$$
M=\left(N_{u}-N_{d}\right) \frac{M_{s}}{N}=M_{s}\left(\frac{2 N_{u}}{N}-1\right) .
$$

Derivando en función del tiempo obtenemos

$$
\frac{d M}{d t}=2 \frac{M_{s}}{N} \frac{d N_{u}}{d t}
$$

La variación temporal de las poblaciones de cada pozo se puede escribir como la población por la probabilidad de inversión

$$
\frac{d N_{u}}{d t}=-\frac{d N_{d}}{d t}=p_{d \rightarrow u} N_{d}-p_{u \rightarrow d} N_{u}
$$

Usando esto en 2.24 se obtiene finalmente

$$
\frac{d M}{d t}=2 M_{s} p_{0}\left\{e^{-C(1-h)^{2}}-\frac{N_{u}}{N}\left(e^{-C(1-h)^{2}}+e^{-C(1+h)^{2}}\right)\right\}
$$

con $C=K V /(k T)$.

De 2.23 también se obtiene

$$
\frac{N_{u}}{N}=\frac{1}{2}\left(\frac{M}{M_{s}}+1\right)
$$

que combinado con 2.26 y definiendo la magnetización relativa $m=\frac{M}{M_{s}}$ resulta en

$$
\frac{d m}{d t}=2 p_{0} e^{-C\left(1+h^{2}\right)}\{\operatorname{senh}[2 C h]-m \cosh [2 C h]\}
$$

Así, se cuenta con la ecuación diferencial que, junto con las condiciones iniciales de magnetización y campo $M_{i}$ y $H_{i}$, determina la evolución temporal de la magnetización y a partir de la cual se pueden simular las curvas resultantes de varios experimentos de magnetrometría considerando la dependencia temporal de las variables de control. Se consideran las dos variables de control experimentales típicas: campo y temperatura.

\subsubsection{Magnetización en función del campo}

Para modelar la evolución de la magnetización en función del campo aplicado H, es necesario resolver la ecuación diferencial para $d m / d H$ que se obtiene mediante la igualdad

$$
\frac{d m}{d H}=\frac{d m}{d t} \frac{d t}{d H}
$$

Se consideran dos tipos de dependencias temporales del campo:

- Dependencia temporal lineal del campo. Es el tipo de dependencia que se utiliza en los magnetómetros. 
Sea un campo magnético dependiente linealmente del tiempo y su derivada

$$
H[t]=A t-H_{0} \Rightarrow \frac{d H}{d t}=A
$$

con $A$ constante. La combinación de 2.28 y 2.29 queda

$$
\frac{d m}{d H}=\frac{1}{A} \frac{d m}{d t}=\frac{2 p_{0}}{A} e^{-C\left(1+h^{2}\right)}\{\operatorname{senh}[2 C h]-m \cosh [2 C h]\} .
$$

Resolviendo esta ecuación es posible obtener los ciclos de magnetización en función del campo que resultarían de un experimento típico de magnetometría para diferentes condiciones de medida. Dado que no es posible su resolución analítica, se escribió e implementó un protocolo en lenguaje Matlab ${ }^{\circledR}$ basado en la función ODE15s [147] para resolverla numéricamente y generar las curvas definidas por la misma. Lo mismo se hizo para el resto de las ecuaciones diferenciales de este trabajo.

Para generar los ciclos $\mathrm{M}$ vs. $\mathrm{H}$, se resolvió primero la ecuación 2.31 entre $H=0 \mathrm{y}$ $H=H_{\max }$ con $M_{i}=0$ para obtener la curva virgen. Luego se resolvió la misma ecuación entre $H=H_{\max }$ y $H=-H_{\max }$ con el valor final de la curva virgen como valor inicial. Para completar el ciclo, se resolvió la ecuación entre $H=-H_{\max }$ y $H=H_{\max }$ de nuevo tomando el valor final de la curva anterior como condición inicial.

En la figura 2.7 se muestran los resultados para NPM de $10 \mathrm{~nm}$, con una constante de anisotropía de $60 \mathrm{~kJ} / \mathrm{m}^{3}$ a las temperaturas $80 \mathrm{~K}$ y $300 \mathrm{~K}$. Se puede observar al sistema describiendo un ciclo SPM para la temperatura alta y un ciclo histerético para la temperatura baja. Esta dependencia del campo coercitivo con la temperatura se desarrollará más adelante.

- Dependencia temporal sinusoidal del campo

Es el tipo de dependencia en un experimento de radiofrecuencia. En este caso

$$
H[t]=H_{0} \operatorname{sen}[\omega t] \Rightarrow t[H]=\frac{1}{\omega} \arcsin \left[\frac{H}{H_{0}}\right] \Rightarrow \frac{d t}{d H}=\frac{\omega H_{0}}{\sqrt{1-\left(\frac{H}{H_{0}}\right)^{2}}}
$$

por lo que finalmente

$$
\frac{d m}{d H}=\frac{2 p_{0} H_{0} \omega}{\sqrt{1-\left(\frac{H}{H_{0}}\right)^{2}}} e^{-C\left(1+h^{2}\right)}\{\operatorname{senh}[2 C h]-m \cosh [2 C h]\} .
$$

Resolviendo esta ecuación de la misma manera que en el caso de campo lineal, se pueden simular los ciclos que se obtendrían en un experimento RF. En la figura 2.8 se muestran los resultados para diferentes frecuencias. Se observa como para la frecuencia más alta, el ciclo de magnetización no está cerrado y la magnetización máxima no corresponde al máximo valor de campo. Este efecto se debe al retraso en la respuesta de la magnetización al campo. Partiendo de $M=0$ y aplicando un campo positivo, el sistema pasa por un transitorio en el que el valor 


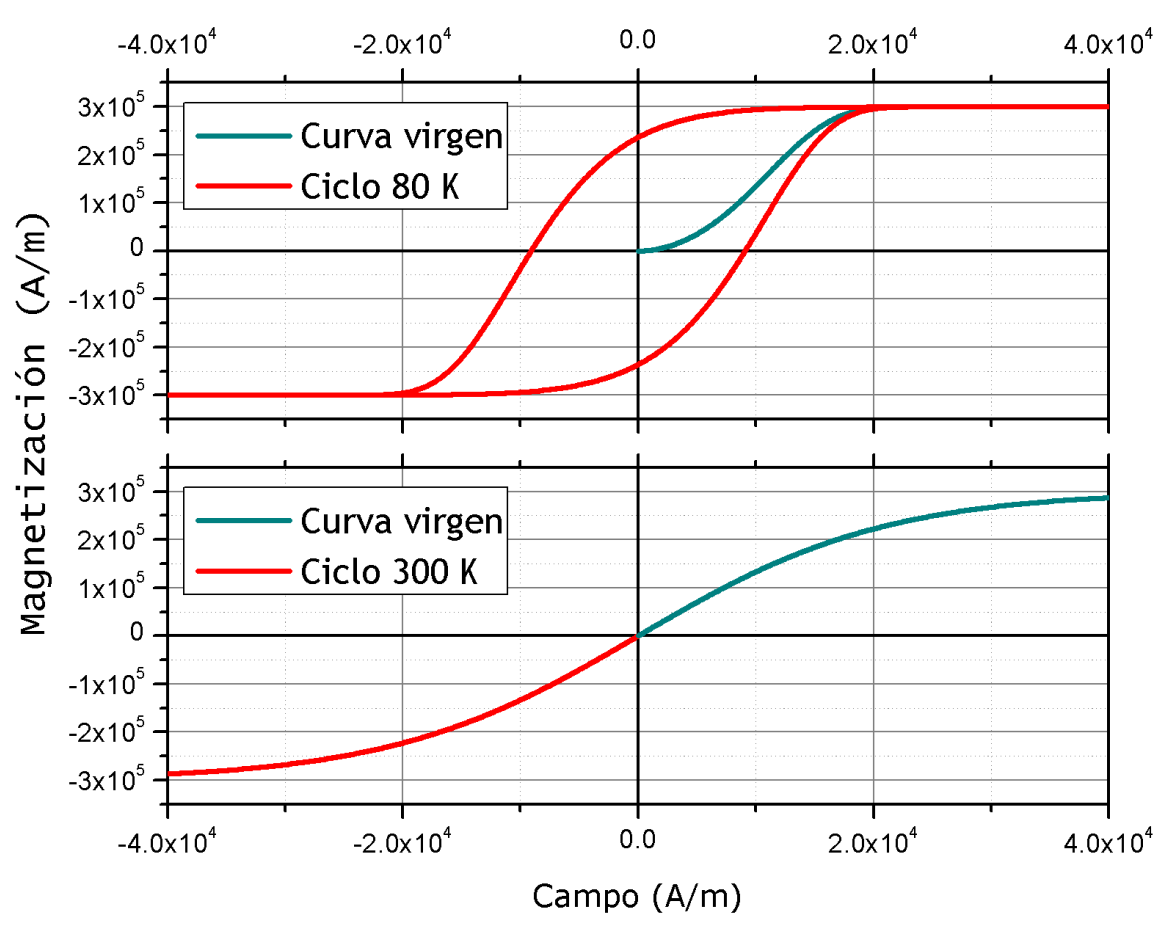

Figura 2.7: Resultados de la resolución numérica de la ecuación 2.31 para NPM de 10 nm de diámetro a diferentes temperaturas incluyendo la curva virgen con condición inicial $M=0$.

medio por ciclo de $\mathrm{M}$ es no nulo con signo positivo. Son necesarios algunos períodos para que la respuesta se estabilice en un ciclo cerrado de valor medio nulo.

Debido a este efecto, a fin de obtener el ciclo estable representativo a altas frecuencias, fue necesario extender el algoritmo de simulación para que calculara una sucesión de ciclos hasta que el valor medio de la magnetización llegara a cero. En la figura 2.9 se muestra la evolución del valor medio en función del número de ciclo junto con la evolución temporal de $\mathrm{M}$ y $\mathrm{H}$ y la secuencia de ciclos resultantes. Se observa cómo después de 4 ciclos se alcanza el estado estacionario.

Una vez considerado este comportamiento, es posible comparar los ciclos de magnetización en todo el rango de frecuencias observando la evolución de los parámetros representativos $H_{c} \mathrm{y}$ $M_{R}$ (fig. 2.10). La magnetización remanente crece como una ley de potencia para luego decrecer de forma aproximadamente exponencial cuando la frecuencia es tan alta que el sistema ya no puede seguir al campo. El campo coercitivo crece monótonamente con derivada decreciente. En la zona de interés para hipertermia sigue casi exactamente una tendencia exponencial.

Simulando ciclos a frecuencia fija para varias amplitudes de campo se puede observar el límite de validez de la teoría de respuesta lineal. Esta aproximación de susceptibilidad constante utilizada para obtener la expresión 2.12 determina una relación lineal entre la energía disipada durante un ciclo (cantidad proporcional al área del mismo) y el cuadrado de la amplitud de campo $H_{0}^{2}$ (fig. 2.11). Se observa directamente de los resultados como la saturación de lo ciclos a partir de una cierta amplitud de campo, deviene a su vez en una saturación de la dependencia del área con $H_{0}$ (fig. 2.12). Este comportamiento es usualmente reportado en la bibliografía 


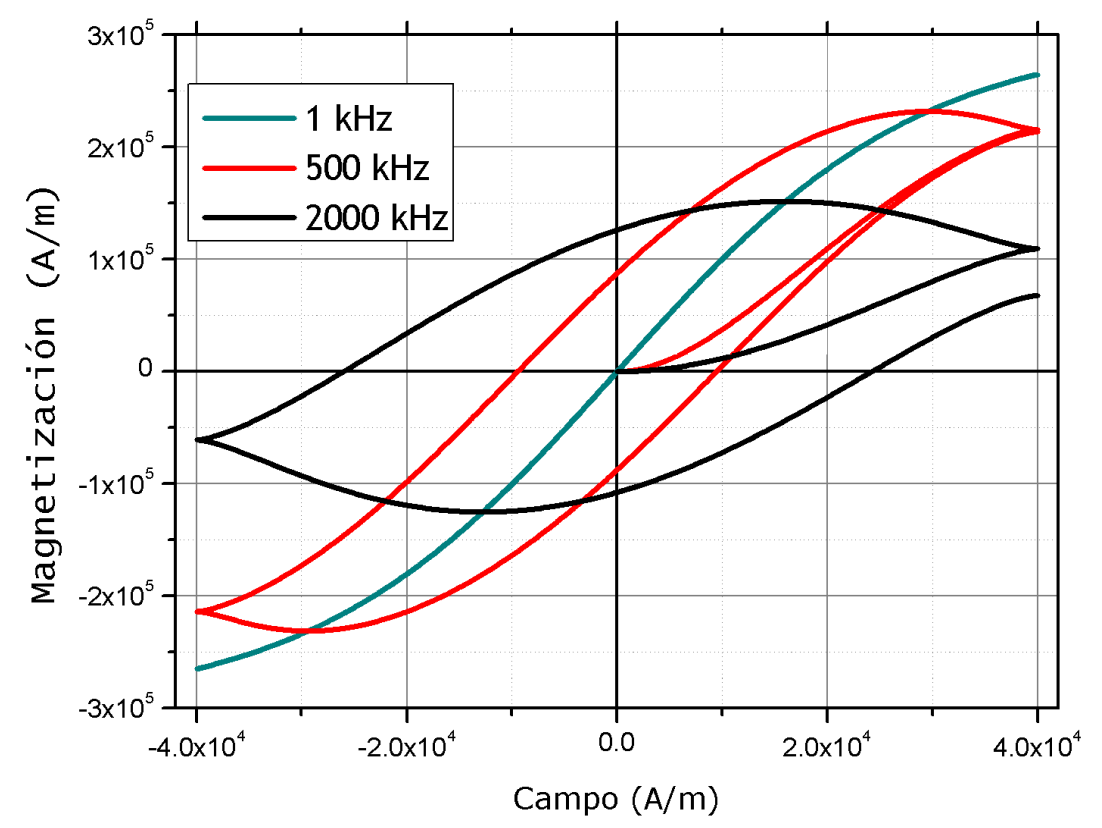

Figura 2.8: Resultados de la resolución numérica de la ecuación 2.33 para NPM de 10 nm de diámetro a diferentes frecuencias de campo. Se observa el cambio en la magnetización remanente y el campo coercitivo. El ciclo de mayor frecuencia tiene valor medio no nulo y no está cerrado debido al retraso en la respuesta de la magnetización al campo.
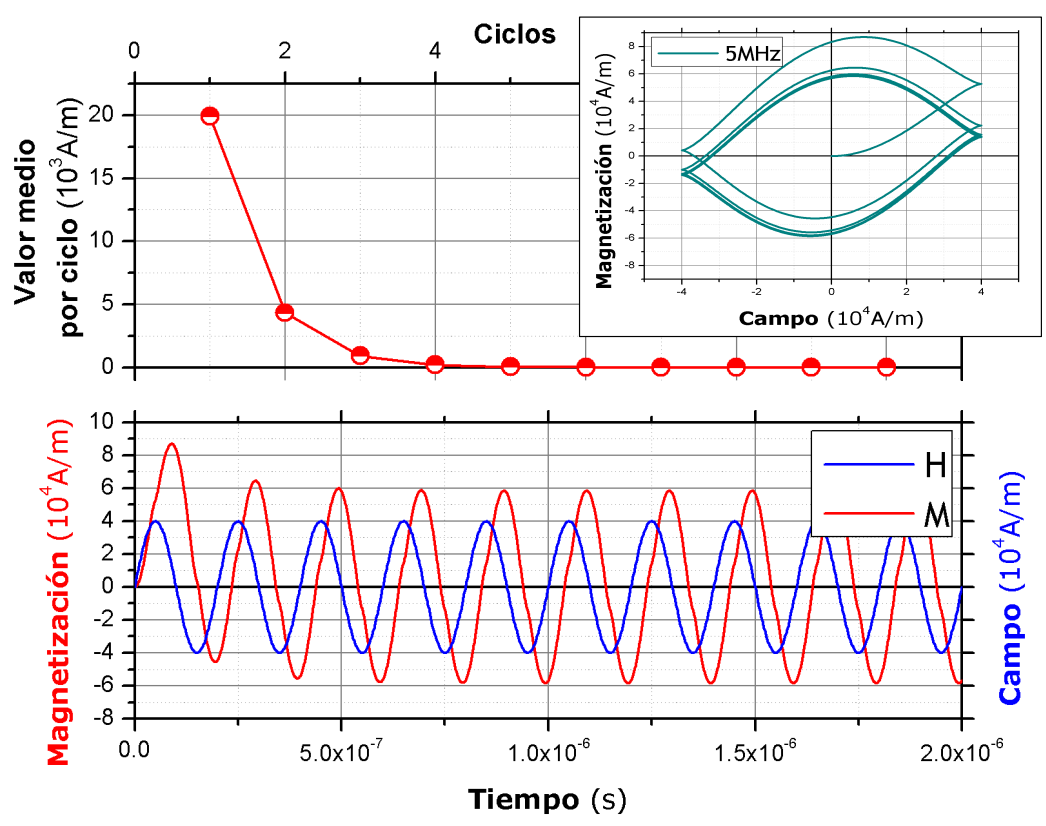

Figura 2.9: Evolución del valor medio por ciclo (arriba) y magnetización y campo en función del tiempo (abajo) para la simulación a $5 \mathrm{MHz}$. Inserto: Sucesión de ciclos M vs. H resultante.

([59, 141]) sin comprobar el fenómeno que lo origina. 

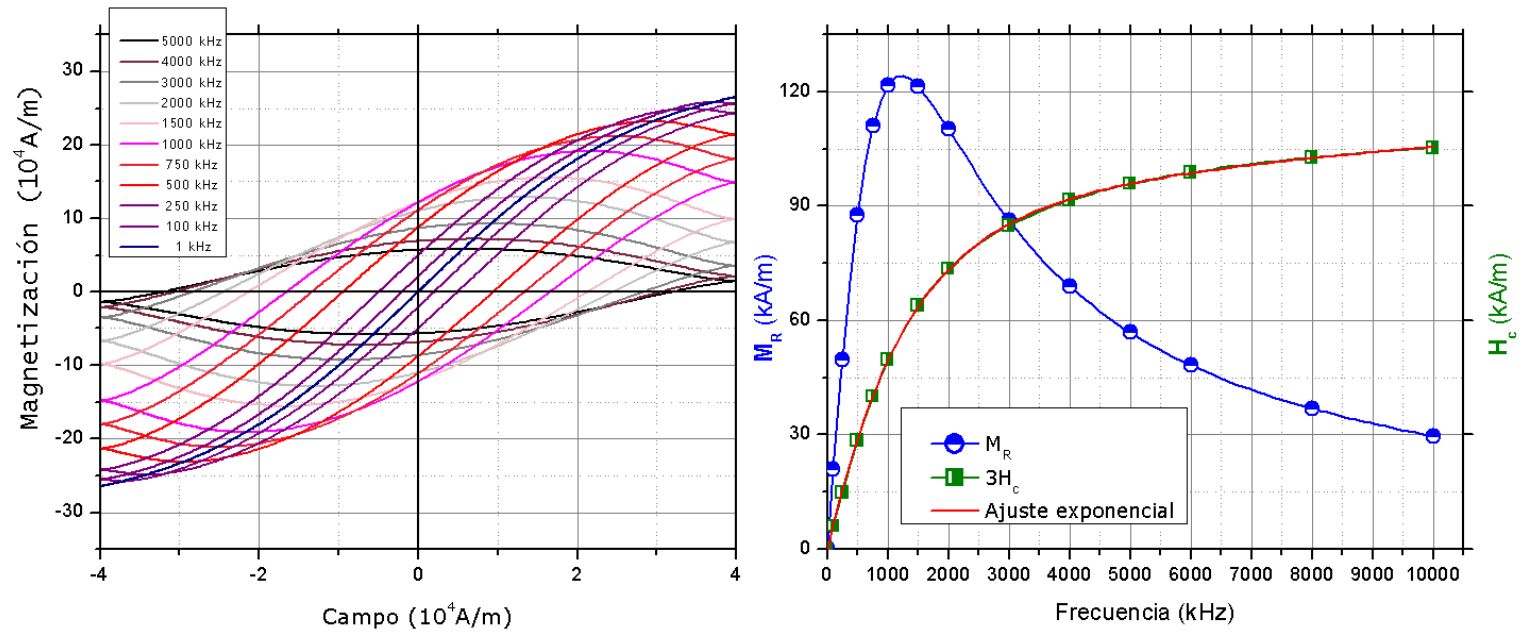

Figura 2.10: Simulación de ciclos de magnetización para varias frecuencias entre $1 \mathrm{kHz}$ y $10 \mathrm{MHz}$ (izquierda) y variación de $H_{c}$ y $M_{R}$ con la frecuencia (derecha). En el rango utilizado en hipertermia, $H_{c}$ sigue un comportamiento aproximadamente exponencial.
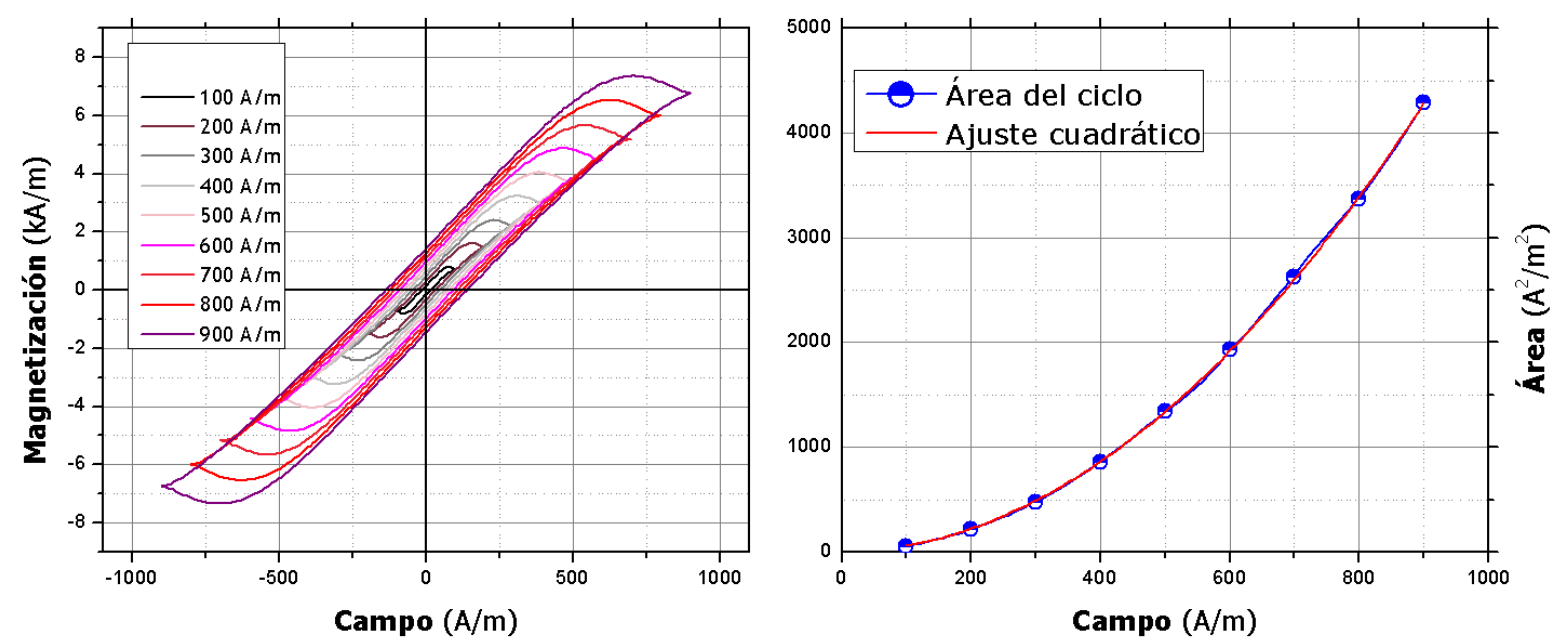

Figura 2.11: Simulación de ciclos de magnetización para pequeñas amplitudes de campo (izquierda) y valores de área correspondientes con ajuste cuadrático (derecha). Se observa como en este rango los resultados cumplen exactamente con la predicción de la teoría de respuesta lineal.

\subsubsection{Dependencia del campo coercitivo con la temperatura}

En estas condiciones también es posible deducir la relación del campo coercitivo $H_{c}$ con la temperatura a la que se realiza el ciclo $\mathrm{M}$ vs. $\mathrm{H}$.

Por definición (ver sección 1.1), el campo coercitivo es aquel al que la magnetización de un ciclo es nula. Si el valor de $H_{c}$ es distinto de cero, el ciclo presenta histéresis.

Fuera de la saturación, un ciclo histerético realizado en tiempos de laboratorio recorre una secuencia de estados fuera del equilibrio i.e. considerando el modelo de dos pozos, en cada punto de medida no se espera el tiempo típicamente grande, necesario para que el sistema 

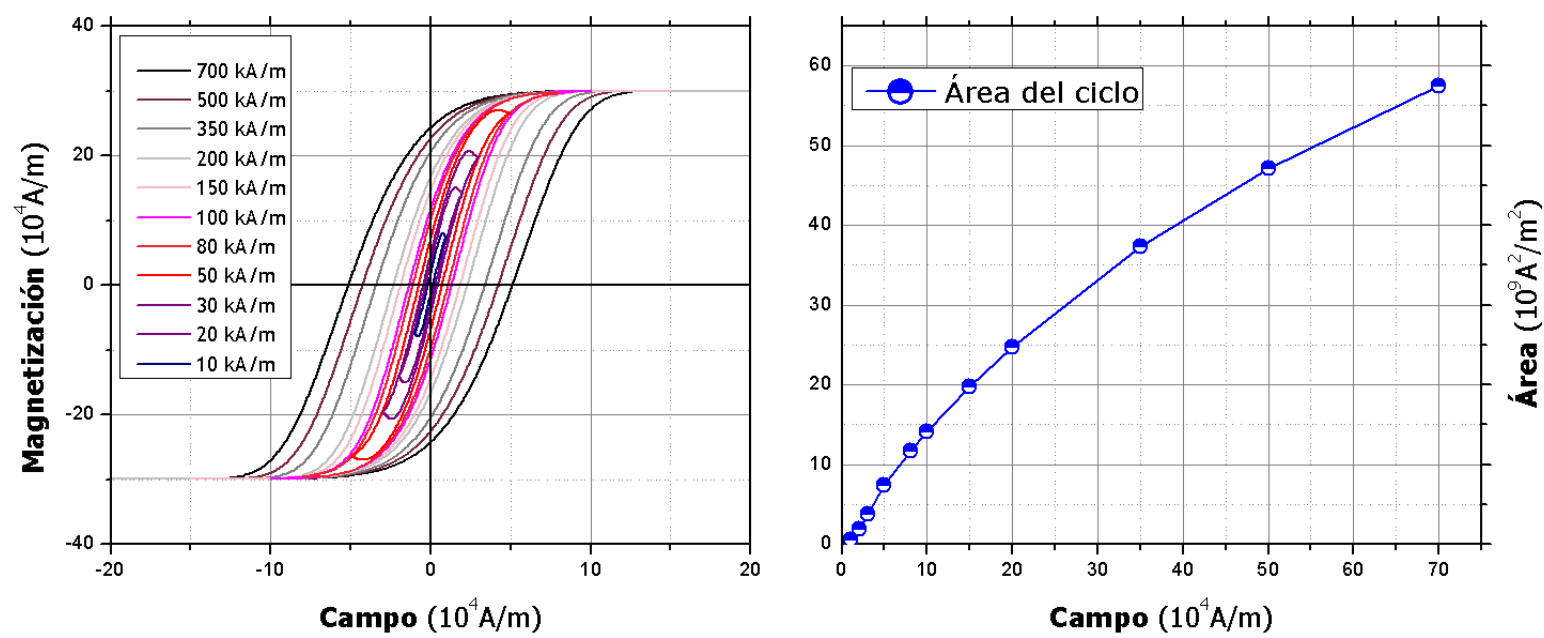

Figura 2.12: Simulación de ciclos de magnetización para grandes amplitudes de campo (izquierda) y valores de área correspondientes (derecha). Se observa como en este rango los resultados se apartan de lo predicho por la teoría de respuesta lineal debido a la saturación de los ciclos.

estabilice las poblaciones en los valores de equilibrio. Así, para medir magnetización nula con campo aplicado, el tiempo entre inversiones debe ser menor o igual al tiempo de medida $\left(\tau \leq \tau_{m}\right)$.

El tiempo entre inversiones depende de la altura de la barrera de energía según la expresión de Nèel 2.2 modificada por campo aplicado según 2.22

$$
\tau=\tau_{0} e^{\zeta(1-h)^{2}}, \zeta=\frac{K V}{k T}
$$

en donde se realiza la aproximación de considerar sólo las inversiones hacia el sentido del campo, despreciando las que de todas maneras ocurren en sentido opuesto con una barrera más alta $\Delta E=\zeta(1+h)^{2}$. La altura de las barreras se calcula como la diferencia de energía entre el mínimo y el máximo correspondientes.

Así, al variar el campo, se modifica el tiempo de inversión hasta que eventualmente este iguala y supera al tiempo de medida. Debido a la dependencia exponencial de $\tau$ con $h$ según 2.34, en el entorno de la igualdad (zona de bloqueo), la respuesta del sistema es tal que permite observar estados cercanos al equilibrio

$$
H=H_{c} \Rightarrow \tau=\tau_{m} \Rightarrow M=0 .
$$

De esta relación se puede entonces obtener el valor de $H_{c}$ en función de la temperatura para un sistema de NPM alineadas, no interactuantes

$$
\begin{gathered}
\tau_{m}=\tau=\tau_{0} e^{\zeta\left(1-h_{c}\right)^{2}}, h_{c}=\frac{H_{c}}{H_{K}}, H_{K}=\frac{2 K}{\mu_{0} M_{s}} \Rightarrow h_{c}=1-\sqrt{\zeta \log \left[\frac{\tau_{m}}{\tau_{0}}\right]} \\
\therefore H_{c}=\frac{2 K}{\mu_{0} M_{s}}\left(1-\sqrt{\left.\frac{k T}{K V} \log \left[\frac{\tau_{m}}{\tau_{0}}\right]\right)}\right.
\end{gathered}
$$


Este comportamiento es verificado por las simulaciones. El campo coercitivo mantiene una relación lineal con la raíz cuadrada de la temperatura en todo el rango de bajas temperaturas hasta la zona de transición al estado SPM (fig. 2.13).

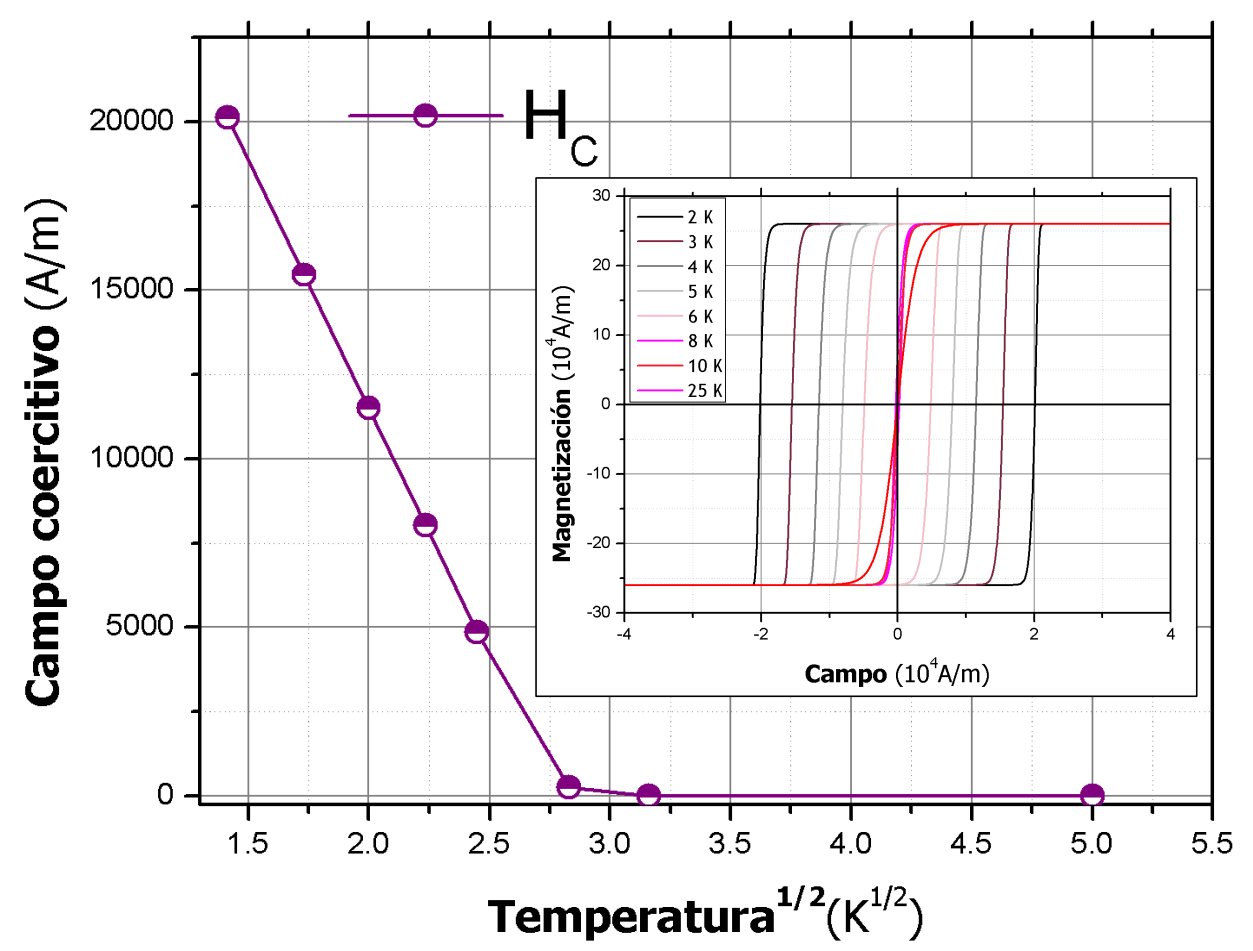

Figura 2.13: Campo coercitivo de los ciclos simulados (inserto) a diferentes temperaturas. Se observa la dependencia lineal con la raíz cuadrada de la temperatura por debajo la zona de bloqueo.

Como se mencionó en la introducción, la distribución de tamaños que presentan todas las muestras reales condiciona fuertemente su comportamiento. Con el modelo desarrollado y la implementación numérica, es posible estudiar la respuesta magnética efectiva $M_{e f}[H]$ de una población de NPM con distribución de tamaños. Analíticamente esto se logra convolucionando la función magnetización $\mathrm{M}[\mathrm{H}, \mathrm{V}]$ con la distribución de volúmenes en términos de fracción de volumen total $f_{V}$

$$
M_{e f}[H]=\frac{\int M[H, V] V f_{V} d V}{\int V f_{V} d V} .
$$

En el cálculo numérico es necesario discretizar la integral en una suma sobre los valores de momento $\mu_{N P}=M V$ pesados por $f_{V}$. Calculando para una distribución lognormal de volúmenes, se puede observar el apartamiento de la relación lineal entre $H_{c}$ y la raíz cuadrada de la temperatura (fig. 2.14). 


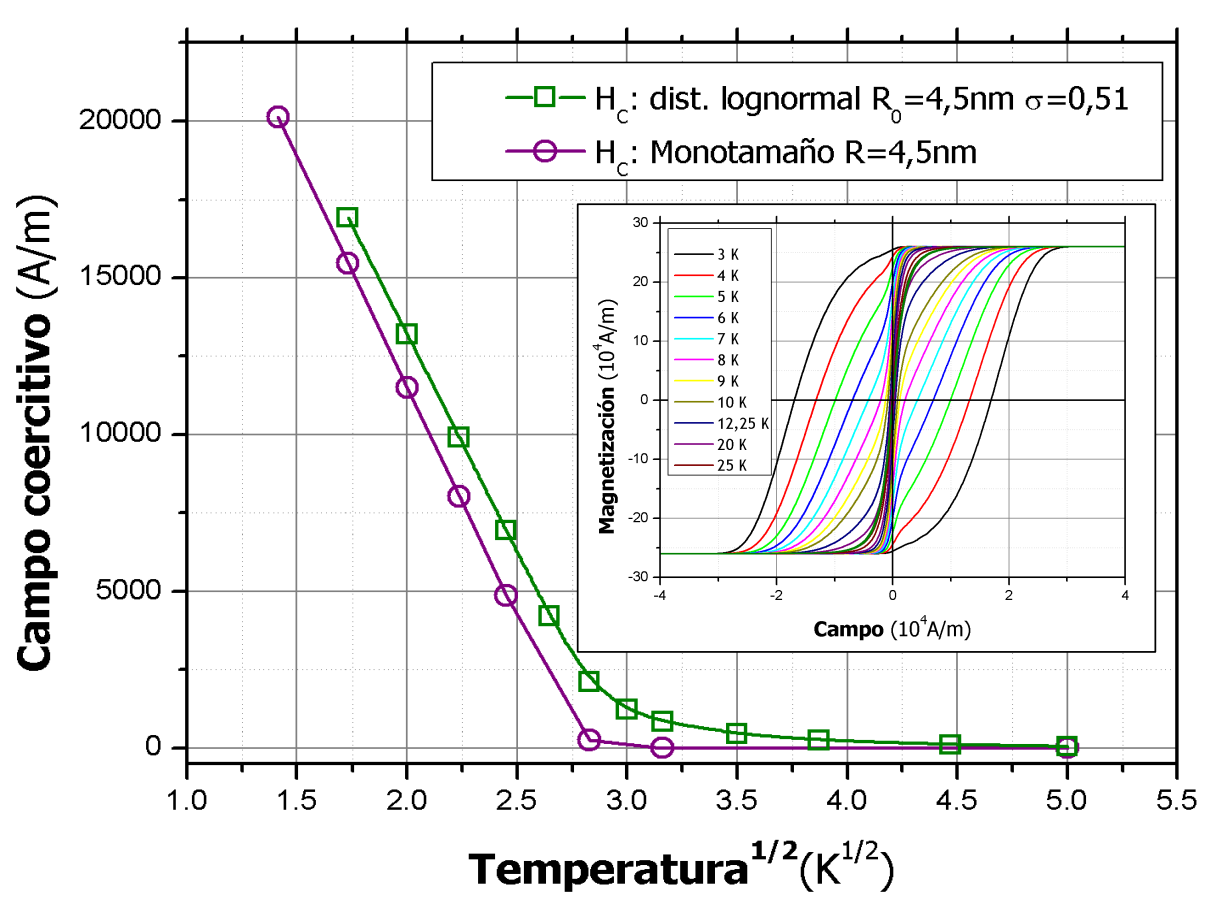

Figura 2.14: Campo coercitivo de los ciclos simulados con distribución de volúmenes lognormal (mediana $R_{0}=4,5 \mathrm{~nm}$, desv. est. log. $\sigma=0,5$ ) a diferentes temperaturas (inserto) comparado con los valores para una muestra monotamaño en las mismas condiciones.

\subsubsection{Magnetización en función de la temperatura}

De la misma manera que se realizó el cambio de variables 2.29 para obtener la dependencia con el campo, se puede hacer lo mismo para obtener la dependencia con la temperatura $\mathrm{T}$ y estudiar por ejemplo, procesos de magnetización a campo constante en función de T. Así, para un sistema cuya temperatura varía linealmente con el tiempo según $T[t]=B t+T_{0}$, la magnetización en el caso de NPM ordenadas cumple

$$
\frac{d m}{d T}=\frac{1}{B} \frac{d m}{d t}=\frac{2 p_{0}}{B} e^{-C\left(1+h^{2}\right)}\{\operatorname{senh}[2 C h]-m \cosh [2 C h]\}
$$

Resolviendo numéricamente esta ecuación, es posible simular las curvas de magnetización en función de la temperatura para diferentes condiciones de medida y propiedades de la muestra.

Enfriamiento con y sin campo: ZFC-FC de un sistema ordenado

La evolución de la magnetización de una muestra sometida a un campo constante en función de la temperatura resulta particularmente interesante dado que permite obtener parámetros de interés como la constante de anisotropía y la intensidad de las interacciones. Debido a esto, se modelaron las condiciones de un experimento estándar de magnetometría conocido como "Enfrianmiento sin campo - Enfriamiento con campo" (ZFC-FC por sus siglas en inglés). 
Para introducir este tipo de experimentos y explicar de manera detallada la respuesta obtenida, se describen los pasos de un experimento ZFC-FC ideal, para un sistema de NPM idénticas tipo SW ordenadas con sus ejes de anisotropía paralelos al campo en el marco del modelo de dos pozos cuyo resultado se muestra en la figura 2.15:

- Se inicia el experimento con el sistema desmagnetizado i.e. poblaciones iguales en cada pozo.

- Se baja la temperatura del sistema (ZFC), en esta descripción ideal, hasta $0 \mathrm{~K}$.

- Se aplica un pequeño campo (en el experimento real, el mínimo para obtener señal). Esto aumenta la profundidad del pozo en $\theta=0$ y disminuye la profundidad del pozo en $\theta=\pi$ por lo que la orientación paralela al campo se vuelve más favorable energéticamente, pero a $\mathrm{T}=0$ no hay energía disponible para que las NPM inviertan sus momentos, las poblaciones no cambian y la magnetización se mantiene en cero.

- Se comienza a elevar la temperatura del sistema (Zero Field Cooling Warming: ZFCW). $\mathrm{Al}$ acercarse a una cierto valor llamado "Temperatura de bloqueo" $\left(T_{B}\right)$ la magnetización crece bruscamente debido a la dependencia exponencial $\tau_{N}=\tau_{0} e^{K V / k T\left(1 \pm h^{2}\right)}$ del tiempo de relajación con la temperatura. La energía térmica es suficiente para que las NPM en exceso del pozo menos profundo inviertan su momento y la relación de poblaciones tienda al valor de equilibrio para cada temperatura.

- La temperatura sigue aumentando, la energía térmica incrementa la precesión de los momentos en torno del mínimo (disminuyendo la proyección en la dirección del campo) y la frecuencia de las inversiones. Al aumentar la energía media de las NPM, disminuye la diferencia de poblaciones provocada por la barrera asimétrica y la magnetización tiende a cero como una ley de Curie.

- Cuando el sistema llega a la temperatura máxima del experimento (que debe ser mayor a $T_{B}$ ), se vuelve a enfriar manteniendo el campo aplicado (FC). La precesión y la frecuencia de las inversiones vuelven a disminuir y la magnetización a aumentar tomando los mismos valores que tomó durante el calentamiento hasta llegar a $T_{B}$.

- Al alcanzar temperaturas por debajo de $T_{B}$, la precesión y la frecuencia de las inversiones siguen disminuyendo. En este caso el balance de poblaciones está más cerca del de equilibrio para cada temperatura. La magnetización sigue aumentando obteniéndose valores mayores que durante el calentamiento. A temperaturas por debajo de la zona de bloqueo las inversiones prácticamente cesan y la magnetización se vuelve constante. Cuanto menor sea la tasa de enfriamiento, más se acercará el sistema al estado de equilibrio a cada temperatura y mayor será el valor de magnetización alcanzado cuando la frecuencia de inversiones se vuelva marginal. Esto separa el espectro de temperaturas en una zona reversible (por encima de $T_{B}$ ) en donde la magnetización sólo depende del campo y la temperatura y una irreversible (por debajo de $T_{B}$ ) en donde el valor de magnetización medido depende de la historia del sistema. 


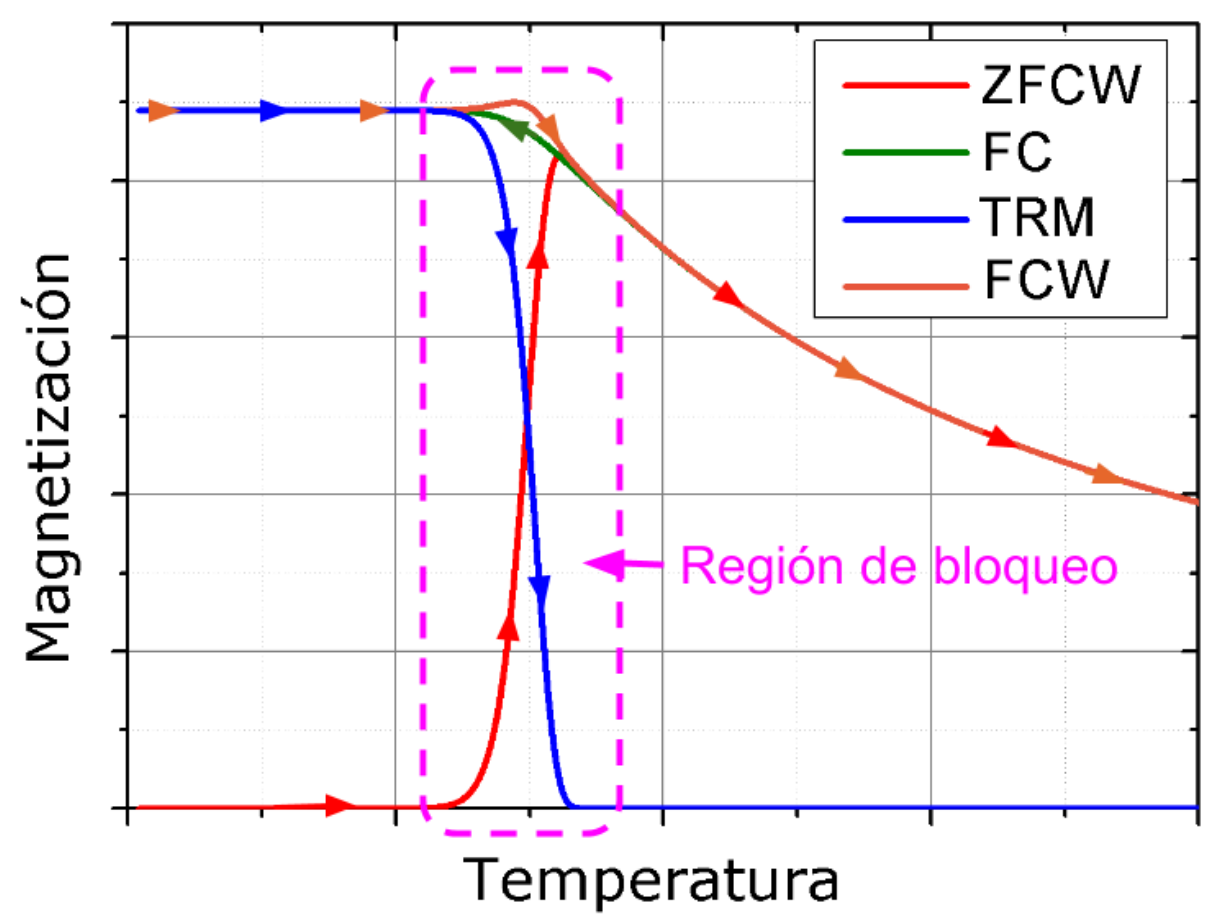

Figura 2.15: Simulación numérica de la magnetización en función de la temperatura para un sistema monotamaño y ordenado tipo $S W$. Se muestran las curvas para el calentamiento con campo aplicado habiendo enfriado sin campo (ZFCW), el enfriamiento con campo (FC), y los calentamientos con campo (FCW) y sin campo (TRM), habiendo enfriado con campo aplicado. Se resalta la zona de bloqueo que contiene la temperatura de bloqueo y separa las curvas en una región reversible (derecha) y una irreversible (izquierda).

- Una vez alcanzada la temperatura mínima se puede volver a calentar el sistema manteniendo o retirando el campo. Si el campo se mantiene (Field Cooling Warming: FCW) se obtiene una curva prácticamente idéntica al FC. La única diferencia se observa en la zona de bloqueo en donde, al volver a calentar, antes de comenzar a disminuir, la magnetización aumenta ligeramente por encima del valor de mínima temperatura. Esto se debe a que en esa región, las NPM desbloqueadas pueden seguir acercándose a la configuración de equilibrio correspondiente a un proceso cuasiestático.

- Si a la temperatura mínima se retira el campo, los pozos vuelven a ser iguales pero sin energía térmica para las inversiones y la magnetización se mantiene.

- Al aumentar la temperatura sin campo aplicado (Thermoremanent magnetization : TRM), la magnetización toma los mismo valores que durante el enfriamiento con campo en todo el rango de temperaturas por debajo de la zona de bloqueo.

- Al entrar en la zona de bloqueo, la magnetización comienza a decaer exponencialmente hasta hacerse cero. Realmente se trata de una zona de bloqueo distinta a la correspondiente a la curva $\mathrm{ZFCW}$, centrada en una $T_{B}$ ligeramente superior debido a que durante el calentamiento con campo, la barrera de energía para orientarse en la dirección del mismo es más baja. 


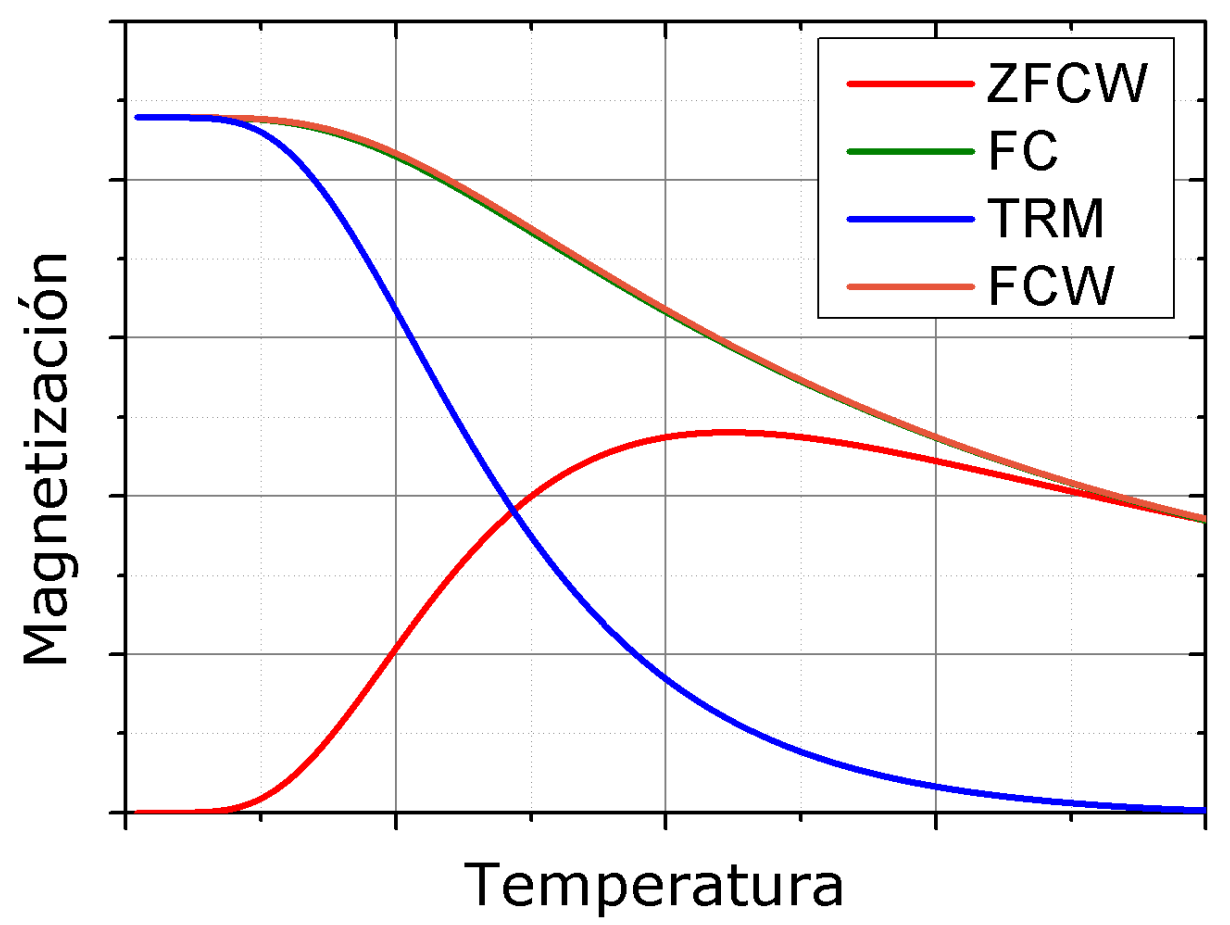

Figura 2.16: Simulación numérica de la magnetización en función de la temperatura para un sistema con distribución de tamaños lognormal y ordenado tipo $S W$. Se muestran las curvas para el calentamiento con campo aplicado habiendo enfriado sin campo ( $\mathrm{FFCW}$ ), el enfriamiento con campo (FC), y los calentamientos con campo (FCW) y sin campo (TRM), habiendo enfriado con campo aplicado.

En la figura 2.15 se muestra la simulación de un experimento ZFC-FC para una muestra monotamaño. Esto permite apreciar los efectos correspondientes a cada proceso descrito.

En el caso más realista en el que el sistema está formado por NPM con cierta distribución de tamaños, la respuesta se ve distorsionada por esta. Para simular este comportamiento, se implementó un código que calcula las curvas de magnetización en diferentes condiciones de medida para un sistema de NPM con distribución lognormal de tamaños. La curva resultante se obtiene con una suma pesada por la distribución de momentos de las curvas correspondientes a cada volumen, de la misma manera que para los ciclos de histéresis. En la figura 2.16 se muestran las curvas de $\mathrm{M}$ vs. T para un sistema con distribución de tamaños lognormal con mediana $V_{0}$ igual al tamaño utilizado en la figura 2.15 y desviación estándar del logaritmo de la variable $\sigma=0,5$. Dado que para una NPM de volumen V, la barrera de energía entre los pozos tiene una altura $\mathrm{KV}$ con $\mathrm{K}$ la constante de anisotropía correspondiente, una distribución de volúmenes implica una distribución de temperaturas de bloqueo, aún suponiendo que la constante de anisotropía sea la misma para todas las NPM. Así, el crecimiento exponencial en torno a $T_{B}$ se ve reemplazado por un crecimiento más suave que comienza a una temperatura menor y se extiende hasta el desbloqueo de las NPM de mayor tamaño. Además, se pierde la diferencia entre las curvas FC y FCW. En este caso, la región de reversibilidad queda definida por la máxima temperatura de bloqueo del sistema. 
Dependencia de la temperatura de bloqueo con las condiciones de medida

Se definió a la temperatura de bloqueo $T_{B}$ como aquella a partir de la cual el sistema se mide como SPM para una dada combinación campo-temperatura. Como ya se mencionó en el capítulo 1, el régimen SPM y por ende el valor de $T_{B}$, están además determinados por el tiempo de medida $\tau_{m}$ durante el cual se releva cada valor de magnetización. Además, como se observa en la figura 2.15, aún para un sistema monotamaño, la transición al estado SPM es abrupta pero de pendiente finita por lo que en lugar de un valor de temperatura, se define una región de transición. A fin de estudiar la dependencia de $T_{B}$ con los parámetros del experimento, es necesario definir un valor representativo. Una opción natural es el punto de inflexión de la curva ZFCW que, durante el cálculo numérico, se obtiene como el vértice de un ajuste cuadrático sobre la segunda derivada de la curva.

Si bien el tiempo de medida $\tau_{m}$ no es un parámetro de la simulación, una cantidad que naturalmente condiciona a $\tau_{m}$ es la variación temporal de la temperatura $d T / d t=\mathrm{B}$ introducida en la ecuación 2.38. Suponiendo una relación de proporcionalidad inversa entre el tiempo de medida y B del tipo $\tau_{m}=\vartheta / B$ y recordando la condición de bloqueo

$$
\tau_{m}=\tau_{0} e^{\lambda / T_{B}}
$$

con $\lambda=K V(1-h)^{2} / k$, se obtiene la relación

$$
\frac{1}{T_{B}}=\Theta-\Omega \log [B]
$$

En la figura 2.17 se observa como en las simulaciones (en las que no se impone la condición de bloqueo), la dependencia de $T_{B}$ con $\tau_{m}$ se verifica para $T_{B}$ y la inversa de $\mathrm{B}$, lo que confirma la relación de proporcionalidad entre este parámetro numérico y el tiempo de medida experimental o tiempo de bloqueo. A partir de los valores de $T_{B}$, se pueden obtener los valores de los tiempos de bloqueo $\tau_{m}$ suponiendo que estos corresponden a los tiempos de relajación de la transición hacia el mínimo más pronunciado (ec. 2.34), aproximación usualmente utilizada en la literatura. Graficando los valores obtenidos en función de 1/B (fig.2.17), se observa como la relación lineal no se verifica exactamente. Esto es una evidencia de que la ecuación 2.34 es sólo una aproximación por lo que una descripción exacta del fenómeno debe considerar las inversiones en ambos sentidos.

\subsubsection{Anisotropías con orientación aleatoria}

Los sistemas de NPM con anisotropías paralelas al campo son los casos más simples de tratar y más sencillos de entender en lo que a su respuesta magnética se refiere, pero distan de ser los más representativos. La única manera de obtener un sistema totalmente ordenado, es congelando o gelificando suspensiones de NPM expuestas a altos campos para asegurar la saturación. En el caso de suspensiones congeladas, se presenta la evidente limitación de no poder superar la temperatura de fusión de la matriz, lo que no es practicable en muchas de las caracterizaciones realizadas. Así, se vuelve interesante y necesario modelar sistemas en donde las NPM se encuentran orientadas al azar como es el caso de los FF y los geles fabricados sin campo aplicado que se estudian en el capítulo 4. El primer paso en esta dirección es encontrar 


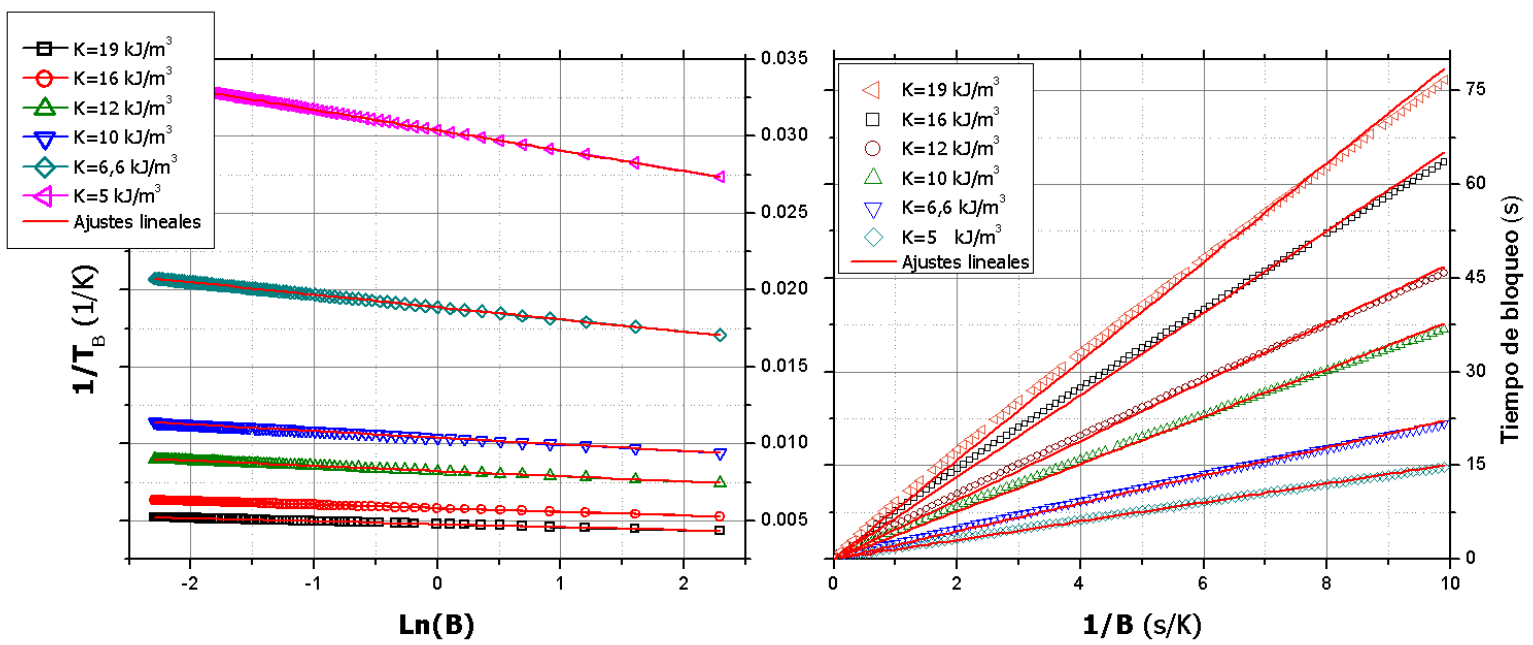

Figura 2.17: Inversa de la temperatura de bloqueo $T_{B}$ en función del logaritmo de la variación temporal de la temperatura $B$ (izquierda) y tiempo de bloqueo $\tau_{m}$ resultante en función de la inversa de $B$ para partículas con diferente constante de anisotropía $K$ (derecha). Se observa como los ajustes lineales son exactos en el caso de $T_{B}$ y solo aproximados para $\tau_{m}$.

las ecuaciones para NPM orientadas en una dirección arbitraria. Luego se pueden utilizar estos resultados generales para simular la respuesta de un sistema con orientaciones aleatorias.

Para el caso de un sistema de NPM orientadas en una dirección arbitraria $\phi \neq n \pi$, los ceros de la derivada de la energía 2.18 respecto de $\theta$

$$
\frac{\partial E}{\partial \theta}=K V\{\operatorname{sen}[2(\theta-\phi)]+2 h \operatorname{sen}[\theta]\}=0
$$

no tienen solución analítica para $\phi \neq n \pi / 2, n \in Z$ por lo que no se cuenta con la expresión exacta de la posición ni del valor de la energía en los puntos extremos, que para estos valores de $\phi$, dependen de $h$. Se puede observar gráficamente que la energía en función del ángulo $\theta$ presenta 4 puntos extremos en el rango $0<\theta<\pi$, dos máximos $\left(\theta_{\text {Max }}\right.$ y $\left.\theta_{\max }\right)$ y dos mínimos $\left(\theta_{\text {Min }}\right.$ y $\left.\theta_{\text {min }}\right)$ (fig. 2.18). Debido a esto, las NPM en cada pozo tiene dos opciones de inversión, una por cada altura de barrera $\Delta_{k}$.

Desde el mínimo absoluto al relativo:

$$
\begin{gathered}
\Delta_{M m m}=E\left[\theta_{\max }\right]-E\left[\theta_{\text {Min }}\right] \\
\Delta_{M M m}=E\left[\theta_{\text {Max }}\right]-E\left[\theta_{\text {Min }}\right],
\end{gathered}
$$

y desde el mínimo relativo al absoluto:

$$
\begin{aligned}
\Delta_{m m M} & =E\left[\theta_{\max }\right]-E\left[\theta_{\min }\right] \\
\Delta_{M M m} & =E\left[\theta_{\text {Max }}\right]-E\left[\theta_{\min }\right] .
\end{aligned}
$$




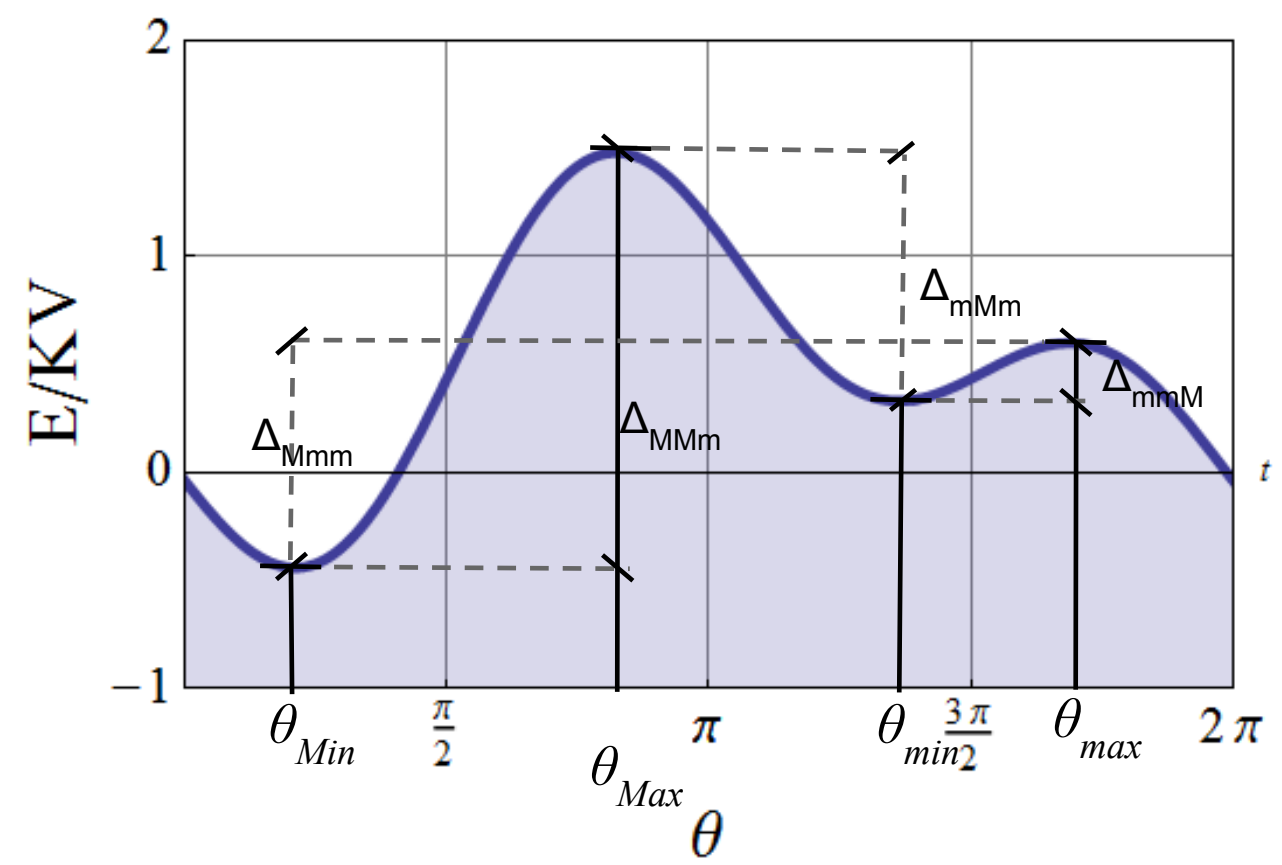

Figura 2.18: Perfil de energía en función de $\theta$ para $h=0,3$ y $\phi=\pi / 3,7$. Se observa un máximo y un mínimo absolutos $\left(\theta_{\text {Max }}\right.$ y $\left.\theta_{\text {Min }}\right)$ y un máximo y un mínimo relativos $\left(\theta_{\max }\right.$ y $\left.\theta_{\min }\right)$ por lo que existen dos inversiones posibles desde cada posición. Desde el mínimo relativo al absoluto las alturas de barrera son $\Delta_{m M M}$ y $\Delta_{m m M}$, y desde el mínimo absoluto son $\Delta_{M m m}$ y $\Delta_{M M m}$.

En donde las letras $M$ corresponden a los máximos y mínimos absolutos y las $m$ a los relativos de manera que, por ejemplo, la secuencia $M M m$ denota la inversión que parte del mínimo absoluto, pasa por el máximo absoluto y llega al mínimo relativo.

Siguiendo el mismo razonamiento que en el caso de $\phi=0$, la probabilidad de éxito de cada una de las 4 inversiones se puede escribir como

$$
p_{k}=p_{0} e^{-\beta \Delta_{k}}
$$

por lo que la variación temporal de las poblaciones queda, teniendo en cuenta que existen dos inversiones posibles desde cada pozo:

$$
\begin{gathered}
\frac{d N_{M}}{d t}=-\frac{d N_{m}}{d t}=\left(\frac{p_{m M M}+p_{m m M}}{2}\right) N_{m}-\left(\frac{p_{M m m}+p_{M M m}}{2}\right) N_{M} \\
\therefore \frac{d N_{M}}{d t}=P_{m} N_{m}-P_{M} N_{M}
\end{gathered}
$$

en donde se ha comprimido la notación con los reemplazos

$$
\begin{aligned}
P_{m} & =\frac{p_{m M M}+p_{m m M}}{2} \\
P_{M} & =\frac{p_{M m m}+p_{M M m}}{2}
\end{aligned}
$$


y la población total $N=N_{M}+N_{m}$ se mantiene constante.

Para calcular la magnetización $M$ en este caso, hay que tener en cuenta la proyección de la orientación de los mínimos en la dirección de campo

$$
M=\mu\left(N_{m} \cos \left[\theta_{m}\right]+N_{M} \cos \left[\theta_{M}\right]\right)
$$

con la magnetización de saturación $M_{s}=\mu N=\mu\left(N_{m}+N_{M}\right)$ y $\mu$ el momento de cada NPM, por lo que la magnetización relativa queda

$$
\begin{gathered}
m=\frac{M}{M_{s}}=\frac{1}{N}\left(N_{m} \cos \left[\theta_{m}\right]+N_{M} \cos \left[\theta_{M}\right]\right)=\cos \left[\theta_{m}\right]-\frac{N_{M}}{N}\left(\cos \left[\theta_{M}\right]-\cos \left[\theta_{m}\right]\right) \\
\therefore m=\cos \left[\theta_{m}\right]-\frac{N_{M}}{N} \Delta \operatorname{Cos}_{M m}
\end{gathered}
$$

con

$$
\Delta \operatorname{Cos}_{M m}=\cos \left[\theta_{M}\right]-\cos \left[\theta_{m}\right] .
$$

Para $h<0,1$, como es el caso de los ciclos RF en hipertermia, la variación en la posición de los extremos $\theta_{M, m}$ con el tiempo es pequeña y puede ser despreciada. Así, la derivada temporal de $m$ queda

$$
\frac{d m}{d t}=\left\{\frac{P_{m} N_{m}-P_{M} N_{M}}{2 N}\right\} \Delta \operatorname{Cos}_{M m} .
$$

De la ecuación 2.43 también se obtiene la igualdad

$$
\frac{N_{M}}{N} \Delta \operatorname{Cos}_{M m}=\cos \theta_{m}-m
$$

que, combinada con 2.44 permite encontrar la expresión final para la derivada temporal de la magnetización reducida

$$
\frac{d m}{d t}=\frac{1}{2} P_{m} \Delta \operatorname{Cos}_{M m}+\left(\cos \left[\theta_{m}\right]-m\right)\left(P_{m}+P_{M}\right)
$$

Con esta ecuación entonces, es posible estudiar el comportamiento de un sistema de NPM orientadas en una dirección arbitraria y, con las suma de soluciones para todo el rango de orientaciones, el comportamiento de un sistema con orientaciones aleatorias.

\subsubsection{Magnetización en función del campo}

Procediendo de la misma manera que en el caso con $\phi=0$, se puede obtener una expresión para $d m / d H$ utilizando la ecuación 2.29. Se contemplan las mismas dependencias temporales de $H$ para obtener las expresiones finales de manera de poder simular ciclos de histéresis DC y RF.

En la aproximación $\theta_{M, m}$ constante, se utilizan los valores para $h=0$, que son accesibles analíticamente 


$$
\begin{gathered}
E(h=0)=K V \operatorname{sen}^{2}[\theta-\phi] \Rightarrow \frac{\partial E}{\partial \theta}(h=0)=2 K V \operatorname{sen}[\theta-\phi] \cos [\theta-\phi] \\
\therefore \frac{\partial E}{\partial \theta}(h=0)=0 \Rightarrow \theta=n \pi+\phi \vee \theta=(n+1 / 2) \pi+\phi
\end{gathered}
$$

de manera que quedan definidos explícitamente los valores extremos en el rango $\theta \in[0 ; 2 \pi]$

$$
\begin{gathered}
E[\phi+\pi / 2]=1+2 h \operatorname{sen}[\phi] \\
E[\phi]=-2 h \cos [\phi] \\
E[\phi+\pi]=2 h \cos [\phi] \\
E[\phi+3 \pi / 2]=1-2 h \operatorname{sen}[\phi]
\end{gathered}
$$

y, a partir de estos, las barreras de energía

$$
\begin{aligned}
& \Delta_{m M M}=1+2 h(\operatorname{sen}[\phi]-\cos [\phi]) \\
& \Delta_{m m M}=1-2 h(\operatorname{sen}[\phi]+\cos [\phi]) \\
& \Delta_{M M m}=1+2 h(\operatorname{sen}[\phi]+\cos [\phi]) \\
& \Delta_{M m m}=1-2 h(\operatorname{sen}[\phi]-\cos [\phi]) .
\end{aligned}
$$

Resolviendo estas ecuaciones numéricamente se puede simular el ciclo de magnetización en función del campo para cualquier orientación del eje fácil. En la figura 2.19 se muestran ciclos RF $\left(f=100 \mathrm{kHz}, H_{0}=40 \mathrm{kA} / \mathrm{m}\right)$ obtenidos para $\phi=\{0,3 / 8 \pi, \pi / 4, \pi / 2\}$ junto con el ciclo simulado con la ecuación 2.31 para un sistema ordenado, como control. Se observa una muy buena coincidencia entre este último y el ciclo con $\phi=0$ lo que respalda la equivalencia de ambos modelos y la implementación numérica del caso con orientación arbitraria, que es más compleja.

$\mathrm{Al}$ aumentar $\phi$, los valores de magnetización para cada campo son cada vez menores hasta volverse nulos para $\phi=\pi / 2$. Este ciclo nulo se debe a la aproximación utilizada que considera fijas las posiciones de los mínimos de energía para todas los valores de $\phi=0$.

Combinando contribuciones en todo el espectro de $\phi$ se puede simular la respuesta de un sistema de NPM orientadas al azar. En la figura 2.20 se compara un ciclo simulado con la ecuación para sistemas ordenados con uno simulado con una distribución uniformes de valores de $\phi$. Se observa claramente cómo el área, y por ende la energía disipada durante el ciclo del sistema ordenado es mucho mayor para las mismas condiciones de medida. El ciclo de un sistema ordenado con los ejes de anisotropía paralelos al campo aplicado es el que presenta la mayor área posible para una dada amplitud y frecuencia. Por otro lado se observa que el valor de $H_{C}$ de ambos ciclos es idéntico, lo que no concuerda con los resultados experimentales de bibliografía. Es posible que esto sea una consecuencia de la aproximación de mínimos de posición angular fija. 


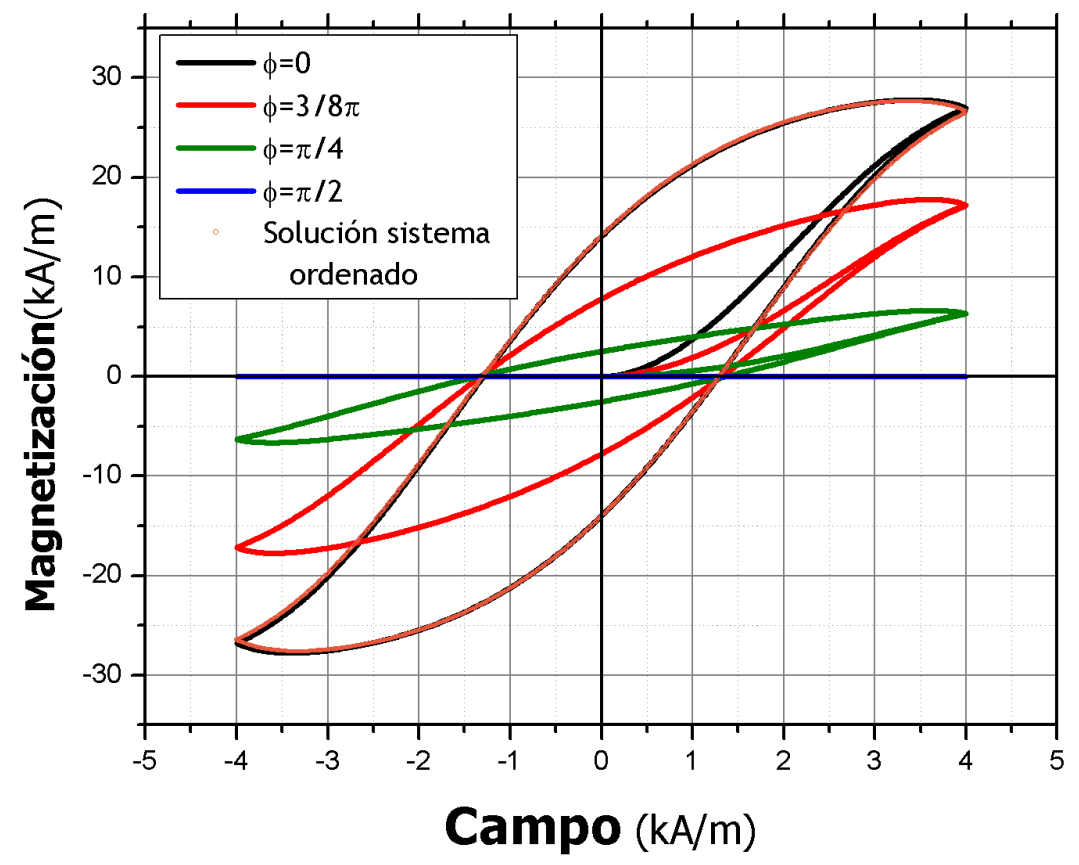

Figura 2.19: Ciclos calculados para diferentes valores de $\phi$ junto con el ciclo calculado con las ecuaciones de sistema ordenado. La coincidencia entre el ciclo ordenado y el ciclo con $\phi=0$ es muy buena. A mayor valor de $\phi$, menores los valores de magnetización alcanzados. En el caso extremo $\phi=\pi / 2$ la magnetización es nula. Esto último no concuerda con el comportamiento real de estos sistemas dado que es el resultado de la aproximación de mínimos fijos.

\subsubsection{Magnetización en función de la temperatura}

A partir de la ecuación para $d m / d T$ para un sistema con orientación arbitraria obtenida de la misma manera que en el caso ordenado i.e. considerando la variación $d T / d t$, se pueden simular curvas ZFC-FC para un sistema desordenado con distribución uniforme de orientaciones. En la figura 2.21 se muestra la comparación entre las curvas obtenidas para un sistema ordenado y uno desordenado con los mismos parámetros. Se observa una clara disminución en los valores de magnetización para el sistema desordenado mientras que la temperatura de bloqueo no se ve afectada ya que sólo depende del producto KV. 


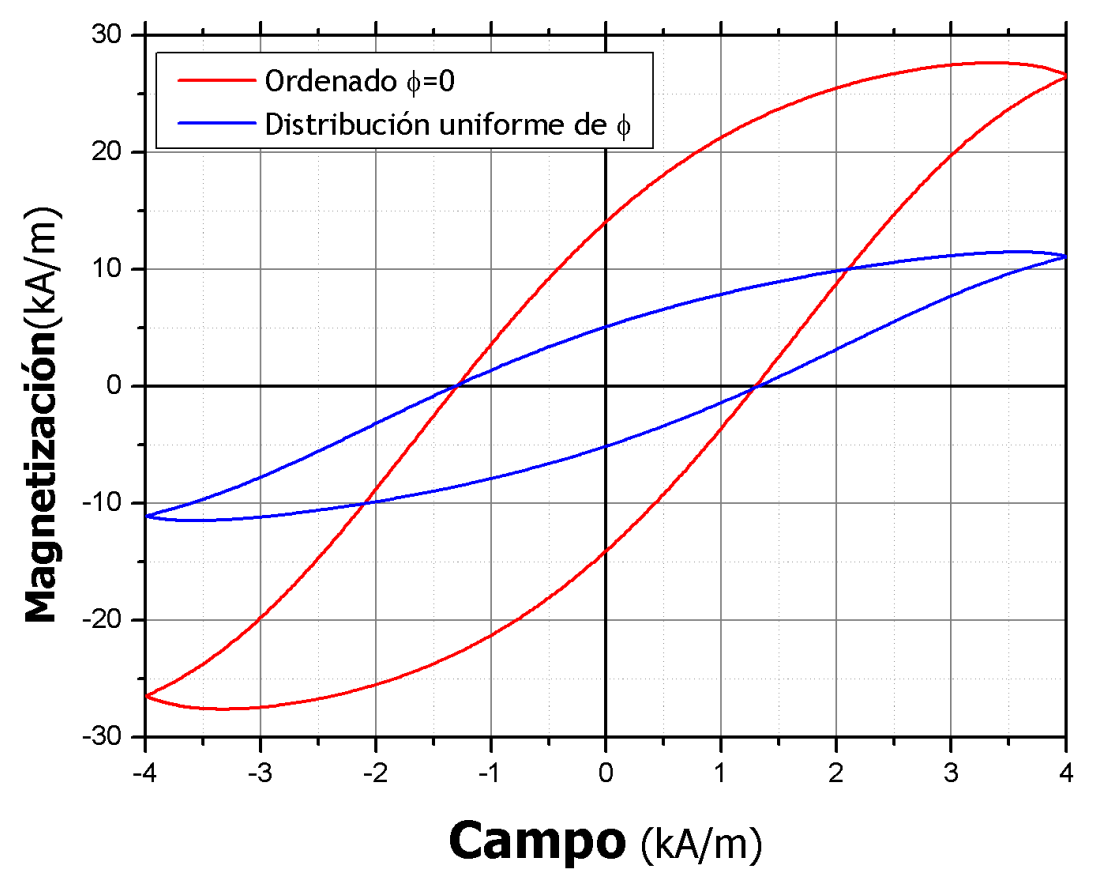

Figura 2.20: Comparación entre el ciclos de magnetización de un sistema ordenado con los ejes de anisotropía paralelos al campo y el ciclo de un sistema idéntico con los ejes de anisotropía orientados con distribución uniforme.

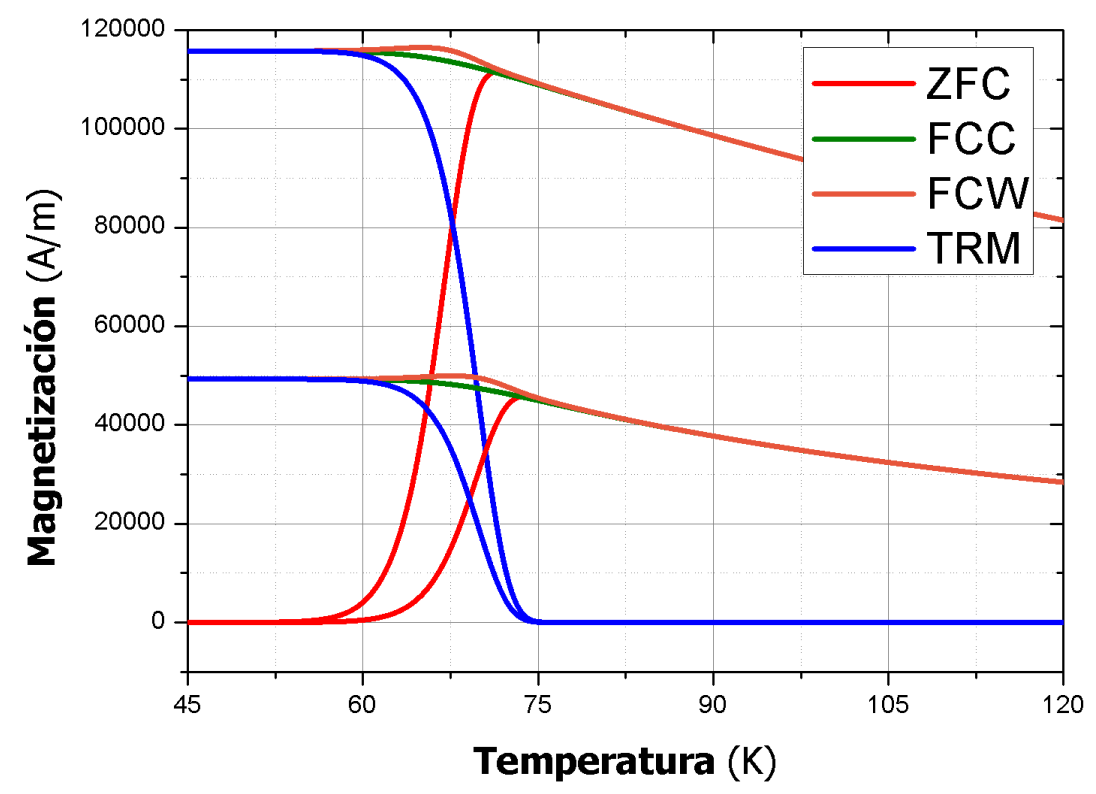

Figura 2.21: Comparación entre las curvas ZFC-FC de un sistema ordenado con los ejes de anisotropía paralelos al campo y las correspondientes a un sistema idéntico, con los ejes de anisotropía orientados con distribución uniforme. Para todas las curvas, los valores de magnetización del sistema desordenado disminuyen en más del $50 \%$ respecto al ordenado mientras que la temperatura de bloqueo no se ve afectada. 



\section{Técnicas experimentales}

Capítulo 3 
"[The new term] Physicist is both to my mouth and ears so awkward that I think I shall never use it. The equivalent of three separate sounds of $i$ in one word is too much.»

[El nuevo término] Físico (Physicist), es tan extraño para mi boca y oídos que creo que nunca lo usaré. Tres sonidos 'i' separados en una misma palabra es demasiado.

Michael Faraday Físico británico

Sydney Ross, "Nineteenth-Century Attitudes: Men of Science" (1991), 10. 
Se detallan a continuación las técnicas experimentales utilizadas en este trabajo. Se describen primero las condiciones de medida y los equipos utilizados para las caracterizaciones convencionales como las magnetometrías, la espectroscopía Mössbauer, la difracción y absorción de rayos X y las microscopías de electrones. Luego se detalla el fundamento y las características de las técnicas específicas para la caracterización de NPM para hipertermia incluyendo el sistema de medición de ciclos de magnetización a RF desarrollado durante esta tesis.

\subsection{Técnicas convencionales}

- Magnetometría: Se realizaron medidas de magnetización DC en función del campo y de la temperatura en el magnetómetro MMPS-SQuID (Quantum Design) del Laboratorio de Bajas Temperaturas de la FCEyN-UBA. Las ferritas de zinc (muestras I) fueron medidas en forma de polvo seco mientras que las NPM de magnetita (muestra II) se midieron en forma de FF con matriz de hexano sellado en un polímero termocontraible. Se utilizó el modo RSO de medida en todos los casos.

Se realizaron ciclos con un campo máximo de $600 \mathrm{kA} / \mathrm{m}$ a temperaturas entre $2 \mathrm{~K}$ y 300 $\mathrm{K}$.

Se realizaron medidas ZFC-FC $(\mathrm{H}=8 \mathrm{kA} / \mathrm{m})$ entre $2 \mathrm{~K}$ y $140 \mathrm{~K}$.

- Espectroscopía Mössbauer: Se obtuvieron espectros Mössbauer ${ }^{57} \mathrm{Fe}$ a $300 \mathrm{~K}$ en geometría de transmisión con una fuente nominal ${ }^{57} \mathrm{Co}$ de $20 \mathrm{mCi}$ en matríz $R_{h}$ con un perfil de velocidad triangular. El corrimiento isomérico está referido a $\alpha-F e$ metálico a temperatura ambiente.

- Microscopía de electrones: Las imágenes TEM de la muestra I fueron tomadas en un microscopio Philips EM-301 con un potencial acelerador de $100 \mathrm{kV}$. Para realizar las medidas, se depositó una gota de FF sobre una rejilla de cobre recubierta en carbono. Las imágenes SEM se obtuvieron en un microscopio FEI Helios NanoLab 650 luego de depositar una gota de FF en un monocristal de silicio, dejar secar al aire y observar sin metalizar la muestra.

Las imágenes TEM de las muestra II fueron obtenidas en el Laboratorio de Microscopía Avanzada del Instituto de Nanociencia de Aragón (España) en un microscopio FEI Tecnai T20 con un potencial acelerador de $200 \mathrm{kV}$.

- Difracción de rayos X: Se obtuvieron espectros DRX en un difractómetro X-Pert (radiación $C u_{K \alpha}$ con $\lambda=1,5406 \AA$ ). Se recogieron datos en el rango $15^{\circ}<2 \theta<60^{\circ}$ barriendo a una tasa de $5 \mathrm{~s}$ por paso, en pasos de $0,02^{\circ}$. Los difractogramas fueron analizados usando el programa MAUD (Lutterotti 2010), que está basado en el método de análisis Rietveld.

- Absorción de rayos X: Se obtuvieron espectros XANES y EXAFS de la muestra I a temperatura ambiente para el borde K del Fe $(7112$ eV) y le borde K del Zn (9659 eV) en geometría de transmisión utilizando un monocromador Si (lllll) en las lineas XAS del Laboratorio Nacional de Luz Sincrotrón en Campinas, Brasil. El análisis espectral fue realizado substrayendo el fondo prepico y normalizando la región EXAFS. Las oscilaciones de estructura fina $\chi(k)$ de cada espectro en la región extendida fueron aisladas 
mediante el programa ATHENA [134] y transformada de Fourier sobre rangos de k específicos.

\subsection{Caracterización de NPM para hipertermia}

A fin de caracterizar las NPM para hipertemia es necesario utilizar técnicas específicas orientadas a determinar los parámetros más interesantes para la aplicación. El más relevante de estos parámetros es el SAR o SLP, la disipación específica de potencia de las muestras que cuantifica su capacidad para transferir energía de un campo RF al medio mediante calor. El modo más utilizado de obtener esta cantidad es bastante directo, se realizan medidas calorimétricas de las muestras mientras se las expone a un campo RF. Midiendo la elevación de temperatura en un sistema adiabático, es posible cuantificar la potencia transferida del campo al medio.

Un enfoque más lateral del problema, pero potencialmente más rico en tanto la información que brinda, es el de relevar el ciclo de magnetización de las muestras al ser expuestas al campo RF. Como se desarrolló en el capítulo 2, el área del ciclo de magnetización es igual a la energía disipada durante el mismo. Además, contar con la información del comportamiento magnético del sistema en las condiciones de la aplicación presenta considerables ventajas. Con este fin se desarrollaron y utilizaron un sistema de bobinas captoras y un programa de procesamiento de datos que permite obtener el SAR de las muestras por este método alternativo.

Finalmente en esta enumeración pero al principio de la sección se describe el método utilizado para determinar la concentración de los FF. Este paso es fundamental para obtener valores absolutos confiables de los parámetros.

\subsubsection{Determinación de concentración de Fe en FF}

Resulta imprescindible para la caracterización de un FF el conocer su concentración, i.e. su contenido específico de Fe. Si bien típicamente se conocen de forma más o menos precisa las cantidades de los precursores utilizadas para la síntesis, el contenido específico de Fe puede variar de forma sensible entre el momento de la fabricación y el de la caracterización. Típicamente esto se debe a la evaporación del solvente en el que están suspendidas las NPM y/o a la aglomeración de las mismas que deviene en diferencias de concentración entre las alicuotas utilizadas para caracterizar.

La concentración de los FF fue determinada por un método espectroscópico en el que todo el Fe de la muestra forma un complejo con tiocianato de potasio que presenta absorción en el visible.

Los FF de base acuosa son atacados directamente con una mezcla de $\mathrm{HCl} 6 \mathrm{M}$ y $\mathrm{HNO}_{3}$ con el fin de disolver las NPM y garantizar la oxidación de todo el $\mathrm{Fe}^{2+}$ a $\mathrm{Fe}^{3+}$, dado que el $\mathrm{Fe}^{2+}$ no forma complejo con el tiocianato.

El ión tiocianato de potasio reacciona con el $\mathrm{Fe}^{3+}$ para dar un ión complejo rojo púrpura con un pico de absorción en torno de $480 \mathrm{~nm}$ según

$$
F e^{3+}(a c)+6 S C N^{-}(a c) \Rightarrow[F e(S C N) 6]^{3-}
$$


La concentración de Fe en el FF se determina a partir de una curva de calibración obtenida midiendo la absorbancia de soluciones patrón de Fe con un rango de concentraciones que contiene a la esperada para la muestra[25]. Los FF con base orgánica no hidrosoluble deben ser primero calcinados en horno a $1200^{\circ} \mathrm{C}$ para asegurar que todo el $\mathrm{Fe}$ contenido sea atacado por los ácidos.

\subsubsection{Determinación de SAR mediante medidas calorimétricas}

La determinación de la disipación específica de potencia se realizó en principio mediante un método calorimétrico. La muestra de FF es colocada en un recipiente Dewar con capacidad de aproximadamente $5 \mathrm{~mL}$. El recipiente está diseñado para poder ubicarse en el centro de una bobina de bronce con circulación interna de agua para refrigeración (bobina generadora). La bobina está conectada a un conjunto resonador+fuente RF Hüttinger TIG 2,5/300 que puede entregar una potencia máxima de $2,5 \mathrm{~kW}$ y trabajar en el rango de frecuencias $[30,300] \mathrm{kHz}$. La frecuencia generada puede variarse de forma discreta dentro del rango antedicho modificando los valores de capacidad e inductancia del resonador. Para esto se cuenta con un conjunto de capacitores intercambiables y una inductancia variable de 4 posiciones además de la elección libre de la bobina aplicadora.

La temperatura de la muestra es registrada en tiempo real mientras se aplica el campo RF mediante un sensor de fibra óptica Neoptix T1 inmune al campo AC conectado a una interfaz Neoptix Reflex con un muestreo de $1 \mathrm{~Hz}$ y una precisión de $0,1^{\circ} \mathrm{C}$. El sensor se introduce a través del tapón de caucho del Dewar y se sumerge en el seno del FF (fig. 3.1). La interfaz se conecta a una computadora en la que se visualizan y almacenan los datos mediante un software desarrollado en el laboratorio de electrónica aplicada del Departamento de Física.

Los datos de temperatura vs. tiempo obtenidos son luego tratados en el programa Origin 8 para obtener el SAR como

$$
S A R=\frac{m_{F F} c \Delta T}{m_{N P M} \Delta t}=\frac{c}{[N P M]} \frac{d T}{d t}
$$

en donde $m_{F F}$ y $c$ son respectivamente la masa y el calor específico del FF y $\Delta T$ es la elevación de temperatura, por lo que el numerador $m_{F F} c \Delta T$ es la energía en forma de calor que se divide por $m_{N P M}$ para obtener energía específica por masa de NPM y por $\Delta t$ para obtener potencia. Esto puede reescribirse con la concentración masa en masa de NPM $[N P M]=m_{N P M} / m_{F F}$ y la tasa de calentamiento $d T / d t$ obtenida como la pendiente de un ajuste lineal o exponencial sobre los datos (fig. 3.2).

El tipo de ajuste depende de la duración temporal de la medida. Las muestras de alto SAR se calientan rápidamente con una respuesta lineal dado que para cortos períodos de tiempo, la adiabaticidad del sistema es casi ideal. Las muestras de bajo SAR pueden tardar varios minutos en aumentar su temperatura un par de grados. En estos casos se disipa calor al medio y la curva de calentamiento se ajusta con una función exponencial $T[t]=T_{f}-\Delta T e^{-t / \tau}$ de donde se obtiene la pendiente inicial como $d T[0] / d t=\Delta T / \tau$, entendiendo por momento inicial el correspondiente a la temperatura de equilibrio alcanzada por una muestra sin NPM en las mismas condiciones. El calor específico de la muestra se calcula como una combinación lineal de los calores específicos de los constituyentes. Dadas las concentraciones utilizadas, típicamente el 


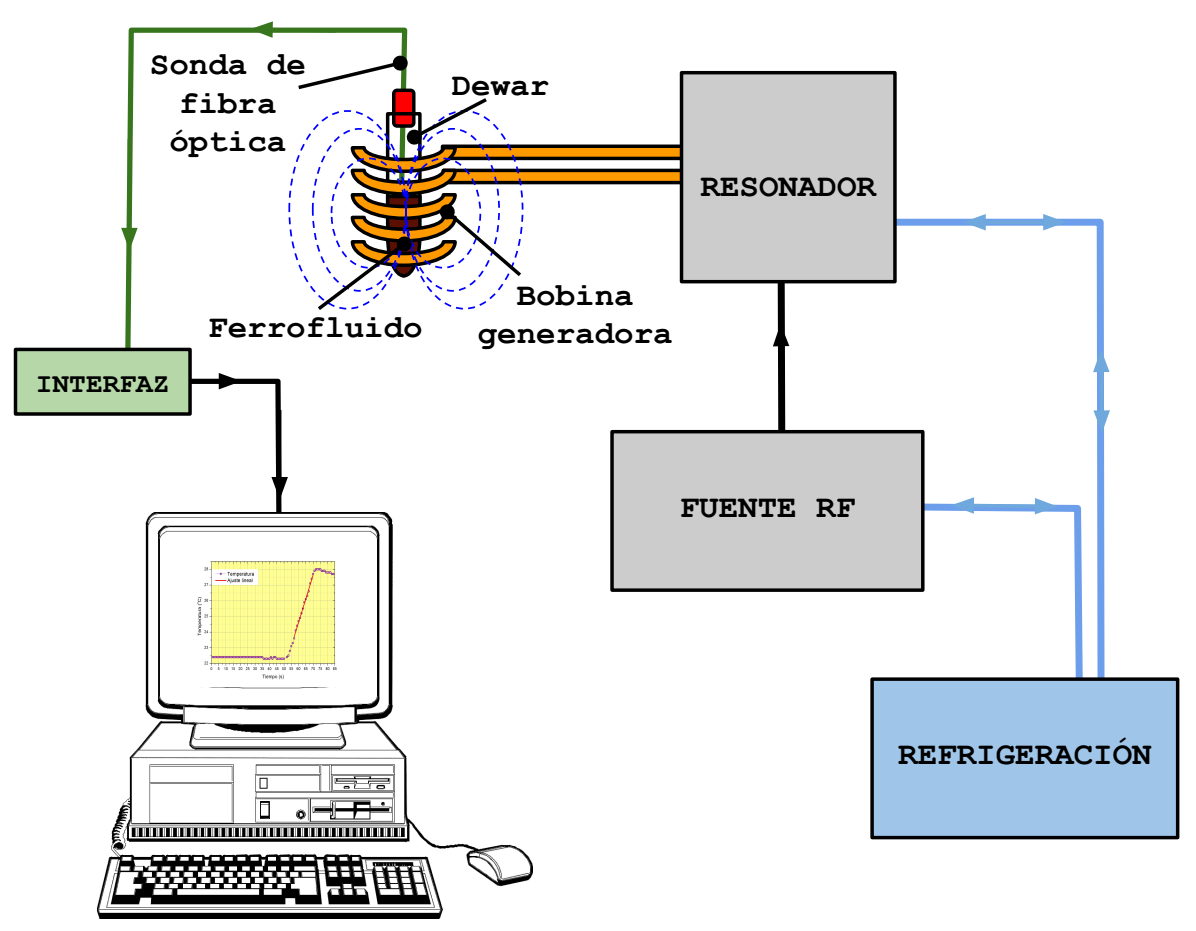

Figura 3.1: Esquema del sistema utilizado para determinar la potencia disipada por los FF bajo campo RF. Las NPM absorben energía del campo y la liberan al medio mediante calor elevando la temperatura del FF. Una sonda de fibra óptica inmune al campo, sumergida en la muestra y conectada a una interfaz, releva la temperatura del FF. Los datos son recogidos en una computadora conectada a la interfaz y registrados en formato ASCII a dos columnas (temperatura, tiempo).

resultado es muy próximo al calor específico de la matriz líquida.

Si bien se tienen en cuenta las incertidumbres en $c$ y $[N P M]$, la mayor contribución a la incertidumbre en el SAR proviene de la dispersión en los valores de $d T / d t$ obtenida a partir de la repetición de experimentos sobre una misma muestra a intensidad de campo y frecuencia fijas.

\subsubsection{Caracterización de la relación Campo-Frecuencia del generador RF}

El resonador utilizado para generar el campo RF permite modificar sus valores de capacidad $C$ e inductancia $L$ internos a fin de seleccionar la frecuencia de resonancia $f$ según la expresión para un circuito RLC serie $f=1 / \sqrt{L C}$.

La inductancia interna consta de una bobina de 3 vueltas con 4 posiciones de contacto de manera de poder seleccionar la cantidad de espiras que se incluyen en el circuito resonador. Cada espira agrega aproximadamente $0,3 \mu \mathrm{H}$ por lo que la inductancia interna puede variar entre 0 $\mu H$ y aproximadamente $0,9 \mu H$. A este valor hay que sumar el correspondiente a la inductancia de la bobina generadora externa en serie. Si bien todos los experimentos de este trabajo se realizaron con una bobina generadora de $0,57 \mu H$, también se cuenta con una bobina de 1,5 $\mu H$ y otra de $1,86 \mu H$.

La capacidad interna está dada por hasta 4 capacitores de alta potencia conectados en paralelo. Al ser adquirido, el equipo contaba con dos capacitores de $0,33 \mu F$. Con el fin de ampliar el 


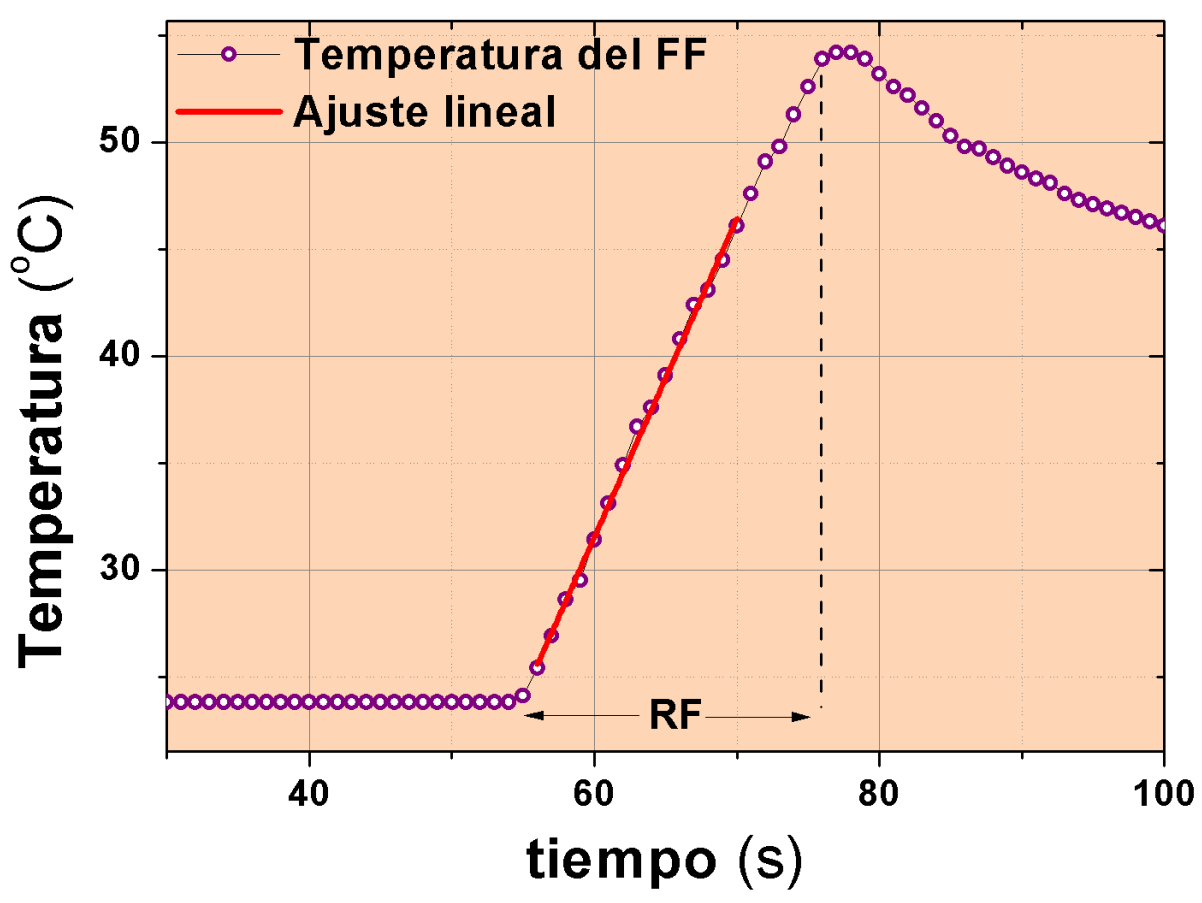

Figura 3.2: Curva de calentamiento típica temperatura vs. tiempo para un experimento calorimétrico. Se indica el intervalo de tiempo durante el que se aplicó el campo $R F$ y el ajuste lineal del que se obtiene la pendiente $\frac{d T}{d t}$.

conjunto de frecuencias disponibles, se adquirieron posteriormente 5 capacitores adicionales con valores en el rango $[0,17 ; 1,33] \mu F$ que permiten barrer de forma bastante uniforme todo el rango de frecuencias del equipo. Con estos, se dispone entonces de aproximadamente 80 frecuencias accesibles en el rango $(40 ; 285) \mathrm{kHz}$ para cada bobina externa.

La corriente máxima entregada por la fuente, y por lo tanto la máxima amplitud de campo, está condicionada tanto por la potencia como por la relación entre las reactancias capacitiva e inductiva del resonador. Así, dependiendo de estas cantidades, la amplitud y estabilidad del campo RF generado tuvo que ser relevada para las combinaciones de capacidad e inductancia disponibles(fig. 3.3). En la figura 3.4 se representan las mayores amplitudes de campo accesibles para la bobina utilizada con las diferentes inductancias internas. Los valores de $f$ accesibles están limitados por el generador al rango [30;300]kHz. Los valores de $H$ están limitados por la máxima corriente que soporta el resonador. El producto $f H$ está limitado por la potencia de la fuente, y la relación entre impedancias capacitiva e inductiva limita las configuraciones estables en la zona de altos campos y bajas frecuencias.

\subsubsection{Caracterización de la geometría del campo de la bobina utilizada}

Es evidente que siendo el campo aplicado una de las variables de control de las medidas $\mathrm{RF}$, conocer su intensidad y homogeneidad en la región donde se coloca la muestra resulta fundamental. Con el fin de conocer la geometría de campo de la bobina utilizada (BI) se realizó 


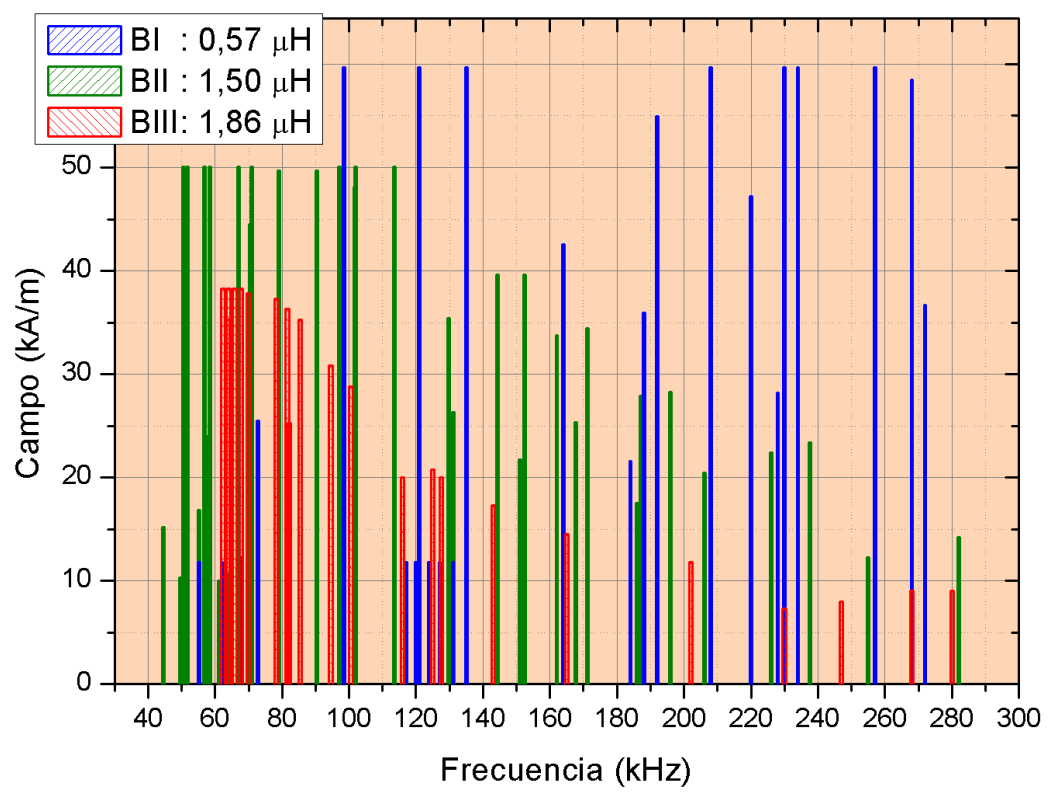

Figura 3.3: Amplitud de campo y frecuencias accesibles con las bobinas externas disponibles. Para la mayor inductancia se observa claramente la modulación del campo máximo en función de la frecuencia.

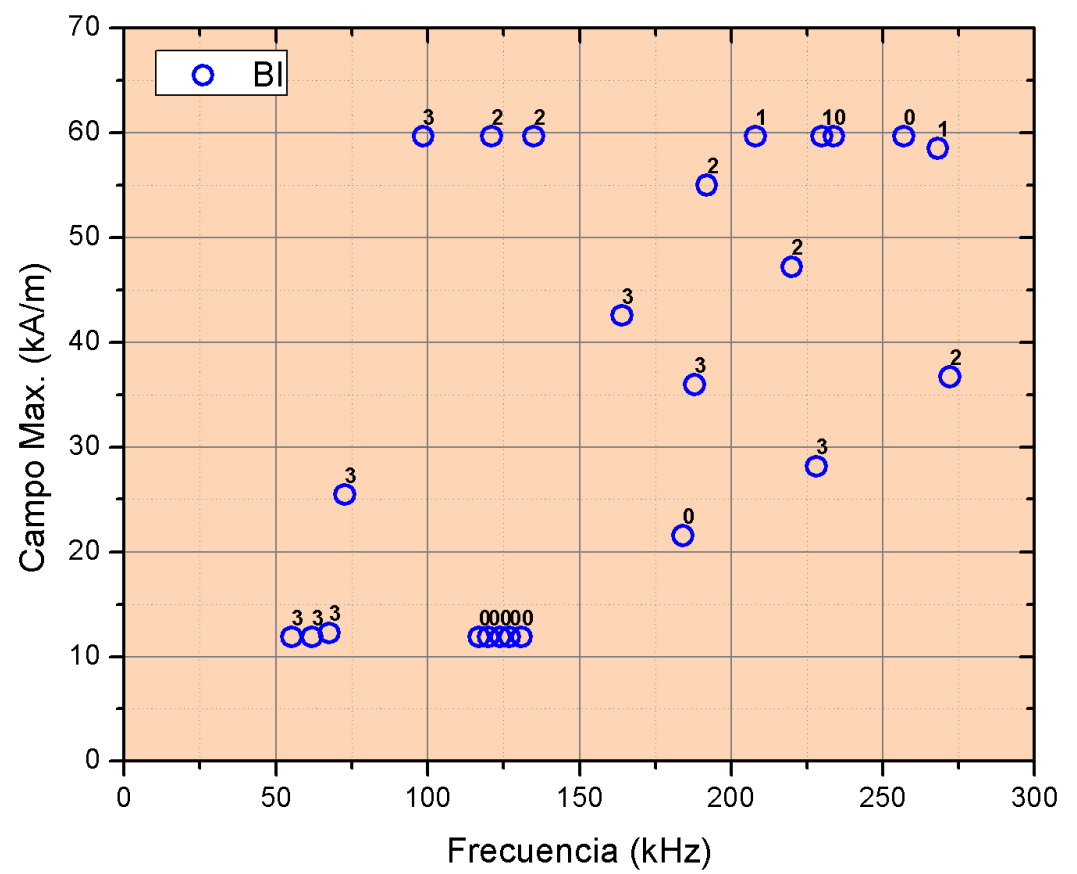

Figura 3.4: Máximos valores de campo accesibles a cada frecuencia para la bobina utilizada. Los números junto a cada punto indican la cantidad de vueltas de la inductancia interna que se incluyen en el circuito resonador. Cada una de estas vueltas suma aproximadamente $0,3 \mu \mathrm{H}$.

una calibración en posición e intensidad. Para esto se utilizaron el posicionador y una de las 
bobinas del par serie oposición descritas en la sección 3.2.3. Se relevó la amplitud de campo magnético $H_{0}$ en función de la posición de la bobina captora dentro de la bobina generadora, para diferentes corrientes circulando por esta última a una frecuencia de $268 \mathrm{kHz}$ (fig. 3.5).

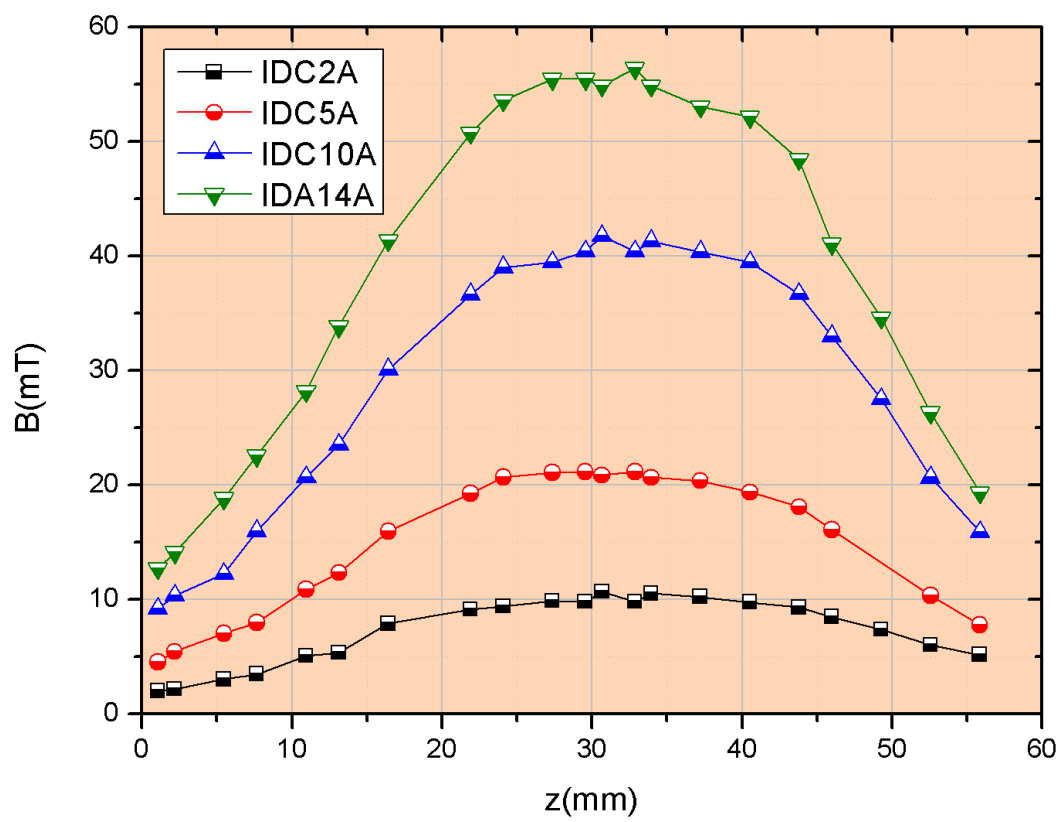

Figura 3.5: Amplitud de campo $B$ en función de la posición z sobre el eje de la bobina generadora para una frecuencia de $268 \mathrm{kHz}$ y diferentes intensidades de corriente IDC de la fuente de potencia.

\subsubsection{Desarrollo de sistema inductivo de relevamiento del ciclo de magnetización a RF y determinación del SAR}

Se implementó un arreglo experimental con el fin de relevar el ciclo magnético M vs. H de un FF expuesto a un campo RF según se presentó en varios trabajos recientes [52, 53].

Para ello se construyó un par de bobinas captoras $\left(C_{c}\right.$ y $\left.C_{m}\right)$ en serie oposición de 10 vueltas y $5 \mathrm{~mm}$ de diámetro separadas una distancia fija de $23 \mathrm{~mm}$ sobre un posicionador a rosca que permite mover el conjunto a lo largo del eje central de la bobina generadora RF con el plano de las captoras paralelo al de la bobina generadora (figuras 3.6 y 3.7). Se utilizó alambre de cobre esmaltado de $60 \mu \mathrm{m}$.

La diferencia de potencial $\varepsilon$ inducida por un campo magnético $B(t)$ variable en una bobina conductora de $N$ vueltas y área transversal $A$ es

$$
\varepsilon[t]=-\frac{\partial \varphi}{\partial t}=-\frac{\partial(N A B[t])}{\partial t}=-N A \frac{\partial B[t]}{\partial t}
$$

si el campo varía en el tiempo de forma sinusoidal con frecuencia angular $\omega$ y amplitud $B_{0}$

$$
\varepsilon[t]=-N A \omega B_{0} \cos [\omega t]
$$




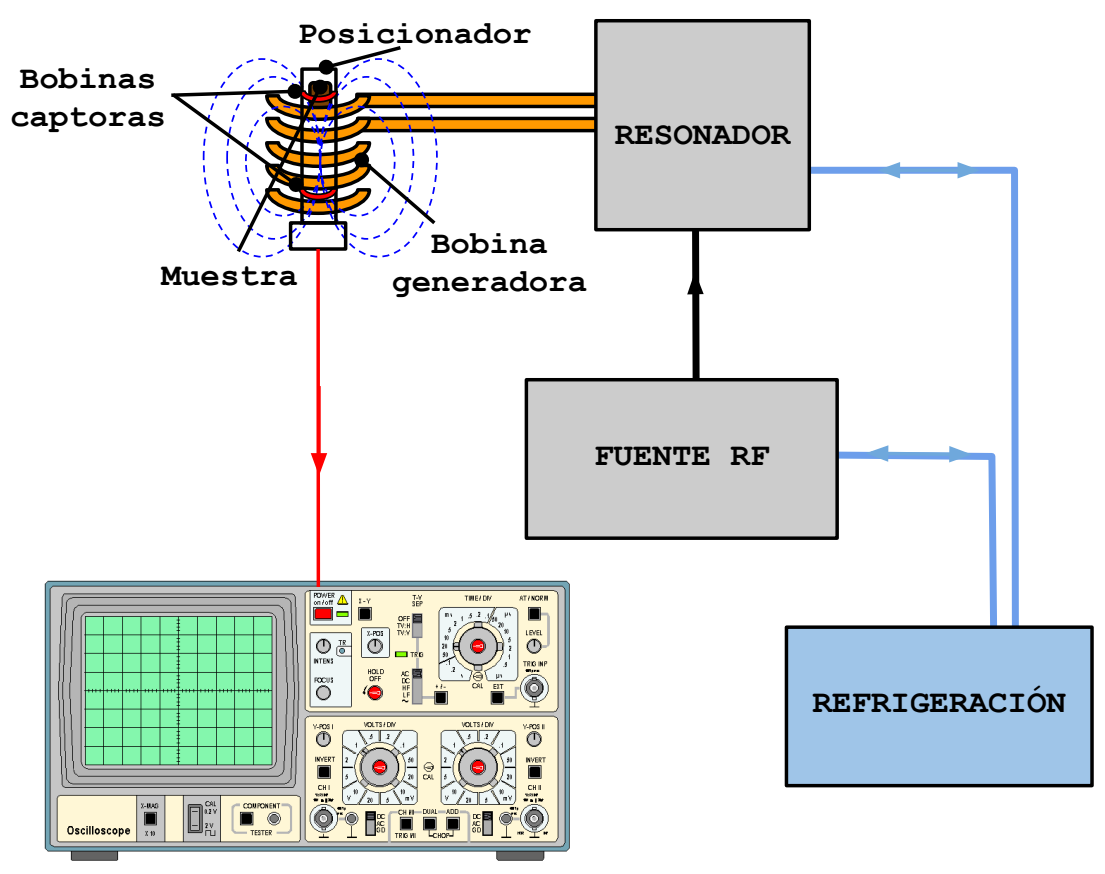

Figura 3.6: Esquema del sistema utilizado para relevar ciclos de magnetización RF. El campo RF de la bobina generadora induce FEM en las bobinas captoras que se encuentran en serie-oposición. La diferencia de potencial entre los extremos del par es relevada en función del tiempo por el osciloscopio.

con la relación entre inducción magnética $B$, campo magnético $H$ y magnetización $M$ según la ecuación 1.1. Así, la diferencia de potencial entre los extremos del arreglo será la suma de las FEM inducidas en cada una de las captoras que, al estar en serie oposición, tendrán signos opuestos.

$$
\varepsilon=\varepsilon_{m}+\varepsilon_{c}=-N A\left[\frac{\partial B_{m}}{\partial t}-\frac{\partial B_{c}}{\partial t}\right]=-N A \frac{\partial\left(B_{m}-B_{c}\right)}{\partial t}
$$

Si las dos bobinas son iguales y no se coloca un material de magnetización apreciable como núcleo, para ambas valdrá

$$
\varepsilon_{i}=-N A B_{0}^{(i)} \cos [\omega t]=-N A \mu_{0} H_{0}^{(i)} \cos [\omega t]
$$

dado que $H$ y $B$ siempre están en fase en este caso. En la posición del arreglo en la que ambas sean atravesadas por el mismo flujo se cumple $H_{0}^{(m)}=-H_{0}^{(c)}$ por lo que la diferencia de potencial $\varepsilon$ será nula.

Si se coloca una muestra de magnetización $M$ en $C_{m}$

$$
\varepsilon_{m}=-N A \mu_{0} \frac{\partial[H+M]}{\partial t}=-N A \mu_{0}\left(H_{0} \cos [t]+\frac{\partial M}{\partial t}\right) \Rightarrow \varepsilon=-\varepsilon_{m}+\varepsilon_{c}=N A \mu_{0} \frac{\partial M}{\partial t}
$$

por lo que la diferencia de potencial entre los extremos del arreglo será proporcional a la 

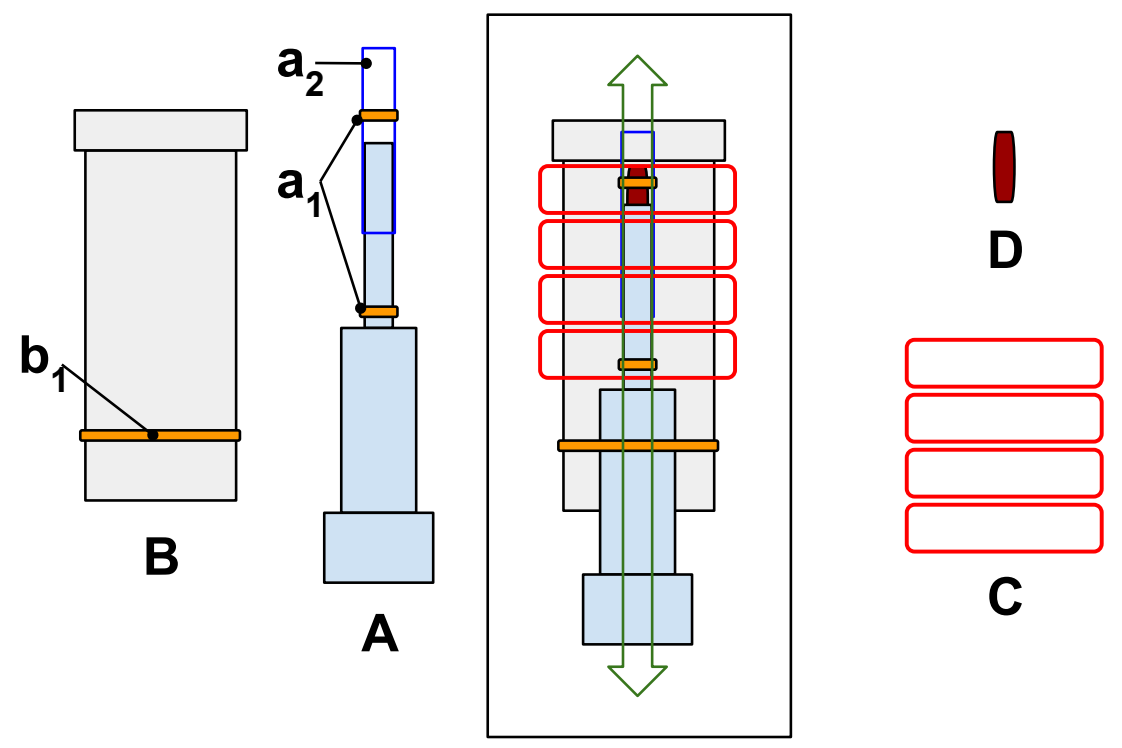

Figura 3.7: Detalle del elemento sensor del sistema utilizado para relevar los ciclos de magnetización RF. El macho del posicionador $(A)$ en cuyo eje se empalma un tubo de plástico $\left(a_{2}\right)$ y sobre el que se enrollan las bobinas captoras $C_{c}$ y $C_{m}\left(a_{1}\right)$, se enrosca en la hembra $(B)$ en donde está enrollada la bobina de referencia $R\left(b_{1}\right)$. La hembra se encuentra fija dentro de la bobina generadora $(C)$. La muestra $(D)$ se coloca por el extremo superior. El pequeño paso de la rosca del posicionador $(\approx 1 \mathrm{~mm}$ de desplazamiento vertical por vuelta) permite colocar el par de bobinas captoras en la posición de cancelación de forma repetitiva y confiable. Los cables de las bobinas captoras pasan por un canal que atraviesa el posicionador longitudinalmente saliendo por la base del macho.

derivada temporal de la magnetización de la muestra.

Así, se puede determinar la magnetización de la muestra como la integral temporal de la diferencia de potencial entre los extremos del par de bobinas captoras.

$$
M=-\frac{1}{N A \mu_{0}} \int \varepsilon d t
$$

El arreglo permite medir la diferencia de potencial tanto entre los extremos terminales como entre uno de ellos y el punto medio de manera de poder registrar la señal en cada captora por separado. La salida del sistema se registra en un osciloscopio Tektronix TDS 3012 previo paso por un filtro analógico pasa bajos con frecuencia de corte en $2 \mathrm{MHz}$ utilizado para atenuar la interferencia de alta frecuencia proveniente de la conmutación de la fuente RF.

La señal de una tercera bobina de 2 vueltas y $2 \mathrm{~cm}$ de diámetro (indicada como $R$ ) bobinada sobre la hembra del posicionador a una distancia fija de $1 \mathrm{~cm}$ del extremo inferior de la bobina generadora (fig. 3.7) se utiliza como señal de sincronía con el campo y como disparo del osciloscopio. Esta bobina externa no está expuesta al mismo valor de campo que la muestra, pero la dependencia temporal de la señal es la misma. El valor absoluto de campo se obtiene a partir de la calibración realizada sobre la bobina generadora en la sección 3.2.2.2.

Así, el valor de campo magnético se calcula como la integral temporal de la diferencia de 
potencial entre los extremos de $R$, multiplicada por un factor de calibración $\gamma$.

$$
H=\gamma \int \varepsilon_{R} d t
$$

En el rango de frecuencias de trabajo, cualquier mínima diferencia de construcción (difícilmente evitable) entre las bobinas captoras se manifiesta como una diferencia de fase entre $\varepsilon_{m} \mathrm{y} \varepsilon_{c}$ que hace imposible la cancelación de $\varepsilon$. Esto provoca una señal de fondo no nula aún con ambas bobinas vacías y expuestas a flujos iguales. Debido a esto, es necesario realizar una medida previa de esta señal de fondo con las bobinas vacías o con una muestra de matriz "blanca"(sin NPM) para luego restarla a la señal tomada con muestra dentro de $C_{m}$.

Así, el procesado de la señal obtenida consta de los siguientes pasos:

(I) Con $C_{m}$ vacía o con muestra blanca, se registran simultáneamente $\varepsilon$ y $\varepsilon_{R}$ en función del tiempo en sendos canales del osciloscopio. Mediante una función interna del mismo, se realiza un promediado sobre 128 registros. El resultado se exporta vía puerto serie-USB mediante un protocolo Python obteniéndose un archivo ASCII (“fondo") de dos pares de columnas (tiempo $\varepsilon$, voltaje $\varepsilon$; tiempo $\varepsilon_{R}$, voltaje $\varepsilon_{R}$ ).

(II) Se coloca la muestra en $C_{m}$ y se vuelven a registrar ambos canales obteniendo el archivo "muestra" de igual estructura que el archivo "fondo"(fig. 3.8).

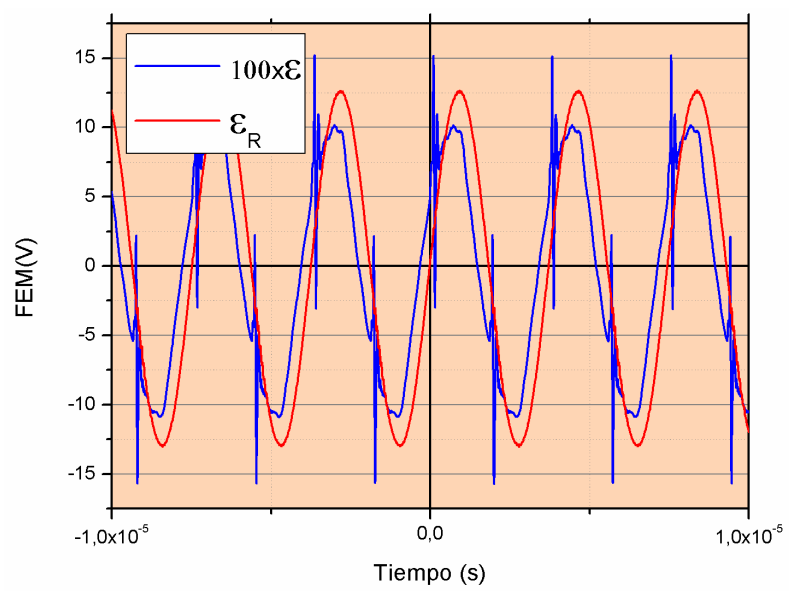

Figura 3.8: Ejemplo de los datos sin procesar obtenidos en el osciloscopio. En un canal se registra la FEM $\varepsilon$ entre los extremos del par de serie oposición, en el otro canal se registra la FEM $\varepsilon_{R}$ inducida en la bobina de referencia $R$. Se realiza un promedio sobre 128 registros. El voltaje $\varepsilon$ se muestra amplificado 100 veces. Se puede observar en el mismo la interferencia de alta frecuencia proveniente de la conmutación de la fuente $R F$.

Mediante un programa en lenguaje Matlabß:

(III) Se le ajusta a la señal $\varepsilon_{R}$ de cada archivo ("muestra" y "fondo") una función seno de la forma

$$
a+b \sin (c 2 \pi t-d)
$$


obteniendo la información de la amplitud $b$, la frecuencia $c$, la fase $d$ y el valor medio $a$.

(IV) Se sincronizan "muestra" y "fondo" haciendo coincidir las señales $\varepsilon_{R}$ (proporcional a la FEM inducida por el campo) de cada una a partir de los valores de fase obtenidos en el paso anterior. Contemplando la posibilidad de que el disparo del osciloscopio pueda variar entre el registro de "muestra" y el de"fondo", con este procedimiento se igualan las fases de $\varepsilon_{R}$ en ambas medidas.

(V) Se restan los respectivos valores medios.

(VI) Se selecciona una porción de los datos tal que contenga un número entero de períodos.

(VII) Se interpolan las señales para que coincidan las bases de tiempo.

(VIII) Se restan punto a punto las señales $\varepsilon$ de fondo y con muestra. Al resultado se le resta el valor medio y se le aplica un filtro pasabajos para eliminar la interferencia de alta frecuencia (fig. 3.9).

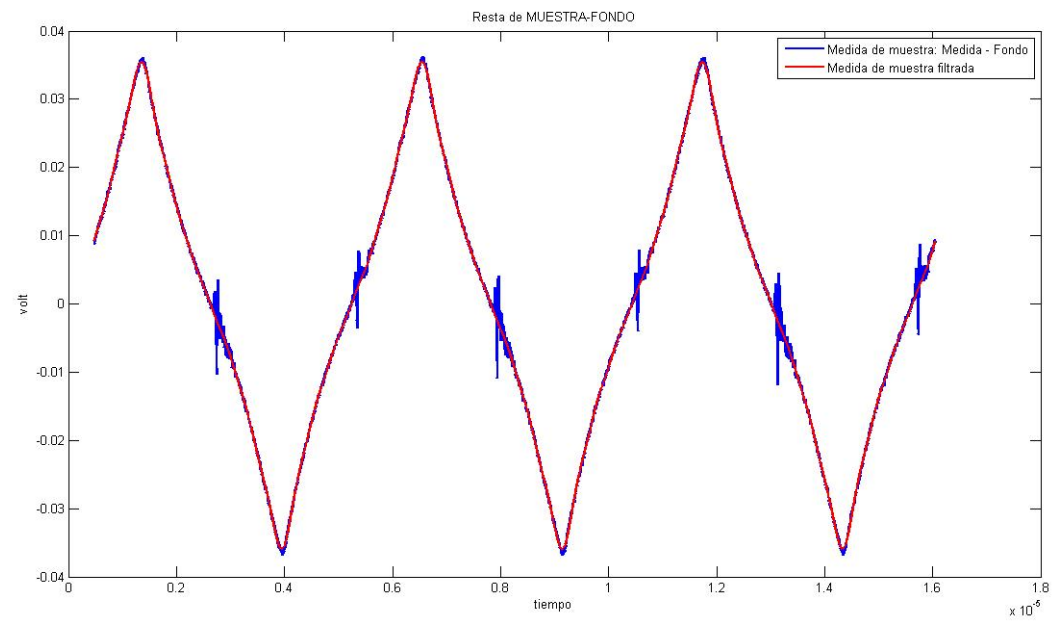

Figura 3.9: Ejemplo de la señal resultado de la resta entre muestra y fondo antes (azul) y después (rojo) de aplicar un filtro pasa bajos FFT con frecuencia de corte en $3 \mathrm{MHz}$.

(IX) Se integran el resultado del paso anterior y una de las referencias y se multiplica cada una por el factor correspondiente para llevarlas a unidades de magnetización y campo magnético respectivamente.

(X) Se calcula el área del ciclo $M$ vs. $H$. Se promedia sobre todos los períodos disponibles. Esta cantidad es la energía disipada por ciclo a partir de la cual se calcula el SAR (fig. 3.10).

Al quedar registrado el ciclo $\mathrm{M}$ vs $\mathrm{H}$, el sistema permite, además de obtener el valor de $\mathrm{SAR}$, caracterizar la respuesta magnética de la muestra de forma precisa extrayendo parámetros de interés como $H_{C}$ y $M_{R}$ entre otros. 


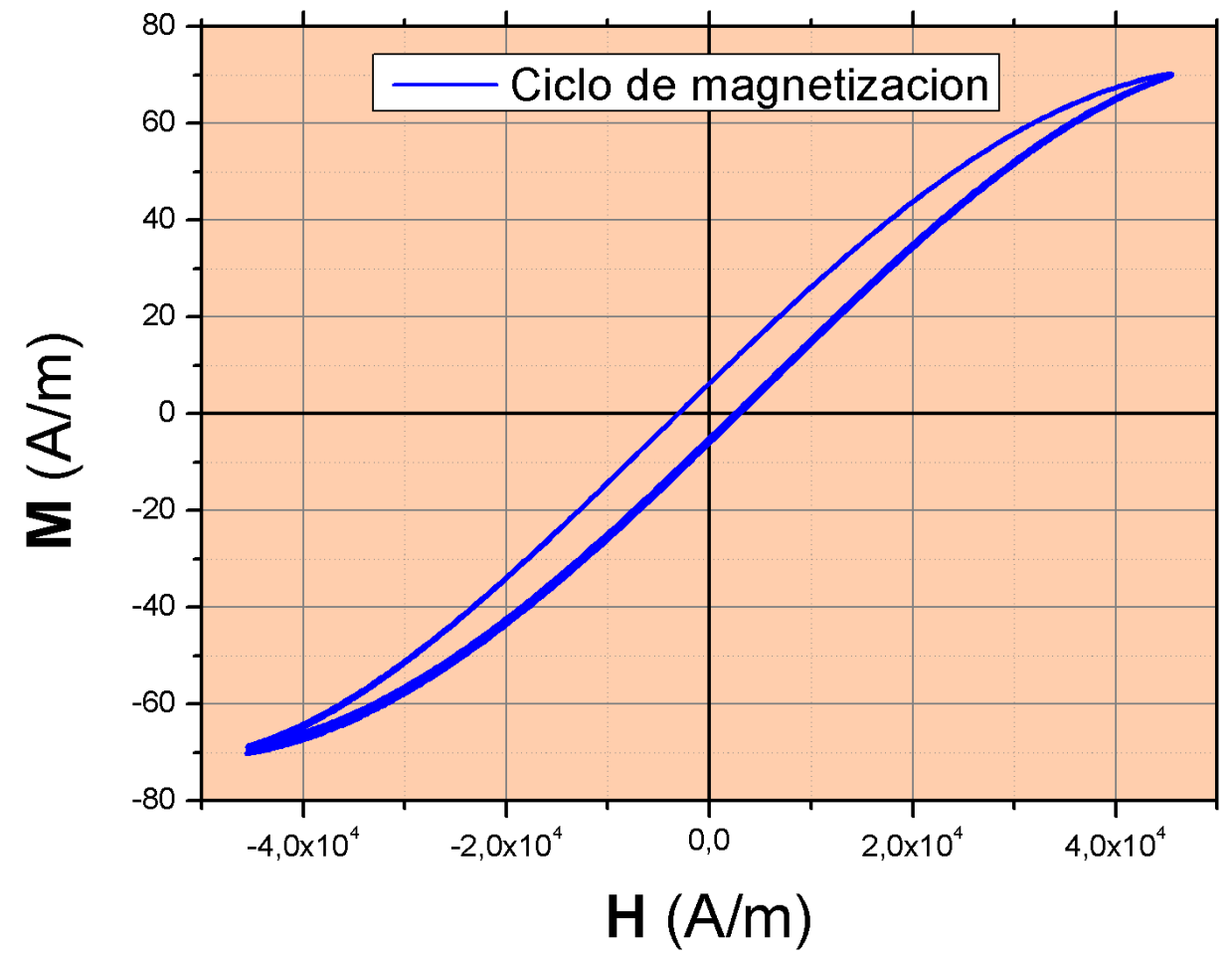

Figura 3.10: Ejemplo de ciclo de magnetización generado a partir de los datos procesados. Se muestra en realidad la superposición de varios ciclos, tantos como períodos del campo RF fueron utilizados para el análisis. 


\section{Caracterización de NPM. Relación entre el SAR y los parámetros de las NPM}

Capítulo 4 
«Der Mensch kann tun was er will; er kann aber nicht wollen was er will.»

El hombre puede hacer lo que quiera, pero no puede querer lo que quiera.

Arthur Schopenhauer Filósofo alemán

“Über die Freiheit des menschlichen Willens"(1839) 


\subsection{Muestra I. Magnetitas dopadas con zinc. Estudio de la dependencia del factor de frecuencia con el tamaño y del efecto del dopado con Zn. Determinación del mecanismo predominante de disipación.}

Se sintetizaron y estudiaron 3 series (S1, S2, S3) de NPM de magnetita dopada con Zn con el fin de aumentar su magnetización de saturación $M_{s}$ [29]. La síntesis fue realizada por el grupo de la Dra. Silvia Jacobo de la Facultad de Ingeniería de la UBA.

La magnetita $\left(\mathrm{Fe}_{3} \mathrm{O}_{4}\right)$ presenta una temperatura de orden $T_{N}=860 \mathrm{~K}[30]$ y una magnetización de saturación a temperatura ambiente $M_{s}=90 \mathrm{Am}^{2} / \mathrm{kg}$ [31]. Posee una estructura cristalina de espinela inversa en donde dos tercios de los iones de $\mathrm{Fe}$ son $\mathrm{Fe}^{3+}$ y ocupan los sitios A (tetraedrales) y los B (octaedrales) en partes iguales. El resto de los iones son $\mathrm{Fe}^{2+}$ y se ubican exclusivamente en sitios B. Así, su fórmula unidad se puede expresar como $\left[\mathrm{Fe}^{3+}\right]_{A}\left[\mathrm{Fe}^{3+} \mathrm{Fe}^{2+}\right]_{B} \mathrm{O}_{4}$.

La interacción magnética en la magnetita está dominada por una combinación de superintercambio antiferromagnético (SI) y doble intercambio ferromagnético (DI). El material presenta tres interacciones SI antiferromagnéticas: $\mathrm{AA}, \mathrm{BB}$ y $\mathrm{AB}$ entre los $\mathrm{Fe}^{3+}$ en los sitios $\mathrm{A}$ y $\mathrm{B}$, todas mediadas por un oxígeno. Además existe una interacción ferromagnética DI mediada por los electrones itinerantes $t_{2 g}$ que saltan entre los Fe de valencia mixta de los sitios B. Debido a la regla de Hund, el espín de estos electrones itinerantes se encuentra acoplado antiferromagnéticamente a los espines de los electrones 3d localizados. En el modelo más simple para la magnetita, se obtiene ferrimagnetismo con alta $T_{N}$ sin necesidad de una interacción DI para $\mathrm{AB} \gg \mathrm{BB}$, con AA forzando un alineamiento antiparalelo entre los momentos de los sitios A y B. Como los momentos antiparalelos de los $\mathrm{Fe}^{3+}$ de los sitios A y B se compensan, se espera una $M_{S}$ de $4 \mu_{B}$ por fórmula unidad proveniente de los $\mathrm{Fe}^{2+}$ en los sitios $\mathrm{B}$.

Un modelo más elaborado consiste en dividir la subred de sitios $\mathrm{B}$ en una red $\mathrm{de} \mathrm{Fe}^{3+}$ y otra de $\mathrm{Fe}^{2+}$. Si se debilita la interacción $\mathrm{AB}$ y se intensifica la $\mathrm{BB}$, los momentos en los sitios $\mathrm{B}$ ya no se mantienen rígidamente paralelos a los momentos en los sitios $\mathrm{A}$. La intensificación de la interacción BB resulta en una inclinación de los espines que provoca la disminución de $M_{S}$ (fig. 4.1).[127]

Existen varias opciones para modificar las propiedades magnéticas de la magnetita. Una de ellas consiste en reemplazar los $\mathrm{Fe}^{3+}$ de los sitios A con iones divalentes no magnéticos como el $\mathrm{Zn}^{2+}$. La bibliografía indica que los iones de $\mathrm{Zn}$ se ubican preferentemente los sitios A, coordinados tetraédricamente en la estructura de la espinela inversa. Esto elimina un parte de los acoplamientos antiferromagnéticos de los sitios A, provocando inicialmente un aumento de $M_{S}$ a bajos niveles de sustitución . Si la sustitución sigue aumentando, en el material macroscópico, la paulatina disminución de la interacción AB frente a la BB lleva a una disminución de $M_{S}$ como se mencionó antes.

NPM de composición $\mathrm{Zn}_{\mathrm{x}} \mathrm{Fe}_{3-\mathrm{x}} \mathrm{O}_{4}$ con $x \in[0 ; 0,7]^{1}$ fueron sintetizadas y suspendidas en forma

\footnotetext{
${ }^{1}$ Denotaremos las muestras según la serie a la que pertenecen y su contenido de Zn de manera que S100 y S345 serán las muestras de la serie 1 con $x=0,0$ y de la serie 3 con $x=0,45$ respectivamente.
} 
a)

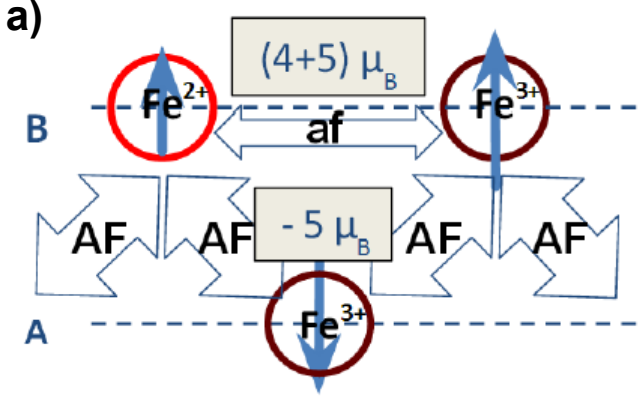

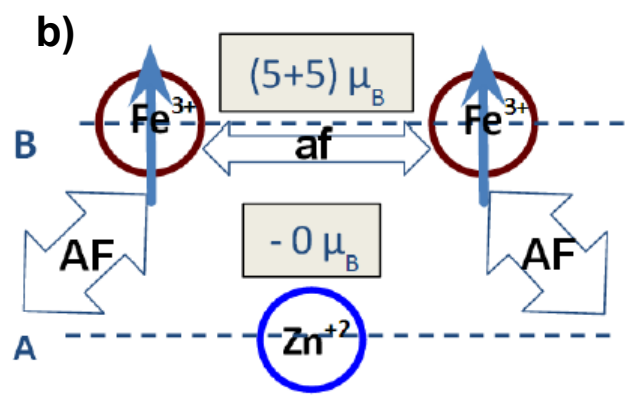

Figura 4.1: Esquema del efecto de la sustitución de iones $\mathrm{Fe}^{3+}$ por $\mathrm{Zn}^{2+}$ en la estructura de la magnetita. A la izquierda se observa la estructura original con la interacción antiferromagnética dominante entre los sitios A y los sitios $B$ con un momento resultante de $4 \mu_{B}$. A la derecha se observa como el ión $\mathrm{Fe}^{3+}$ en el sitio A desplaza al $\mathrm{Fe}^{3+}$ al sitio $B$ lo que resulta en una momento neto de $10 \mu_{B}$.

de ferrofluidos de base acuosa mediante coprecipitación de precursores químicos por el grupo dirigido por la Dra. Silvia Jacobo de la Facultad de Ingeniería (UBA). Se eligió este tipo de síntesis pensando en el bajo costo requerido para su aplicación terapéutica. Se trabajó con un amplio rango de composiciones y tamaños medios con la intención de identificar los parámetros óptimos para la obtención de altos valores de SAR[32].

Se observó que el comportamiento de las muestras se ve afectado tanto por el contenido de zinc como por la distribución de tamaños. Distinguir entre las influencias de estos dos parámetros resulta dificultoso principalmente debido a la gran dispersión de tamaños. Esto hizo necesaria la combinación de varias técnicas experimentales para una correcta caracterización. Se determinaron los valores de SAR de los ferrofluidos en función de su concentración y de la amplitud del campo RF aplicado. Las NPM fueron suspendidas en agua y en solución acuosa de quitosano, un polisacárido biocompatible de mayor viscosidad para aumentar su estabilidad.

\subsubsection{Síntesis}

Se utilizó el mismo protocolo de síntesis para las tres series con ligeras variaciones en pos de mejorar la estabilidad y disminuir la dispersión de tamaños.

\section{Síntesis serie $1(\mathrm{~S} 1)$}

Se obtuvieron NPM dopadas con $\mathrm{Zn}, \mathrm{Zn}_{\mathrm{x}} \mathrm{Fe}_{3-\mathrm{x}} \mathrm{O}_{4}(\mathrm{x}=0,0 ; 0,1 ; 0,2 ; 0,3 ; 0,4 ; 0,5)$ mediante un procedimiento similar al empleado por Vergés et al[33] . Se precipitó y estacionó $\mathrm{FeSO}_{4}$ en un sistema cerrado constituido por un balón de tres entradas sumergido en un baño térmico con agitación mecánica. La solución de hierro (II) fue agregada a tasa constante en atmósfera de nitrógeno.

Para preparar la muestra de magnetita sin dopar, se burbujeó nitrógeno en las dos soluciones independientemente: (i) $180 \mathrm{ml}$ de agua destilada conteniendo $\mathrm{NaOH}$ a una concentración final de 7,0 x $10^{-2} \mathrm{~mol} / \mathrm{L}_{\text {y }} \mathrm{KNO}_{3}$ a una concentración de $0,022 \mathrm{~mol} / \mathrm{L}$, y (ii) $20 \mathrm{~mL}$ de FeSO $7 \mathrm{H}_{2} \mathrm{O}$ a 7,4 x $10^{-1}$ disuelto en $\mathrm{H}_{2} \mathrm{SO}_{4}$ a $10^{-2} \mathrm{~mol} / \mathrm{L}$ calentado a $70^{\circ} \mathrm{C}$. Luego de 30 minutos, la solución 
básica fue agregada a tasa constante y bajo agitación mecánica a la solución de sulfato de hierro. La temperatura de la solución y la tasa de burbujeado de nitrógeno se mantuvieron constantes durante toda la síntesis. Cuando se completó la precipitación, se mantuvo el flujo de nitrógeno por otros 5 minutos. La síntesis se dejó descansar en baño térmico a la misma temperatura por 2 horas luego de las cuales se enfrió la solución a temperatura ambiente. El sólido fue separado por decantación magnética, lavado varias veces con agua destilada y centrifugado. Luego, fue secado en vacío a $40^{\circ} \mathrm{C}$ por 24 horas. Para las muestras dopadas con zinc, se reemplazó parte del $\mathrm{FeSO}_{4} 7 \mathrm{H}_{2} \mathrm{O}$ por $\mathrm{ZnSO}_{4} 7 \mathrm{H}_{2} \mathrm{O}$ en la fracción correspondiente a la composición deseada. Los FF de la $\mathrm{S} 1$ fueron obtenidos dispersando $10 \mathrm{mg}$ de NPM lavadas en 3,5 mL de una solución al $2 \%$ de quitosano en ácido acético $(1 \%$ p/p). La suspensión se agitó durante 6 horas para asegurar que las NPM se recubrieran uniformemente y luego se sometió a ultrasonido durante 30 minutos. El recubrimiento ocurre por interacción específica entre la superficie de las NPM y la composición estructural del polímero.

El FF se purificó a temperatura ambiente centrifugando a $3500 \mathrm{rpm}$ durante 15 minutos y luego se resuspendió en la solución de quitosano. El polímero posee un grupo amino que se carga positivamente en medio ácido; lo que provee al coloide de una estabilidad de varios días.

Síntesis serie $2(\mathrm{~S} 2)$

Las NPM fueron preparadas mediante el mismo procedimiento que S1 excepto por el paso (i) en donde los $180 \mathrm{~mL}$ de agua destilada fueron reemplazados por $100 \mathrm{~mL}$ de etanol absoluto y $80 \mathrm{~mL}$ de agua destilada.

Los FF correspondientes se obtuvieron dispersando $50 \mathrm{mg}$ de NPM lavadas en $50 \mathrm{~mL}$ de agua destilada y aplicando ultrasonido durante 12 horas. En este caso, el método de preparación induce carga eléctrica superficial en las NPM (iones sulfato) que estabilizan la suspensión y vuelven innecesario el uso de surfactante.

Síntesis serie 3 (S3)

Se utilizó el mismo procedimiento que para la S2 ampliando el rango de concentraciones de $Z n$ hasta $x=0,8[34]$.

\subsubsection{Análisis de composición y estructura: DRX, TEM y SEM}

Los difractogramas de todas las muestras muestran solo picos de Bragg correspondientes a la estructura de espinela cúbica indicando la existencia de una sola fase cristalina (JCPDS 19-629) (fig 4.2). Para todas las composiciones se refinó el patrón completo de la magnetita considerando el ensanchamiento debido al tamaño de cristalita. Para las muestras S1, al aumentar x, el tamaño medio de cristalita decrece desde $117 \mathrm{~nm}$ hasta $26 \mathrm{~nm}$. Para las muestras S2, la tendencia está menos definida con tamaños de cristalita entre $38 \mathrm{~nm}$ para S200 y $15 \mathrm{~nm}$ para S250. En los espectros de S3 se observa una tendencia creciente hasta S330 y decreciente luego con tamaños de entre $62,9 \mathrm{~nm}$ y $9,3 \mathrm{~nm}$.

El relevamiento TEM de las muestras S1 fue incompleto, contando sólo con imágenes bastante parciales de S100, S110 y S120. Se observan partículas poliédricas, mayoritariamente 

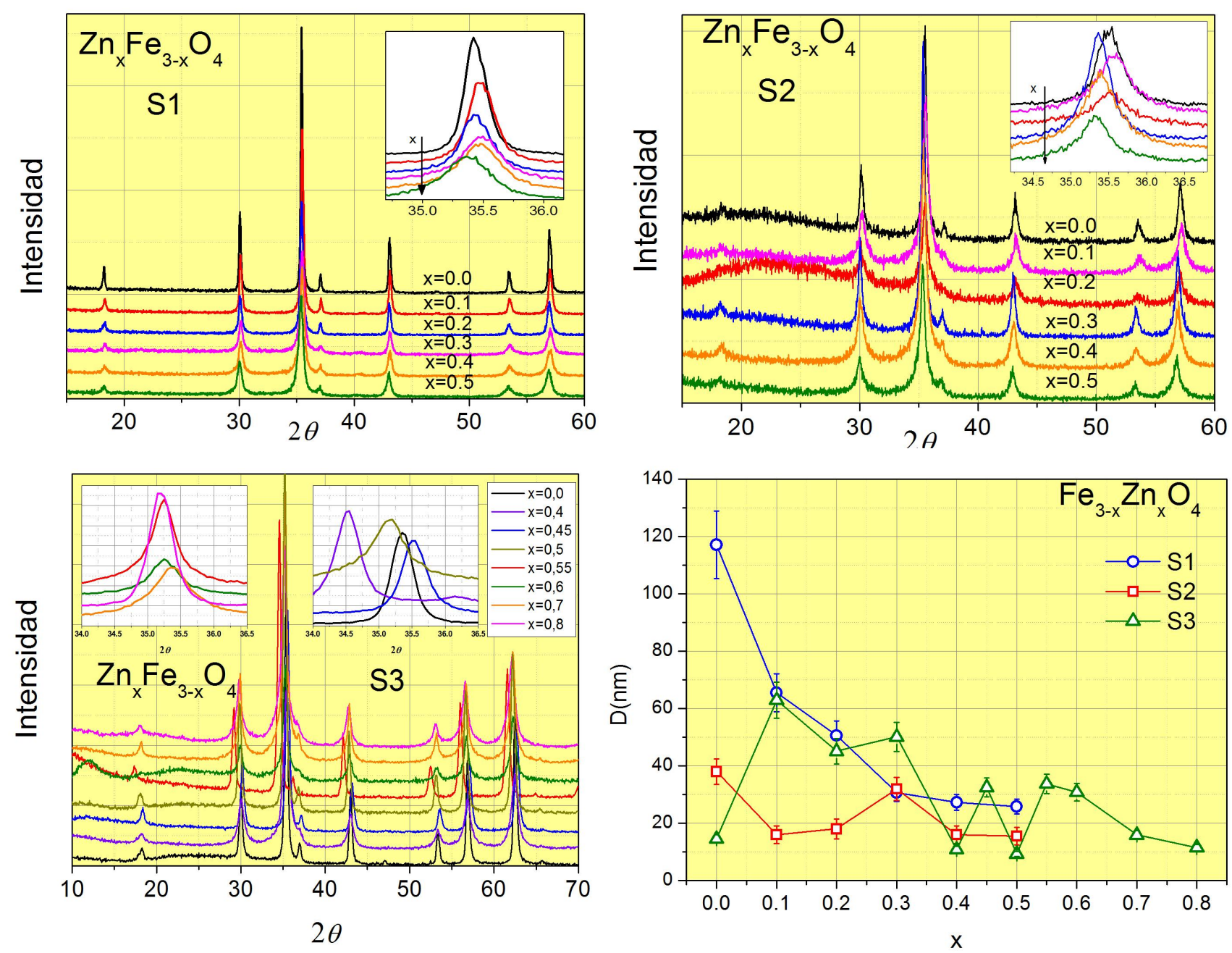

Figura 4.2: Difractogramas de las 3 series $(S 1, S 2, S 3)$ de muestras de magnetita dopada con Zinc y variación del tamaño de cristalita con el agregado de Zn a la estructura para cada serie. Insertos: evolución del pico central.

cúbicas con una distribución de tamaños variable de muestra a muestra. Ajustando los histogramas con una función lognormal se obtienen desviaciones estándar menores al $10 \%$ del valor medio. En la imagen de la muestra S120 se observa claramente el recubrimiento orgánico de cada partícula con espesores del orden del nm (fig.4.3). Los tamaños medios obtenidos de las imágenes TEM no son compatibles con los tamaños determinados por DRX. El caso de S102, en donde el tamaño TEM es superior a sus correspondiente DRX, puede tratarse del efecto de una cristalinidad incompleta de las NPM, pero para S100 y S110 la diferencia es en sentido opuesto. Posiblemente esto se deba a la poca representatividad de las imágenes TEM, tanto por contener las mismas una porción sesgada de la población total como por haber sufrido la alicuota utilizada una selección involuntaria de tamaños al prepararla para el microscopio.

Las imágenes de las partículas S2 muestran el mismo tipo de geometría mayoritariamente cúbica con un rango total de tamaños menor, pero con mayor dispersión para cada muestra. 

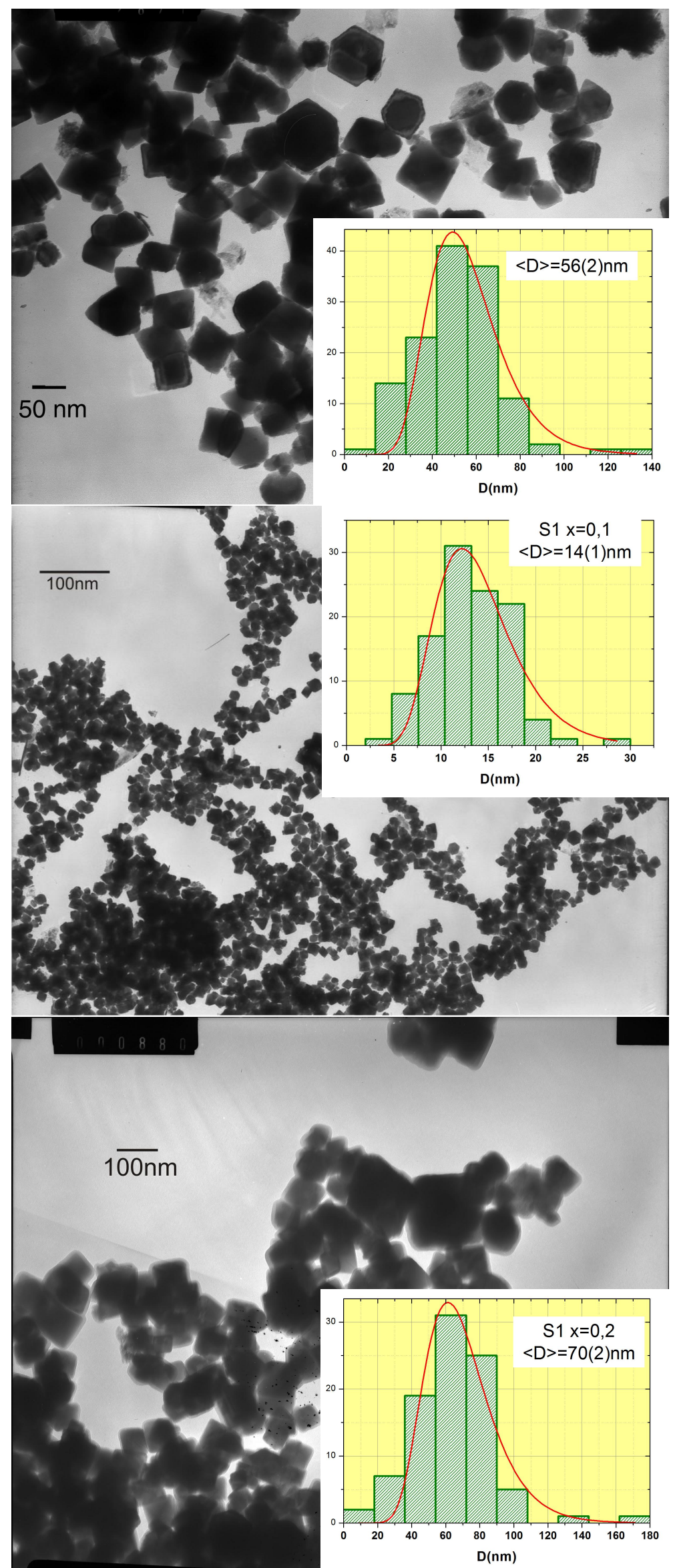

Figura 4.3: Imágenes TEM de las partículas $S 1: S 100$ (superior), $S 110$ (medio) y $S 120$ (inferior). Se observa la geometría cúbica y el recubrimiento orgánico. Distribución de tamaños inserta. 
Los ajustes con funciones normales y lognormales devuelven desviaciones estándar de hasta el $50 \%$ del valor medio. En este caso el acuerdo con los tamaños obtenidos por DRX es bueno aunque para S200, S220 y S220 y S230 se vuelve a observar un valor medio superior para las determinaciones TEM (fig. 4.4).

Las partículas S3 fueron observadas por SEM. Su obtención y análisis forma parte de la tesis de grado de la licenciada Patricia Quispealaya. Excepto por S300 que exhibe la misma geometría cúbica de las series anteriores, la serie se caracteriza por partículas poliédricas con gran cantidad de caras, hasta el punto de ser casi esféricas para algunas composiciones (fig. 4.5). Hay buena correspondencia entre los resultados SEM y DRX para la mayoría de las composiciones. En los casos en que las diferencias son grandes, estas se dan siempre a favor del tamaño SEM. Además de la cristalinidad incompleta, en este caso cabe mencionar que SEM tiene un resolución menor que TEM por lo que se podrían estar perdiendo las NPM más pequeñas, sobreestimando así el valor medio de la población.

La comparación entre los tamaños obtenidos por DRX y microscopía electrónica puede verse en la tabla 1. 


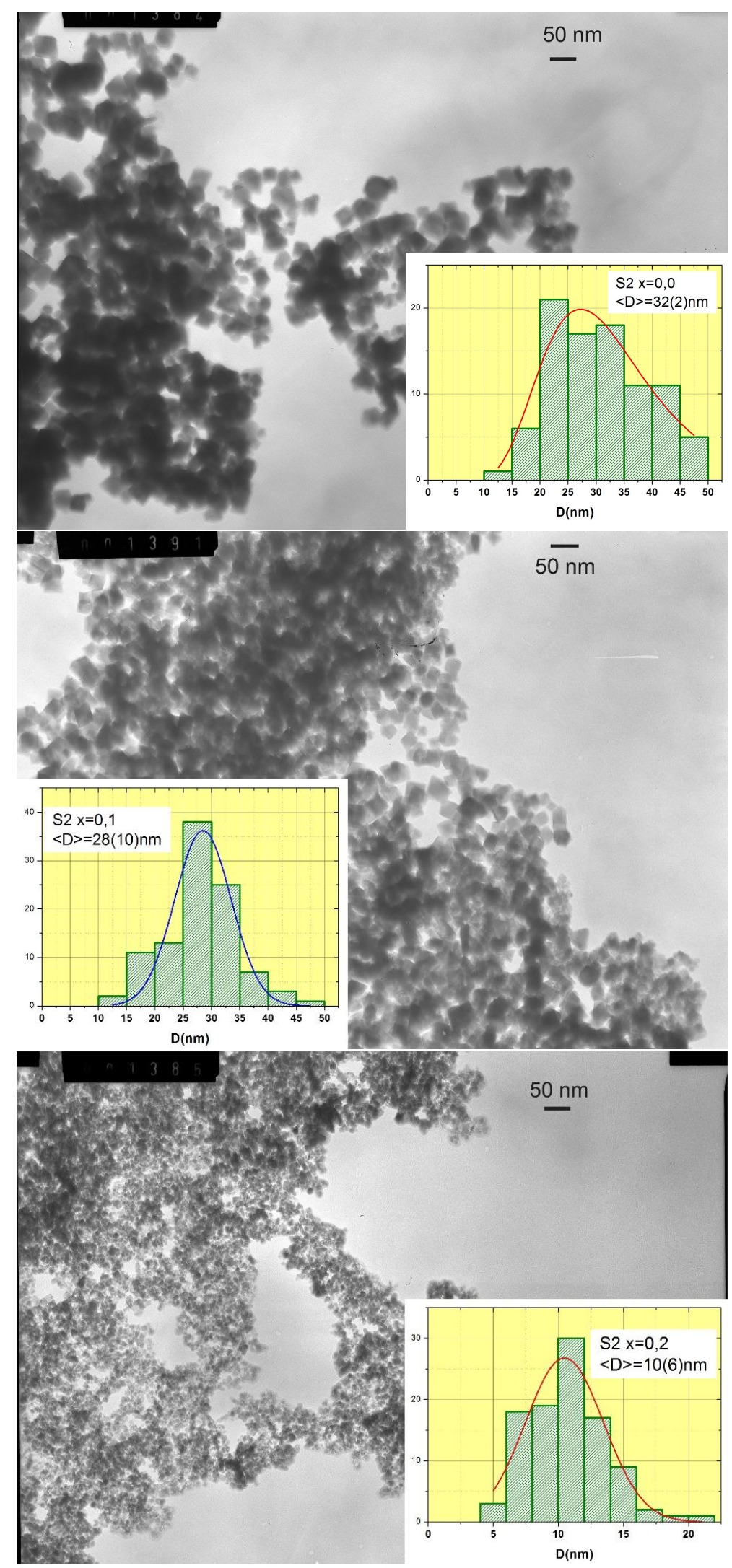




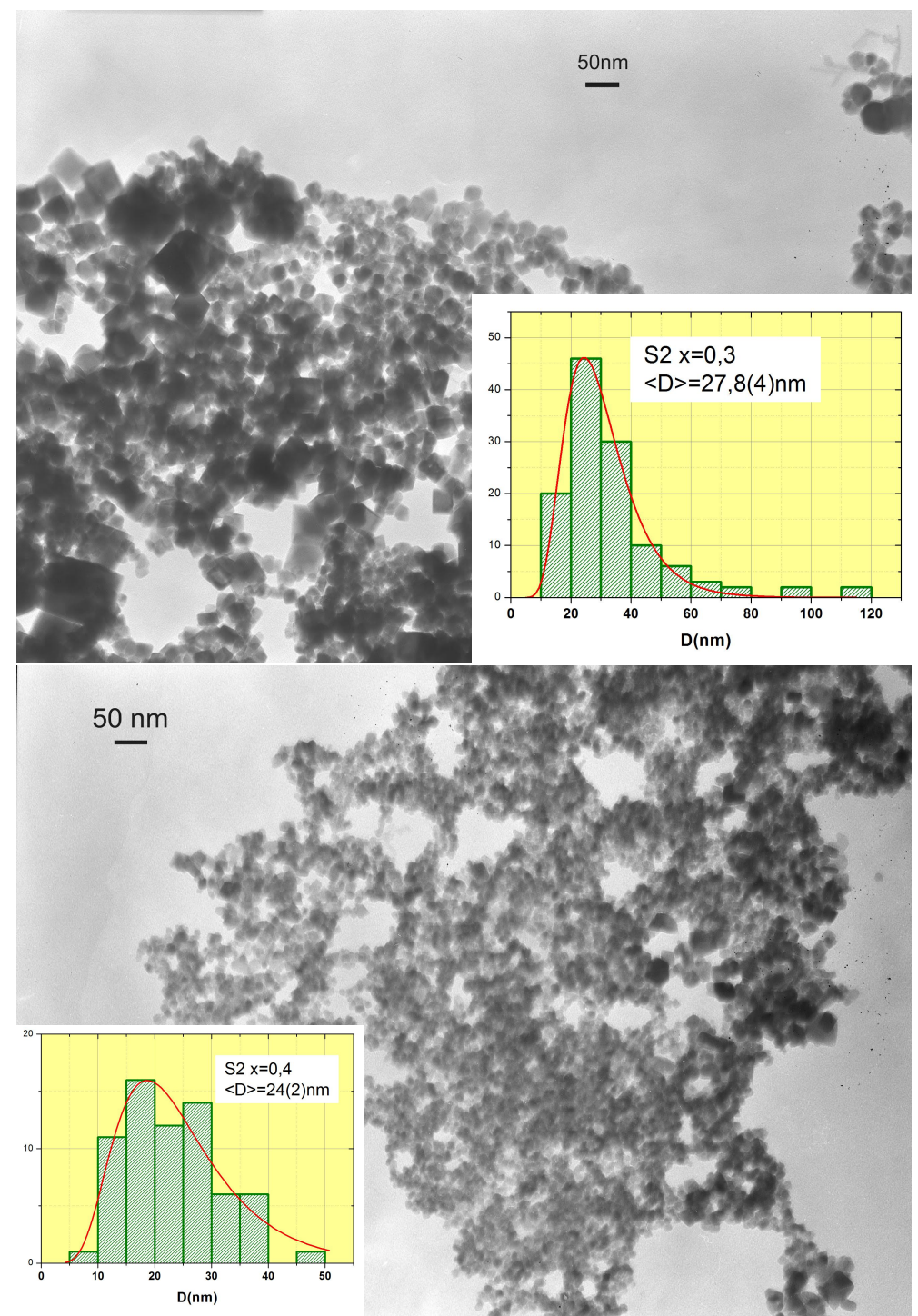

Figura 4.4: Imágenes TEM de las partículas S2 de S200 (superior pg. anterior) a S240 (sobre esta leyenda). 


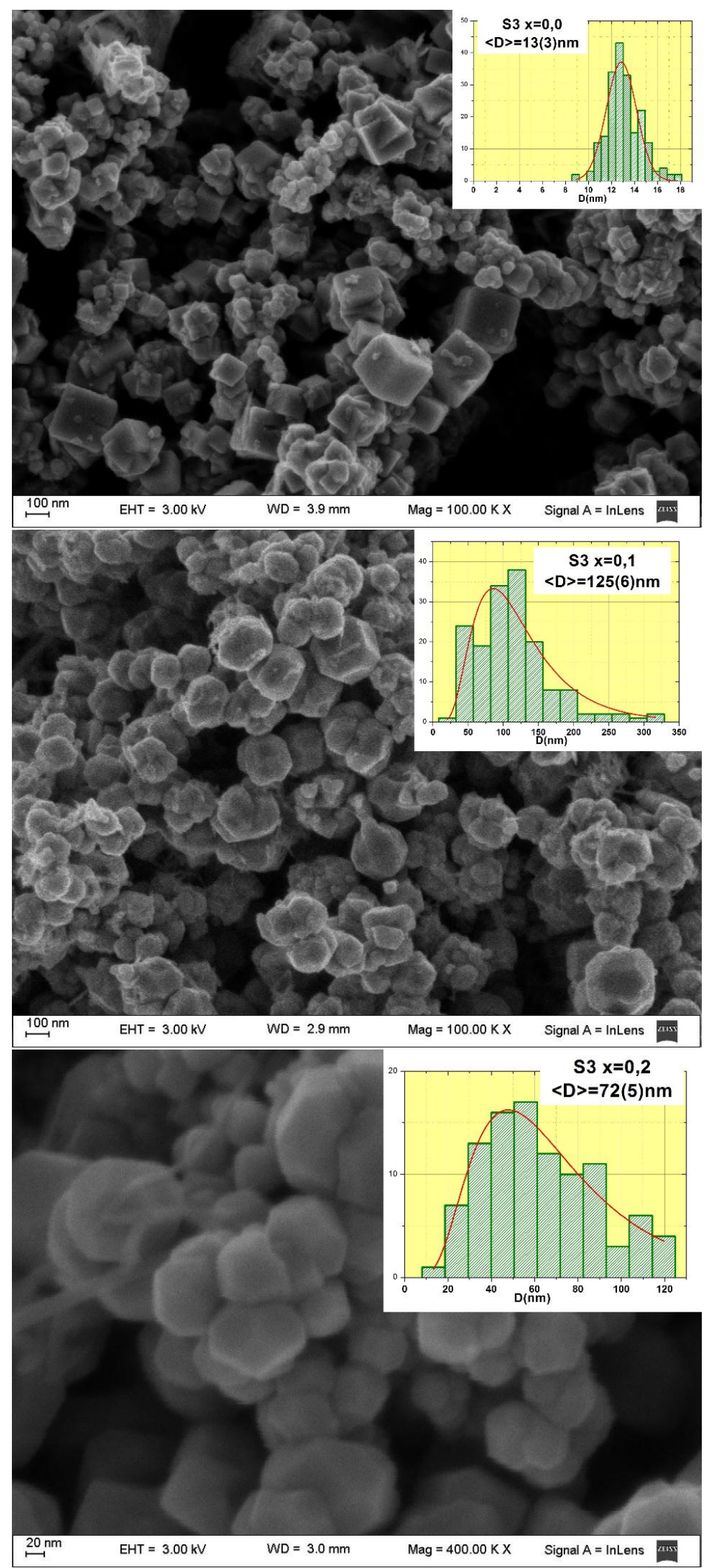



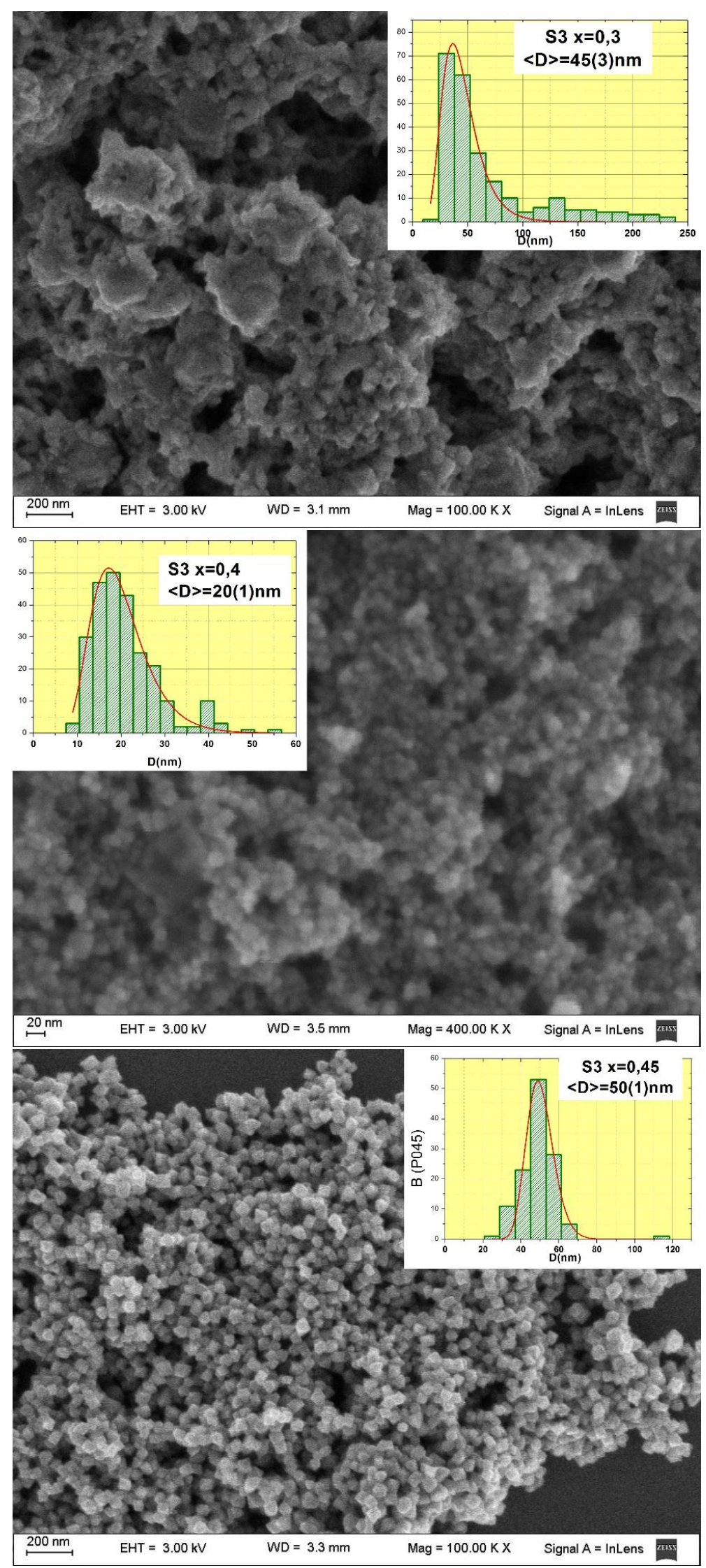


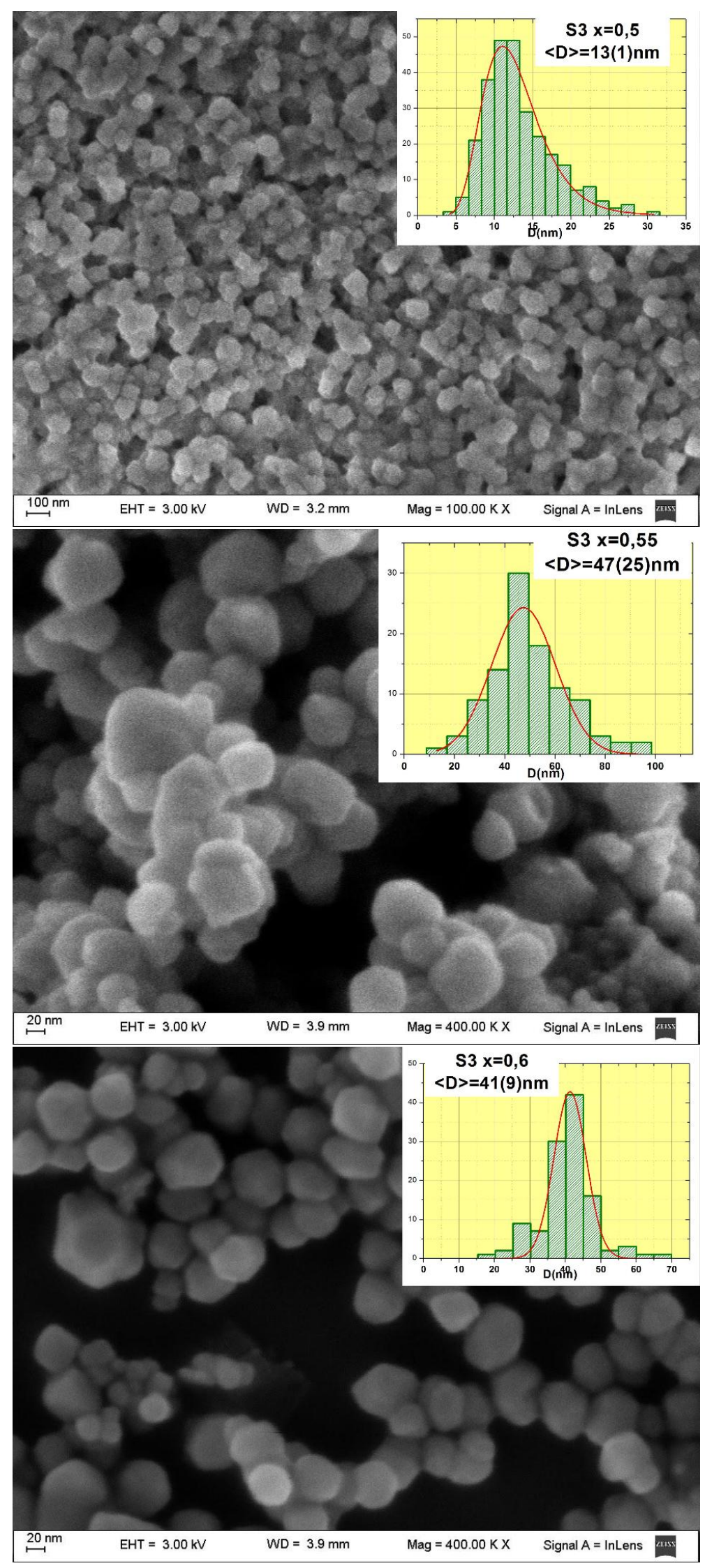



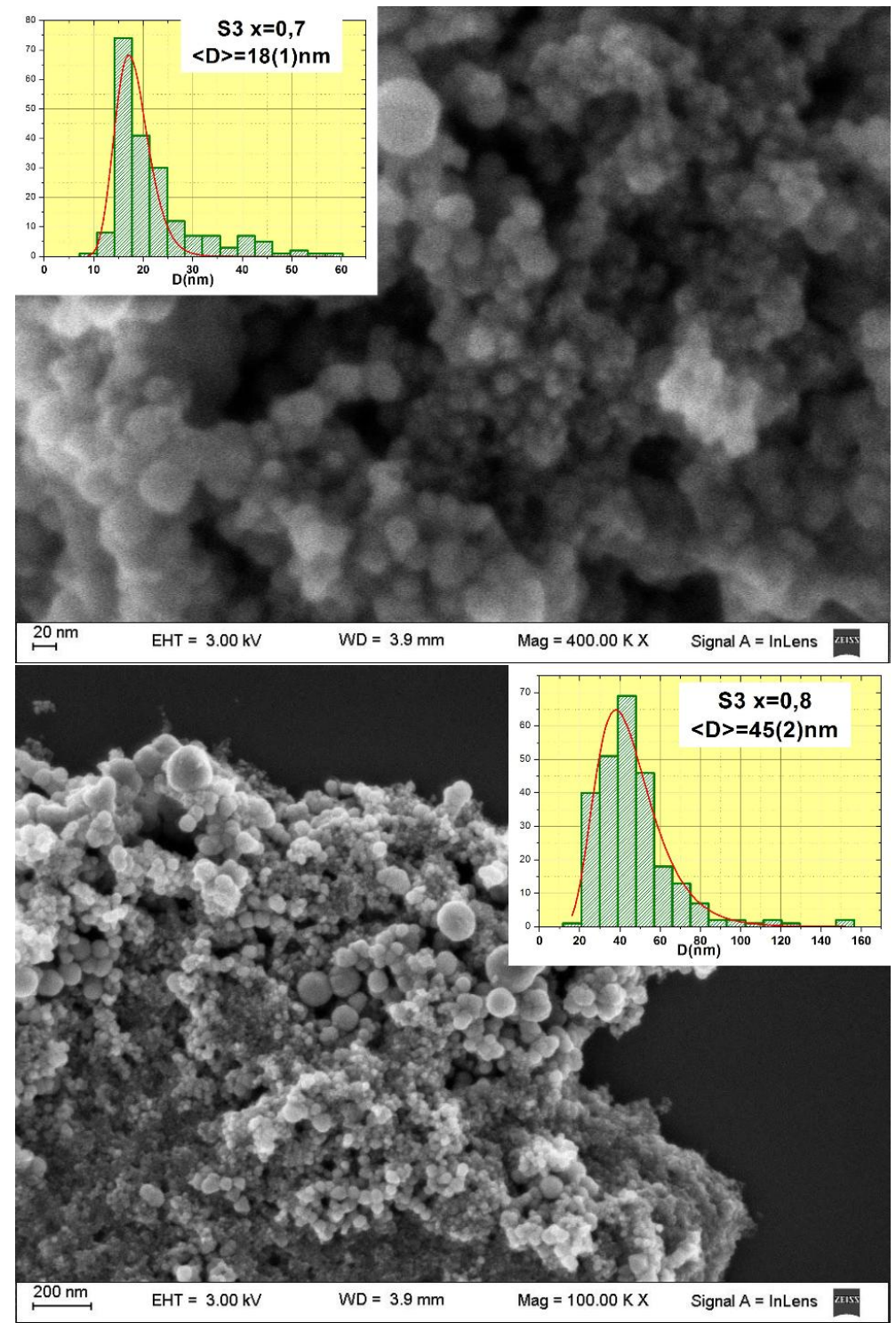

Figura 4.5: Imágenes SEM de las partículas $S 3$ de $S 300$ a $S 380$ (sobre estas leyenda). 


\begin{tabular}{|c|c|c|c|c|c|c|c|c|}
\hline Muestra & DRX (nm) & TEM (nm) & Muestra & DRX (nm) & TEM (nm) & Muestra & DRX (nm) & SEM (nm) \\
\hline $\mathbf{S 1 0 0}$ & $117(12)$ & $56(2)$ & $\mathbf{S 2 0 0}$ & $38(4)$ & $32(2)$ & $\mathbf{S 3 0 0}$ & $14(1)$ & $13(3)$ \\
\hline $\mathbf{S 1 1 0}$ & $65(7)$ & $14(1)$ & $\mathbf{S 2 1 0}$ & $16(3)$ & $28(10)$ & $\mathbf{S 3 1 0}$ & $62(6)$ & $125(6)$ \\
\hline $\mathbf{S 1 2 0}$ & $50(5)$ & $70(2)$ & $\mathbf{S 2 2 0}$ & $18(3)$ & $10(6)$ & $\mathbf{S 3 2 0}$ & $45(4)$ & $75(5)$ \\
\hline $\mathbf{S 1 3 0}$ & $30(3)$ & & $\mathbf{S 2 3 0}$ & $32(4)$ & $27.8(4)$ & $\mathbf{S 3 3 0}$ & $50(5)$ & $45(3)$ \\
\hline $\mathbf{S 1 4 0}$ & $27(3)$ & & $\mathbf{S 2 4 0}$ & $16(3)$ & $24(2)$ & $\mathbf{S 3 4 0}$ & $10(1)$ & $20(1)$ \\
\hline $\mathbf{S 1 5 0}$ & $25(3)$ & & $\mathbf{S 2 5 0}$ & $15(3)$ & & $\mathbf{S 3 4 5}$ & $32(3)$ & $50(1)$ \\
\hline & & & & & & $\mathbf{S 3 5 0}$ & $9,3(9)$ & $13(1)$ \\
\hline & & & & & & $\mathbf{S 3 5 5}$ & $33(3)$ & $47(25)$ \\
\hline & & & & & & $\mathbf{S 3 6 0}$ & $30(3)$ & $41(9)$ \\
\hline & & & & & & $\mathbf{S 3 7 0}$ & $15(2)$ & $18(1)$ \\
\hline & & & & & & $\mathbf{S 3 8 0}$ & $11(1)$ & $45(2)$ \\
\hline
\end{tabular}

Tabla 1:Comparación de tamaños obtenidos a partir de difracción de rayos X (DRX) y microscopía de electrones (TEM y SEM) para las distintas series. 


\subsubsection{Caracterización XAS}

Las series 1 y 2 fueron estudiadas por absorción de rayos X.

El espectro XANES del borde $\mathrm{K}$ del Zn se origina en la transición $1 \mathrm{~s} \rightarrow 4 \mathrm{p}$. El espectro de la magnetita de $\mathrm{Zn}$ completa $\mathrm{ZnFe} e_{2} \mathrm{O}_{4}$ presenta picos con energías 9664 eV (A en la figura 4.6), $9668 \mathrm{eV}$ (B), $9672 \mathrm{eV}$ (C), un hombro en 9677 (D) y una contribución extra a mayor energía (E).

Como se muestra en la figura 4.6, todos estos picos se encuentran en todos los espectros de ambas series. En particular, no se detecta un incremento apreciable del pico B que sería el efecto esperado de la sustitución del Fe por el Zn en los sitios octaédricos [38, 39].

Se observa un ligero corrimiento a mayores energías del pico B en las muestras S110 y S220, pero al aumentar el contenido de $\mathrm{Zn}$, el patrón XANES se asemeja al de $\mathrm{ZnFe}_{2} \mathrm{O}_{4}$. En contraste, las muestras $\mathrm{S} 2$ presentan el mismo espectro para todas las concentraciones de $\mathrm{Zn}$. Finalmente, la prominencia del pico D en todas las muestras S1 y S2 indicaría que la transición electrónica en el Zn implica principalmente sitios con simetría Td.

El espectro XANES del borde $\mathrm{K}$ del Fe se muestra en la figura 4.6. La estructura preborde proviene de la transición cuadrupolar $1 \mathrm{~s} \rightarrow 3 \mathrm{~d}$ y la transición dipolar $1 \mathrm{~s} \rightarrow 3 \mathrm{~d} / 4 \mathrm{p}$. En ambas series se observa una intensidad prepico notablemente mayor que la observada para $\mathrm{ZnFe}_{2} \mathrm{O}_{4}$ pero menor que la medida para $\mathrm{Fe}_{3} \mathrm{O}_{4}$ masiva. Esto indica la presencia de átomos de $\mathrm{Fe}$ ocupando tanto sitios B centrosimétricos como sitios A no centrosimétricos [39]. Las muestras sin dopar presenta una intensidad de picos correspondiente a una ocupación mayoritaria de los sitios A por parte de los iones Fe.

Las muestras S120, S130, S140, S220, S230 y S240 generan intensidades prepico similares mientras que las contribuciones menores de las muestras con $\mathrm{x}=0,5$ indicarían más iones $\mathrm{Zn}$ ocupando sitios A en reemplazo de los iones Fe. Por otro lado, el desplazamiento del borde hacia energías mayores es más pronunciado para S130, S140 y S150. Esto es compatible con una tendencia hacia un estado de oxidación 3+ cuando el Zn reemplaza progresivamente a los $\mathrm{Fe}^{2+}$ en los sitios A.

\subsubsection{Resultados Mössbauer}

La figura 4.7 muestra los espectros Mössbauer obtenidos a temperatura ambiente para las muestras S1 y S2. En ambas series se observa, al aumentar x, un cambio gradual desde el estado del material volumétrico a estados magnéticamente relajados y/o composicionalmente desordenados, i.e. las líneas de absorción se ensanchan mientras la contribución espectral central crece cuando el contenido de $\mathrm{Zn}$ aumenta.

Los espectros correspondientes a $\mathrm{x}=0,0$ presentan dos subespectros magnéticos bien resueltos, especialmente para la muestra $S 100(\mathrm{D}=117 \mathrm{~nm})$ con campos hiperfinos $B_{h f 1}=49,0(1) \mathrm{T}$ y $B_{h f 2}=46,0(1) \mathrm{T}$, corrimientos isoméricos $\delta_{1}=0,26(1) \mathrm{mm} / \mathrm{s}$ y $\delta_{2}=0,63(1) \mathrm{mm} / \mathrm{s}$ y desdoblamiento cuadrupolar prácticamente nulo. Esto parámetros presentan un buen acuerdo con los reportados para magnetita volumétrica[40].

El sextete de líneas más angostas con mayor $B_{h f}$ y menor $\delta$ se asocia a iones $\mathrm{Fe}^{3+}$ de alto espín ocupando sitios A, mientras que el restante se asigna a iones $F e^{3+} / F e^{2+}$ en sitios B. 

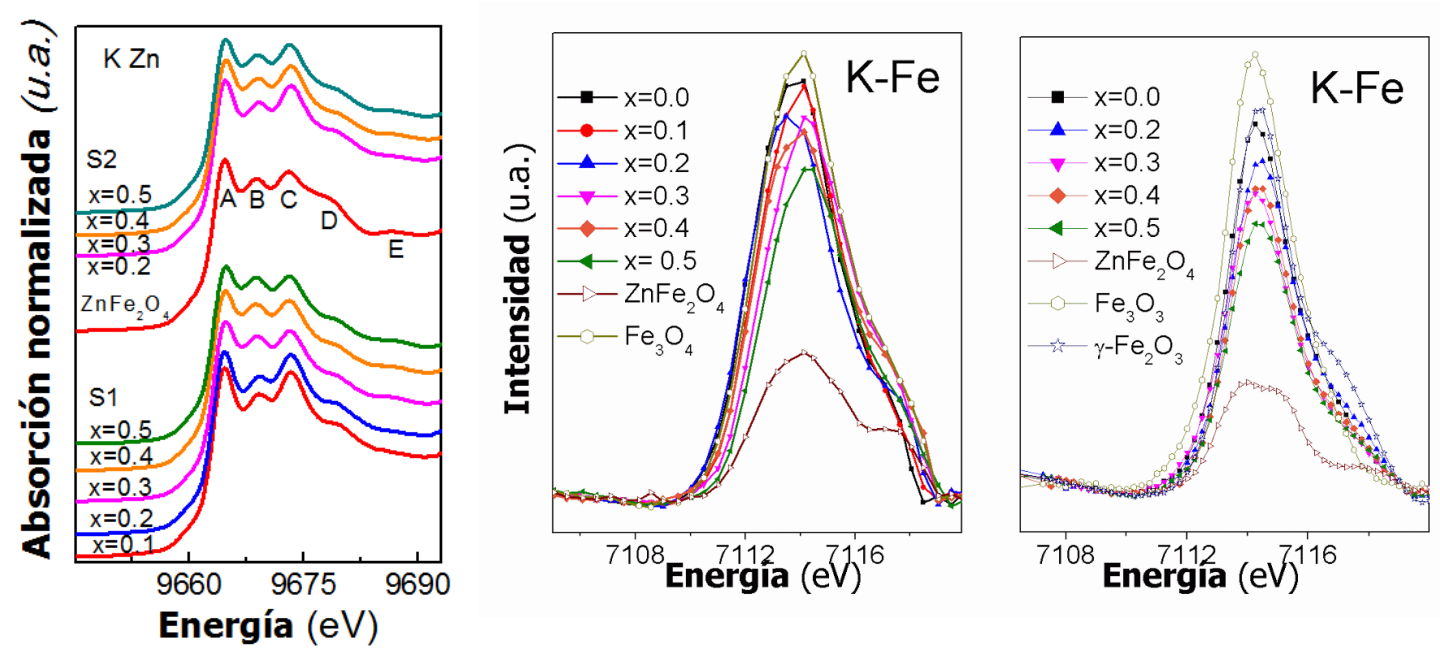

Figura 4.6: Espectro XANES en el borde $K$ del Zn y del Fe para $S 1$ y $S 2$.

Se observa un ensanchamiento de la distribución de Bhf en los sitios B como consecuencia de la incorporación gradual de $\mathrm{Fe}^{2+}$ en los sitios $\mathrm{A}$ y la aparición de diferentes configuraciones de iones metálicos alrededor de los sitios B.

Los espectros fueron ajustados suponiendo picos con forma Voigtiana (distribución gausiana con dispersión variable $\sigma$ de picos lorentzianos con un ancho de $0,21 \mathrm{~mm} / \mathrm{s}$ constante). Se obtuvo un ajuste consistente de todos los espectros considerando:

- Una interacción magnética asociada a los sitios A. Dos interacciones asociadas a los sitios B con diferente ancho de distribución pero con la restricción de tener la misma correlación entre los parámetros hiperfinos.

- Un sextete parcialmente resuelto asociado a sondas Fe con un tiempo de relajación $\tau \sim 1 / f_{L}$ (componente de relajación lenta). Un doblete asociado a sondas con $\tau<1 / f_{L}$ (componente de relajación rápida) siendo $f_{L}$ la frecuencia de Larmor.

La influencia del tamaño de partícula en la forma del espectro se puede distinguir del efecto de la concentración de $\mathrm{Zn}$ considerando los siguientes argumentos: la reducción del tamaño de partícula aumenta los efectos de la relajación debido a la reducción de la barrera de energía de anisotropía magnética que separa las dos direcciones preferenciales de magnetización. El agregado de $\mathrm{Zn}$ aumenta los efectos de relajación debido al debilitamiento de la interacción de intercambio entre sitios A y B. Además, produce un ensanchamiento de los picos debido al aumento del desorden químico, especialmente alrededor de los iones Fe en los sitios B.

Debido a los efectos de tamaño, los espectros de S1 están mejor resueltos que los de S2 para todas las composiciones. En S2, los efectos de la relajación son más notorios para S220 (18(3) $\mathrm{nm})$ que para S230 (32(4) $\mathrm{nm}$ ) lo que indicaría que los efectos de tamaño son mayores que los 


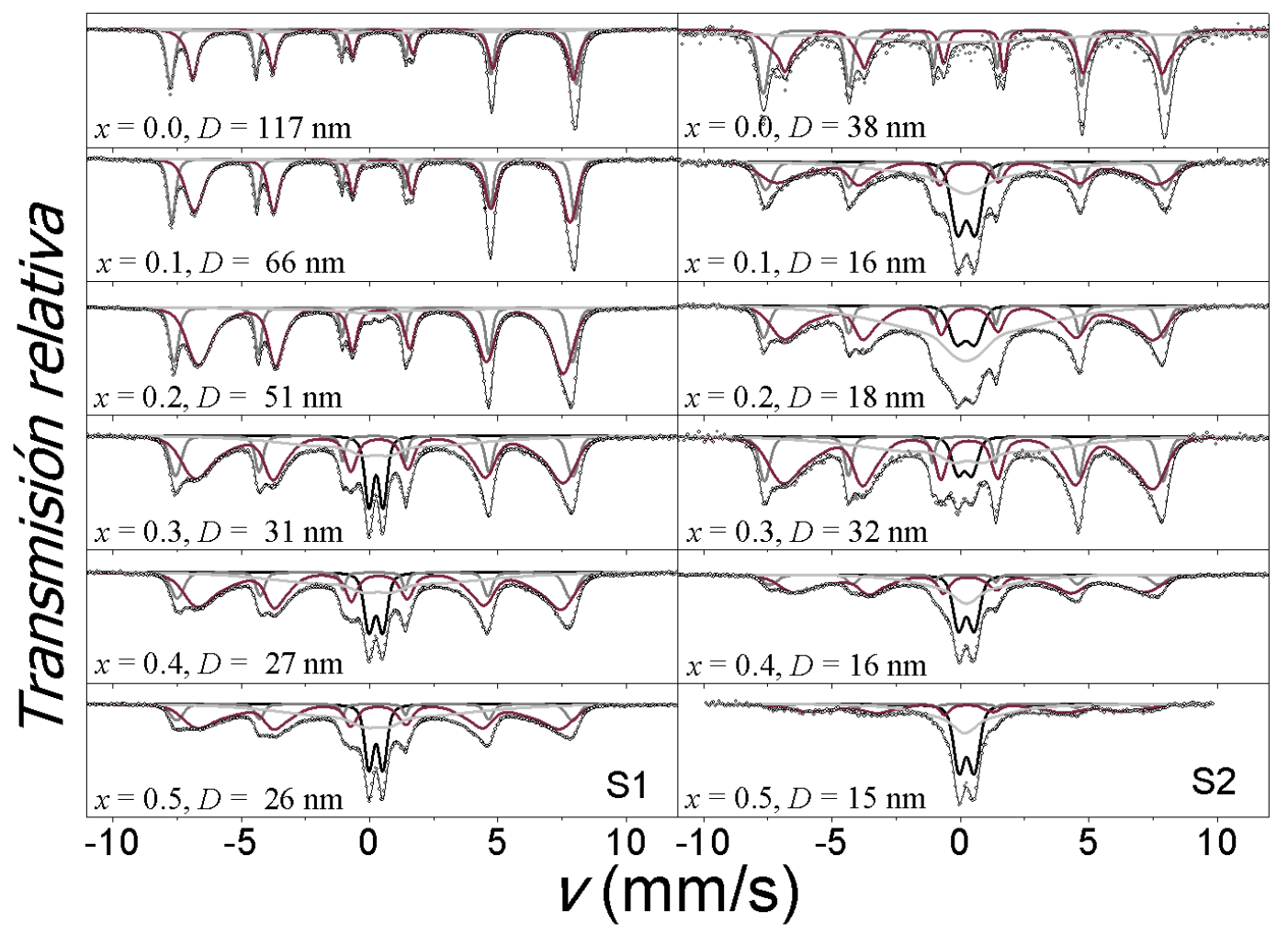

Figura 4.7: Espectros Mossbauer a temperatura ambiente de $S 1$ y $S 2$. Datos experimentales (línea punteada) ,ajustes (línea negra)y componentes espectrales: espinela sitio B (línea gris oscura delgada), espinela sitio A (gris intermedia), relajación lenta (gris claro) y relajación rápida (línea negra gruesa). Cada muestra está identificada por su contenido de zinc $x$ y su tamaño medio de cristalita $D$. 


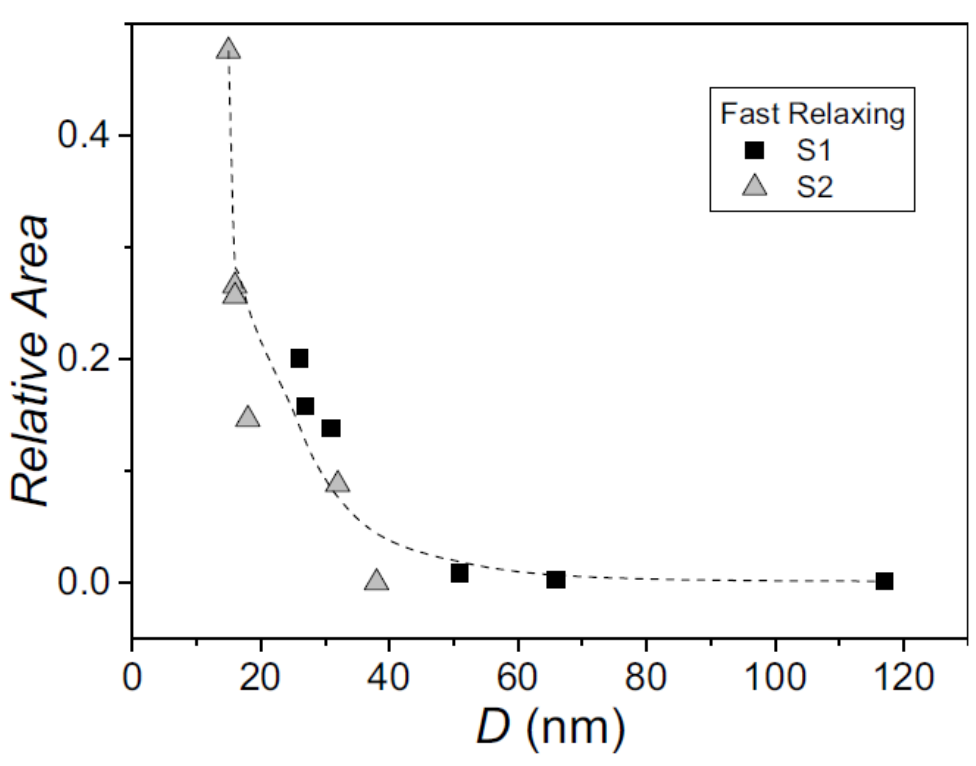

Figura 4.8: Área Mossbauer relativa normalizada de la contribución de los sitios de relajación rápida en función del tamaño de cristalita para $S 1$ y $S 2$. La normalización se realizó respecto a la suma de las contribuciones de relajación rápida y no relajadas. La línea punteada es una guía para el ojo.

efectos de la incorporación de Zn. Una característica común a ambas series es que las muestras con tamaños medios menores a $32 \mathrm{~nm}$ presentan una importante componente relajada. El tamaño al que la componente bien resuelta y la componente de relajación rápida contribuyen con áreas similares define el tamaño medio de bloqueo $D_{B}$ para esta técnica y se encuentra en torno de los 14 nm (figs. 4.7 y 4.8). Para realizar esta estimación se consideró que las componentes de relajación lenta corresponden a partículas con un tamaño cercano a $D_{B}$.

La ventana de tiempo del efecto Mössbauer está dada por $1 / f_{L}$. Se consideró sólo el mecanismo de relajación de Nèel dado que el de Brown es imposible en muestra sólida. Usando $K=1,89 \times 10^{4} \mathrm{~J} / \mathrm{m}^{3}[43]$, se estimó el tamaño de bloqueo del núcleo magnético de las NPM en

$$
D_{C}=\left[(k T / K) \ln \left(1 / f_{L} \tau_{0}\right)\right]^{1 / 3} \approx 9,5 n m .
$$

A partir de su campo hiperfino $B_{h f}$, se puede estimar que para ${ }^{57} \mathrm{Fe}$ en magnetita volumétrica $f_{L} \sim 30 \times 10^{6} \mathrm{~Hz}$. Suponiendo una capa superficial magnéticamente muerta de espesor [2,0; $2,5] \mathrm{nm}[44,45,46]$, se puede obtener un tamaño $D \sim D_{c}+t$ en torno de $14 \mathrm{~nm}$ consistente con la estimación previa. Este acuerdo apoya la elección de los valores numéricos de $\tau_{0} \mathrm{y} \mathrm{K}$ por lo que se utilizaron luego para el tratamiento de datos en los estudios SAR.

Cuando aumenta x y/o disminuye $\mathrm{D}$, se observa que:

- Las áreas relativas de la componente bien resuelta originada por los Fe en sitios A disminuye.

- $B_{h} f$ decrece más rápido en los sitios $\mathrm{B}$ que en los sitios A (fig. 4.9).

- La componente de relajación rápida disminuye monótonamente con el tamaño a partir 


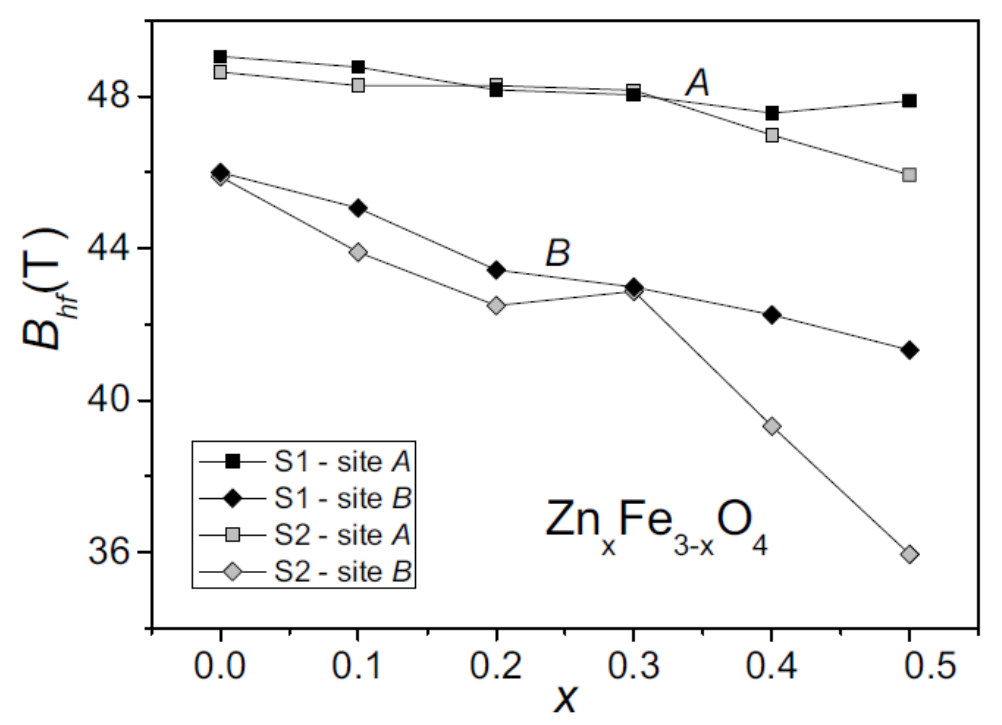

Figura 4.9: Valores medios de $B_{h} f$ para las contribuciones de los sitios A y B en función de x para $S 1$ y $S 2$.

de $38 \mathrm{~nm}$ (fig. 4.7). Para $D>38 \mathrm{~nm}$ el peso relativo de las dos componentes relajadas se encuentra en torno del $12 \%$ y corresponde casi exclusivamente a la componente de relajación lenta.

- Los parámetros hiperfinos correspondientes a los sitios B se ven fuertemente afectados por la incorporación de Zn y sus líneas se ensanchan notoriamente con x (fig. 4.7).

En las muestras con $x \geq 0,3$ o $D \leq 32 \mathrm{~nm}$, dominan los efectos de relajación. La componente de relajación lenta aumenta fuertemente mientras que aparece y crece el doblete central con con un desdoblamiento cuadrupolar de $\Delta=0,54 \mathrm{~mm} / \mathrm{s}, \delta=0,35 \mathrm{~mm} / \mathrm{s}$ y $\sigma=0,24 \mathrm{~mm} / \mathrm{s}$ (fig. 4.9).

El campo hiperfino decrece con $\mathrm{x}$ en ambos sitios aunque más intensamente en los sitios B (fig. 4.9). La coexistencia de contribuciones con desdoblamiento magnético y contribuciones con doblete indica la presencia simultánea de NPM bloqueadas y desbloqueadas en cada muestra. Este análisis en términos de partículas bloqueadas y desbloqueadas es consistente con la estimación teórica de la máxima dimensión lineal para nanopartículas de magnetita monodomio en torno de los $130 \mathrm{~nm}[47]$.

Se puede denotar la distribución de iones al incorporar $\mathrm{Zn}$ en los sitios A [48] $\operatorname{como}\left(\mathrm{Zn}_{x}^{2+} \mathrm{Fe} \mathrm{e}_{1-x}^{3+}\right) \mathrm{A}$ $\left[\mathrm{Fe}_{1-x}^{2+} \mathrm{Fe}_{1+x}^{3+}\right]_{B} \mathrm{O}_{4}^{2-}$. Como cada $\mathrm{Fe}$ en un sitio $\mathrm{B}$ tiene seis primeros vecinos en sitios $\mathrm{A}$, la forma de línea Mössbauer puede ser considerada una superposición de componentes provenientes de las distintas configuraciones de primeros vecinos en los sitios A . La incorporación de cada $Z n^{2+}$ en un sitio A rompe cuatro caminos de supertintercambio $F e[A]-O-F e[B]$. Por cada camino A-B roto, el campo hiperfino en los sitios B afectados decrece y provoca un ensanchamiento en la componente espectral correspondiente. En contraste, se espera que el efecto sobre el campo en los sitios A sea mucho menor debido a la menor contribución de estos al superintercambio[49]. Por lo tanto, la reducción del valor medio del campo hiperfino en B, el 


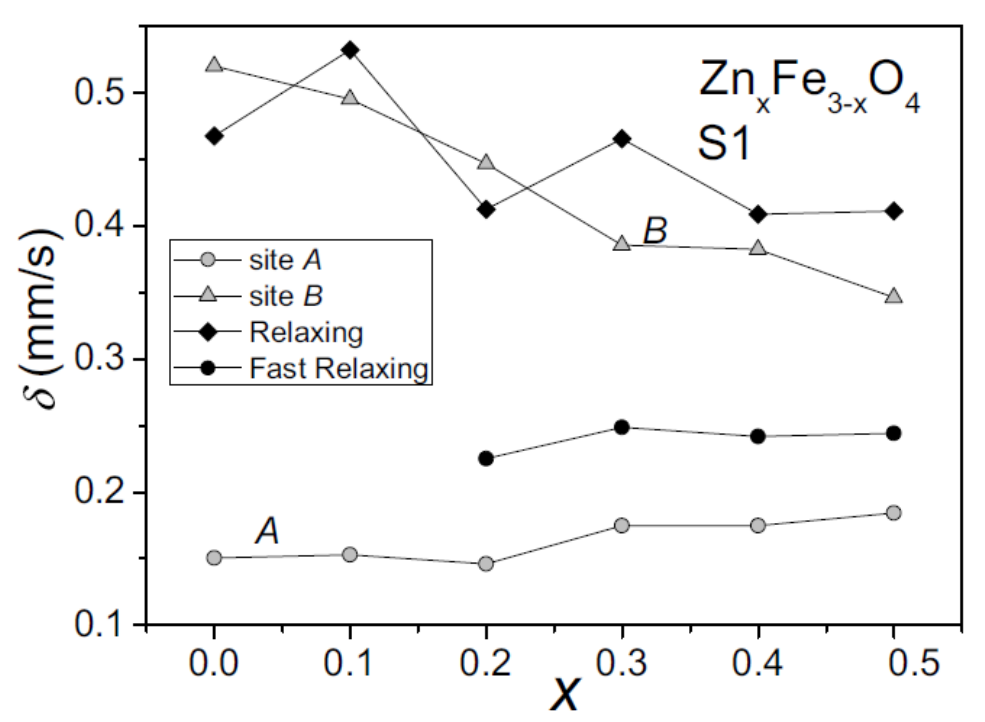

Figura 4.10: Valores del corrimiento isomérico $\delta$ en función de $x$ para $S 1$.

ensanchamiento de sus picos y la disminución en el área relativa de la contribución A con el dopaje pueden ser asociados con la inclusión de $Z n^{2+}$ en los sitios A en reemplazo de iones $\mathrm{Fe}^{3+}$. Para mantener la neutralidad de carga deben generarse algunas vacancias de oxígeno $\mathrm{o}$ bien algunos $\mathrm{Fe}^{2+}$ deben transformarse en $\mathrm{Fe}^{3+}$ como se propone en la bibliogafía [50]. En la figura 4.10 se observa que mientras $\delta_{A}$ permanece casi constante al incorporar $\mathrm{Zn}$, el valor medio de $\delta_{B}$ decrece monótonamente desde $0,52 \mathrm{~mm} / \mathrm{s}$ hasta $0,35 \mathrm{~mm} / \mathrm{s}$. Este comportamiento es consistente con un aumento en la fracción de iones Fe en los sitios B que cambian su valencia de $+2 \mathrm{a}+3$. Los valores de $\delta$ correspondientes a la contribución con relajación lenta son similares a los de los $\mathrm{Fe}$ en sitios $\mathrm{B}$ para todo el rango de concentración de $\mathrm{Zn}$ mientras que la componente de relajación rápida presenta valores intermedios entre $\delta_{A}$ y $\delta_{B}$. El comportamiento de $\delta$ mostrado en la figura 4.10 indica que las componentes de relajación lenta y rápida corresponden a los Fe en sitios B, y en los sitios A y B respectivamente. Usando los valores de $\delta$ se estimó la fracción relativa de Fe en sitios A y B. Estos resultados se muestran en la figura 4.11. Para $\mathrm{x}=0,0$ la relación $\mathrm{B} / \mathrm{A}$ es cercana a 2, el valor esperado para la estructura $\mathrm{Fe}_{3} \mathrm{O}_{4}$. Las fracciones relativas calculadas suponiendo que los iones $\mathrm{Zn}$ sólo se ubican en los sitios A se muestran en linea intermitente en la figura 4.11 que muestra un buen acuerdo con los datos experimentales. Las contribuciones relajadas son originadas por el comportamiento superparamagnético de las NPM de menor tamaño cuya fracción presenta en promedio una tendencia creciente al disminuir aumentar x. Como se dijo antes, la relajación puede estar originada también por la interrupción de los caminos de superintercambio A-B debida a la presencia de los iones no magnéticos de $\mathrm{Zn}$ en los sitios A. Esto, junto con la distribución aleatoria de los iones Zn, provocaría agregados magnéticos con relajación de espín y superparamagnetismo.

\subsubsection{Análisis magnético}

Se relevó la dependencia de la magnetización M con el campo H a $300 \mathrm{~K}$ para todas las muestras (fig. 4.12). 


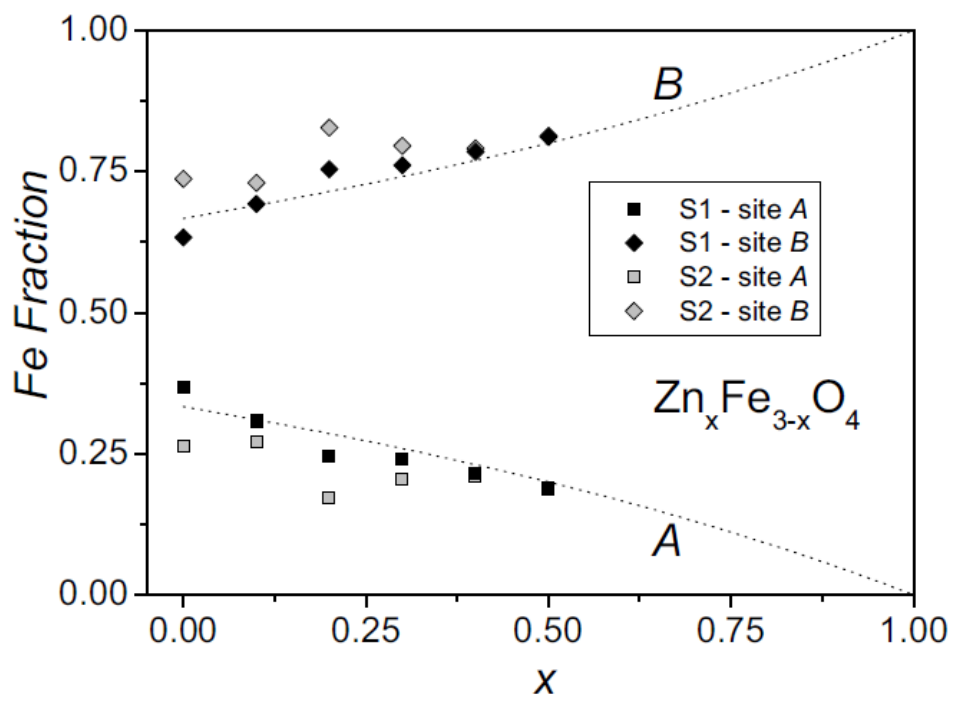

Figura 4.11: Fracción de $\mathrm{Fe}$ en $\operatorname{los}$ sitios $A$ y $B$ en función de $x$ para $S 1$ y $S 2$ obtenidos a partir del análisis Mössbauer. Las líneas segmentadas representan las fracciones calculadas considerando que el Zn sólo se ubica en los sitios A.
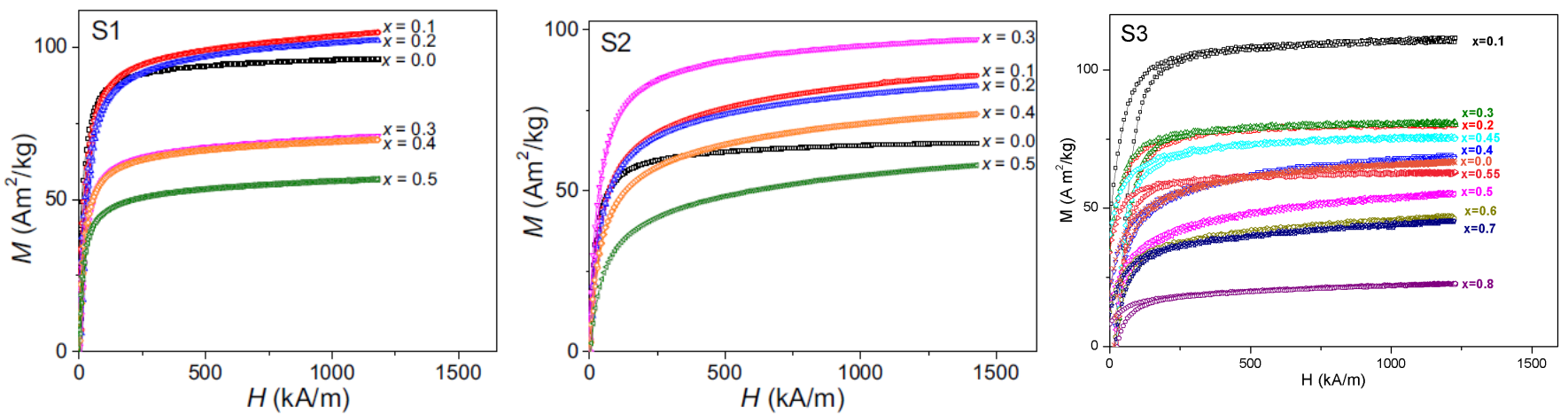

Figura 4.12: Magnetización en función del campo para todas las muestras a temperatura ambiente. Para mayor claridad se muestras sólo los datos del primer cuadrante. Se observa un comportamiento SPM para S1 y S2 y con coercitividad pequeña para $S 3$. 


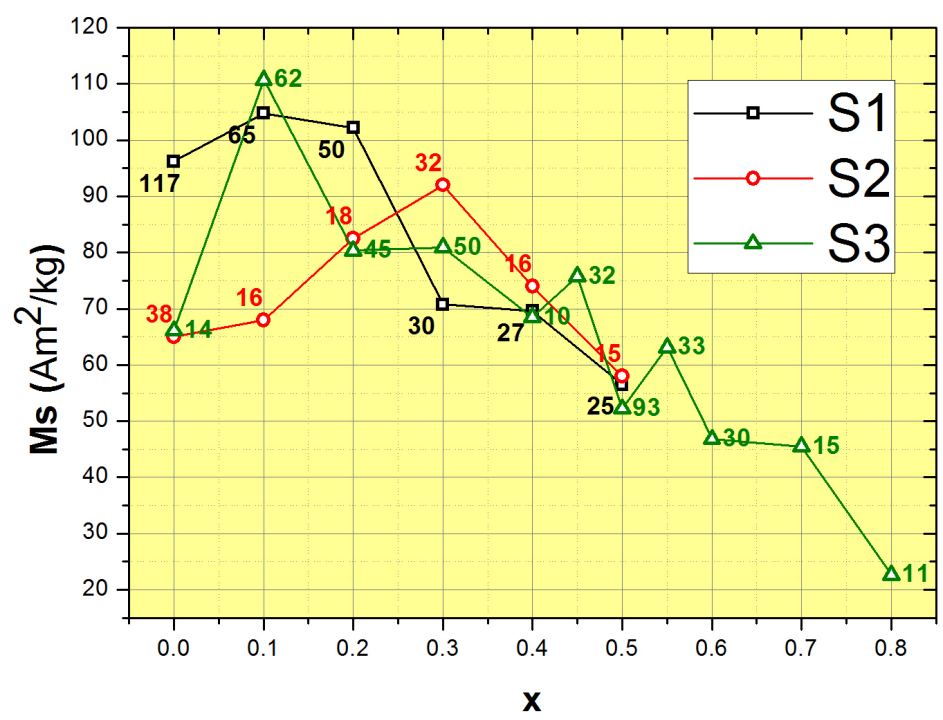

Figura 4.13: Dependencia de la magnetización de saturación $M_{s}$ en función del contenido de Zn x para todas las series. Se observa el aumento inicial y la disminución para grandes concentraciones de Zn predicho por la teoría de sustitución mencionada. Se indica el tamaño medio en nm para cada muestra.

Se observa una modificación de la respuesta ferrimagnética con el agregado de Zn. En las series 1 y 3 la mayor magnetización de saturación $M_{s}$ corresponde a las muestras con x=0,1 mientras que para la serie 2 esto ocurre para $\mathrm{x}=0,3$. En todos los casos, luego de alcanzar el máximo la tendencia es decreciente.

El campo coercitivo se comporta de manera similar a $M_{s}$ en las series 1 y 2 mientras que la progresión es errática en la serie 3 (fig. 4.13).

El aumento de $M_{s}$ como efecto del dopaje se puede entender en términos de la modificación del balance ferrimagnético al eliminar la cancelación de superintercambio entre momentos de $\mathrm{Fe}^{3+}$ en sitios A y B vecinos. El momento por celda unidad pasa de $4 \mu_{B}$ a $10 \mu_{B}$ al incorporar el Zn. Por otro lado, la disminución de $M_{s}$ pasado el máximo se debería mayoritariamente al efecto composicional de la disminución de la población de Fe en los sitios A y B que se traduce en una disminución del momento promedio. A dopajes aún mayores se suma la disminución de la interacción B-B cuando la ocupación de Zn en los sitios A es suficientemente alta. En las tres series, el comportamiento de $M_{s}$ en función de $x$ se asemeja al de $D$ (fig. 4.2) por lo que es posible que el efecto de la composición en $M_{s}$ sea más importante para $x \geq 0,3$ en donde la variación de tamaño es menos pronunciada.

\subsubsection{Disipación de potencia}

Para caracterizar la disipación de potencia de las NPM, se realizaron medidas de temperatura $\mathrm{T}$ vs. tiempo t para todas las muestras, a diferentes concentraciones, aplicando un campo de frecuencia $f=260 \mathrm{kHz}$ y amplitud $H_{0} \leq 45 \mathrm{kA} / \mathrm{m}$. En todos los casos, la temperatura aumentó linealmente con el tiempo pudiendo obtenerse la tasa de calentamiento mediante el ajuste de 

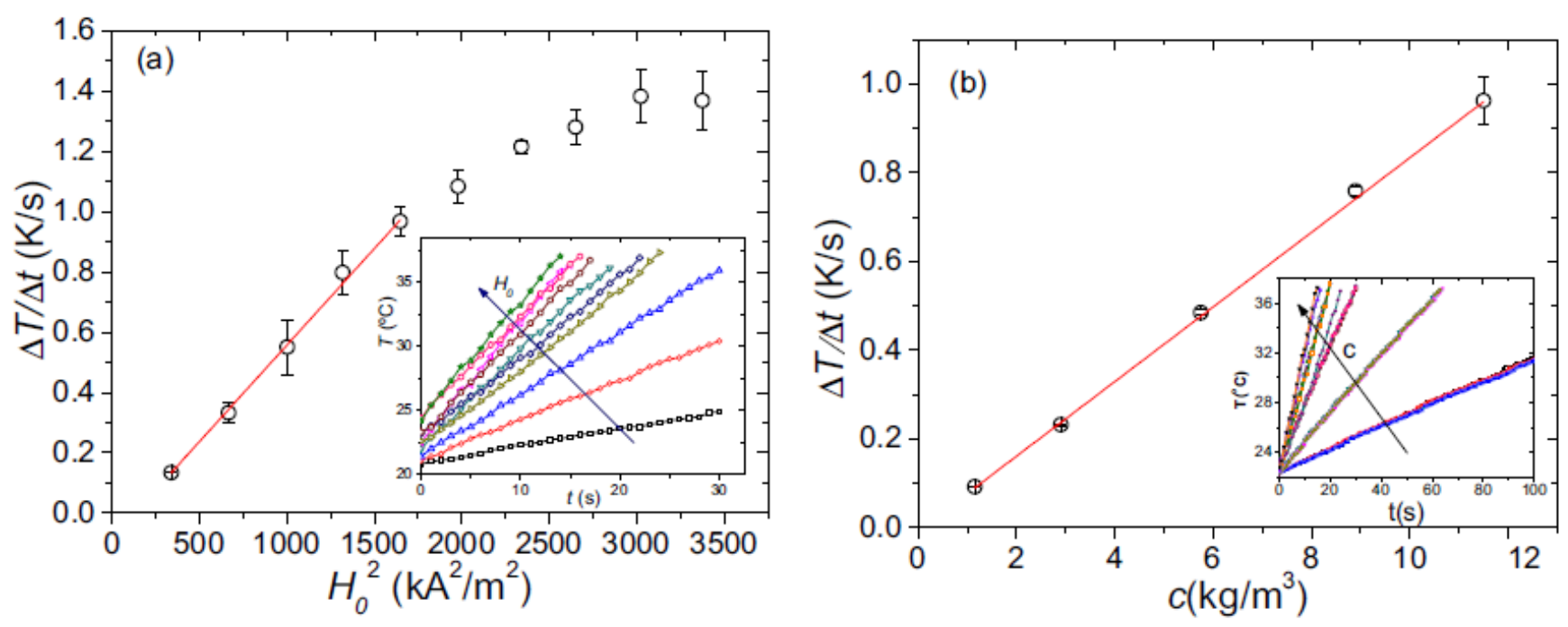

Figura 4.14: (a)Pendientes $d T / d t$ en función de el cuadrado de la amplitud de campo $H_{0}^{2}$ para la muestra $S 220$. Se observa un efecto de saturación para $H_{0}>40 \mathrm{kA} / \mathrm{m}$ que marca el límite de validez para la teoría de respuesta lineal.(b) $d T / d t$ en función de la concentración de NPM en el FF para la muestra $S 210$. Se observa linealidad en todo el rango medido. Insertos: curvas $T(t)$ de las que se obtuvieron las pendientes correspondientes.

una recta (fig. 4.14).

La dependencia de la pendiente de calentamiento (proporcional al SAR) con el cuadrado del campo conserva la linealidad predicha por la ecuación 2.12 para $H_{0}<40 \mathrm{kA} / \mathrm{m}$. Más allá de ese valor, se observa el amesetamiento originado por la saturación de los ciclos de magnetización predicho por las simulaciones del capítulo 2 y usualmente reportado en bibliografía (fig. 4.14).

La dependencia de la pendiente de calentamiento con la concentración mantuvo la linealidad en todo el rango medido, indicando la ausencia de interacción entre NPM a las concentraciones de trabajo (fig. 4.14).

En la figura 4.15 se muestran los valores de SAR para cada serie bajo un campo de amplitud $H_{0}=40 \mathrm{kA} / \mathrm{m}$ y frecuencia $f=260 \mathrm{kHz}$.

Para S1, la tendencia es monótona y con cierta correlación con el tamaño de partícula (fig. 4.2). El valor más alto de SAR corresponde a la muestra $S 100(\mathrm{D}=117(12) \mathrm{nm})$ con $323(5) \mathrm{W} / \mathrm{g}$. El ILP correspondiente es de $5,7 \times 10^{-4} \mathrm{~m}^{3} / \mathrm{s} A$, un valor bajo comparado con lo reportado para sistemas similares [128]. La gran dispersión de tamaños de estas muestras es posiblemente la principal causa de este bajo rendimiento dado que sólo una pequeña porción de la masa de muestra considerara se encuentra disipando en condiciones óptimas.

Los valores de SAR para S2 son erráticos, sin tendencia clara, con un pronunciado máximo de $367(20) \mathrm{W} / \mathrm{g}$ para la muestra S210 ( $\mathrm{D}=16(3) \mathrm{nm})$.

La serie 3 muestra un máximo de aproximadamente $280 \mathrm{~W} / \mathrm{g}$ para las muestras $\mathrm{S} 345(\mathrm{D}=32(3)$ $\mathrm{nm}), \mathrm{S} 355(\mathrm{D}=33(3) \mathrm{nm})$ y $\mathrm{S} 360(\mathrm{D}=30(3) \mathrm{nm})$ lo que apoya nuevamente la idea de que la disipación está principalmente dominada por efectos de tamaño.

Para revelar el efecto del tamaño sobre la disipación de potencia, se normalizaron todos los valores de SAR dividiendo por el factor $H_{0}^{2} M_{S}^{2} V$ de manera de obtener una cantidad propor- 


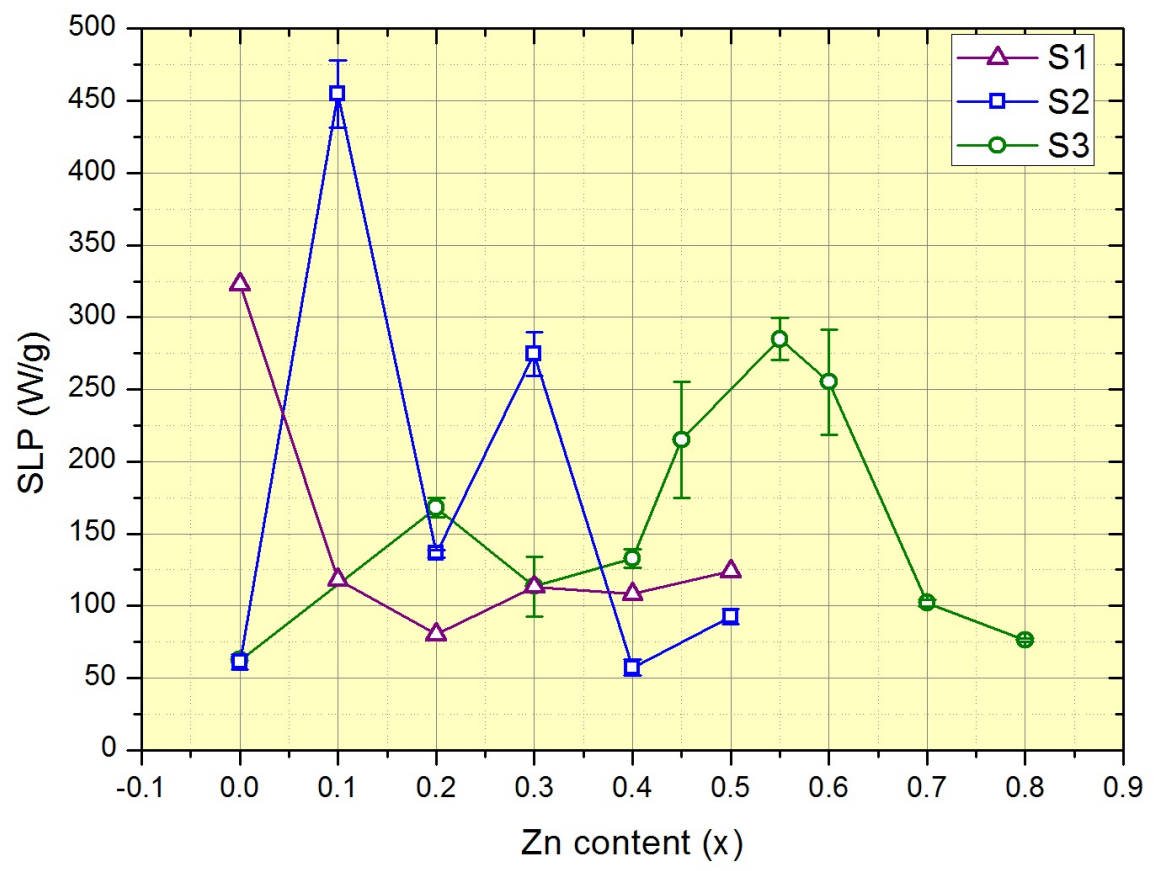

Figura 4.15: Resultados de potencia específica disipada en función del contenido de Zn x bajo un campo de amplitud $H_{0}=40 \mathrm{kA} / \mathrm{m}$ y frecuencia $f=260 \mathrm{kHz}$. Se observan diferentes comportamientos para cada serie.

cional al factor de frecuencia $\omega \tau /\left(1+(\omega \tau)^{2}\right)$ según dicta la ecuación 2.12. Esta cantidad fue normalizada a 0,5 que es el máximo valor que puede tomar el factor de frecuencia. Los valores obtenidos se muestran en la figura 4.16 donde se puede observar el comportamiento sistemático de todo el conjunto de muestras. Estos datos fueron analizados considerando la posibilidad de que presentaran los procesos de relajación de Nèel y Brown, determinando el $\tau$ efectivo a través de la ecuación 2.15. Para el primero se consideraron los valores de $K$ y $\tau_{0}$ consistentes con el análisis de los resultados Mössbauer $\left(K=1,89 \times 10^{4} \mathrm{~J} / \mathrm{m}^{3}, \tau_{0}=10^{-9} \mathrm{~s}\right)$. Para el mecanismo de Brown se consideraron valores de $\eta$ entre $1 \times 10^{-3}$ y $6 \times 10^{-3}$ Pas. Como se observa en la figura 4.17 se logra una razonable descripción del comportamiento del factor de frecuencia en función del diamétro de las NPM, encontrándose el mejor acuerdo con $\eta=2 \mathrm{mPa}$, un valor de viscosidad superior a la del agua. Este es un valor aceptable, considerado que la mayoría de los datos utilizados provienen de S1, suspendida en quitosano que presenta una viscosidad de $6 \mathrm{mPa}$ s a $293 \mathrm{~K}$ con una tendencia decreciente con la temperatura. La mayoría de las muestras S2, suspendidas en agua, poseen tamaños por debajo de la transición entre el mecanismo de Nèel y el de Brown (18 nm, fig. 4.17) por lo que no afectan el comportamiento general de los valores en la zona de relajacion de Brown. Las muestras S3 no fueron incluidas en este análisis. El factor de frecuencia máximo se obtiene para $D \sim 16 \mathrm{~nm}$, sin embargo los mayores valores de SAR se obtuvieron para muestras de mayor diámetro. Esta diferencia se debe al factor $M_{s}^{2} V$ que se presenta entre el SAR y el factor de frecuencia.

Conociendo el factor de frecuencia, es posible obtener el valor de $\tau$ para cada muestra. Estos valores, junto con las curvas calculadas considerando los dos mecanismos posibles de 


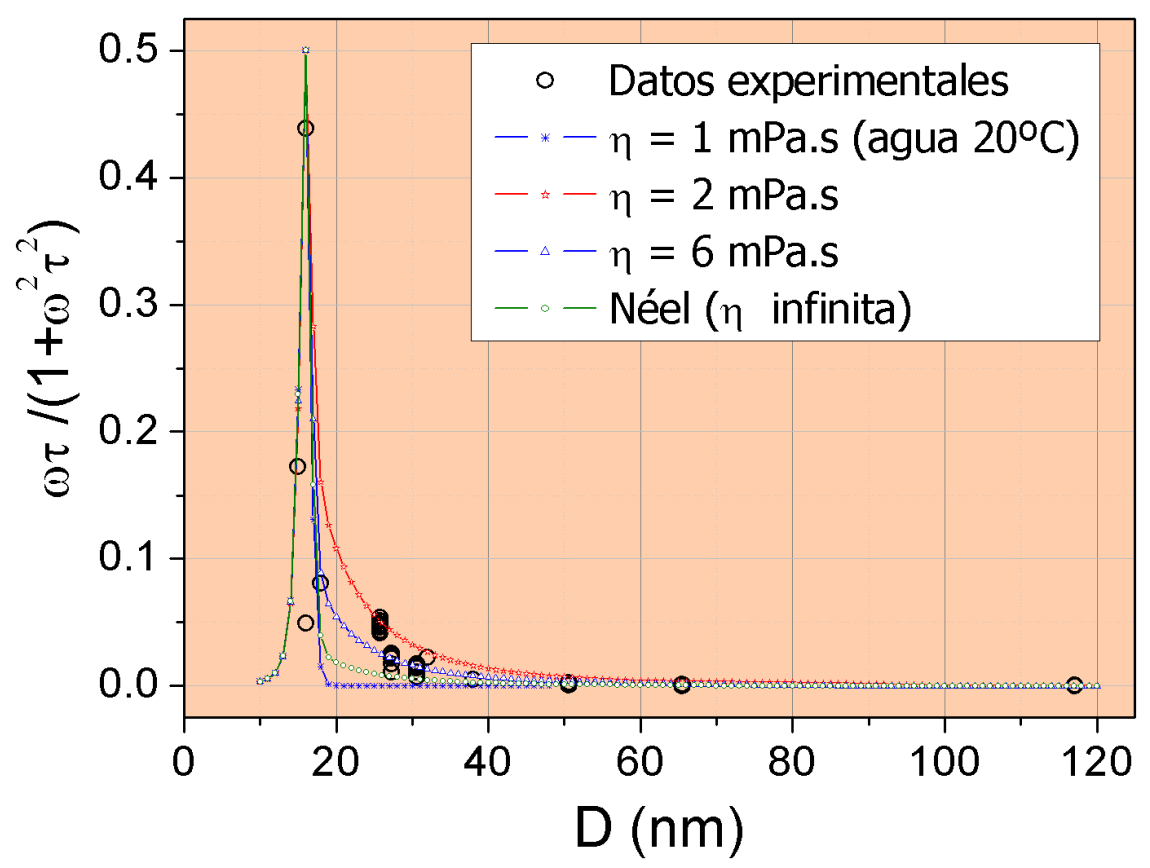

Figura 4.16: Factor de frecuencia para cada muestra de $S 1$ y $S 2$ obtenido como $S A R /\left(H_{0}^{2} M_{S}^{2} V\right)$. Las lineas continuas representan las funciones definidas para fluidos de diferentes viscosidades.

relajación, con dos valores extremos para la viscocidad $1 \mathrm{mPa}$ s y $6 \mathrm{mPa} s$, se muestran en la figura 4.17. En la misma se observa la correcta descripción de la dependencia de $\tau$ con el tamaño de partícula. También se indica el límite por debajo del cual domina el mecanismo de Nèel y por encima del cual domina el de Brown.

El valor de $\tau$ obtenido de las medidas realizadas con $H_{0}=41 \mathrm{kA} / \mathrm{m}$ se presenta en función del diamétro de partícula en escala log-log en la figura 4.18. Un ajuste lineal muestra una relación proporcional de $\tau$ con el volumen $D^{3}$ consistente con la relajación por mecanismo de Brown (fig. 4.18).

\subsubsection{Conclusiones}

Se realizó un estudio detallado de varias muestras de NPM dirigido a la caracterización minuciosa de las propiedades que determinan la absorción de potencia de campos de radiofrecuencia en el marco de la teoría de respuesta lineal.

Se investigó un amplio rango de composiciones y tamaños entre $5 \mathrm{~nm}$ y $100 \mathrm{~nm}$.

Se demostró la ubicación selectiva de los iones $\mathrm{Zn}^{2+}$ en los sitios A de la espinela de la magnetita. Consistentemente, la magnetización de saturación presenta sus valores máximos para los contenidos de $\mathrm{Zn} \mathrm{x} \in[0,1 ; 0,3]$ debido a la influencia de estos iones en los caminos de superintercambio.

De la observación de la relajación de los momentos de las NPM mediante espectroscopía Mössbauer se seleccionaron valores plausibles para $\tau_{0}=1 \times 10^{9}$ y $\mathrm{K}=1,89 \times 10^{4} \mathrm{~J} / \mathrm{m}^{3}$. Estos valores fueron adoptados para los subsecuentes análisis.

La dependencia del SAR con $x$ y $D$ puede ser descrita con la teoría de respuesta lineal para 


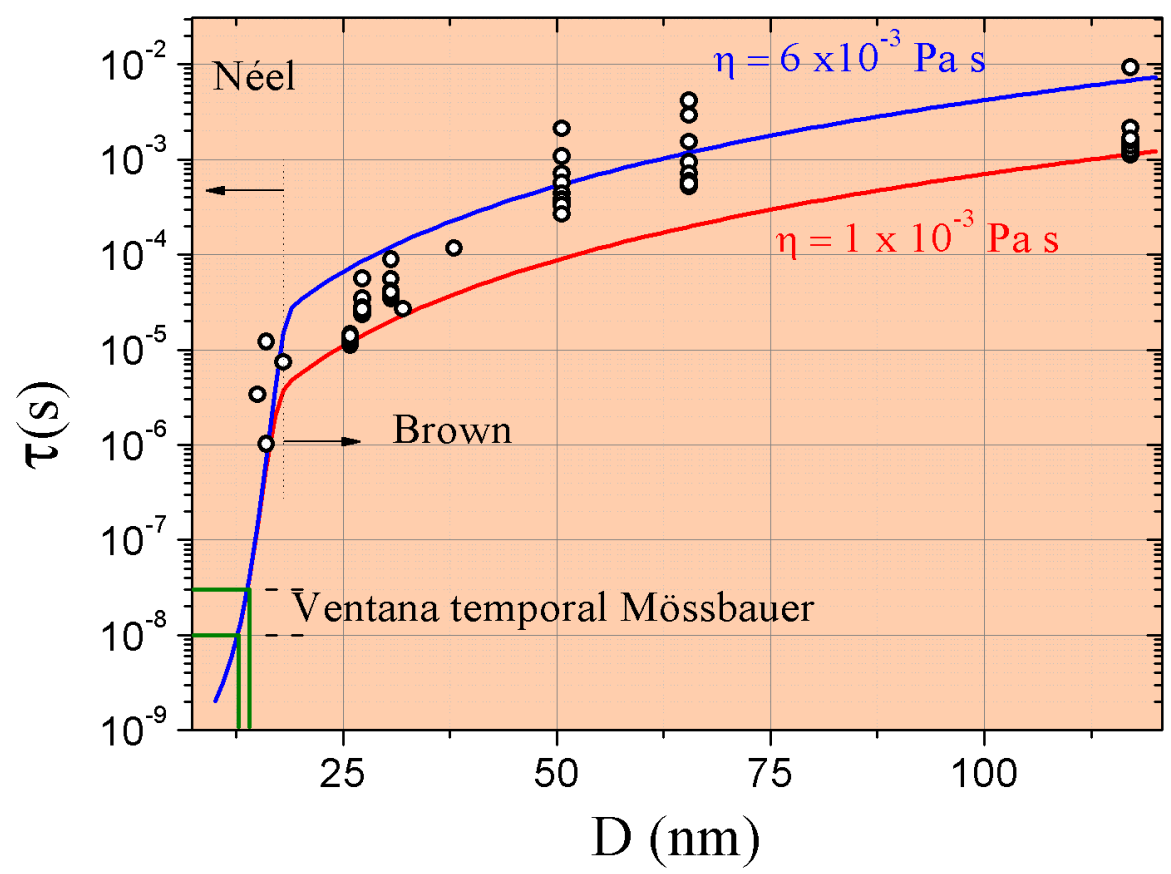

Figura 4.17: Tiempo de relajación de cada muestra de S1 y S2 en función del diámetro.

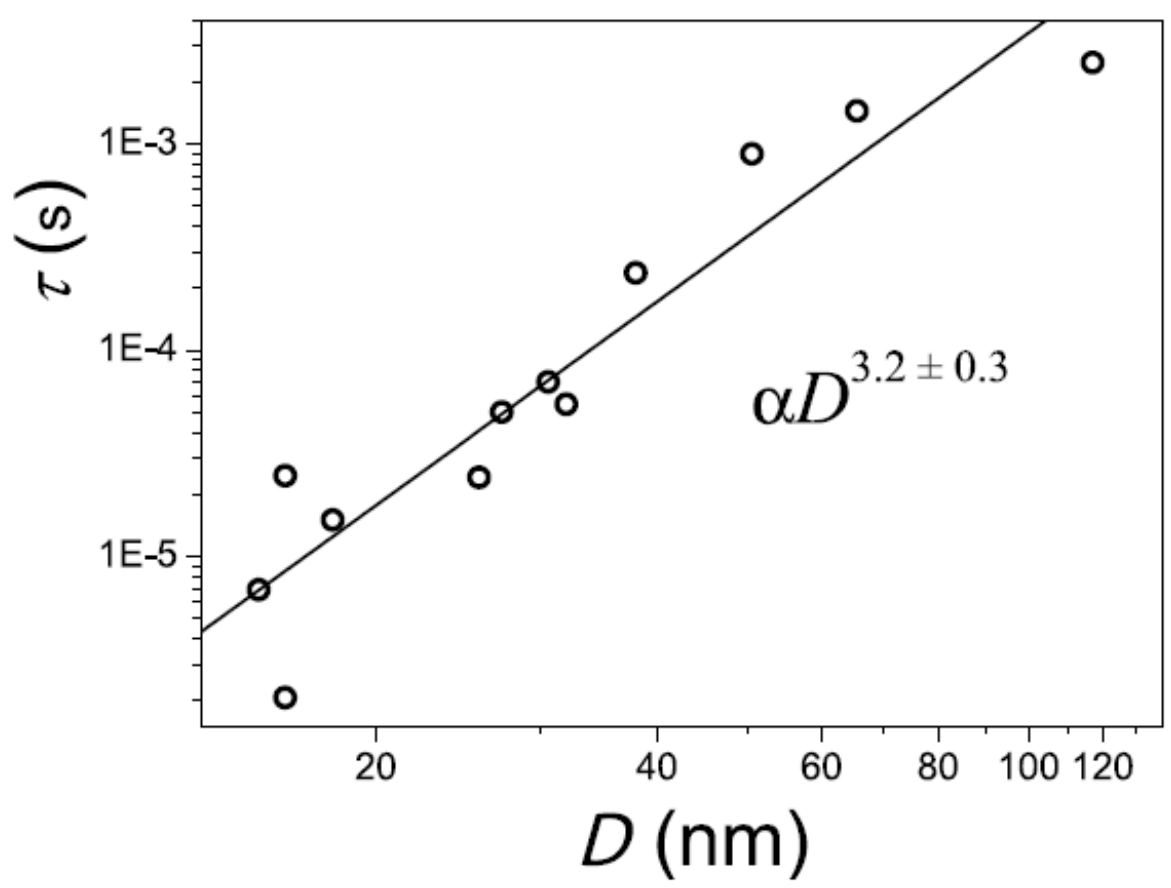

Figura 4.18: Tiempo de relajación $\tau$ obtenido a partir del factor de frecuencia $\omega \tau /\left(1+(\omega \tau)^{2}\right)$ en función del diámetro medio DRX para $S 1$ y $S 2$ (log-log). Un ajuste lineal indica una relación proporcional con el volumen $D^{3}$ consistente con una relajación por mecanismo de Brown. 
amplitudes de campo $H_{0}<41 \mathrm{kA} / \mathrm{m}$. Para $H_{0}=41 \mathrm{kA} / \mathrm{m}$ se obtuvo el valor máximo $367 \mathrm{~W} / \mathrm{g}$ con la muestra $\mathrm{x}=0,1 ; \mathrm{D}=16 \mathrm{~nm}$. Se observan efectos de saturación a campos mayores como los observados en las curvas simuladas con el modelo de dos pozos en el capítulo 2.

Utilizando la información obtenida a partir de la exhaustiva caracterización de las NPM, se logró una descripción autoconsistente del comportamiento de todo el set de muestras.

El factor de frecuencia $\omega \tau /\left(1+(\omega \tau)^{2}\right)$ de la componente disipativa de la susceptibilidad fue obtenido a partir de los datos SAR. Este factor exhibe un máximo agudo para D 16 nm. Este máximo corresponde con el tamaño resonante de las NPM para la frecuencia de trabajo 260 $\mathrm{kHz}$.

El tiempo de relajación $\tau$ obtenido del factor de frecuencia se compara satisfactoriamente con el calculado considerando los mecanismos de Neel y Brown. El análisis es consistente con una transición del mecanismo de Nèel al de Brown para $\mathrm{D} \approx 18 \mathrm{~nm}$.

El análisis lleva a la conclusión que, para mejorar el desempeño disipativo de los materiales basados en magnetita es necesario aumentar $M_{s}$ mediante el dopaje con Zn mientras manteniendo un tamaño cercano al resonante para la frecuencia de trabajo. 


\title{
4.2. Muestra II : NPM de magnetita recubiertas con ácido oléico en medio orgánico. Relevamiento de la dependencia del SLP y del ILP con la intensidad y frecuencia de campo para NPM en suspensión y gelificadas. Aplicación del sistema de medición de magnetización RF. Comparación con resultados de SLP calorimétricos.
}

\begin{abstract}
4.2.1. Síntesis
Se obtuvieron nanopartículas de $\mathrm{Fe}_{3} \mathrm{O}_{4}$ mediante descomposición de precursores férricos orgánicos según trabajos citados[36], [35], en el Instituto de Nanociencia de Aragón, España. Las muestras se sintetizaron usando acetilacetonato de hierro y diferentes solventes (fenil éter, trioctilamina) que implicaron diferentes temperaturas de síntesis. Con el fin de controlar el tamaño final de partícula, se utilizaron diferentes relaciones molares precursor/surfactante. Las nanopartículas resultantes fueron lavadas varias veces con etanol luego de someterlas a precipitación magnética. El producto final fue redispersado en hexano.
\end{abstract}

\subsubsection{Caracterización estructural: TEM}

Se tomaron varias imágenes TEM en un microscopio Tecnai T20 (FEI) con filamento Lab6 operado a 200 kV. Para ello, una gota del FF diluido fue depositada en una rejilla de microscopía Holey Carbon y secada en campana.

Se observan partículas entre esféricas y poliédricas irregulares (fig. 4.19) con un diámetro medio de 9(1) nm obtenido a partir de todas las imágenes mediante ajustes lognormal. En el máximo aumento (fig. 4.20) se puede observar la cristalinidad de las NPM.

\subsubsection{Caracterización magnética}

\subsubsection{Magnetización en función de la temperatura a campo constante: ZFC-FC}

Se realizaron medidas de magnetización en función de la temperatura sobre una alicuota de FF encapsulada. Una vez dentro del equipo, la muestra fue congelada con un campo aplicado de 7 T llevándola a $140 \mathrm{~K}$ para obtener un sistema tipo SW, magnéticamente saturado de NPM orientadas con sus ejes fáciles paralelos al campo.

En estas condiciones se inició un protocolo ZFC-FC. Dado que este tipo de experimentos se basa en medir la magnetización de la muestra en torno de la temperatura de bloqueo, es importante asegurarse que la temperatura máxima programada sea superior a $T_{B}$. Por otro lado, para conservar el orden del sistema, es necesario mantenerse por debajo de la temperatura de fusión de la matriz. Considerando esto, el experimento se realizó en los siguientes pasos:

(I) La muestra se enfría hasta $2 \mathrm{~K}$ sin campo aplicado.

(II) Se aplica un campo de $10^{-2} \mathrm{~T}$ (correspondiente a $\left.100 \mathrm{Oe}\right)$. 


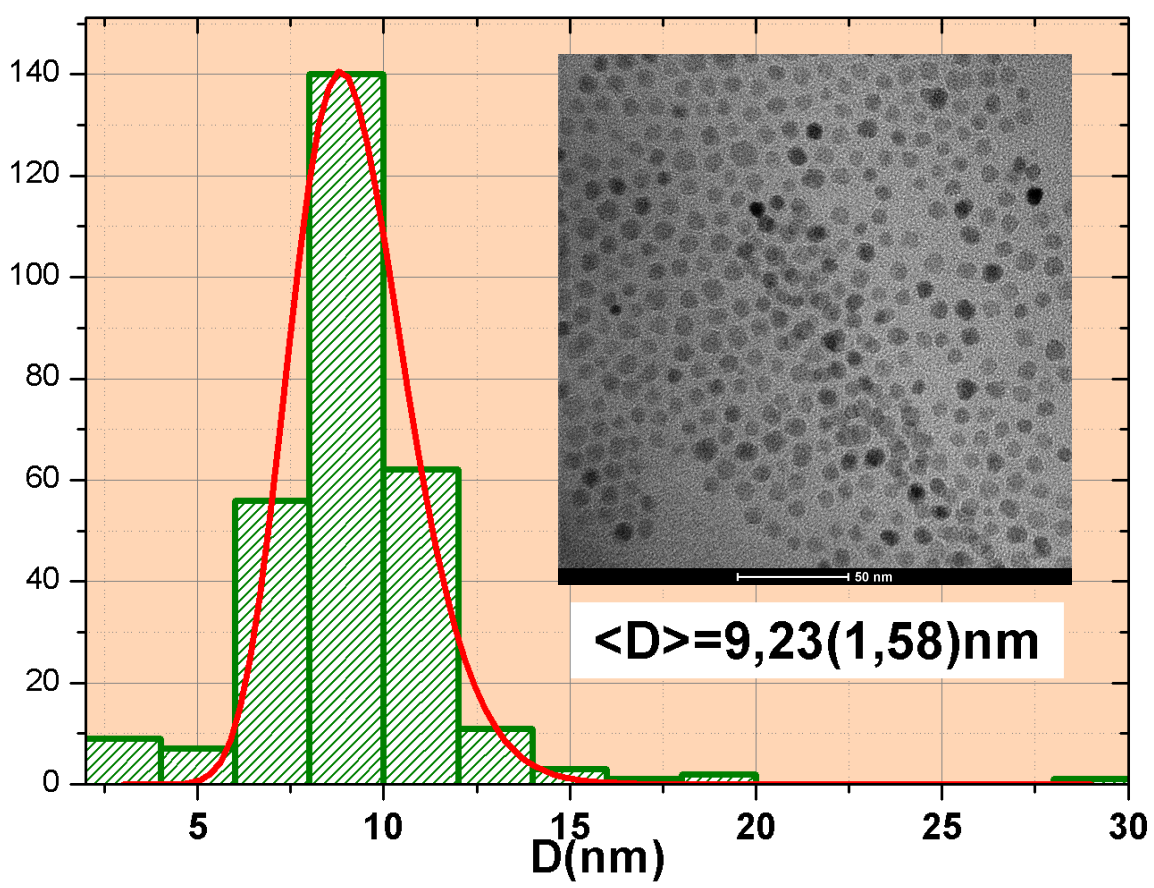

Figura 4.19: Ejemplo de imagen TEM de la muestra II. Se detallan el valor medio y la desviación estándar obtenidos a partir de un ajuste lognormal.

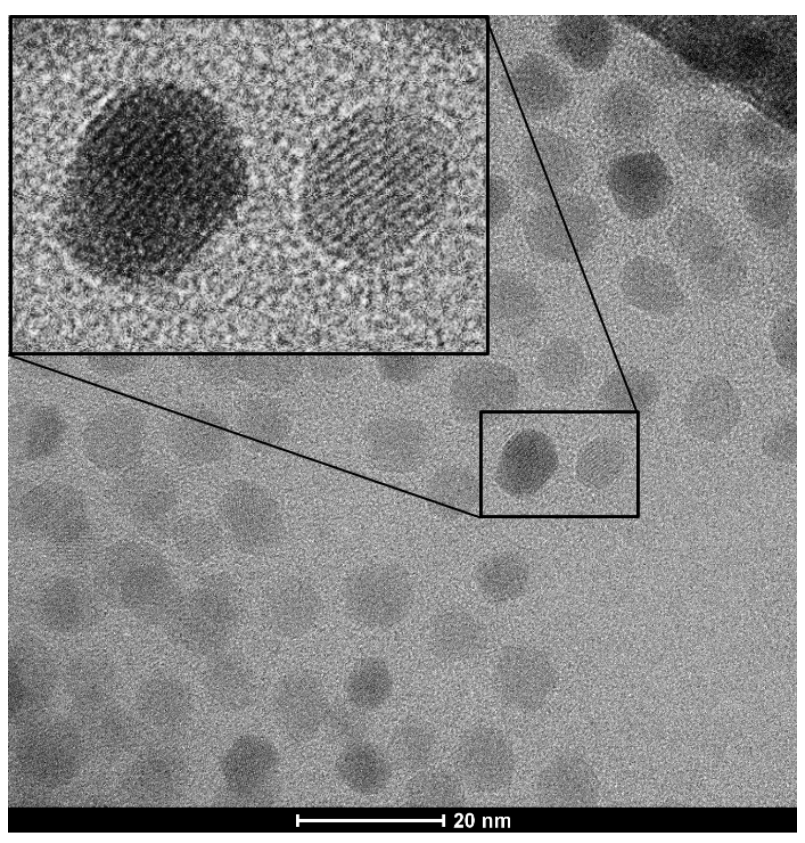

Figura 4.20: Imagen TEM de la muestra II. Con este aumento es posible observar los planos cristalinos de las NPM. 


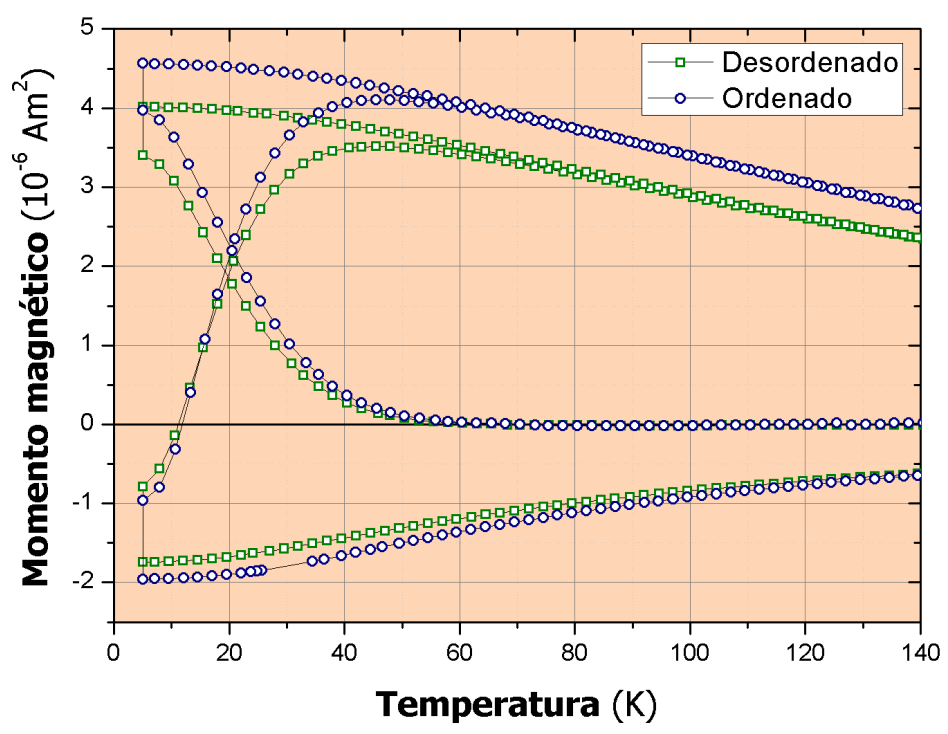

Figura 4.21: Momento magnético de la muestra II en función de la temperatura durante el protocolo ZFC-FC. Se muestran las curvas para el sistema ordenado y desordenado. Los valores negativos se deben a la presencia de un pequeño campo remanente inicial en las bobinas del magnetómetro .

(III) Con el campo aún aplicado, se calienta la muestra hasta $140 \mathrm{~K}\left(\mathrm{ZFC}^{2}\right)$.

(IV) Manteniendo el campo se vuelve a enfriar hasta 2 K (FC).

(V) Se retira el campo y se calienta la muestra hasta $140 \mathrm{~K}$ (TRM).

El experimento fue repetido luego de que la muestra fuera calentada por encima del punto de fusión de la matriz de hexano $(168 \mathrm{~K})$ y vuelta a congelar sin campo para obtener un sistema desordenado. En este caso, también es necesario mantenerse por debajo de la temperatura de fusión de la matriz al calentar la muestra con campo aplicado. De lo contrario el sistema originalmente desordenado, al pasar a estado fluido, se vería modificado por el campo.

Se observan valores menores de magnetización para el sistema desordenado. Las curvas ZFCC y ZFCW están afectadas por el campo remanente negativo presente en las bobinas del magnetómetro al iniciar el experimento.

A partir de estas medidas, se determinó la distribución de temperaturas de bloqueo según el método presentado por Micha et al [133] cuyos fundamentos para un sistema ordenado se puntualizan a continuación de manera mucho más detallada que en la fuente :

\footnotetext{
${ }^{2}$ La nomenclatura convencional para las etapas de este experimento no es clara. Si bien ZFC se traduce como "enfriamiento sin campo", dado que en esa etapa del experimento no se detecta señal, se suele usar esta sigla para referirse a la curva correspondiente al calentamiento luego de haber enfriado sin campo i.e. se indica el estado en el que fue preparada la muestra antes de medir. En este trabajo, cuando se considera necesario para mayor claridad, se extiende esta nomenclatura agregando una sigla que a la preparación del estado suma la acción que se realiza (W para calentamiento y $\mathrm{C}$ para enfriamiento) e.g. ZFCW para el calentamiento luego de enfriar sin campo y FCC para el propio enfriamiento con campo aplicado.
} 
- En un sistema ordenado con distribución de tamaños, para cada temperatura de la región irreversible (ver 2.4.1.3), existirá una cierta cantidad de NPM en régimen SPM (las que se encuentren por encima de su $T_{B}$ ) mientras que el resto de la muestra se encontrará "bloqueada"(por debajo de su $T_{B}$ ) i.e. sin posibilidad de invertir su magnetización.

- El sistema se enfrió desde un estado desmagnetizado, por lo que durante todo el enfriamiento sin campo (ZFC), la población se encuentra dividida en una mitad con magnetización paralela y una mitad con magnetización antiparalela a la dirección y sentido en los que se mide la magnetización.

- Al aplicar un pequeño campo, se obtiene una configuración fuera del equilibrio en donde la orientación paralela es ligeramente más favorable. El estado estable correspondiente implica la inversión de una pequeña porción de las NPM orientadas antiparalelamente que sólo es posible si la energía térmica disponible es suficiente para superar la barrera de anisotropía durante el tiempo de la medida.

- Al aumentar la temperatura con el campo aplicado (FW) las NPM más pequeñas comienzan a disponer de energía para invertir su magnetización. La porción de la población que supera su $T_{B}$ comienza a invertir su macromomento de un pozo a otro, pero manteniéndose más tiempo en la dirección favorable, dando lugar así a una magnetización neta. Las NPM de mayor tamaño continúan bloqueadas y por ende en la configuración de campo cero (la misma cantidad en ambas direcciones).

- Eventualmente la temperatura es lo suficientemente alta como para que todas las NPM estén desbloqueadas. El sistema alcanza la configuración de equilibrio para el valor de campo aplicado.

- Al enfriar nuevamente manteniendo el campo (FC), el sistema conserva su configuración de equilibrio por lo que, en la región irreversible ahora se mide una mayor magnetización, dada por la suma de las NPM desbloqueadas que pasan más tiempo en la dirección favorable y las NPM más grandes que ya no invierten, pero quedaron bloqueadas en la configuración de equilibrio.

- Así, la diferencia entre las curvas FC y FW a una dada temperatura es proporcional al momento de las NPM bloqueadas. Derivando esta diferencia en función de T se obtiene la distribución porción de volumen de temperaturas de bloqueo del sistema que está gobernada principalmente por la distribución de tamaños.

La validez de este razonamiento puede ser verificada simulando numéricamente las curvas ZFC-FC de un sistema con distribución de tamaños. Al controlar todos los parámetros del sistema, es posible comparar la distribución de $T_{B}$ obtenida como los puntos de inflexión de las curvas ZFC calculadas para cada tamaño de la distribución, con el resultado obtenido con el método recién descrito.

En la figura 4.22 se muestran las distribuciones de $T_{B}$ obtenidas de forma directa a partir de la distribución de volúmenes y mediante la derivada de la diferencia de las curvas FW y FC. Se observa una coincidencia total entre ambos resultados, lo que verifica la validez del método propuesto por Micha et al. Adicionalmente, es posible comparar la 
temperatura de bloqueo media según estas distribuciones con la temperatura correspondiente al punto de inflexión de la curva ZFC politamaño, dato que se suele reportar en la literatura como $T_{B}$ representativa del sistema. En el caso simulado, un sistema con una mediana correspondiente a un diámetro de $9 \mathrm{~nm}$ y una desviación estándar del logaritmo del volumen $\sigma=0,51$, con una magnetización de saturación $M_{s}=321 \mathrm{kA} / \mathrm{m}$, una constante de anisotropía $\mathrm{K}=16 \mathrm{~kJ} / \mathrm{m}^{3}$ medido con una rampa de temperatura de $10 \mathrm{~K} / \mathrm{min}$ y un campo de $8 \mathrm{kA} / \mathrm{m}$, la temperatura de bloqueo media según las distribuciones es de 20,6 K mientras que el punto de inflexión de la curva ZFC se encuentra en 14,0 K. Esto evidencia que esta última cantidad no es adecuada para caracterizar al sistema.

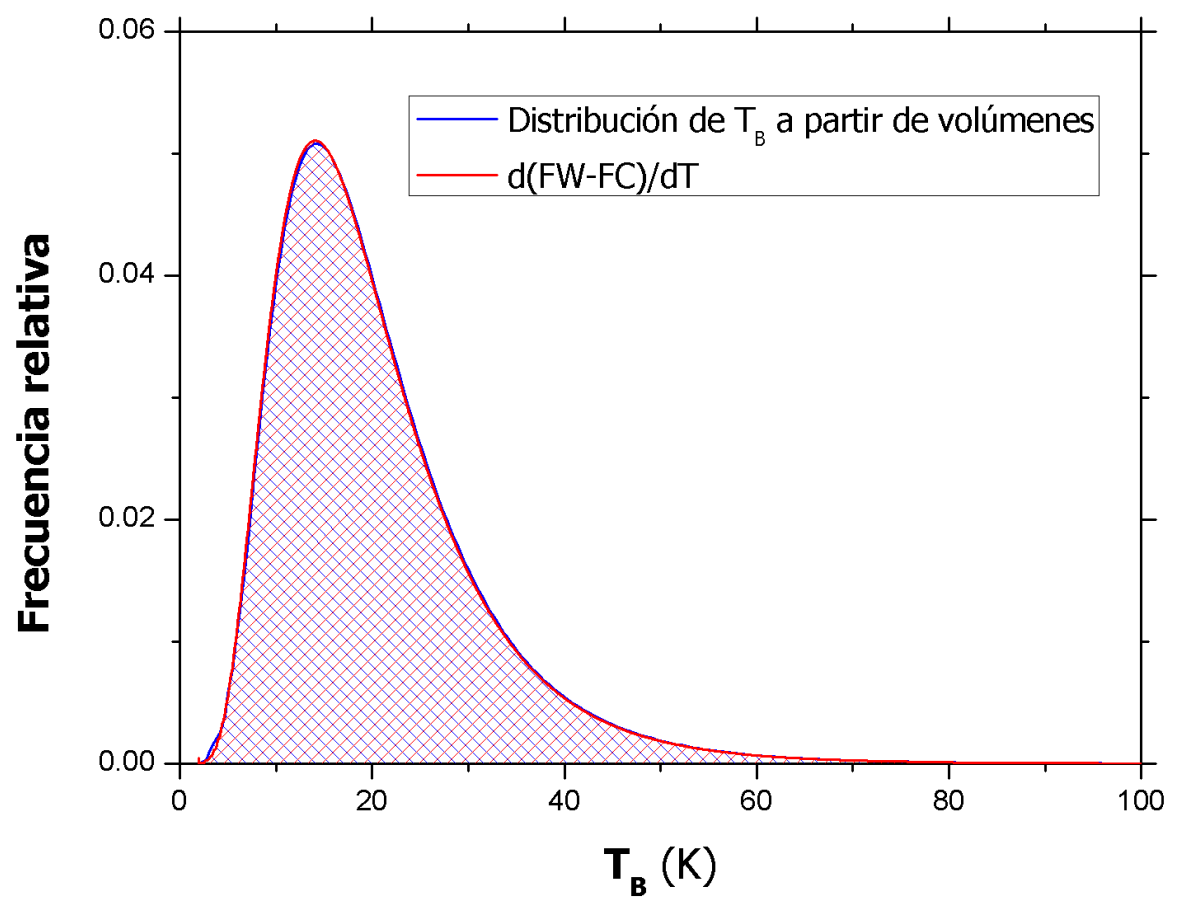

Figura 4.22: Comparación entre la distribución de temperaturas de bloqueo obtenida a partir de la distribución de volúmenes y la obtenida como la derivada en $T$ de la resta de las curvas FW y FC.

A partir de los resultados experimentales, con el método verificado, se obtuvo una temperatura de bloqueo de $27(21) \mathrm{K}$ (valor medio y desviación estándar de la lognormal) lo que corresponde a una constante de anisotropía efectiva $\mathrm{K}=16(1) \mathrm{kJ} / \mathrm{m}^{3}$ (fig. 4.23). Este valor se obtuvo ajustando primero la distribución de volúmenes con una función lognormal para luego utilizar el parámetro $\sigma$ obtenido (desviación estándar del logaritmo de la variable) como parámetro fijo de un ajuste lognormal sobre la distribución de $T_{B}$ según el método de Micha. Según un trabajo de Denardin et al ([150]), la presencia de interacciones interpartícula modifica el resultado de este procedimiento disminuyendo el ancho de la distribución de $T_{B}$ obtenida respecto al de la distribución de volúmenes. Así, haber podido ajustar ambas distribuciones con el mismo $\sigma$ es un indicio de que las interacciones no son importantes. A partir de estos ajustes, se obtuvo la mediana $T_{B 0}$ de la distribución de temperaturas de bloqueo que se relaciona con la mediana $V_{0}$ de la distribución de volúmenes vía la constante de anisotropía según la ecuación 


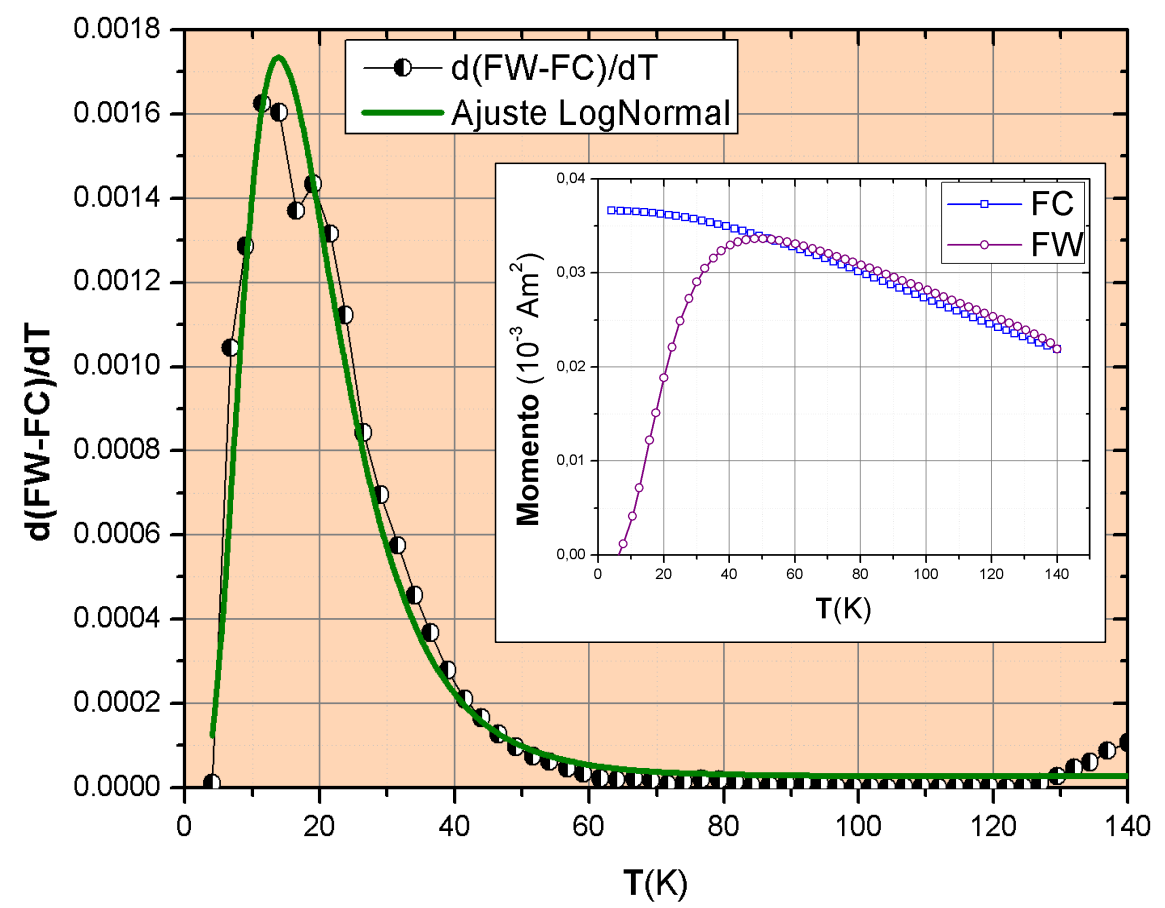

Figura 4.23: Distribución de temperaturas de bloqueo calculada a partir de la derivada en T de la diferencia entre las curvas FW y FC (insertas). El resultado se ajusta con una función lognormal para obtener la temperatura de bloqueo media y su desviación estándar.

$$
\tau=\tau_{0} e^{K V(1-h)^{2} / k T_{B}}=\tau_{m} \Rightarrow T_{B}=\frac{K V(1-h)^{2}}{k \log \left[\tau_{m} / \tau_{0}\right]}
$$

en donde se considera que a la temperatura de bloqueo, el tiempo de medida $\tau_{m}$ es igual al tiempo de inversión en la dirección del campo para el mecanismo de Nèel $\tau_{N}$ (fig. 4.24). Este proceso se justifica en la distribución lognormal de una cantidad proporcional a una variable también lognormal: si dos variables lognormales

$$
f[V] d V=\operatorname{Lognorm}\left[V, \sigma_{V}, V_{0}\right] d V=\frac{A_{V}}{\sigma_{V} V} \exp \left[\frac{-\log \left[V / V_{0}\right]^{2}}{2 \sigma_{V}^{2}}\right] d V
$$

$\mathrm{y}$

$$
f\left[T_{B}\right] d T_{B}=\operatorname{Lognorm}\left[T_{B}, \sigma_{T}, T_{B 0}\right]=\frac{A_{T}}{\sigma_{T} T_{B}} \exp \left[\frac{-\log \left[T_{B} / T_{B 0}\right]^{2}}{2 \sigma_{T}^{2}}\right] d T_{B}
$$

están relacionadas por

$$
T_{B}=\alpha V
$$

sus distribuciones se relacionan según 


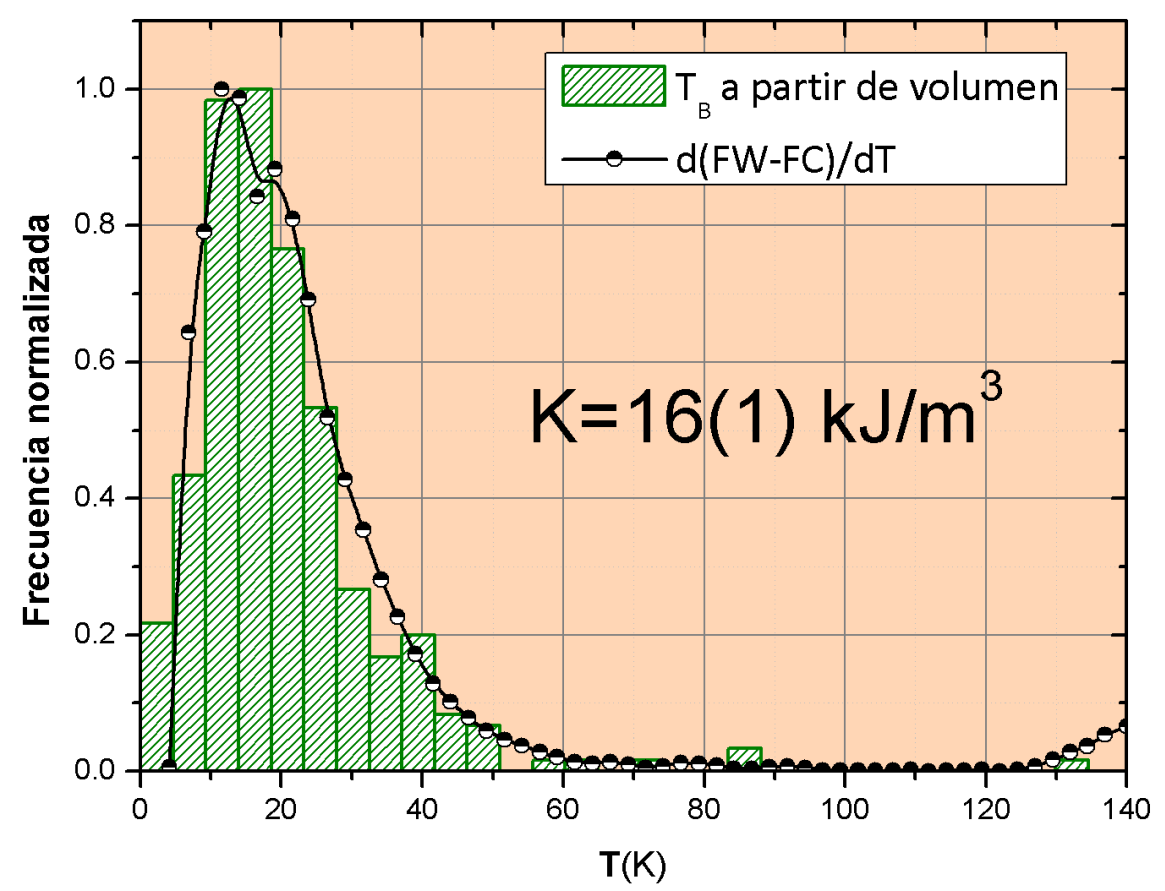

Figura 4.24: Comparación de la distribución de temperaturas de bloqueo obtenida como la derivada de la diferencia de las curvas FW y FC y la obtenida a partir de la distribución de volúmenes TEM según la ecuación 4.1 para el valor de $K$ que maximiza la coincidencia.

$$
f\left[T_{B}\right] d T_{B}=f[\alpha V] \alpha d V=\frac{A_{T}}{\sigma_{T} V} \exp \left[\frac{-\log \left[\alpha V / T_{B 0}\right]^{2}}{2 \sigma_{T}^{2}}\right] d V=\text { Lognorm }\left[V, \sigma_{T}, V_{0}\right] d V
$$

por lo que

$$
T_{B 0}=\alpha V_{0} \wedge \sigma_{T}=\sigma_{V}
$$

La relación de proporcionalidad 4.2 fue verificada en las simulaciones graficando la temperatura correspondiente al punto de inflexión de la curva ZFC para cada población, en función del volumen de la misma.

En la figura 4.25 se comparan las curvas FCC y FCW experimentales con la simulación numérica obtenida a partir de las ecuaciones del capítulo 2 para la magnetización en función de la temperatura de una muestra con distribución de tamaños. Se utilizaron los parámetros estructurales obtenidos de las medidas TEM (distribución de volúmenes), los ciclos $\mathrm{M}$ vs. $\mathrm{H}\left(M_{S}\right)$ y las curvas ZFC-FC experimentales (constante de anisotropía). Se encuentra un acuerdo razonable con el modelo presentándose las mayores discrepancias en las temperaturas extremas. En particular se observa como en la medida experimental, la magnetización cambia bruscamente tanto al aplicar como al retirar el campo a $2 \mathrm{~K}$, evidenciando que una porción de la población 


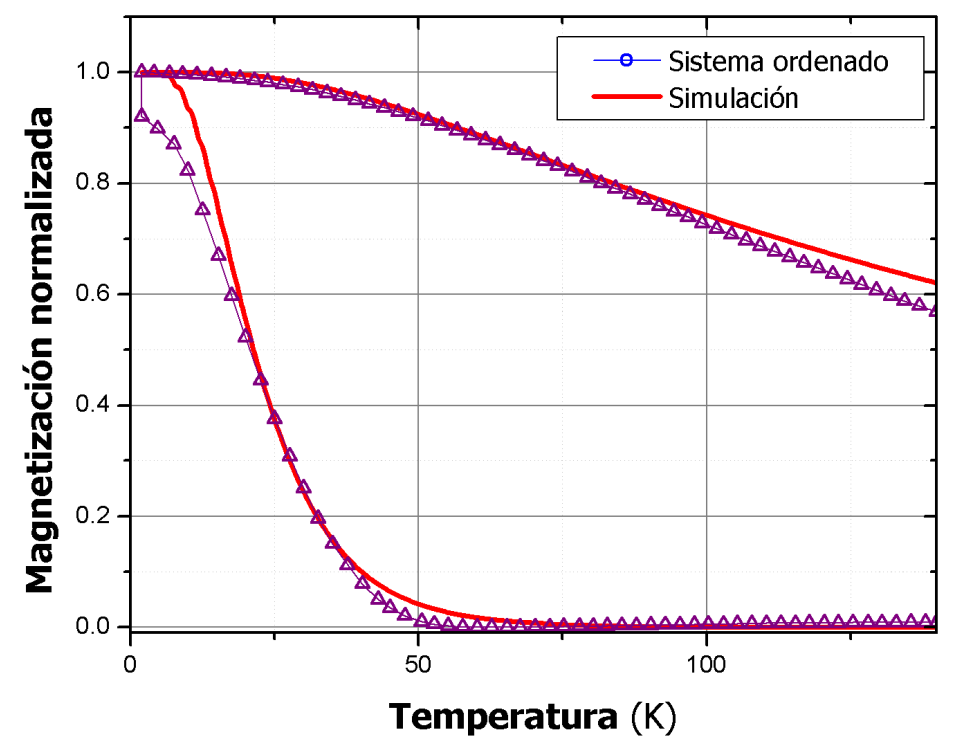

Figura 4.25: Comparación de las curvas FCC y TRM experimentales (línea continua) con las simuladas a partir del modelo de dos pozos expuesto en el capítulo 2 (triángulos unidos por línea).

se encuentra en estado desbloqueado a esa temperatura. Este comportamiento no es reproducido por la simulación, posiblemente porque el ajuste lognormal realizado haya subestimado la cantidad de partículas de menor tamaño como se puede vislumbrar de las figuras 4.19, 4.23 y 4.24.

\subsubsection{Magnetización en función del campo a temperatura constante: ciclos M vs. H.}

Se relevaron ciclos de magnetización M vs. H a varias temperaturas. Se determinó el campo coercitivo de cada uno de estos ciclos corrigiendo el efecto del campo remanente en las bobinas superconductoras. La coercitividad disminuye con la temperatura desde un valor de $3 \mathrm{kA} / \mathrm{m}$ a $2 \mathrm{~K}$ hasta desaparecer por encima de $\operatorname{los} 25 \mathrm{~K}$.

Graficando los valores de $H_{C}$ en función de la raíz cuadrada de la temperatura, se observa la dependencia lineal predicha por la sección 2.4.1.2 (fig.4.26). Así, es posible obtener la constante de anisotropía efectiva a partir de un ajuste lineal sobre los valores no nulos de $H_{C}$ según la ecuación 2.36 como

$$
K=\frac{\mu_{0}}{2} M_{S} H_{C}[T=0] .
$$

Utilizando el valor de $M_{S}$ de los mismos ciclos, se obtiene una constante efectiva $\mathrm{K}=6,6(3)$ $k J / m^{3}$. 


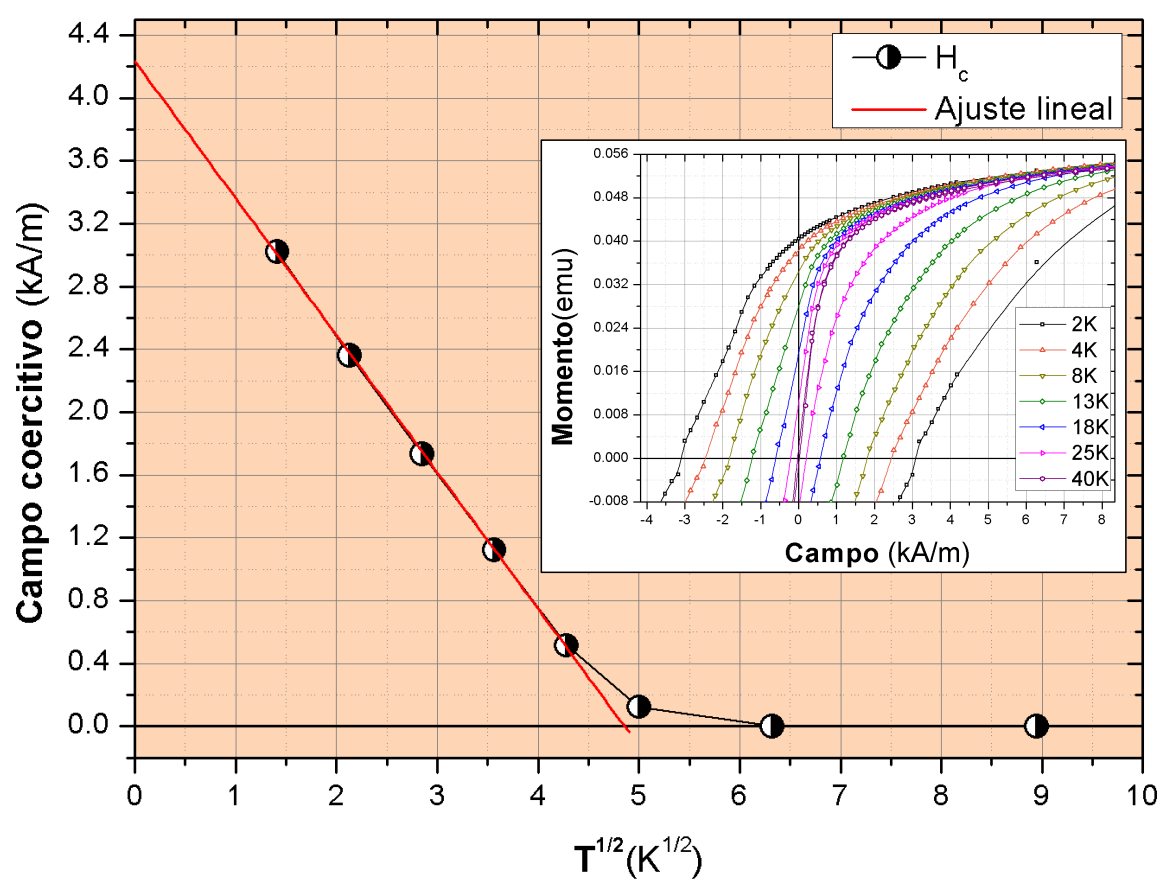

Figura 4.26: Campo coercitivo en función de la temperatura para la muestra II. Se ajusta una función lineal para obtener el corte por cero. Inserto: detalle de los ciclos en la región de bajo campo.

\subsubsection{Medición de ciclos RF}

Mediante el sistema descrito en la sección 3.6 se relevaron los ciclos de magnetización RF de la muestra II en forma de FF y como ferrogel (FG) con el fin último de obtener los mapas SLP vs. amplitud de campo vs. frecuencia e ILP vs. amplitud de campo vs. frecuencia. El formato FG se utilizó por dos razones: la estabilidad y facilidad de manipulación, dado que la matriz del FF original consisten en hexano y este hidrocarburo es sumamente volátil, y la posibilidad de observar la diferencia de comportamiento entre NPM en suspensión y NPM fijas.

\subsubsection{NPM en suspensión: Ferrofluido}

Se colocaron $250 \mu l$ de FF en una cápsula de gelatina. La cápsula se cerró y se comprobó que es capaz de contener el hexano por varias horas sin que se observe evaporación. Para evitar efectos de deterioro o desestabilización del FF, se utilizó una alicuota nueva para cada repetición. Así, se obtuvieron primero los ciclos para distintas amplitudes de campo a frecuencia fija (fig. 4.27).

A partir de estos ciclos se calculó el SLP para cada combinación (amplitud, frecuencia) de campo. El comportamiento cualitativo es el esperado según el modelo expuesto, el SLP crece de manera monótona en la dirección de mayores campos y frecuencias. En la figura 4.29 se muestra un mapa de color de los valores de SAR obtenidos en donde se evidencia este comportamiento. En tanto las irregularidades presentes en este y el resto de los mapas de color, hay que tener en cuenta que la rutina que realiza esta representación no considera las incertidumbres de los puntos que, como se muestra en la figura 4.28, no son despreciables. 


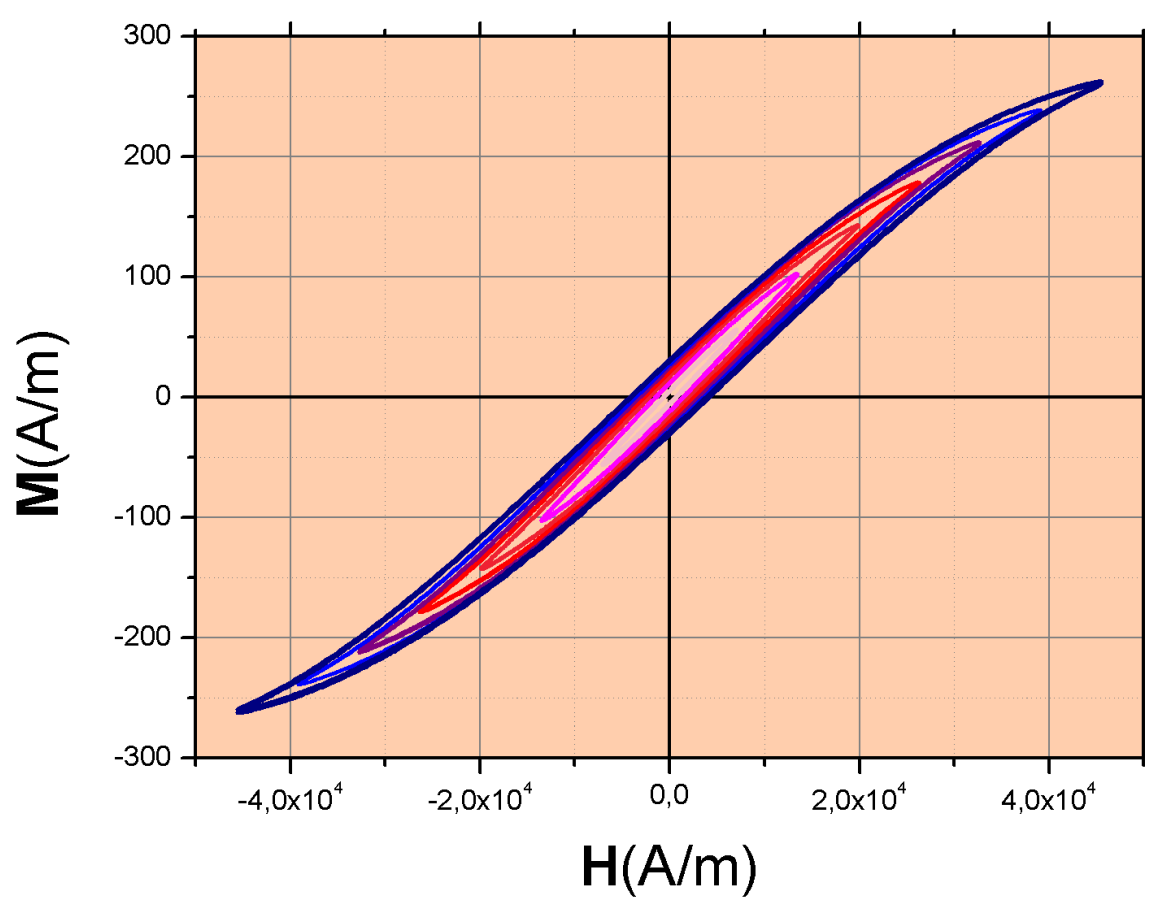

Figura 4.27: Ciclos de magnetización en función del campo para distintas amplitudes a $268 \mathrm{kHz}$ para el FF de la muestra II.

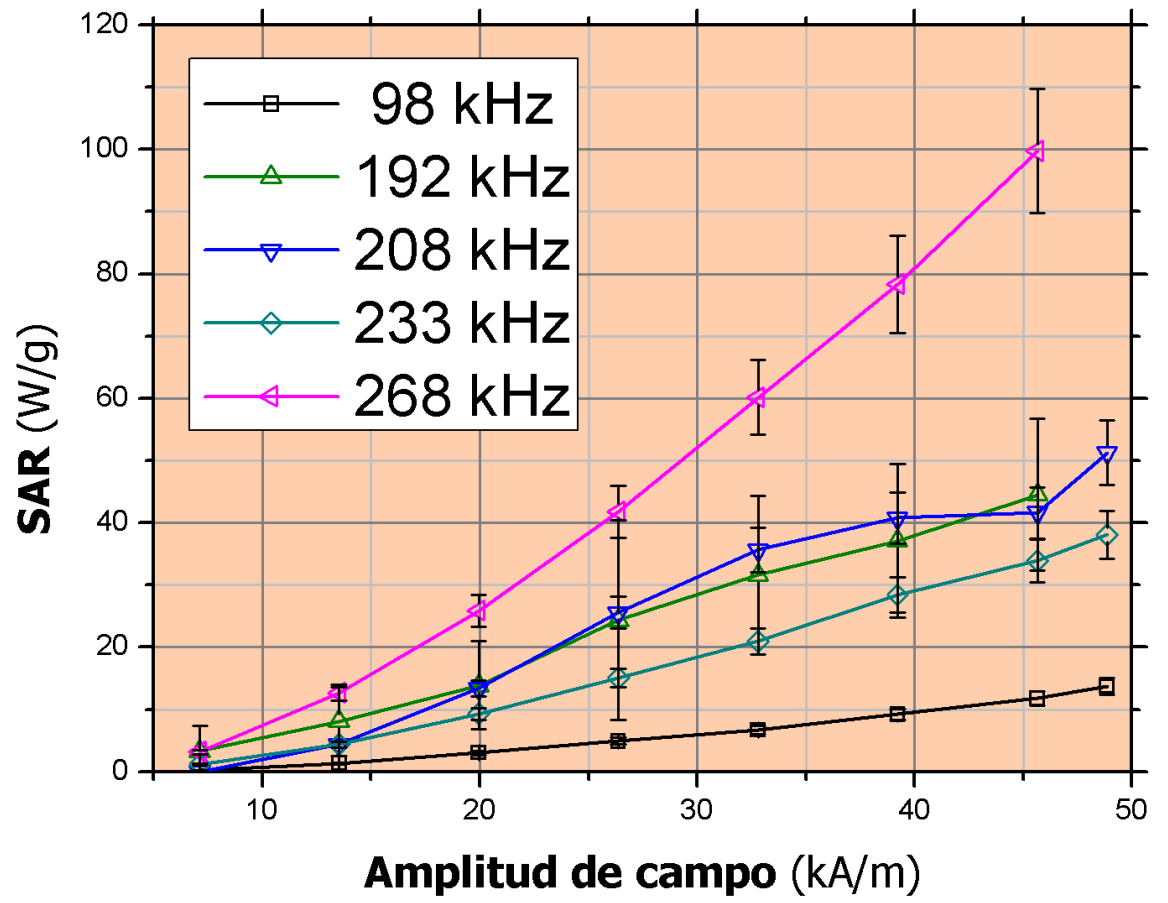

Figura 4.28: Valores de $S A R$ del FF en función de la amplitud de campo para diferentes frecuencias.

Dividiendo cada valor de SLP por el factor $H^{2} f$, se obtiene el ILP, que es proporcional al 


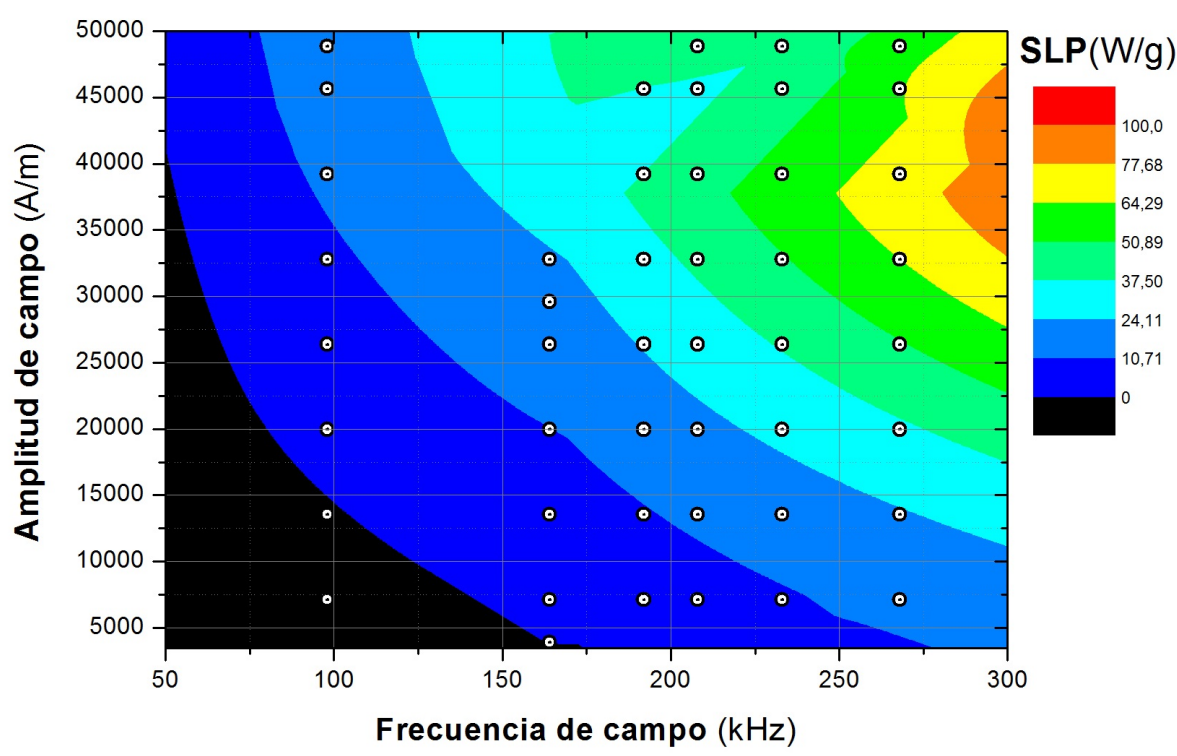

Figura 4.29: Mapa de SLP vs. amplitud de campo vs. frecuencia para el FF de la muestra II. Los círculos blancos indican las medidas experimentales. El mapa de color se genera por interpolación con el programa Origin 8 . Se observa un crecimiento prácticamente monótono del SLP en la dirección de mayores amplitudes y frecuencias.

factor de frecuencia. En la figura 4.30 se observa como los mayores valores de ILP se alcanzan en la región de altas frecuencias y bajas amplitudes lo que pone de manifiesto el efecto de saturación que surge cuando la respuesta del sistema se aparta de la teoría de respuesta lineal.

\subsubsection{NPM fijadas: Ferrogel}

Se fabricó un ferrogel (FG) a partir de la muestra II mezclando 500(5) $\mu L$ de la misma con 390(1) mg de cera en gel (GelWax) fundida. Se obtuvo así un gel estable con NPM a una concentración de $1,2 \mathrm{~kg} / \mathrm{m}^{3}$ que se colocó en una cápsula de gelatina transparente procurando una distribución homogénea. Una segunda cápsula se rellenó con cera en gel pura para utilizar como blanco en las medidas de referencia.

De la misma manera que con el FF, se midieron los ciclos de magnetización RF en varias combinaciones (amplitud, frecuencia) (fig. 4.31), esta vez, utilizando siempre la misma muestra de FG y de gel blanco.

Se obtuvieron también los mapas de SLP e ILP.

En la figura 4.32 se observa el mismo comportamiento cualitativo que para el FF. El SLP crece monótonamente con el campo y la frecuencia. La tendencia del ILP es también similar a la del FF, los mayores valores se encuentran en la región de altas frecuencias y bajas amplitudes debido a la saturación de la respuesta fuera de la región de validez de la aproximación de susceptibilidad constante (fig. 4.33).

\section{Comparación entre FG, FF y simulaciones}

Contar con dos muestras constituidas por sendas alicuotas de una misma muestra madre soportadas en diferentes matrices, permite estudiar la influencia del medio en la respuesta mag- 


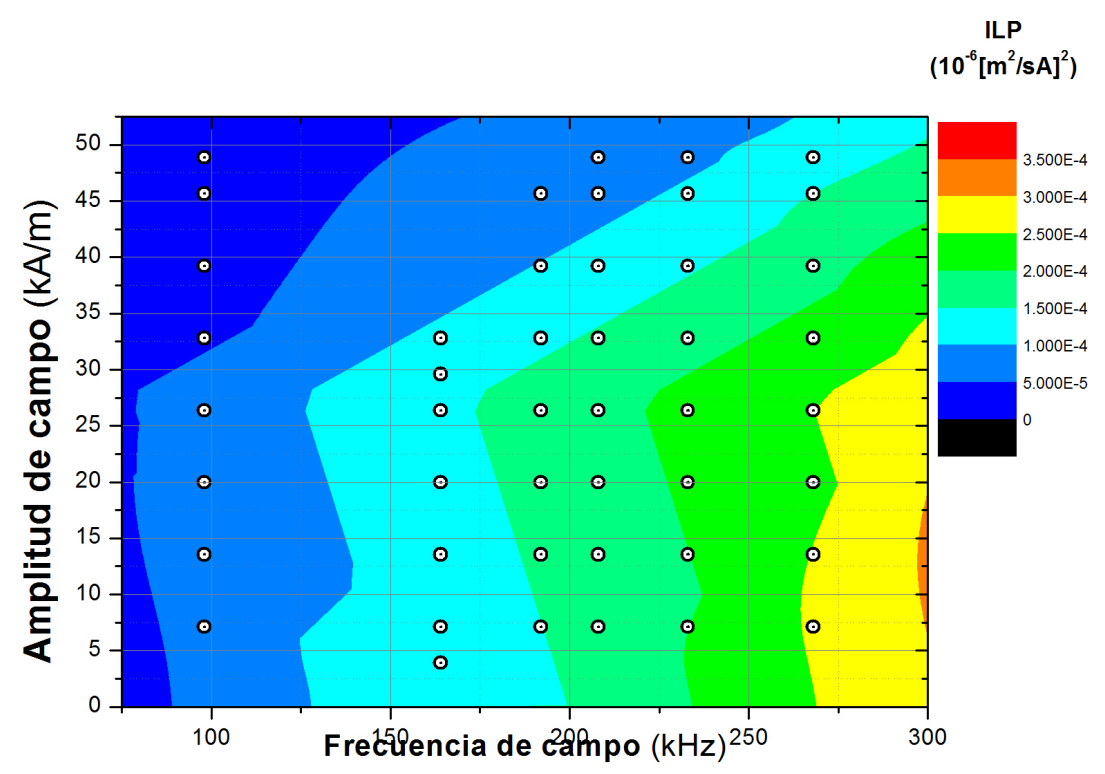

Figura 4.30: Mapa de ILP vs. amplitud de campo vs. frecuencia para el FF de la muestra II. Los círculos blancos indican las medidas experimentales. El mapa de color se genera por interpolación con el programa Origin 8 . Se observa el apartamiento del modelo de respuesta lineal para altos campos.

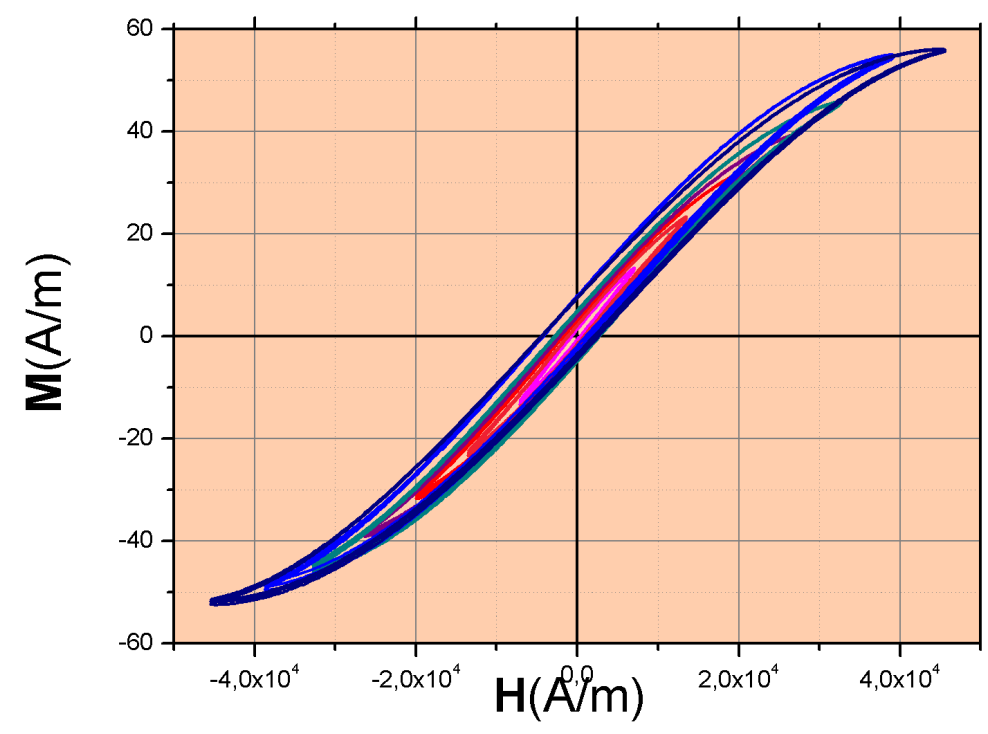

Figura 4.31: Ciclos de magnetización en función del campo para distintas amplitudes a $268 \mathrm{kHz}$ para el FG de la muestra II. 


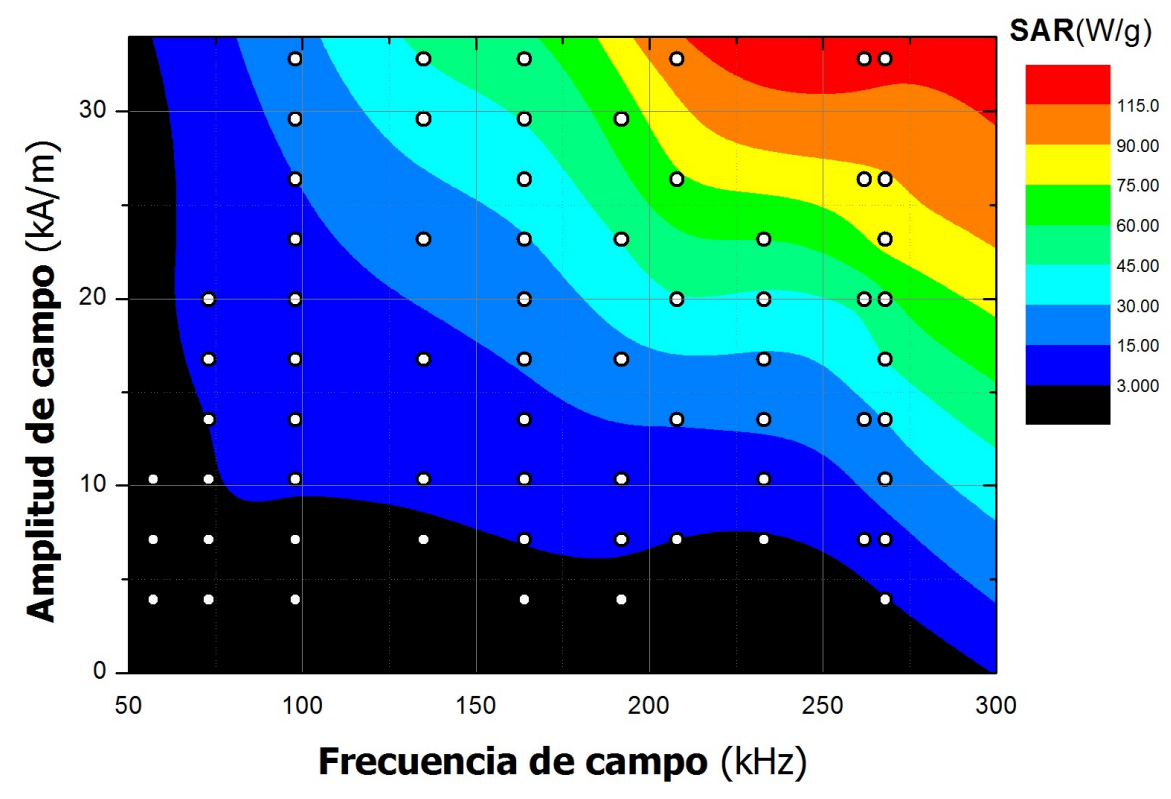

Figura 4.32: Mapa de SLP vs. amplitud de campo vs. frecuencia para el FG de la muestra II. Los círculos blancos indican las medidas experimentales. El mapa de color se genera por interpolación con el programa Origin 8. Se observa un crecimiento prácticamente monótono del SLP en la dirección de mayores amplitudes y frecuencias.

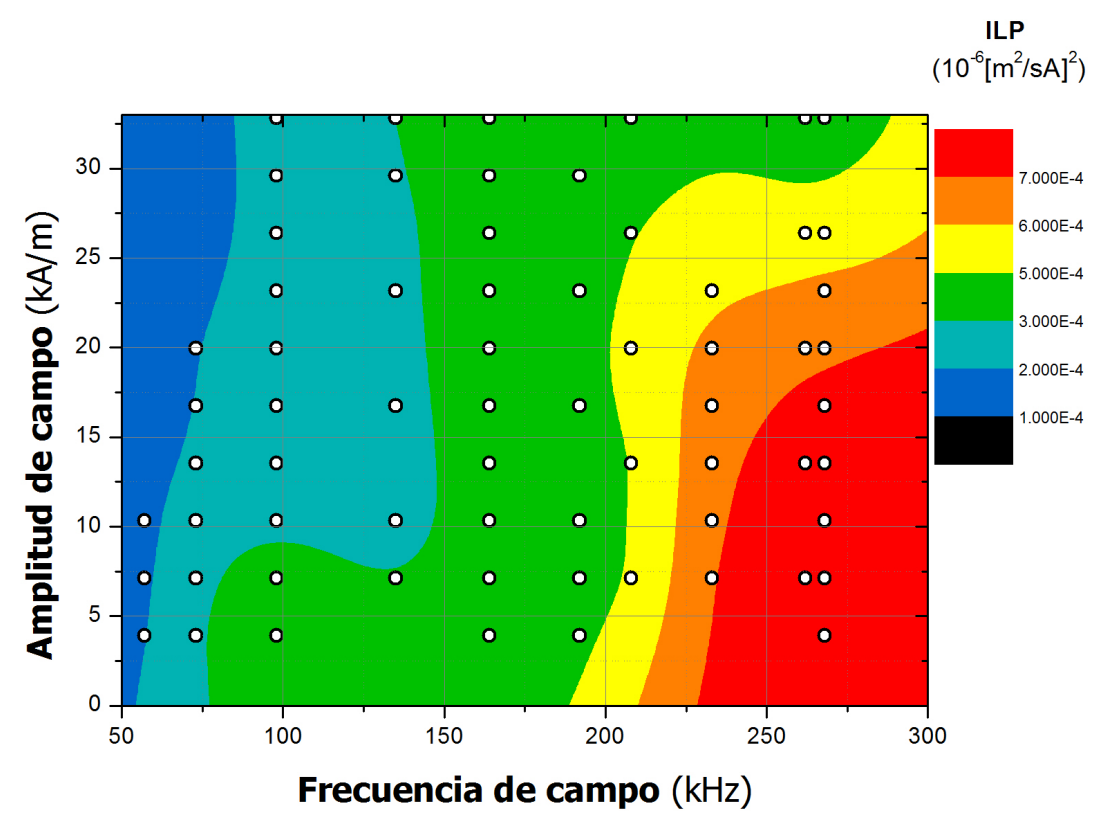

Figura 4.33: Mapa de ILP vs. amplitud de campo vs. frecuencia para el FG de la muestra II. Los círculos blancos indican las medidas experimentales. El mapa de color se genera por interpolación con el programa Origin 8. Se observa el apartamiento del modelo de respuesta lineal para altos campos. 
nética de las NPM. En el caso del FF en matriz de hexano, las partículas son libres de trasladarse y rotar durante la exposición al campo RF mientras que en el FG no pueden realizar ninguno de los dos movimientos. Para las medidas calorimétricas es necesario considerar también la diferencia de calor específico entre las matrices, pero dada la despreciable diferencia de susceptibilidad magnética de los materiales orgánicos respecto al vacío, para las medidas inductivas no se requieren otras consideraciones.

En la figura 4.34 se muestran los ciclos RF del FG y el FF normalizados por la concentración, para un campo de $268 \mathrm{kHz}$ y $32,8 \mathrm{kA} / \mathrm{m}$. Se observa como la magnetización máxima, la remanencia y el área del ciclo son sensiblemente menores en el FF mientras que el campo coercitivo es mayor. Todas estas diferencias se pueden entender como consecuencias de la disminución del tiempo de relajación en el FF al sumarse la contribución del mecanismo de Brown. Como se expuso en el capítulo 2, los tiempos de relajación de los dos mecanismos se combinan por suma de las inversas, por lo que el tiempo resultante siempre será menor que cualquiera de los individuales. Como se observa en los mapas de color, las frecuencias de resonancia de ambos sistemas se encuentran a valores mayores que los utilizados. Se entiende por frecuencia de resonancia del sistema al valor $\omega=1 / \tau$ que maximiza el factor de frecuencia $\omega \tau /\left(1+(\omega \tau)^{2}\right)$ que modula la disipación de potencia. Así, el menor tiempo de relajación de las NPM en el FF implica una frecuencia de resonancia más alejada de la zona estudiada (más a la derecha en los mapas de color) lo que se traduce en menores valores de SAR para las mismas NPM. El aumento del campo coercitivo también es consecuencia de la disminución de $\tau$ en el FF como se desprende de la ecuación 2.36, en donde se explicita una dependencia entre $H_{c}$ y el tiempo de relajación, que si bien es suave, puede ser apreciable para coercitividades pequeñas.

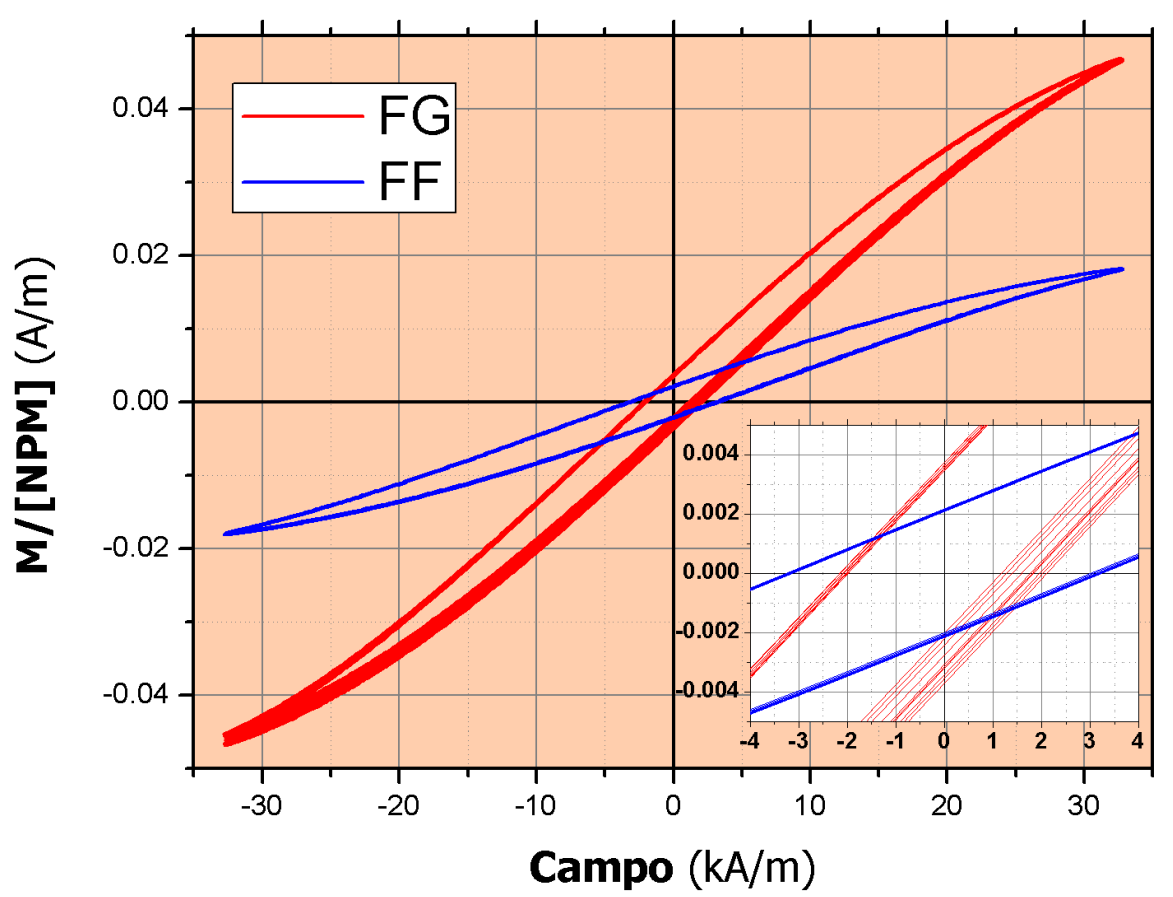

Figura 4.34: Ciclos de magnetización RF del FF y el FG para un campo de $268 \mathrm{kHz}$ y 32,8 $\mathrm{kA} / \mathrm{m}$. Inserto: ampliación de la zona de baja magnetización en la que se aprecia la diferencia de coercitividad. 
Los resultados obtenidos para los dos sistemas se pueden comparar con las simulaciones numéricas con las siguientes consideraciones:

- Si bien el comportamiento cualitativo de las predicciones teóricas presenta un buen acuerdo con los resultados experimentales, las aproximaciones realizadas en el modelo (mínimos de ancho nulo, tiempo de inversión en un sólo sentido, etc.) devienen en general, en valores de magnetización superiores a los medidos, por lo que no se realizan comparaciones en valores absolutos.

- Si bien tanto el FG como el FF son sistemas desordenados, se puso de manifiesto en el capítulo 2 que el modelo de anisotropías arbitrariamente orientadas no reproduce la variación del campo coercitivo con la orientación. Debido a esto, para comparar la dependencia de $H_{C}$ con la frecuencia por ejemplo, es conveniente realizar las simulaciones a partir de las ecuaciones para anisotropías ordenadas ya que requieren menos tiempo de cálculo.

- Los modelos desarrollados tampoco consideran la relajación de Brown como mecanismo de respuesta magnética, por lo que es esperable que las ecuaciones no describan adecuadamente el comportamiento del FF en estado líquido.

En la figura 4.35 se muestra la dependencia de $H_{c}$ con la frecuencia a una amplitud de campo de $13,54 \mathrm{kA} / \mathrm{m}$ para el FF y el FG junto con los resultados numéricos para diferentes valores de la constante de anisotropía K. Como ya se mencionó, el valor de $\mathrm{K}$ efectivo es particular para cada tipo de experimento por lo que es el único parámetro de la simulación del que no se tiene referencia experimental. En la figura se observa como el valor de $\mathrm{K}=16 \mathrm{~kJ} / \mathrm{m}^{3}$ obtenido del experimento ZFC-FC no reproduce los valores de $H_{c}$ experimentales del FG. Naturalmente, el valor $\mathrm{K}=6,6 \mathrm{~kJ} / \mathrm{m}^{3}$ obtenido de la dependencia del $H_{c}$ de los ciclos DC con T presenta un acuerdo aún peor, dado que la coercitividad crece con la constante de anisotropía. Si bien con un valor de $26 \mathrm{~kJ} / \mathrm{m}^{3}$ se logra un buen acuerdo entre los datos simulados y los experimentales, este no debe considerarse definitivo. El FG es un sistema desordenado por lo que, si el modelo reprodujera la disminución de $H_{c}$ de un sistema con orientaciones aleatorias respecto a su correspondiente ordenado, sería necesario un valor aún mayor de $\mathrm{K}$ para reproducir los valores experimentales. También se incluyen en la figura los valores de $H_{c}$ obtenidos de los ciclos RF del FF que son sistemáticamente mayores a los del FG.

\subsubsection{Comparación de resultados electromagnéticos y calorimétricos}

El sistema de relevamiento de ciclos de magnetización RF demostró su buen funcionamiento, tanto para la caracterización de la respuesta magnética de las NPM como para determinar su disipación de potencia específica. En ambos casos los resultados obtenidos mostraron acuerdo cualitativo con las demás técnicas utilizadas. El paso natural entonces es comparar cuantitativamente los resultados de SAR obtenidos con este sistema inductivo con los obtenidos mediante el método calorimétrico convencional.

En la figura 4.36 se muestran los valores absolutos de SAR determinados con ambos sistemas para la muestra II, en función de la amplitud de campo, para una frecuencia de $164 \mathrm{kHz}$. 


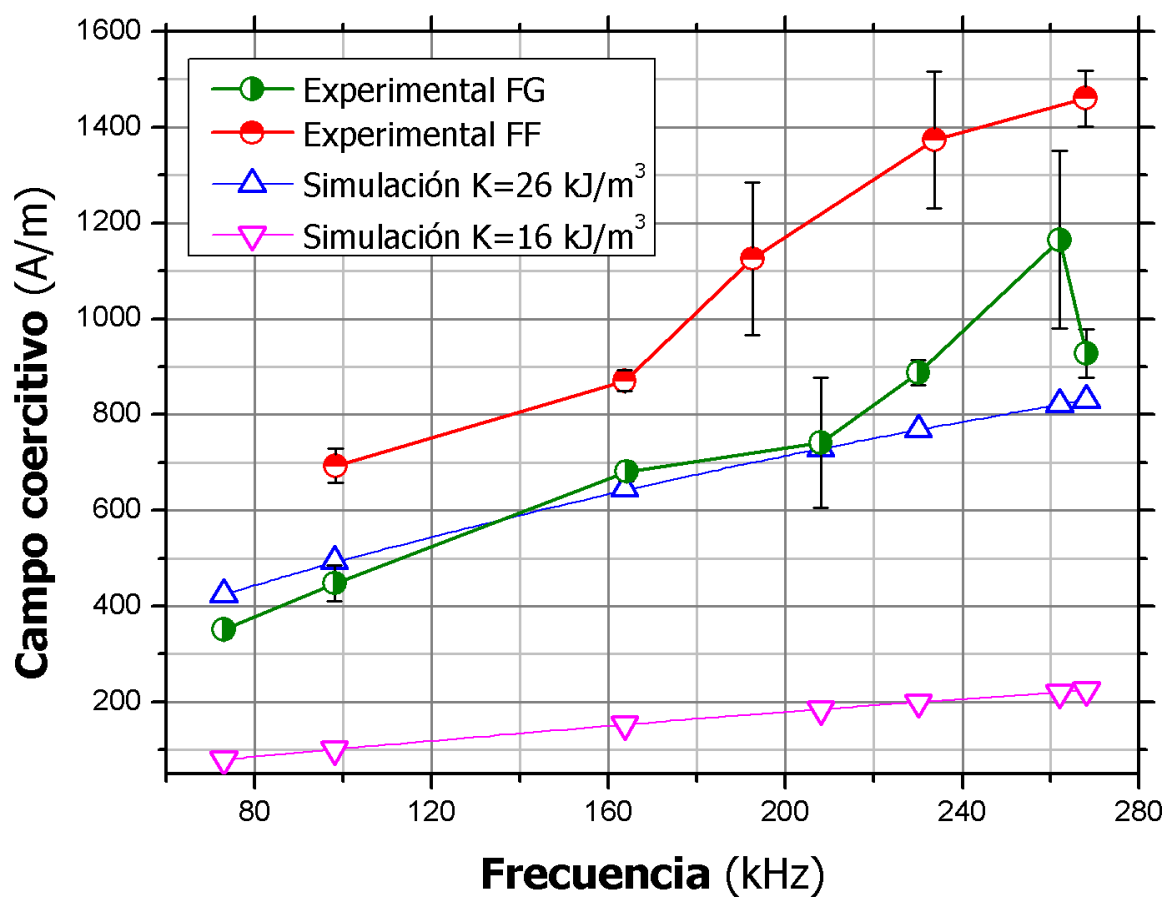

Figura 4.35: Valores de campo coercitivo para los ciclos RF del FG y el FF comparados con resultados de cálculo numérico para diferentes valores de $K$.

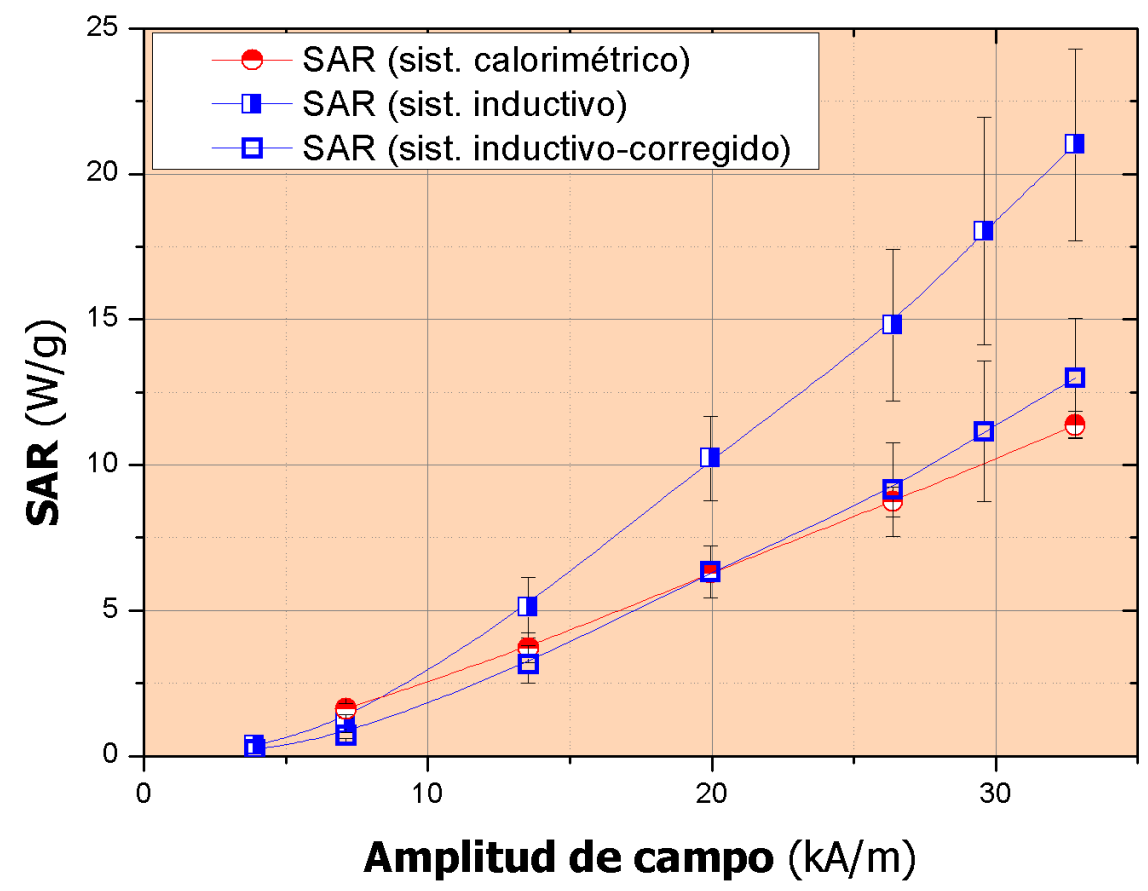

Figura 4.36: Comparación de valores absolutos de SAR para el FF obtenidos con el sistema inductivo y el calorimétrico para una frecuencia de $164 \mathrm{kHz}$. 
Se observa que si bien se encuentran en el mismo rango, siguen tendencias diferentes. En la figura también se incluyen los valores de SAR para el sistema inductivo multiplicados por un factor de escala calculado como el valor medio del cociente entre ambos conjuntos de datos. Estos datos corregidos se superponen con los de SAR calorimétrico a todas las amplitudes de campo. Esto indica que la discrepancia en valores absolutos se debe a un factor de escala que bien puede estar originado por inexactitudes en las cantidades utilizadas en la ecuación 3.7 mediante la que se obtiene la magnetización a partir de la diferencia de potencial en el sistema de bobinas.

\subsubsection{Conclusiones}

Se caracterizó una muestra de NPM de magnetita recubierta con ácido oléico con el fin comprobar las predicciones de los modelos desarrollados en el capítulo 2 y verificar el funcionamiento del sistema de relevamiento de ciclos de magnetización RF cuyo diseño y construcción se explicitó en el capítulo 3.

La muestra utilizada fue elegida por su representatividad en tanto materiales para hipertermia y por sus características estructurales de fácil modelado. La magnetita que compone las NPM de la muestra II es el material más utilizado para la fabricación de FF y su comportamiento macroscópico está bien caracterizado. Además, de todos los materiales contemplados para hipertermia, el hierro y sus óxidos son los únicos aprobados por la FDA para su utilización en humanos. La muestra en cuestión, sintentizada en el Instituto de Nanociencia de Aragón por la doctora Pilar Calatayud, se presentó en forma de FF con matriz de hexano altamente estable, con una distribución de tamaño de partícula bien definida, lognormal un valor medio de $9 \mathrm{~nm}$ y una desviación estándar de $1 \mathrm{~nm}$. Tanto la estabilidad como la distribución de tamaños angosta simplificaron la caracterización y el modelado, por lo que se esperaba un comportamiento similar al predicho, sin anomalías.

Se realizaron medidas ZFC-FC sobre una muestra de FF encapsulada. Se preparó al sistema en dos estados: desordenado, congelando sin campo aplicado; y ordenado, congelando con un campo de 7T para asegurar que todas las NPM se encontraran con su eje de anisotropía paralelo a la dirección del campo. Los resultados mostraron la esperada disminución en los valores de magnetización en el sistema desordenado respecto al ordenado. No se observaron indicios de interacción entre NPM que, de existir, modificarían las curvas ZFC-FC. Debido a que las aproximaciones realizadas en los modelos devienen en general en valores de magnetización mayores que los medidos, la comparación del ZFC-FC del sistema ordenado con su correspondiente simulación debió realizarse entre las curvas normalizadas. Se observa un acuerdo cualitativo razonable, con discrepancias en las temperaturas extremas. La principal diferencia radica en la zona de temperaturas bajas en donde las medidas experimentales muestras un considerable aumento de la magnetización al aplicar el campo. Esto indicaría la existencia de NPM tan pequeñas como para que su temperatura de bloqueo se encuentre por debajo de los 2 K. La simulación no reproduce este comportamiento, posiblemente debido a que las partículas de menor tamaño hayan sido ignoradas en las imágenes TEM o bien por el ajuste lognormal realizado a partir de las mismas para obtener la distribución considerada en la simulación.

Se desarrolló la justificación de un método para determinar la distribución de temperaturas de bloqueo de la muestra, presentado de forma escueta por Micha et al en un trabajo de 2004 
[133]. Se verificó la validez del método mediante simulaciones numéricas comprobando que la derivada en temperatura de la diferencia entre las curvas FW y FC devuelve de forma exacta la distribución de temperaturas de bloqueo. Adicionalmente se comprobó que para sistemas con dispersión de tamaño, la temperatura correspondiente al punto de inflexión de la curva ZFC no es un valor representativo de la distribución como se utiliza extendidamente. A partir de la distribución de volúmenes TEM y de temperaturas de bloqueo obtenidas por el método de Micha, se determinó un valor efectivo para la constante de anisotropía de 16(1) $\mathrm{kJ} / \mathrm{m}^{3}$.

Se relevaron los ciclos de magnetización en función del campo en el rango de temperaturas [2 ; $300]$ K. Se estudió la dependencia del campo coercitivo con la temperatura observando una relación lineal casi exacta entre $H_{c}$ y la raíz cuadrada de T en el rango [2; 18] K cualitativamente idéntica a la predicha por el modelo de dos pozos. A partir de un estos resultados se obtuvo una constante de anisotropía efectiva para este proceso de 6,6(3) $\mathrm{kJ} / \mathrm{m}^{3}$.

Se relevaron los ciclos de magnetización RF de la muestra en suspensión líquida y gelificada, barriendo el rango de frecuencias $([53 ; 268] \mathrm{kHz})$ y amplitudes $([0 ; 48,5] \mathrm{kA} / \mathrm{m})$ disponible. La presentación en forma de ferrogel (FG) permitió estudiar la respuesta magnética de las NPM cuando se elimina el mecanismo de relajación de Brown. Con los datos obtenidos se elaboraron mapas de SLP y ILP en función de la amplitud y la frecuencia del campo RF. Para ambas presentaciones, los mapas de SLP muestran un crecimiento monótono en la dirección de mayores amplitudes y frecuencias, y los mapas ILP muestran saturación para los mayores campos a alta frecuencia. Estos dos comportamientos están predichos por los modelos desarrollados y respaldados por los ciclos RF registrados en tanto se observa la pérdida de linealidad en la respuesta para grandes campos con la aparición de frecuencias adicionales en la dependencia temporal de M.

La comparación entre la respuesta de las NPM en el FF y en el FG pone de manifiesto el efecto del mecanismo de relajación de Brown presente sólo en el FF. La disminución del tiempo de relajación cuando la rotación es posible, desplaza la frecuencia de máximo ILP (proporcional al factor de frecuencia) hacia valores más altos, alejándola de las frecuencias utilizadas, disminuyendo así la disipación efectiva de la muestra. Debido a esto, los ciclos de magnetización normalizados por concentración del FF presentan menor área, lo que se traduce en menores valores de SAR para cada combinación amplitud-frecuencia. Además se observa el efecto del tiempo de relajación en el campo coercitivo, que es menor en el FG.

La dependencia del campo coercitivo con la frecuencia RF presenta cualitativamente la tendencia creciente predicha por los modelos. Debido a la aproximación de mínimos de posición angular constante utilizada en el modelo para sistemas desordenados, el campo coercitivo calculado en estos casos es el mismo que el que se obtiene para el sistema ordenado. Los sistemas desordenados reales en cambio, presentan la misma dependencia de $H_{c}$ con T pero con valores aproximadamente $50 \%$ menores que su correspondiente ordenado [60]. Teniendo esto en cuenta, se intentó reproducir los valores experimentales absolutos de $H_{c}$ del FG a partir de ciclos simulados con el modelo de sistema ordenado (por economía de cálculo). Siendo la constante de anisotropía efectiva K una cantidad propia de cada proceso de magnetización, y desconociendo su valor para los ciclos RF, se la utilizó como parámetro de ajuste para igualar los valores de la simulación a los experimentales, encontrando la mejor coincidencia para $\mathrm{K}=26 \mathrm{~kJ} / \mathrm{m}^{3}$, valor que no debe ser considerado definitivo sino sólo como referencia ya que, por lo antedicho, un sistema desordenado como el FG presentaría valores de $H_{c}$ menores con 
esa constante.

Finalmente, se compararon los valores de SAR del FF obtenidos con el sistema inductivo con los obtenidos por calorimetría. Si bien los valores absolutos son del mismo orden para ambos métodos, la coincidencia no es buena, pero al reescalear los datos inductivos, se encuentra un acuerdo casi total. Esto indica que la discrepancia se da por un factor de escala. Las cantidades involucradas en el cálculo del SAR calorimétrico son bien conocidas y el método se ha demostrado confiable, por lo que seguramente sea necesario revisar el cálculo del SAR determinado con las medidas inductivas. Para transformar los valores de diferencia de potencial entre los extremos del sistema de bobinas en magnetización, se involucran cantidades como el área y el número de vueltas de las bobinas captoras utilizadas. Al tratarse de bobinas muy pequeñas, de aproximadamente $5 \mathrm{~mm}$ de diámetro, fabricadas con alambre de $60 \mu \mathrm{m}$ de espesor, la posición y magnitud del área efectiva es una cantidad difícil de determinar con precisión por lo que, a fin de obtener valores absolutos confiables, una calibración con un método independiente es necesaria. 



\section{Discusión y conclusiones generales}

Capítulo 5 
«Estas no son horas de perfeccionar cosmogonías ajenas sino de crear las propias. Horas de grandes yerros y de grandes aciertos en que hay que jugarse entero a cada momento. Son horas de biblias y no de orfebrerías»

Raúl Scalabrini Ortiz Intelectual argentino

"El hombre que está solo y espera" (Préstamo: V. Martínez

Damonte) 
En esta tesis se desarrollan de manera innovadora 3 aspectos fundamentales de toda investigación en ciencias naturales: el modelado teórico de los sistemas de interés junto con la resolución numérica no trivial de las ecuaciones resultantes, la caracterización experimental exhaustiva de uno de esos sistemas, y el diseño, instrumentación y aplicación de una nueva técnica de caracterización específica, que aporta información de otra manera inaccesible.

Se plantearon las ecuaciones para describir la evolución de la magnetización $\mathrm{M}$ de un conjunto de NPM idénticas con anisotropías paralelas al campo aplicado $\mathrm{H}$, partiendo del modelo de dos pozos de Stoner y Wohlfarth y considerando el efecto de la agitación térmica. Se obtuvo la ecuación diferencial que describe la evolución de $\mathrm{M}$ respecto al tiempo y a partir de esta, se construyeron las ecuaciones para la variación de $\mathrm{M}$ en función del campo aplicado y de la temperatura T. En pos de estudiar la respuesta del sistema en condiciones similares a las experimentales, se obtuvieron las expresiones de $\mathrm{dM} / \mathrm{dH}$ para campos que varían linealmente con el tiempo, como en el caso de la medición convencional de ciclos de histéresis, y para campos que varían sinusoidalmente, como en el caso de los experimentos RF. Por tratarse de ecuaciones sin solución analítica, se implementó un código en lenguaje Matlab ${ }^{\circledR}$ para resolverlas numéricamente y procesar los resultados.

A partir de la ecuación para campo lineal con el tiempo, se estudió la dependencia del campo coercitivo $H_{c}$ con la temperatura. Se incorporó al programa Matlab ${ }^{\circledR}$ una subrutina que determina $H_{c}$ y la magnetización remanente $M_{R}$ de los ciclos calculados interpolando los valores cercanos a cero. Así, se comprobó que $H_{c}$ presenta la relación lineal con $T^{1 / 2}$ esperada. En la literatura se encuentran varios ejemplos de sistemas reales en los que esta relación no se cumple. Para confirmar que esta discrepancia está relacionada con la dispersión de tamaños, se extendió el modelo a sistemas de partículas con distribución lognormal de volúmenes y se implementó en el código como suma discreta pesada por el momento magnético de cada población. Los resultados obtenidos confirman que la existencia de una distribución de tamaños resulta en una pérdida de la linealidad de $H_{c}$ vs. $T^{1 / 2}$. La obtención de esta dependencia es relevante dado que permite determinar la constante de anisotropía efectiva K correspondiente a ese tipo de procesos magnéticos.

A partir de la ecuación para campo sinusoidal, se obtuvieron las curvas M vs. H para diferentes amplitudes y frecuencias de campo. Para frecuencias RF y superiores se encontró que el sistema transcurre por un régimen transitorio inicial en el que los ciclos de magnetización tienen valor medio no nulo y no son cerrados. Fue necesario ampliar el código para que calculara la evolución del sistema durante el número de ciclos necesario para alcanzar el régimen estacionario. Se estudió el comportamiento de la coercitividad y de la remanencia $M_{R}$ bajo los parámetros de campo utilizados en los tratamientos terapéuticos en función de la frecuencia y la amplitud. Se estudió también la dependencia del área de los ciclos (proporcional al SAR) con la amplitud de campo. Se encontró un crecimiento lineal del área con $H^{2}$ para amplitudes bajas, en coincidencia con lo predicho por la teoría de respuesta lineal (TRL). Para amplitudes de campo grandes se reprodujo el apartamiento de la TRL reportado usualmente en la bibliografía. El modelo y las simulaciones permitieron confirmar que este apartamiento está relacionado con la pérdida de linealidad de $\mathrm{M}$ respecto a $\mathrm{H}$ que precede a la saturación de los ciclos.

De esta manera, es posible utilizar el modelo y su implementación numérica para predecir las condiciones óptimas de disipación de potencia para cada muestra antes de realizar los expe- 
rimentos. Los experimentos en donde se estudia la evolución de la magnetización del sistema en función de la temperatura, con diferentes condiciones iniciales y bajo campo constante o nulo, se utilizan para determinar parámetros relevantes como el valor correspondiente de $\mathrm{K}$, la distribucion de $T_{B}$ y a partir de esta, la distribución de volúmenes. Por esto se obtuvieron las ecuaciones diferenciales necesarias para simular los mencionados experimentos a partir de la expresión para dM/dT. A partir de las mismas, se pudo determinar la proporcionalidad entre el tiempo característico de medida del experimento ZFC-FC, que determina el comportamiento superparamagnético del sistema, y la inversa de la tasa de calentamiento utilizada durante las medidas. Se estudió la dependencia del $\tau_{B}$ en función de la $T_{B}$ del sistema, definida en el caso monotamaño como el punto de inflexión de la curva ZFC. Se verificó la validez de la suposición utilizada en la literatura, en la que se utiliza como tiempo de relajación al tiempo característico correspondiente a la inversión desde el mínimo local al absoluto. Se encontró que esta suposición no es exacta, dado que se ignoran las inversiones en sentido opuesto, pero constituye una buena aproximación. Queda para el futuro determinar de qué manera se deben incorporar las transiciones ignoradas en este cálculo.

Se implementó el cálculo de las curvas ZFC-FC para sistemas con distribucion de tamaño. Se investigó la validez del método propuesto por Micha et al para determinar la distribución de $T_{B}$ desarrollando una explicación detallada del fundamento conceptual de la técnica. Los resultados numéricos confirmaron que la derivada d(ZFC-FCW)/dT coincide con la distribucion de temperaturas de bloqueo y que el punto de inflexión de la curva ZFC no es un buen indicador de la $T_{B}$ representativa de un sistema politamaño. Como aporte más innovador para el modelado de sistemas de NPM, se presentó el incipiente desarrollo de un modelo para sistemas con orientación arbitraria de anisotropías respecto al campo. En el estado actual, este modelo es válido para para campos aplicados pequeños respecto al campo de anisotropía $H_{k}=2 \mathrm{~K} /\left(\mu_{0} M_{s}\right)$. A partir de la expresión de $\mathrm{dM} / \mathrm{dt}$ obtenida para estos sistemas, se implementó un código que permite realizar simulaciones de sistemas con distribución uniforme de orientaciones, como son los FF y las muestras solidificadas sin campo aplicado.

En el Grupo de Magnetismo y Materiales Magnéticos se realizan investigaciones en hipertermia magnética en cultivos celulares de líneas cancerígenas internalizadas con NPM. Como parte de su tesis doctoral [151], Diego F. Coral comparó la disposición espacial que adquieren las nanopartículas dentro de las células cuando el proceso de internalización se realiza con y sin campo aplicado. En la figura 5.1 se muestra una imagen TEM representativa de un cultivo de células A549 (adenocarcinoma de pulmón humano) internalizadas con nanopartículas de maghemita de $13 \mathrm{~nm}$ de diámetro recubiertas con ácido dimercaptosuccínico, que fueron expuestas durante el proceso de internalización a un campo magnético homogéneo de 15,1 kA/m. A diferencia de la imagen TEM obtenida sobre la misma línea celular para internalización sin campo (Ver Figura 5.2), cuando se internaliza con campo aplicado se observa la alineacion de los endosomas que contienen partículas. Esto permite inferir que las NPM se encuentran con sus anisotropías alineadas con el campo aplicado. Con este resultado experimental como motivación, se utilizaron los modelos desarrollados, para comparar el rendimiento de un conjunto de partículas con anisotropías desordenadas (internalización sin campo) y uno con anisotropías ordenadas (internalización con campo). Los resultados se exponen en la figura 2.20 y llevan a concluir que el SAR de un sistema ordenado es notoriamente mayor que el del mismo sistema con distribución uniforme de orientaciones. En este punto es necesario considerar las limitacio- 
nes del modelo, principalmente originadas en la aproximación de mínimos de posición angular fija. Esta aproximación, además de limitar la validez del modelo a campos externos menores a $0,1 H_{K}$, provoca que los ciclos calculados presenten la misma coercitividad que sus equivalente ordenados. Esto no reproduce el comportamiento real, en donde se observa que los sistemas desordenados presentan coercitividades menores que los ordenados. Considerando esto, se concluye que el área de los ciclos de sistemas desordenado debería ser aún menor que la obtenida. Por otro lado, la posición fija de los mínimos es una aproximación más inexacta cuanto más perpendicular es la orientación de la NPM respecto al campo. Así, los ciclos correspondientes a NPM con sus anisotropías a $90^{\circ}$ respecto a la dirección de campo, no presentan magnetización en las simulaciones, mientras el cálculo exacto para esa dirección indica que tienen una respuesta tipo paramagnética. Esto significa que el modelo subestima el aporte a la magnetización total de las NPM menos alineadas con el campo. Aún, así, considerando que en términos de energía disipada este aporte es pequeño, los ciclos obtenidos se pueden tomar como una buena aproximación al comportamiento real. Esto lleva a concluir finalmente que la aplicación de un campo DC durante la introducción de las NPM en la zona de objetivo de la hipertermia y/o durante el calentamiento, podría aumentar la disipación de potencia.

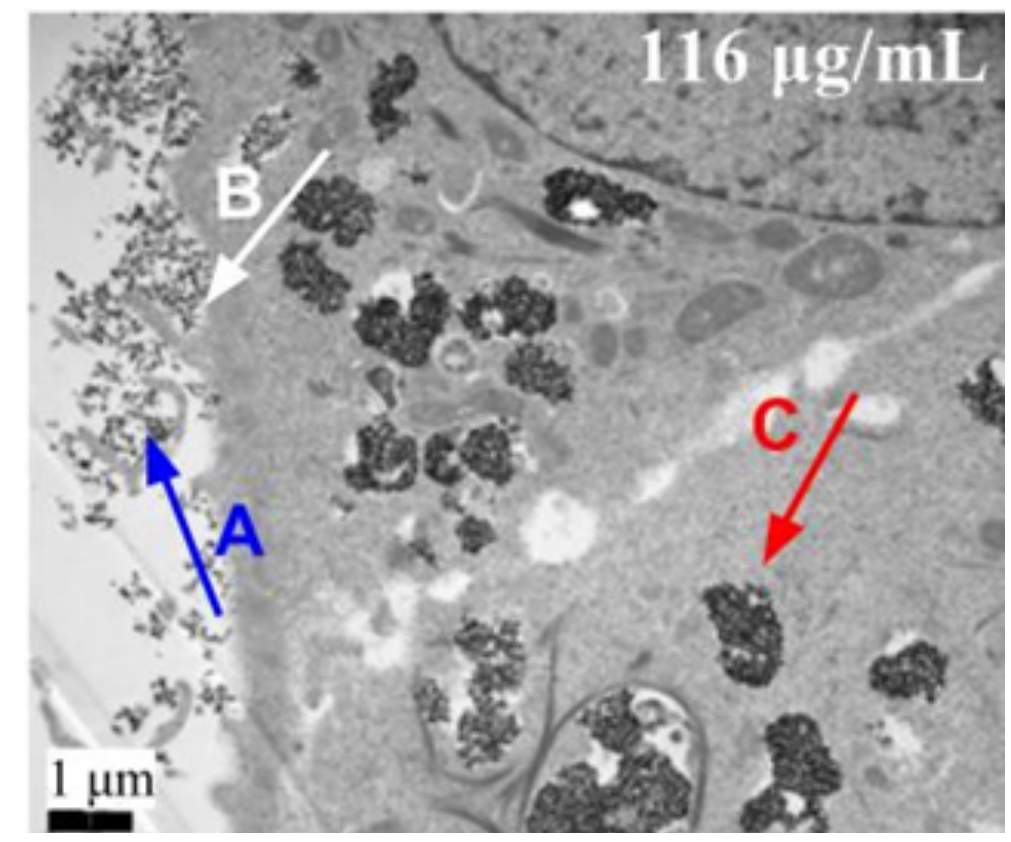

Figura 5.1: Imagen TEM obtenida sobre un cultivo celular internalizado con NPM. Se observan NPM en el exterior de la célula (flecha A), NPM en el estadio inicial de la fagocitosis en el que las NPM comienzan a ser abrazados por los pseudópodos (flecha B), y NPM dentro de los endosomas en el interior de la célula (flecha C).

Debido a la dependencia de las condiciones de medida que presentan varios de los parámetros relevantes para caracterizar NPM para hipertermia, resulta sumamente ventajoso contar con técnicas que permitan estudiar el comportamiento de las muestras en condiciones similares a las de la aplicación. Esto implica tanto a la matriz en la que están soportadas las NPM (densidad, viscosidad, separación entre partículas) como a las características del campo aplicado (amplitud, frecuencia). Así, con el objetivo de estudiar el comportamiento de las partículas en 

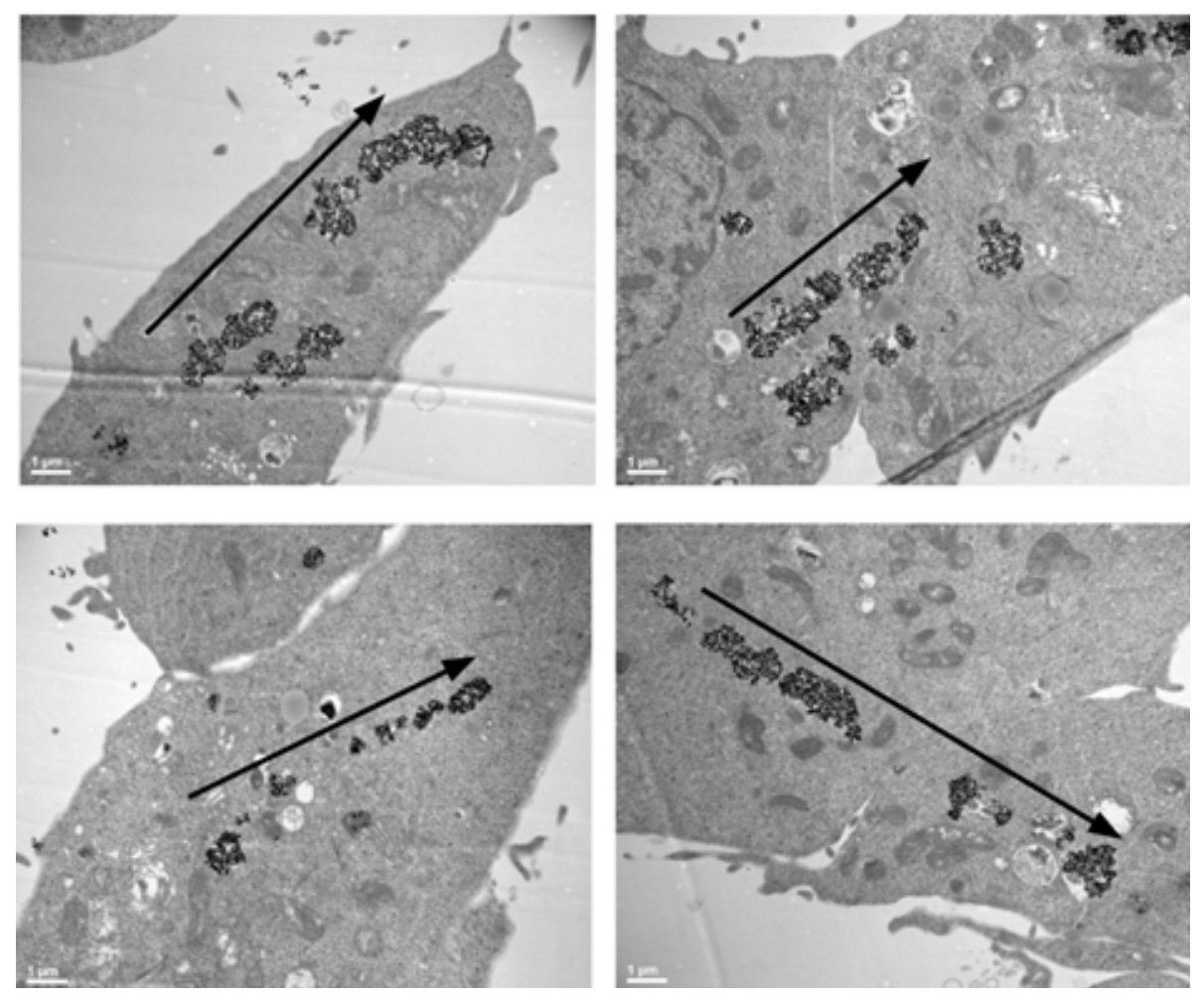

Figura 5.2: Imagen TEM obtenida sobre un cultivo celular internalizado con NPM mientras es expuesto a un campo magnético de $15 \mathrm{kA} / \mathrm{m}$. Se observa la alineación de los endosomas.

suspensión sometidas a los mismos campos utilizados en la aplicación, se diseñó, construyó e implementó un sistema para relevar ciclos de histéresis RF. El sistema completo está constituido por un arreglo de bobinas captoras, un posicionador/portamuestra, un osciloscopio para registrar las diferencias de potencial generadas y un código Matlab $^{\circledR}$ para procesar los datos y calcular las magnitudes relevantes de los ciclos obtenidos. Adicionalmente, el rango de frecuencias y campos accesibles mediante el generador RF fue ampliado con la adquisición de capacitores adicionales y el diseño y construcción de bobinas externas de diferentes características, si bien sólo una de estas se utilizó durante este trabajo. Tanto la estabilidad como la geometría del campo generado para cada una de las nuevas configuraciones debió ser caracterizada explorando los límites de confiabilidad del dispositivo.

Se caracterizó exhaustivamente una serie de muestras de NPM de magnetita dopada con Zn para estudiar el efecto del dopaje en la disipación de potencia vía la modificación de la magnetización de saturación. Las muestras fueron sometidas a todas las técnicas de caracterización disponible en el momento a saber: microscopías TEM y SEM, magnetometrías DC a RT (VSM) y en función de la temperatura (SQuID), dispersión y difracción de rayos X, espectroscopía Mössbauer y medidas calorimétricas de disipación de potencia bajo campos RF. A partir de los resultados obtenidos, se confirmó la incorporación del Zn en los sitios A de la espinela de la magnetita y se verificó el aumento de la magnetización de saturación para un dopaje $\mathrm{x}=[0,1$; 0,3]. Todo el resto de la caracterización estuvo condicionado por la gran dispersión de tamaños 
entre las muestras con diferente dopaje y la dispersión propia de cada muestra. Así, no se encontró una dependencia sistemática del SAR en función del dopaje debido a la preponderancia de los efectos de tamaño sobre la respuesta de las muestras a los campos RF. La caracterización se completó entonces centrándose en determinar el mecanismo de disipación dominante para cada tamaño. De esta manera se encontró una sistematicidad en la dependencia de los tiempos de relajación con el tamaño medio de cada muestra, logrando una descripción autoconsistente del comportamiento de todas las series.

El sistema de medición de ciclos RF fue utilizado para caracterizar una muestra de NPM de magnetita originalmente suspendida en hexano. La muestra se seleccionó por su elevada estabilidad y distribución de tamaños estrecha a fin de facilitar la caracterización experimental y el modelado. Sin embargo, el hexano resultó problemático para la caracterización debido a su volatilidad, por lo que fue necesario realizar los experimentos cuidando que la concentración no se modificara por evaporación. Se relevaron los ciclos de histéresis RF para la muestra original como FF y para un ferrogel fabricado diluyendo el FF en GelWax. De esta manera se contó con dos muestras de nanopartículas provenientes de la misma síntesis, una en matriz fluida y otra en matriz sólida. Así fue posible comparar el comportamiento de las NPM sometidas a campos RF considerando un sólo mecanismo de relajación (el de Nèel en el FG) o la combinación de ambos (Nèel y Brown en el FF). Con los resultados obtenidos se elaboraron mapas de SAR vs. $\mathrm{H}$ vs. f e ILP vs. H vs. f para ambas presentaciones de la muestra encontrando un crecimiento monótono del SAR en la dirección de mayores campos y frecuencias con una saturación para grandes amplitudes de campo. Esta tendencia fue confirmada por los mapas de ILP elaborados que muestran los máximos valores en la región de altas frecuencias y campos bajos. Al contar con los ciclos RF, se pudo asociar este comportamiento con la tendencia a la saturación de las curvas $\mathrm{M}$ vs. H para grandes amplitudes de campo. Esta tendencia determina el límite de validez de la teoría de respuesta lineal utilizada en el formalismo más extendido para la disipación de potencia por NPM bajo campos RF.

De la comparación de los valores del SAR para el FF y el FG se observó como la disminución del tiempo de relajación por la presencia del mecanismo de Brown en el FF se tradujo en una frecuencia de resonancia más elevada y por ende más alejada del rango utilizado. Esto se manifestó como una disminución del SAR de las NPM en suspensión líquida respecto a las fijadas en el FG, evidenciada en la comparación de los ciclos de magnetización RF. Con esto se ilustra de forma cuantitativa como la eficiencia de la hipertermia está determinada por la combinación de las características de las NPM y del campo utilizados y no por estos factores de forma independiente. Vale mencionar que, como se ha reportado extensamente en la bibliografía, las NPM incorporadas en las células se encuentran confinadas en endosomas o adheridas a la membrana, situaciones en las que el mecanismo de Brown no es viable. De esta manera, la respuesta de las NPM soportadas en el FG sería la más correspondiente con la aplicación en hipertermia clínica. Otro factor a tener en cuenta son los efectos de interacción interpartícula seguramente presentes en las NPM internalizadas. Este aspecto no fue tratado en este trabajo pero constituye el tema central de la susodicha tesis de Diego Coral.

Tanto en el formalismo teórico como en los resultados experimentales se pone de manifiesto el papel determinante que juega la constante de anisotropía $\mathrm{K}$, al punto que constituyó un pa- 
rámetro a determinar en la mayoría de los experimentos realizados. Junto con su importancia, $\mathrm{K}$ tiene la característica de estar lejos de ser un parámetro de control. Mediante diferentes estrategias de síntesis es posible controlar en algún grado la distribución de tamaños y geometría de la muestra, su magnetización de saturación o la magnitud de las interacciones interpartícula, pero no K. La constante de anisotropía, si bien se sabe dependiente de la estructura cristalina, la forma y los efectos de superficie, es típicamente difícil de controlar. De hecho hecho su denominación como "constante" es sólo una expresión de deseo en el caso de NPM ya que no sólo está afectada por la temperatura sino que, como quedó sólidamente demostrado en este trabajo, su valor efectivo depende del proceso de magnetización considerado.

Finalmente se comparan los resultados de SAR obtenidos con el sistema inductivo con los determinados a partir del sistema calorimétrico convencional. El sistema inductivo no fue sujeto a ningún tipo de calibración, ni con una muestra patrón (difícil de definir para estas medidas), ni con una determinación alternativa de las mismas cantidades. Los valores absolutos entregados por el sistema surgen de transformar las diferencias de potencial de salida en magnetización y campo, según las ecuaciones de Maxwell y los valores nominales de los componentes del sistema, muchos de los cuales no son fáciles de determinar. Considerando esto, la obtención de valores de SAR en el mismo orden que los calorimétricos constituye un primer resultado alentador dado que el sistema se puso en funcionamiento en los meses previos a la presentación de este trabajo. Además, se comprobó que la discrepancia entre las medidas consiste sólo en un factor de escala y por ende, es fácilmente corregible. Los más probable es que el origen de esta "descalibración" esté en los valores de área de las bobinas captoras que, por su reducido tamaño y limitada regularidad vuelven difícil su estandarización. Estas bobinas son muy susceptibles de dañarse durante los experimentos y tuvieron que ser reemplazadas repetidas veces.

El resultado final de este trabajo incluye conocimiento fáctico sobre el comportamiento de dos sistemas reales particulares y predicciones teóricas generales sobre la respuesta magnéticas de sistemas de nanopartículas. Sin embargo, en opinión del autor y su director, los aportes más valiosos de esta tesis son los desarrollos metodológicos presentados, tanto teóricos como experimentales. Más que la obtención de resultados cuantitativos concretos, se buscó demostrar la potencialidad predictiva de los modelos elaborados en combinación con su implementación numérica, de la combinación de técnicas experimentales para la caracterización de sistemas reales, y de una técnica ad hoc desarrollada desde su diseño hasta su utilización final.

Así es como quedan planteadas dos líneas principales de trabajo a futuro. El modelo para la magnetización de sistemas de NPM orientadas al azar, presentado aquí como una primera aproximación, es susceptible de continuar siendo profundamente desarrollado a fin de mejorar la exactitud de sus predicciones y ampliar su rango de validez. De la misma manera, el sistema de medición de ciclos RF, del que se muestran los primeros resultados, posee varios aspectos a mejorar y los datos obtenidos pueden brindar muchas más información de la detallada en esta memoria.

En resumen, permitiéndome en estas líneas finales el uso de la primera persona y de la licencia poética, creo que esta tesis hace más por abrir puertas que por explorar las habitaciones. 
La invitación a recorrer el edificio queda abierta.

Ignacio J. Bruvera

La Plata, 10 de marzo de 2015 



\section{Referencias Bibliográficas}

[1] OMS I Datos y cifras sobre el cáncer."2012. 1 Jul. 2014

http: / /www.who.int/cancer/about/facts/es/

[2] WHO I The top 10 causes of death - World Health Organization 2007. 29 Nov. 2014

http://www.who.int/mediacentre/factsheets/fs310.pdf

[3] OMS I Tratamiento del cáncer."2005. 29 Nov. 2014

http://www. who.int/cancer/treatment/es/

[4] Hahn, G.M. Metabolic aspects of role of hyperthermia in mammalian-cell inactivation and their possible relevance to cancer treatment.Cancer Res 1974, 34, 3117-3123

[5] Wust, P.; Hildebrandt, B.; Sreenivasa, G.; Rau, B.; Gellermann, J.; Riess, H.; Felix, R.; Schlag, P.M. Hyperthermia in combined treatment of cancer. Lancet Oncol 2002, 3, 487-497.

[6] Vernon, C.C.; Hand, J.W.; Field, S.B.; Machin, D.; Whaley, J.B.; van der Zee, J.; van Putten, W.L.J.; van Rhoon, G.C.; van Dijk, J.D.P.; Gonzalez, D.G.; Liu, F.F.; Goodman, P.; Sherar, M. Radiotherapy with or without hyperthermia in the treatment of superficial localized breast cancer: Results from five randomized controlled trials. Int J Radiat Oncol 1996, 35, 731-744.

[7] V Fortin, J.P.; Wilhelm, C.; Servais, J.; Menager, C.; Bacri, J.C.; Gazeau, F. Size sorted anionic iron oxide nanomagnets as colloidal mediators for magnetic hyperthermia. J Am Chem Soc 2007, 129, 2628-2635.

[8] Jordan, A.;Scholz, R.; Wust, P.; Fähling, H.; Felix, R. Magnetic fluid hyperthermia (MFH): Cancer treatment with AC magnetic field induced excitation of biocompatible superparamagnetic nanoparticles. J Magn Magn Mater 1999, 201, 413-419.

[9] Hilger, I.; Hergt, R.; Kaiser, W.A. Use of magnetic nanoparticle heating in the treatment of breast cancer.IEE Proc Nanobiotechnol. 2005, 152, 33-39.

[10] Tartaj, P.; Del Puerto Morales, M.; Veintemillas-Verdaguer, S.; Gonzalez-Carreño, T.; Serna, C.J.The preparation of magnetic nanoparticles for applications in biomedicine. J Phys D: Appl Phys 2003, 36, R 182-97.

[11] Gazeau, F.; Levy, M.; Wilhelm, C. Optimizing magnetic nanoparticle design for nanothermotherapy. Nanomedicine-UK 2008, 3, 831-844.

[12] Kaman, O.; Pollert, E.; Veverka, P.; Veverka, M.; Hadova, E.; Knizek, K.; Marysko, M.; Kaspar, P.; Klementova, M.; Grunwaldova, V.; Vasseur, S.; Epherre, R.; Mornet, S.; Goglio, G.; Duguet, E. Silica encapsulated manganese perovskite nanoparticles for magnetically induced hyperthermia without the risk of overheating. Nanotechnology 2009, 20, 275610.

[13] Atsarkin, V.A.; Levkin, L.V.; Posvyanskiy, V.S.; Melnikov, O.V.; Markelova, M.N.; Gorbenko, O.Y.; Kaul, A.R. Solution to the bioheat equation for hyperthermia with $\mathrm{La}_{1-x} A g_{y} \mathrm{MnO}_{3-\hat{I}}$, nanoparticles: The effect of temperature autostabilization. Int J Hyperthermia 2009, 25, 240-247.

[14] Gazeau, F.; Levy, M.; Wilhelm, C. Optimizing magnetic nanoparticle design for nanothermotherapy. NanomedicGonzález-Fernández, M.A.; Torres, T.; Andrés-Vergés, M.; Costo, R.; de la Presa, P.; Serna, C.J.; Morales, M.P.; Marquina, C.; Ibarra, M.R.; Goya, G.F. Magnetic Nanoparticles for Power Absorption: optimizing size, shape and magnetic properties. J Solid State Phys doi:10.1016/j.jssc.2009.07.047 
[15] Maier-Hauff, Klaus et al. Intracranial thermotherapy using magnetic nanoparticles combined with external beam radiotherapy: results of a feasibility study on patients with glioblastoma multiforme."Journal of neuro-oncology 81.1 (2007): 53-60

[16] Johannsen, M et al. Çlinical hyperthermia of prostate cancer using magnetic nanoparticles: presentation of a new interstitial technique. "International journal of hyperthermia 21.7 (2005): 637-647.

[17] "MagForce AG-Overview."2005. 29 Nov. 2014

http://www.magforce.de/en/studien.html

[18] Maxwell, James Clerk. A treatise on electricity and magnetism. Clarendon press, 1881.

[19] Neuringer, Joseph L, and Ronald E Rosensweig. "Ferrohydrodynamics. "Physics of Fluids (19581988) 7.12 (1964): 1927-1937.

[20] Streffer, C, and D Van Beuningen. "The biological basis for tumour therapy by hyperthermia and radiation." Hyperthermia and the Therapy of Malignant Tumors (1987): 24-70.

[21] Cullity, Bernard Dennis, and Chad D Graham. Introduction to magnetic materials. John Wiley and Sons, 2009.

[22] Pankhurst, Quentin A et al. "Applications of magnetic nanoparticles in biomedicine."Journal of physics D: Applied physics 36.13 (2003): R167.

[23] Spaldin, Nicola A. Magnetic materials: fundamentals and applications. Cambridge University Press, 2010.

[24] Bruvera, I. J., Hernández, R., Mijangos, C., et Goya, G. F. (2015). An integrated device for magnetically-driven drug release and in situ quantitative measurements: Design, fabrication and testing. Journal of Magnetism and Magnetic Materials, 377, 446-451.

[25] Adams, Paul E. "Determining iron content in foods by spectrophotometry."Journal of chemical education 72.7 (1995): 649.

[26] Niazi, A., Poddar, P., et Rastogi, A. K. (2000). A precision, low-cost vibrating sample magnetometer. current science, 79(1), 99-109.

[27] B. Chesca, R. Kleiner, D. Koelle. The SQUID Handbook Vol. I. Cap 2. SQUID Theory. Ed. Wiley-Vch. 2004.

[28] R.C. Black, F.C. Wellstood. The SQUID Handbook Vol. II. Cap 12.Measurements of Magnetism and Magnetic Properties of Matter. Ed. Wiley-Vch. 2004.

[29] Tasaki, J, and T Izushi. "Behaviors of Additives in Ferrites. "Le Journal de Physique Colloques 38.C1 (1977): C1-175-C1-178.

[30] Smith, DO. "Magnetization of a magnetite single crystal near the curie point. "Physical Review 102.4 (1956): 959.

[31] "Physics of Ferromagnetism - Scribd."2010. 7 May. 2014

http://www.magforce.de/en/studien.html

[32] Hergt, Rudolf et al. "Magnetic properties of bacterial magnetosomes as potential diagnostic and therapeutic tools."Journal of Magnetism and Magnetic Materials 293.1 (2005): 80-86.

[33] C Marquina, M A Gonzalez-Fernandez, M A Verges, R Costo, C J Serna, M P Morales, T.E. Torres, M R Ibarra and G F Goya. $\mathrm{Fe}_{3} \mathrm{O}_{4}$ Nanoparticles for Biomedical Applications. "2009. 17 Apr. 2014 http://www.nanospainconf.org/2009/Posters/NanoSpain2009_Marquina. pdf 
[34] Quispelaya, Patricia. Tesis de grado: "Ferrofluidos biocompatibles: Preparacíon y propiedades". LAFMACEL. FIUBA. Mayo 2013.

[35] Sun, Shouheng et al. "Monodisperse MFe2O4 (M=Fe, Co, Mn) nanoparticles."Journal of the American Chemical Society 126.1 (2004): 273-279.

[36] Roca, AG et al. "Structural and magnetic properties of uniform magnetite nanoparticles prepared by high temperature decomposition of organic precursors. "Nanotechnology 17.11 (2006): 2783.

[37] Salas, G., Casado, C., Teran, F. J., Miranda, R., Serna, C. J., Morales, M. P. Controlled synthesis of uniform magnetite nanocrystals with high-quality properties for biomedical applications. Journal of Materials Chemistry, Vol. 22(39), 21065. 2012

[38] Nakashima, Seisuke et al. "First-principles XANES simulations of spinel zinc ferrite with a disordered cation distribution." Physical Review B 75.17 (2007): 174443.

[39] Stewart, SJ et al. "Cationic exchange in nanosized $\mathrm{ZnFe} \mathrm{e}_{2} \mathrm{O}_{4}$ spinel revealed by experimental and simulated near-edge absorption structure. "Physical Review B 75.7 (2007): 073408.

[40] Vandenberghe, RE et al. "Mössbauer characterization of iron oxides and (oxy) hydroxides: the present state of the art. "Hyperfine Interactions 126.1-4 (2000): 247-259.

[41] Hergt, Rudolf et al. "Magnetic properties of bacterial magnetosomes as potential diagnostic and therapeutic tools. "Journal of Magnetism and Magnetic Materials 293.1 (2005): 80-86.

[42] Fortin, Jean-Paul, Florence Gazeau, and Claire Wilhelm. "Intracellular heating of living cells through Neel relaxation of magnetic nanoparticles." European Biophysics Journal 37.2 (2008): 223228.

[43] Fiorani, D et al. "Magnetic properties of maghemite nanoparticle systems: surface anisotropy and interparticle interaction effects. "Physica B: Condensed Matter 320.1 (2002): 122-126.

[44] Kaiser, $R$, and $G$ Miskolczy. "Magnetic properties of stable dispersions of subdomain magnetite particles."Journal of Applied Physics 41.3 (2003): 1064-1072.

[45] Kim, DK et al. "Synthesis and characterization of surfactant-coated superparamagnetic monodispersed iron oxide nanoparticles. "Journal of Magnetism and Magnetic Materials 225.1 (2001): 30-36.

[46] Knobel, $M$ et al. "Superparamagnetism and other magnetic features in granular materials: a review on ideal and real systems. "Journal of Nanoscience and Nanotechnology 8.6 (2008): 2836-2857.

[47] Sorensen, C. M. (2002) Magnetism, in Nanoscale Materials in Chemistry (ed K. J. Klabunde), John Wiley and Sons, Inc., New York, USA. doi: 10.1002/0471220620.ch6

[48] Vandenberghe, Robert E, and Eddy De Grave. "Mössbauer effect studies of oxidic spinels. "Mössbauer spectroscopy applied to inorganic chemistry (1989): 59-182.

[49] Vandenberghe, RE et al. "Mössbauer characterization of iron oxides and (oxy) hydroxides: the present state of the art."Hyperfine Interactions 126.1-4 (2000): 247-259.

[50] Chen, Wen-Tong et al. "Investigations of group 12 (IIB) metal halide/pseudohalide-Bipy systems: syntheses, structures, properties, and TDDFT calculations (Bipy=2, 2'-bipyridine or 4, 4'bipyridine)." Crystal growth and design 6.10 (2006): 2289-2300.

[51] M. Shliomis, Sov. Phys. Uspekhi (Engl. transl.) 17 (2)(1974) 153.

[52] Beković, Milos et al. "An experimental study of magnetic field and temperature dependence on magnetic fluid's heating power." Journal of Magnetism and Magnetic Materials 331 (2013): 264-268. 
[53] Mehdaoui, B et al. "Influence of a transverse static magnetic field on the magnetic hyperthermia properties and high frequency hysteresis loops of ferromagnetic FeCo nanoparticles." Applied Physics Letters 100.5 (2012): 052403.

[54] Dutz, Silvio, and Rudolf Hergt. "Magnetic particle hyperthermia:a promising tumour therapy?."Nanotechnology 25.45 (2014): 452001.

[55] Mamelak A.N., and Jacoby, D.B. Targeted delivery of antitumoral therapy to glioma and other malignancies with synthetic chlorotoxin (TM 601) Expert Opin. Drug Drliv. (2007) 4(2):175 186.

[56] Guo, Ming, and Bruce A Hay. Cell proliferation and apoptosis. Current opinion in cell biology 11.6 (1999): 745-752.

[57] Kaur, Punit et al. Çombined hyperthermia and radiotherapy for the treatment of cancer.Çancers 3.4 (2011): 3799-3823.

[58] Kallumadil, Mathew et al. "Suitability of commercial colloids for magnetic hyperthermia." Journal of Magnetism and Magnetic Materials 321.10 (2009): 1509-1513.

[59] Zelis, P. M., Pasquevich, G. A., Stewart, S. J., van Raap, M. F., Aphesteguy, J., Bruvera, I. J.,Laborde, C.,Pianciola, B ., Jacobo, et Sanchez, F. H. (2013). Structural and magnetic study of zinc-doped magnetite nanoparticles and ferrofluids for hyperthermia applications. Journal of Physics D: Applied Physics, 46(12), 125006.

[60] Stoner, Edmund C, and EP Wohlfarth. "A mechanism of magnetic hysteresis in heterogeneous alloys." Philosophical Transactions of the Royal Society of London. Series A. Mathematical and Physical Sciences (1948): 599-642.

[61] Lu, Jing Ju, Huei Li Huang, and Ivo Klik. Field orientations and sweep rate effects on magnetic switching of Stoner-Wohlfarth particles. Journal of applied physics 76.3 (1994): 1726*1732.

[62] Usov, NA, and Yu B Grebenshchikov. Hysteresis loops of an assembly of superparamagnetic nanoparticles with uniaxial anisotropy. Journal of Applied Physics 106.2 (2009): 023917.

[63] Carrey, J., Mehdaoui, B., et Respaud, M. (2011). Simple models for dynamic hysteresis loop calculations of magnetic single-domain nanoparticles: Application to magnetic hyperthermia optimization. Journal of Applied Physics, 109(8), 083921.

[64] Usov, NA. Numerical simulation of field-cooled and zero field-cooled processes for assembly of superparamagnetic nanoparticles with uniaxial anisotropy. Journal of Applied Physics 109.2 (2011): 023913.

[65] Daniel, Eric D, C Denis Mee, and Mark H Clark. Magnetic recording: the first 100 years. John Wiley and Sons, 1999.

[66] Heider, Franz, David J Dunlop, and Naoji Sugiura. "Magnetic properties of hydrothermally recrystallized magnetite crystals. "Science 236.4806 (1987): 1287-1290.

[67] De Sousa, M Elisa et al. "Stability and relaxation mechanisms of citric acid coated magnetite nanoparticles for magnetic hyperthermia."The Journal of Physical Chemistry C 117.10 (2013): 54365445.

[68] Dunlop, DJ. “Magnetic properties of fine particle hematite.” Ann. Geophys 27.3 (1971): 269-293.

[69] Dutz, Silvio et al. "Magnetic multicore nanoparticles for hyperthermia influence of particle immobilization in tumour tissue on magnetic properties. "Nanotechnology 22.26 (2011): 265102.

[70] Odenbach, S. "Ferrofluids magnetically controlled suspensions. “ Colloids and Surfaces A: Physicochemical and Engineering Aspects. 217.1 (2003): 171-178. 
[71] Brown W F 1963 Thermal fluctuations of a single domain particle Phys. Rev. 130167786

[72] Khalafalla S E and Reimers GW 1980 Preparation of dilution stable aqueous magnetic fluids IEEE Trans. Magn. 1617883

[73] Massart R 1980 Preparation of aqueous ferrofluids without using surfactant behavior as a function of the pH and the counterions C. R. Hebd. Seances Acad. Sci. C 29113

[74] Hugounenq $P$ et al 2012 Iron oxide monocrystalline nanoflowers for highly efficient magnetic hyperthermia J. Phys. Chem. 1161570212

[75] Lartigue L, Hugouneng P, Alloyeau D, Clarke S P, Levy M, Bacri JC, Bazzi R, Brougham D F, Wilhelm $C$ and Gazeau $F 2012$ Cooperative organization in iron oxide multicore nanoparticles potentiates their efficiency as heating mediators and MRI contrast agents ACS Nano 6 10935-49

[76] Hyeon T, Lee S S, Park J, Chung Y and Bin Na H 2001 Synthesis of highly crystalline and monodisperse maghemite nanocrystallites without a size selection process J. Am. Chem. Soc. 123 12798-801

[77] Park J et al 2005 One nanometer scale size controlled synthesis of monodisperse magnetic iron oxide nanoparticles Angew. Chem. Int. Ed. 44 2872-7

[78] Gonzales-Weimuller M, Zeisberger M and Krishnan K M 2009 Size dependant heating rates of iron oxide nanoparticles for magnetic fluid hyperthermia J. Magn. Magn. Mater. 321 1947-50

[79] Khandhar A P, Ferguson R M, Simon J A and Krishnan K M 2012 Enhancing cancer therapeutics using size optimized magnetic fluid hyperthermia J. Appl. Phys. $1117 B 3061$

[80] Levy M et al 2011 Correlating magneto structural properties to hyperthermia performance of highly monodisperse iron oxide nanoparticles prepared by a seeded-growth route Chem. Mater. 23 4170-80

[81] Hao Y L and Teja A S 2003 Continuous hydrothermal crystallization of alpha-Fe2O3 and Co3O4 nanoparticles J. Mater. Res. 18 415-22

[82] Xи C and Teja A S 2008 Continuous hydrothermal synthesis of iron oxide and PVA-protected iron oxide nanoparticles J. Supercrit. Fluids 44 85-91

[83] Coyle S T and Scheinfein M R 1998 Magnetic ordering in Co films on stepped Cu(100) surfaces J. Appl. Phys. 83 7040-2

[84] Langevin D 1992 Micelles and microemulsiond Annu. Rev. Phys. Chem. 43 341-69

[85] Petrosyan A K and Mirzakhanyan A A 1986 Zero field splitting and $G$ values of D8 ions in a trigonal crystal field Phys. Status Solidi b 133 315-9

[86] Okoli C, Sanchez Dominguez M, Boutonnet M, Jaras S, Civera C, Solans C and Kuttuva G R 2012 Comparison and functionalization study of microemulsion prepared magnetic iron oxide nanoparticles Langmuir 28 8479-85

[87] Zeng Q, Baker I, Loudis J A, Liao Y, Hoopes P J and Weaver J B 2007 Fe/Fe oxide nanocomposite particles with large specific absorption rate for hyperthermia Appl. Phys. Lett. 90233112

[88] Kurland H D, Grabow J, Staupendahl G, Andrae W, Dutz S and Bellemann M E 2007 Magnetic iron oxide nanopowders produced by CO2 laser evaporation J. Magn. Magn. Mater. 311 73-7

[89] Moras K, Schaarschuch R, Riehemann W, Zinoveva S, Modrow H and Eberbeck D 2005 Production and characterisation of magnetic nanoparticles produced by laser evaporation for ferrofluids J. Magn. Magn. Mater. 293 119-26

[90] Stoetzel C, Kurland H D, Grabow J, Dutz S, Mueller E, Sierka M and Mueller F A 2013 Control of the crystal phase composition of FexOy nanopowders prepared by CO2 laser vaporization Cryst. Growth Des. 13 4868-76 
[91] Bazylinski D A, Garrattreed A J and Frankel R B 1994 Electron microscopic studies of magnetosomes in magnetotactic bacteria Microsc. Res. Tech. 27 389-401

[92] Schueler D 1999 Formation of magnetosomes in magnetotactic bacteria J. Mol. Microbiol. Biotechnol. 1 79-86

[93] Schueler D and Frankel R B 1999 Bacterial magnetosomes: microbiology, biomineralization and biotechnological applications Appl. Microbiol. Biotechnol. 52 464-73

[94] Scheffel A, Gruska M, Faivre D, Linaroudis A, Plitzko J M and Schuler D 2006 An acidic protein aligns magnetosomes along a filamentous structure in magnetotactic bacteria Nature $440110-4$

[95] Hergt R, Hiergeist R, Zeisberger M, Schuler D, Heyen U, Hilger I and Kaiser W A 2005 Magnetic properties of bacterial magnetosomes as potential diagnostic and therapeutic tools J. Magn. Magn. Mater. 293 80-6

[96] H Hendriksen P V, Linderoth $S$ and Lindgard $P$ A 1993 Finitesize modification of the magnetic properties of clusters Phys. Rev. B $487259-73$

[97] Marcelo, G., Catalina, F., J Bruvera, I., Marquina, C., et F Goya, G. (2014). Specific Power Absorption of Silica-coated Magnetite Cubes. Current Nanoscience, 10(5), 676-683.

[98] De Sousa, M Elisa et al. "Stability and relaxation mechanisms of citric acid coated magnetite nanoparticles for magnetic hyperthermia."The Journal of Physical Chemistry C 117.10 (2013): 54365445.

[99] Woinska, Magdalena et al. "Magnetic interactions in an ensemble of cubic nanoparticles: A Monte Carlo study."Physical Review B 88.14 (2013): 144421.

[100] Weissleder R, Stark D D, Engelstad B L, Bacon B R, Compton C C, White D L, Jacobs P and Lewis J 1989 Superparamagnetic iron oxide pharmacokinetics and toxicity Am. J. Roentgenol. 152 167-73

[101] Schweiger C, Hartmann R, Zhang F, Parak W J, Kissel T H and Rivera Gil P 2012 Quantification of the internalization patterns of superparamagnetic iron oxide nanoparticles with opposite charge $J$. Nanobiotechnol. 1028

[102] Laurent S, Burtea C, Thirifays C, Rezaee F and Mahmoudi M 2013 Significance of cell 'observer' and protein source in nanobiosciences J. Colloid Interface Sci. 392 431-45

[103] ur Rashid, Amin et al. "Study of specific absorption rate of strontium doped lanthanum manganite nanoparticles for self controlled hyperthermia applications. "Journal of Magnetism and Magnetic Materials 347 (2013): 39-44.

[104] Lapresta-Fernandez A, Doussineau T, Dutz S, Steiniger F, Moro A J and Mohr G J 2011 Magnetic and fluorescent core-shell nanoparticles for ratiometric pH sensing Nanotechnology 22415501

[105] Ferrari $R$ et al 2014 Integrated multiplatform method for in vitro quantitative assessment of cellular uptake for fluorescent polymer nanoparticles Nanotechnology 25045102

[106] Alexiou C, Arnold W, Klein R J, Parak F G, Hulin P, Bergemann C, Erhardt W, Wagenpfeil S and Lubbe A S 2000 Locoregional cancer treatment with magnetic drug targeting Cancer Res. 60 6641-8 http://cancerres.aacrjournals.org/content/60/23/6641.full

[107] Ito A, Shinkai M, Honda $H$ and Kobayashi $T 2005$ Medical application of functionalized magnetic nanoparticles J. Biosci. Bioeng. 100 1-11

[108] Gonzales-Weimuller M, Zeisberger M and Krishnan K M 2009 Size-dependant heating rates of iron oxide nanoparticles for magnetic fluid hyperthermia J. Magn. Magn. Mater. 321 1947-50 
[109] Rosensweig R E 2002 Heating magnetic fluid with alternating magnetic field J. Magn. Magn. Mater. $252370-4$

[110] Chantrell R W, Bradbury A, Popplewell J and Charles SW 1980 Particle cluster configuration in magnetic fluids J. Phys. D: Appl. Phys. 13 L119-22

[111] Castro L L, da Silva M F, Bakuzis A F and Miotto $R 2005$ Aggregate formation on polydisperse ferrofluids: a Monte Carlo analysis J. Magn. Magn. Mater. 293 553-8

[112] Dutz $S$ and Hergt $R 2012$ The role of interactions in systems of single domain ferrimagnetic iron oxide nanoparticles J. Nano Electron. Phys. 4 20101-7

[113] Serantes D et al 2010 Influence of dipolar interactions on hyperthermia properties of ferromagnetic particles J. Appl. Phys. 108073918

[114] Urtizberea A, Natividad E, Arizaga A, Castro M and Mediano A 2010 Specific absorption rates and magnetic properties of ferrofluids with interaction effects at low concentrations J. Phys. Chem. C 114 4916-22

[115] Eberbeck D and Trahms L 2011 Experimental investigation of dipolar interaction in suspensions of magnetic nanoparticles J. Magn. Magn. Mater. 323 1228-32

[116] Falk M H and Issels R D 2001 Hyperthermia in oncology Int. J. Hyperthermia 17 1-18

[117] Douple E B, Strohbehn J W, Bowers E D and Walsh J E 1979 Cancer therapy with localized hyperthermia using an invasive microwave system J. Microw. Power Electromagn. Energy 14 181-6

[118] Brezovich I A and Young J H 1981 Hyperthermia with implanted electrodes Med. Phys. 8 79-84

[119] Roggan A, Beuthan J, Schruender S and Mueller G 1999 Diagnostik und therapie mit dem laser Phys. Bl. $5525-30$

[120] Ardenne MV 1994 Principles and concept 1993 of the systemic cancer multistep therapy (SCMT) Strahlenther. Onkol. $170581-9$

[121] Gneveckow U, Jordan A, Scholz R, Eckelt L, Maier-Hauff K, Johannsen M and Wust P 2005 Magnetic force nanotherapy Biomed. Tech. (Berlin) 50 92-3

[122] Johannsen $M$, Gneueckow U, Thiesen B, Taymoorian K, Cho C H, Waldofner N, Scholz R, Jordan A, Loening $S A$ and Wust $P 2007$ Thermotherapy of prostate cancer using magnetic nanoparticles: feasibility, imaging, and threedimensional temperature distribution Eur. Urol. 52 1653-62

[123] Johannsen M, Gneveckow U, Taymoorian K, Thiesen B, Waldoefner N, Scholz R, Jung K, Jordan A, Wust P and Loening S A 2007 Morbidity and quality of life during thermotherapy using magnetic nanoparticles in locally recurrent prostate cancer: results of a prospective phase I trial Int. J. Hyperthermia 23 315-23

[124] Johannsen M, Thiesen B, Wust P and Jordan A 2010 Magnetic nanoparticle hyperthermia for prostate cancer Int. J. Hyperthermia 26 790-5

[125] Maier-Hauff K, Ulrich F, Nestler D, Niehoff H, Wust P, Thiesen B, Orawa H, Budach V and Jordan A 2011 Efficacy and safety of intratumoral thermotherapy using magnetic iron oxide nanoparticles combined with external beam radiotherapy on patients with recurrent glioblastoma multiforme J. Neurooncol. 103 317-24

[126] Imagen obtenida por el Grupo de mag. y mat. mag. del IFLP en el laboratorio de Mic. Elec. de la FCV-UNLP

[127] Venkateshvaran, Deepak et al. "Epitaxial ZnxFe(3-x)O4 thin films: a spintronic material with tunable electrical and magnetic properties."Physical Review B 79.13 (2009): 134405. 
[128] Behdadfar B, Kermanpur A, Sadeghi Aliabadi H, Morales M P and Mozaffari M 2012 J. Magn. Magn. Mater. 324 2211-7

[129] Pfeiffer, H. (1990). "Determination of anisotropy field distribution in particle assemblies taking into account thermal fluctuations". Physica Status Solidi A 118 (1): 295-306. Bibcode:1990PSSAR.118..295P. doi:10.1002/pssa.2211180133

[130] Balian, Roger. From microphysics to macrophysics: methods and applications of statistical physics. Springer Science and Business Media, 2006.

[131] Neel L 1949 Influence des fluctuations thermiques a l aimantation des particules ferromagnetiques C. R. Acad. Sci. $228664-8$

[132] Aharoni, A. (1996). Introduction to the Theory of Ferromagnetism (Vol. 2). Oxford: Clarendon Press.

[133] Micha, J. S., Dieny, B., Regnard, J. R., Jacquot, J. F., and Sort, J. (2004). Estimation of the Co nanoparticles size by magnetic measurements in Co/SiO 2 discontinuous multilayers. Journal of Magnetism and Magnetic Materials, 272, E967-E968.

[134] Ravel B and Newville M 2005 J. Synchrotron Radiat. 12 537-41

[135] Spalding "Magnetic Materials - Cambridge Books Online - Cambridge

[136] Bean, C. P., and Livingston, J. D. (1959). Superparamagnetism. Journal of Applied Physics, 30(4), S120-S129.

[137] Zhang, Y., Kohler, N., and Zhang, M. (2002). Surface modification of superparamagnetic magnetite nanoparticles and their intracellular uptake. Biomaterials, 23(7), 1553-1561.

[138] Neuberger, T., Schopf, B., Hofmann, H., Hofmann, M., and Von Rechenberg, B. (2005). Superparamagnetic nanoparticles for biomedical applications: possibilities and limitations of a new drug delivery system. Journal of Magnetism and Magnetic Materials, 293(1), 483-496.

[139] Singh, Neenu et al. "Potential toxicity of superparamagnetic iron oxide nanoparticles (SPION). "Nano reviews 1 (2010).

[140] TeraÃ in, Francisco J et al. "Accurate determination of the specific absorption rate in superparamagnetic nanoparticles under non-adiabatic conditions.. ${ }^{A}$ pplied Physics Letters 101.6 (2012): 062413.

[141] Goya, G. F., Marcos Campos, I., Fernandez-Pacheco, R., Saez, B., Godino, J., Asin, L., ... and Tres, A. (2008). Dendritic cell uptake of iron-based magnetic nanoparticles. Cell biology international, 32(8), 1001-1005.

[142] Munnier, E et al. "Novel method of doxorubicin SPION reversible association for magnetic drug targeting. International journal of pharmaceutics 363.1 (2008): 170-176.

[143] J. Garcia Otero, A. J. Garcia-Bastida, and J. Rivas, J. Magn. Magn. Mater. 189, 377 (1998)

[144] Heczko, O., Straka, L., Lanska, N., Ullakko, K., and Enkovaara, J. (2002). Temperature dependence of magnetic anisotropy in Ni-Mn-Ga alloys exhibiting giant field-induced strain. Journal of applied physics, 91(10), 8228-8230.

[145] Shirk, B. T., and Buessem, W. R. (1969). Temperature dependence of Ms and K1 of BaFe12O19 and SrFe12O19 single crystals. Journal of Applied Physics, 40(3), 1294-1296.

[146] Carr Jr, W. J. (1958). Temperature dependence of ferromagnetic anisotropy. Physical Review, 109(6), 1971.

[147] Shampine, L. F. and M. W. Reichelt, "The MATLAB ODE Suite," SIAM Journal on Scientific Computing, Vol. 18, 1997, pp 1-22. 
[148] Lalatonne, Y., Richardi, J., et Pileni, M. P. (2004). Van der Waals versus dipolar forces controlling mesoscopic organizations of magnetic nanocrystals. Nature materials, 3(2), 121-125.

[149] Benkoski, J. J., Bowles, S. E., Jones, R. L., Douglas, J. F., Pyun, J., et Karim, A. (2008). Self assembly of polymer coated ferromagnetic nanoparticles into mesoscopic polymer chains. Journal of Polymer Science Part B: Polymer Physics, 46(20), 2267-2277.

[150] Denardin, J. C., Brandl, A. L., Knobel, M., Panissod, P., Pakhomov, A. B., Liu, H., et Zhang, X. X. (2002). Thermoremanence and zero field cooled/field cooled magnetization study of Co x (SiO 2) 1-x granular films. Physical Review B, 65(6), 064422.

[151] D.F: Coral, Tesis Doctoral. Estructuras Dipolares MagnÃ@ticas en Suspensiones Magnéticas Coloidales y su Influencia en Hipertermia Magnética FCE-UNLP, Argentina, 2014. 